\title{
LIBRARY
}

USE ONLY

\section{Laboratory Characterization of Type N Mortar}

\author{
Erin M. Williams, Stephen A. Akers, and Paul A. Reed
}

March 2009

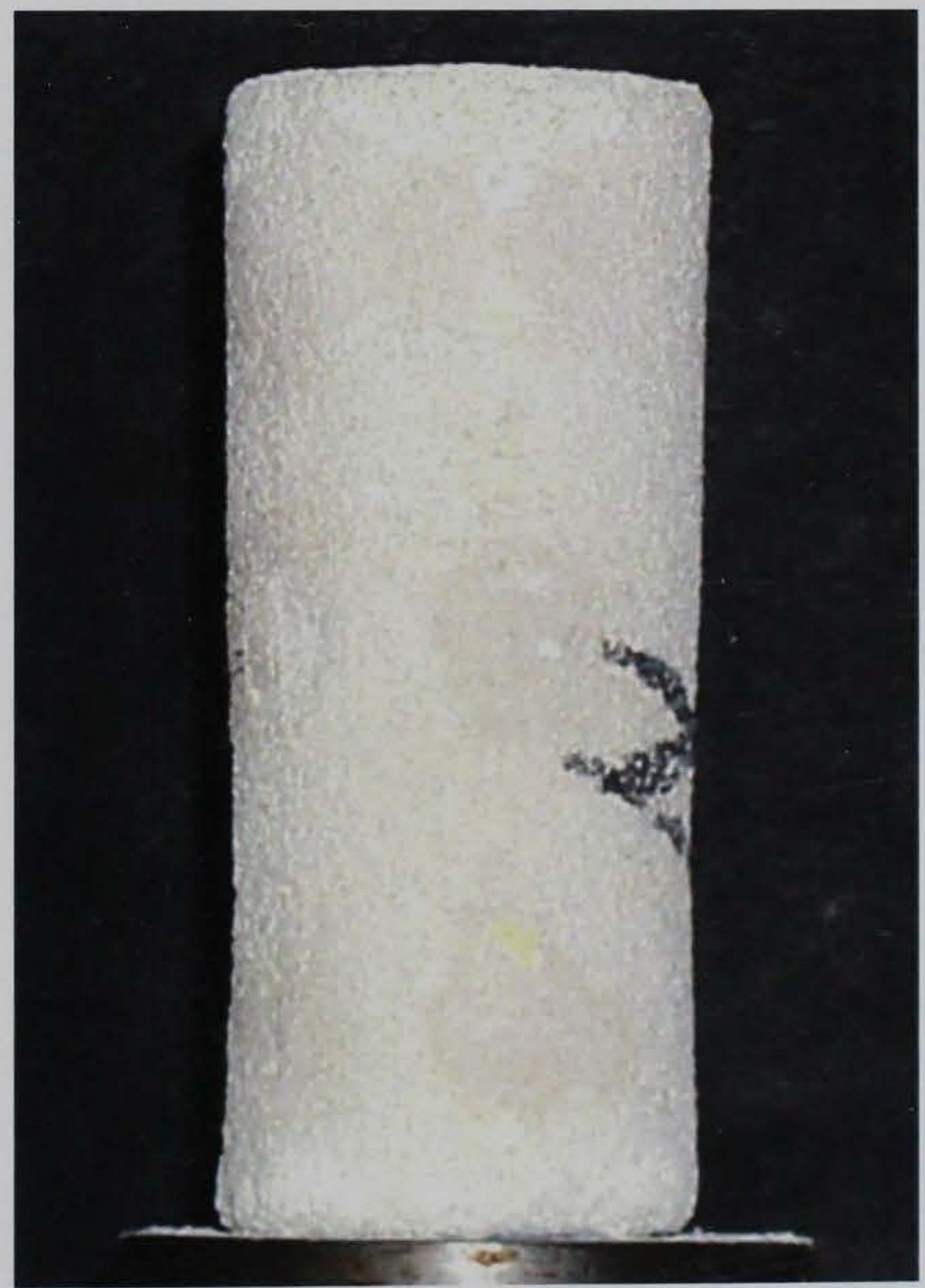




\section{TA7 \\ Laboratory Characterization of Type N Mortar}

Erin M. Williams, Stephen A. Akers, and Paul A. Reed

US - CE - C

PROPERTY OF THE UNITED STATES

Geotechnical and Structures Laboratory GOVERNMENT

U.S. Army Engineer Research and Development Center

3909 Halls Ferry Road

Vicksburg, MS 39180-6199

Final report

Approved for public release; distribution is unlimited.

\section{RESEARCH LIBRARY \\ USACE ERDC \\ VICKSBURG, MS}

Prepared for Headquarters, U.S. Army Corps of Engineers

Washington, DC 20314-1000

Under Hardened Combined Effects Penetrator Warheads Work Package Work Unit No. OPO03, Material Properties of Urban Materials 


\begin{abstract}
Personnel of the Geotechnical and Structures Laboratory, U.S. Army Engineer Research and Development Center, conducted a laboratory investigation to characterize the strength and constitutive property behavior of type $\mathrm{N}$ mortar. A total of 45 mechanical property tests were successfully completed: two hydrostatic compression tests, four unconfined compression (UC) tests, 18 triaxial compression (TXC) tests, four direct pull (DP) tests, six reduced triaxial extension (RTE) tests, two uniaxial strain (UX) tests, four uniaxial strain load/biaxial strain unload (UX/BX) tests, and five uniaxial strain load/constant volume strain loading (UX/CV) tests. In addition to the mechanical property tests, nondestructive pulse-velocity measurements were obtained on each specimen. The TXC tests exhibited a continuous increase in maximum principal stress difference with increasing confining pressure. A compression failure surface was developed from the TXC test results at nine levels of confining pressure and from the results of the UC tests. The results for the DP and RTE tests were used to determine the tensile strength of type N mortar and develop an extension failure surface. Type $\mathrm{N}$ mortar can withstand more deviatoric stress in compression than extension before failure occurs. During UX/BX tests, the test specimens recovered approximately one third of their peak compressive volumetric strain. During most of the CV loading, the stress path followed closely to the failure surface developed from the TXC tests, therefore validating the compression failure surface.
\end{abstract}

DISCLAIMER: The contents of this report are not to be used for advertising, publication, or promotional purposes. Citation of trade names does not constitute an official endorsement or approval of the use of such commercial products. All product names and trademarks cited are the property of their respective owners. The findings of this report are not to be construed as an official Department of the Army position unless so designated by other authorized documents. 


\section{Contents}

Figures and Tables...................................................................................................................................iv

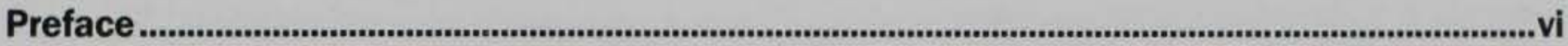

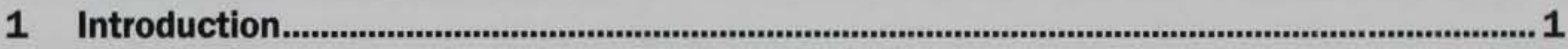

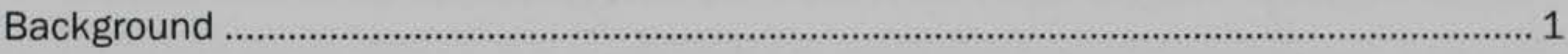

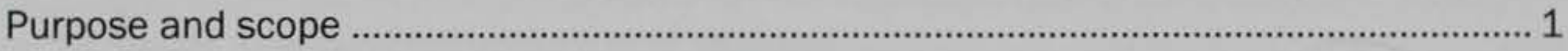

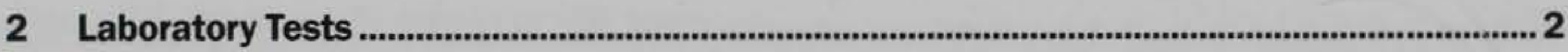

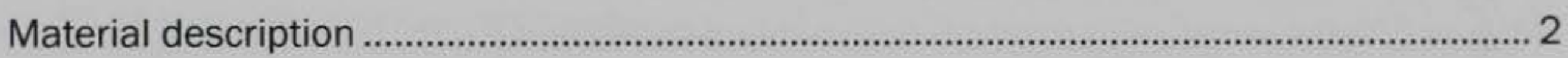

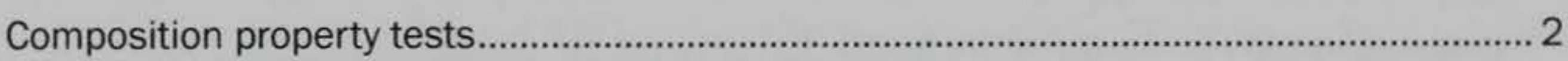

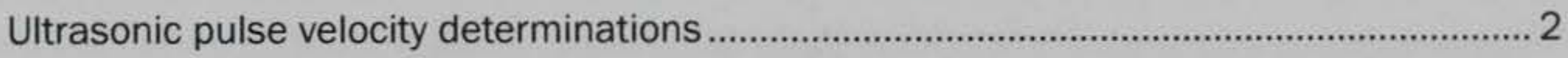

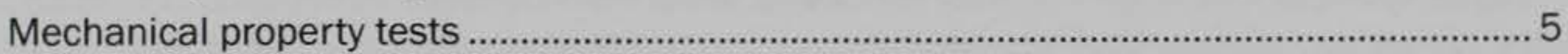

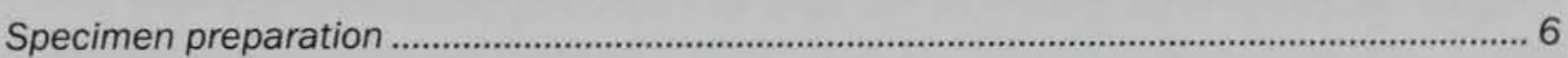

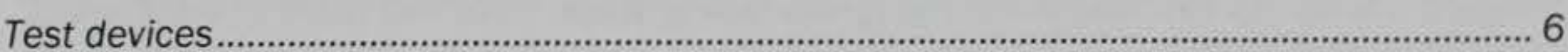

Test instrumentation ...................................................................................................... 10

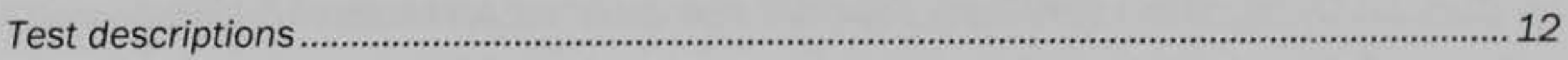

Definition of stresses and strains .............................................................................. 13

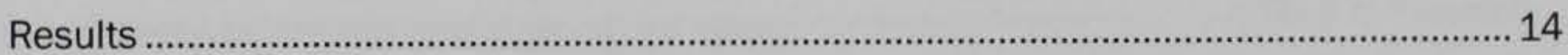

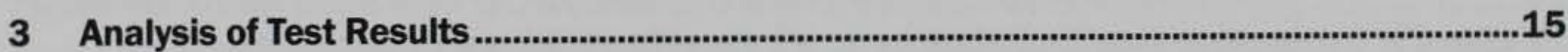

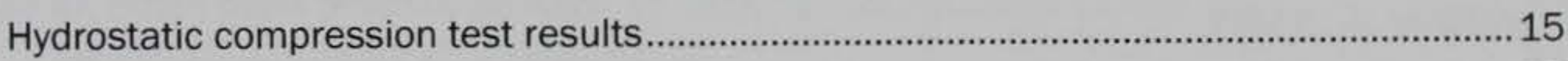

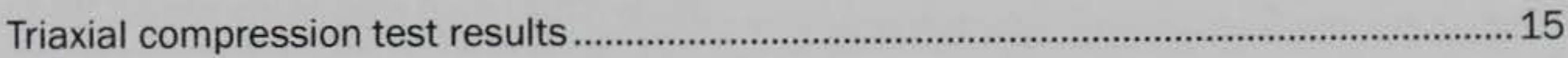

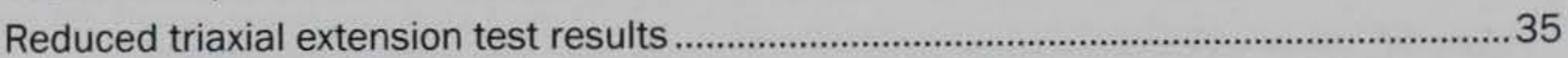

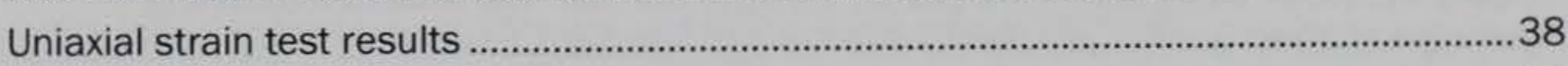

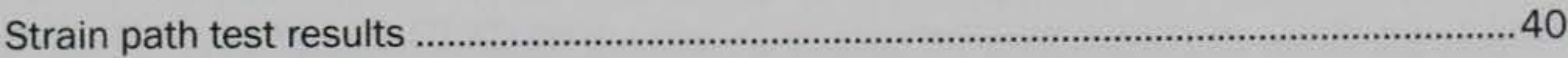

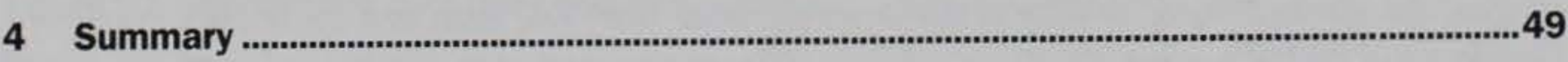

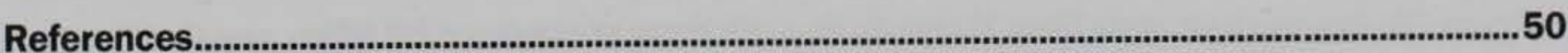

Plates 1-41

Report Documentation Page 


\section{Figures and Tables}

\section{Figures}

Figure 1. Typical test specimen setup 8

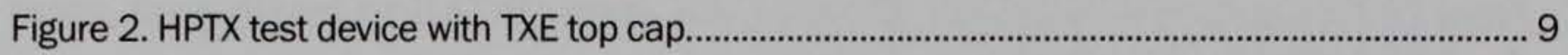

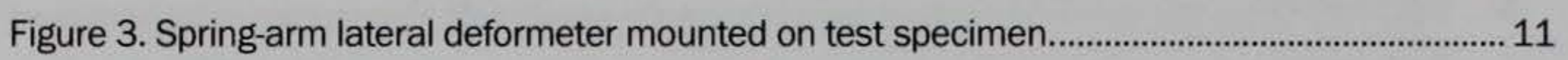

Figure 4. Pressure-volume responses from the HC tests................................................................... 16

Figure 5. Pressure time-histories from the HC tests....................................................................... 16

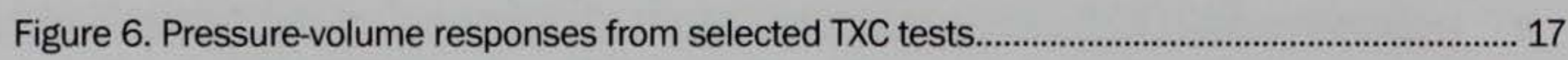

Figure 7. Pressure-volume responses from $\mathrm{HC}$ and TXC tests.................................................... 17

Figure 8. Stress-strain data from UC tests................................................................................... 19

Figure 9. Stress difference-volume strain during shear from UC tests. .......................................... 19

Figure 10. Stress-strain data from TXC tests at a confining pressure of $2.5 \mathrm{MPa}$.............................20

Figure 11. Stress difference-volume strain during shear from TXC tests at a confining pressure of $2.5 \mathrm{MPa}$.

Figure 12. Stress-strain data from TXC tests at a confining pressure of $5 \mathrm{MPa}$.............................. 21

Figure 13. Stress difference-volume strain during shear from TXC tests at a confining

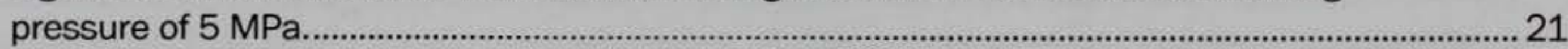

Figure 14. Stress-strain data from TXC tests at a confining pressure of $10 \mathrm{MPa}$..............................2 22

Figure 15. Stress difference-volume strain during shear from TXC tests at a confining

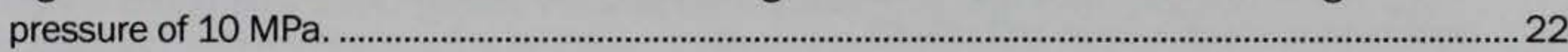

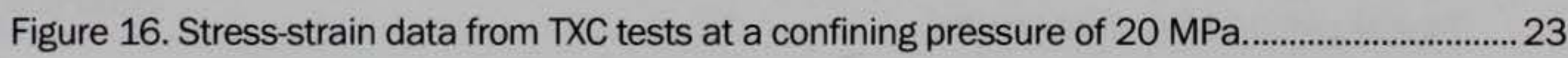

Figure 17. Stress difference-volume strain during shear from TXC tests at a confining

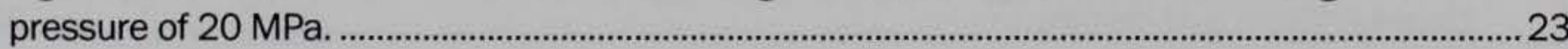

Figure 18. Stress-strain data from TXC tests at a confining pressure of $35 \mathrm{MPa}$.............................. 24

Figure 19. Stress difference-volume strain during shear from TXC tests at a confining

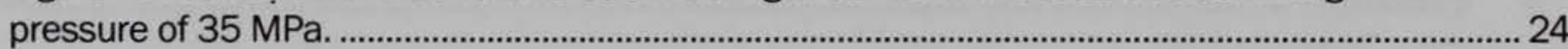

Figure 20. Stress-strain data from TXC tests at a confining pressure of $50 \mathrm{MPa}$...............................2 25

Figure 21. Stress difference-volume strain during shear from TXC tests at a confining pressure of $50 \mathrm{MPa}$

Figure 22. Stress-strain data from TXC tests at a confining pressure of $100 \mathrm{MPa}$..........................26

Figure 23. Stress difference-volume strain during shear from TXC tests at a confining

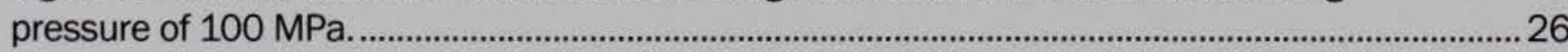

Figure 24. Stress-strain data from TXC tests at a confining pressure of $200 \mathrm{MPa}$........................... 27

Figure 25. Stress difference-volume strain during shear from TXC tests at a confining

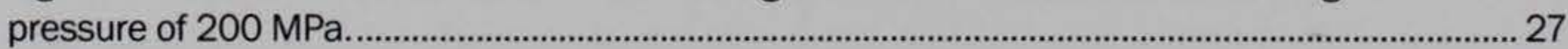

Figure 26. Stress-strain data from TXC tests at a confining pressure of $400 \mathrm{MPa}$............................2 28

Figure 27. Stress difference-volume strain during shear from TXC tests at a confining pressure of $400 \mathrm{MPa}$.

Figure 28. Stress-strain data from selected TXC tests at confining pressures between 2.5 and $20 \mathrm{MPa}$. 
Figure 29. Stress-strain data from selected TXC tests at confining pressures between 35 and $400 \mathrm{MPa}$.

Figure 30. Stress difference-volume strain during shear from selected TXC tests at confining pressures between 2.5 and $20 \mathrm{MPa}$.

Figure 31. Stress difference-volume strain during shear from selected TXC tests at confining pressures between 35 and $400 \mathrm{MPa}$.

Figure 32. Radial strain-axial strain data during shear from TXC tests at confining pressures between 2.5 and $400 \mathrm{MPa}$.

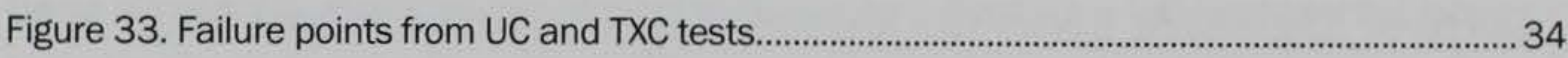

Figure 34. Failure points from $U C$ and $T X C$ tests and recommended failure surface.......................35

Figure 35. Stress paths and failure data from DP tests.................................................................. 36

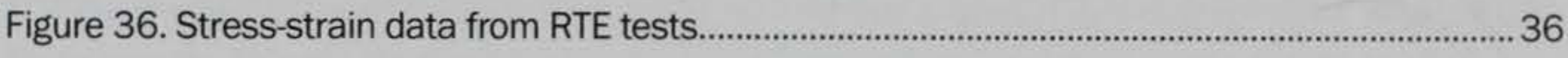

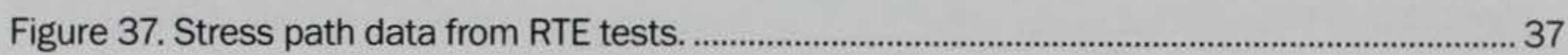

Figure 38. Failure data from DP and RTE tests and recommended failure surface. ..........................37

Figure 39. Failure surfaces and failure data from UC, TXC, DP, and RTE tests.................................38

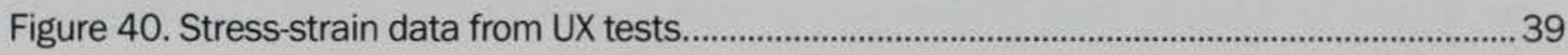

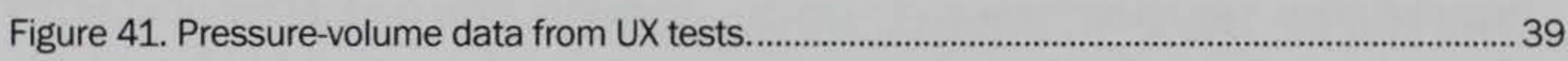

Figure 42. Stress paths from UX tests and failure surface from TXC tests. ..................................... 40

Figure 43. Comparison of pressure-volume data from $\mathrm{HC}$ and UX tests.........................................4 41

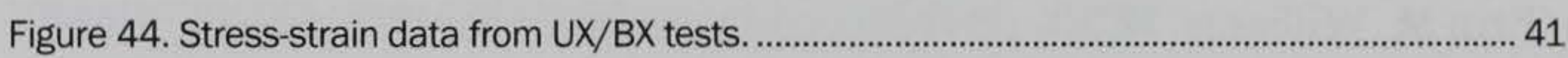

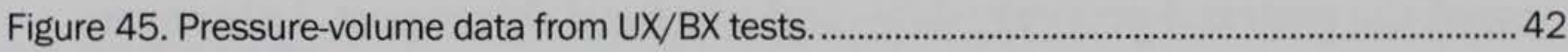

Figure 46. Stress paths from UX/BX tests and failure surface from TXC tests.................................. 42

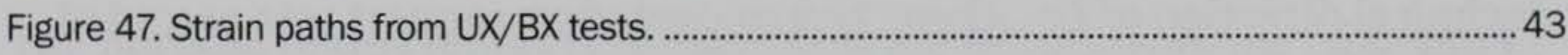

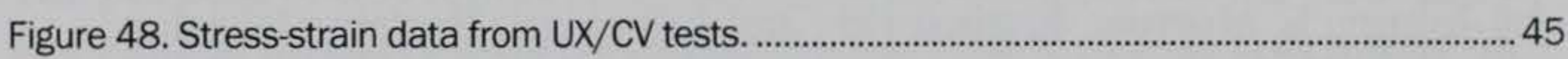

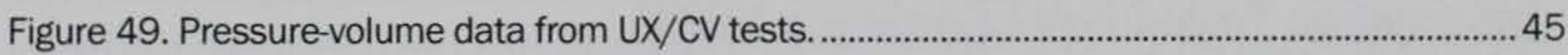

Figure 50. Stress paths from UX/CV tests and failure surface from TXC tests................................ 46

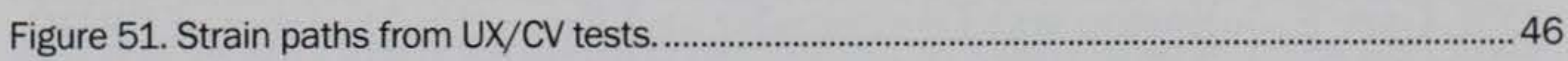

Figure 52. Stress-strain data from selected UX, UX/BX, and UX/CV tests. ....................................47

Figure 53. Pressure-volume data from selected UX, UX/BX, and UX/CV tests. ................................. 47

Figure 54. Stress paths from selected UX, UX/BX and UX/CV tests and failure surface

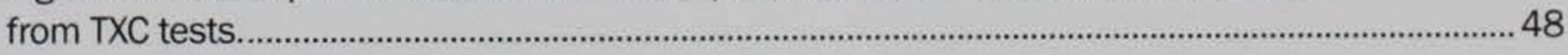

Figure 55. Strain paths from selected UX, UX/BX, and UX/CV tests.................................................. 48

\section{Tables}

Table 1. Physical and composition properties of type $\mathrm{N}$ mortar test specimens............................... 3

Table 2. Completed type N mortar test matrix.................................................................................... 7 


\section{Preface}

This laboratory mechanical property investigation of type $\mathrm{N}$ mortar was conducted by personnel of the U.S. Army Engineer Research and Development Center (ERDC). Funding was provided by Headquarters, U.S. Army Corps of Engineers, under the Military RDT\&E Work Package AT40-WP248A, Hardened Combined Effects Penetrator Warheads, Work Unit "Material Properties of Urban Materials." This study was conducted between May 2005 and July 2005 by staff members of the Impact and Explosion Effects Branch (IEEB), Engineering Systems and Materials Division (ESMD), Geotechnical and Structures Laboratory (GSL), ERDC, under the general direction of Henry S. McDevitt, Jr., Chief, IEEB; Dr. Larry N. Lynch, Chief, ESMD; Dr. William P. Grogan, Deputy Director, GSL; and Dr. David W. Pittman, Director, GSL.

The Principal Investigator for this project was Dr. Stephen A. Akers, IEEB. Erin M. Williams, IEEB, served as co-investigator for this project, processed the material property data, and prepared this report. Laboratory characterization tests were performed by Paul A. Reed, IEEB, under the technical direction of Dr. Akers. Instrumentation support was provided by Johnny L. Morrow, Engineering and Informatic Systems Division, Information Technology Laboratory, ERDC.

COL Gary E. Johnston was Commander and Executive Director of ERDC. Dr. James R. Houston was Director. 


\section{Introduction}

\section{Background}

Personnel of the Geotechnical and Structures Laboratory, U.S. Army Engineer Research and Development Center, conducted a laboratory investigation to characterize the strength and constitutive property behavior of type N mortar for the Material Properties of Urban Materials Work Unit of the U.S. Army Corps of Engineers' Hardened Combined Effects Penetrator Warheads Work Package. A total of 53 mechanical property tests were conducted of which 45 were successfully completed. The 45 tests consisted of two hydrostatic compression tests, four unconfined compression tests, 18 triaxial compression tests, four direct pull tests, six reduced triaxial extension tests, two uniaxial strain tests, four uniaxial strain load/biaxial strain unload tests, and five uniaxial strain load/constant volume tests. In addition to the mechanical property tests, nondestructive pulse-velocity measurements were obtained on each specimen.

\section{Purpose and scope}

The purpose of this report is to document the results from the laboratory mechanical property tests conducted on the type $\mathrm{N}$ mortar specimens. In addition, results from the nondestructive pulse-velocity measurements are documented. The physical and composition properties, test procedures, and test results are documented in Chapter 2. Comparative plots and analyses of the experimental results are presented in Chapter 3. A summary is provided in Chapter 4. 


\section{Laboratory Tests}

\section{Material description}

The test specimens used in this investigation were prepared from samples cored from solid drums of type $\mathrm{N}$ mortar. The type $\mathrm{N}$ mortar was bought from a local hardware store and placed into the drums and allowed to cure outside for over 28 days prior to the samples being cored. The mortar used for the material property tests was used to build walls of brick for projectile penetration tests at the ERDC. The material properties determined from the characterization of the material will be used to develop mathematical models of the mortar's responses for use in numerical simulations of the penetration tests.

\section{Composition property tests}

Prior to performing the mechanical property tests, the height, diameter, and weight of each test specimen were determined. These measurements were used to compute the specimen's wet, bulk, or "as-tested" density. Results from these determinations are provided in Table 1. Measurements of posttest water content ${ }^{1}$ were conducted in accordance with procedures given in American Society for Testing and Materials (ASTM) D 2216 (ASTM 2005d). Based on the appropriate values of posttest water content, wet density, and an assumed grain density of $2.51 \mathrm{Mg} / \mathrm{m}^{3}$, values of dry density, porosity, degree of saturation, and volumes of air, water, and solids were calculated (Table 1). Also listed in Table 1 are maximum, minimum, and mean values and the standard deviation about the mean for each quantity. The type $\mathrm{N}$ mortar specimens had a mean wet density of $1.575 \mathrm{Mg} / \mathrm{m}^{3}$, a mean water content of $1.34 \%$, and a mean dry density of $1.554 \mathrm{Mg} / \mathrm{m}^{3}$.

\section{Ultrasonic pulse velocity determinations}

Prior to performing a mechanical property test, ultrasonic pulse-velocity measurements were collected on each test specimen. This involved measuring the transit distance and time for each P-wave (compressional) or S-wave (shear) pulse to propagate through a given specimen. The

\footnotetext{
${ }_{1}^{1}$ Water content is defined as the weight of water removed during drying in a standard oven divided by the weight of dry solids.
} 
Table 1. Physical and composition properties of type $\mathrm{N}$ mortar test specimens.

\begin{tabular}{|c|c|c|c|c|c|c|c|c|c|c|c|c|c|c|}
\hline $\begin{array}{l}\text { Test } \\
\text { Number }\end{array}$ & $\begin{array}{l}\text { Type of } \\
\text { Test }\end{array}$ & $\begin{array}{l}\text { Plate } \\
\text { No. }\end{array}$ & $\begin{array}{l}\text { Wet } \\
\text { Density } \\
\mathrm{Mg} / \mathrm{m}^{3}\end{array}$ & $\begin{array}{l}\text { Posttest } \\
\text { Water } \\
\text { Content } \\
\%\end{array}$ & $\begin{array}{l}\text { Dry } \\
\text { Density } \\
\mathrm{Mg} / \mathrm{m}^{3}\end{array}$ & $\begin{array}{l}\text { Porosity } \\
\%\end{array}$ & $\begin{array}{l}\text { Degree of } \\
\text { Saturation } \\
\%\end{array}$ & $\begin{array}{l}\text { Volume } \\
\text { of Air } \\
\%\end{array}$ & $\begin{array}{l}\text { Volume } \\
\text { of Water } \\
\%\end{array}$ & $\begin{array}{l}\text { Volume } \\
\text { of Solids } \\
\%\end{array}$ & $\begin{array}{l}\text { Axial } \\
\text { P-Wave } \\
\text { Velocity } \\
\text { km/s }\end{array}$ & $\begin{array}{l}\text { Radial } \\
\text { P-Wave } \\
\text { Velocity } \\
\text { km/s }\end{array}$ & $\begin{array}{l}\text { Axial } \\
\text { S-Wave } \\
\text { Velocity } \\
\mathrm{km} / \mathrm{s}\end{array}$ & $\begin{array}{l}\text { Radial } \\
\text { S-Wave } \\
\text { Velocity } \\
\mathrm{km} / \mathrm{s}\end{array}$ \\
\hline 01 & RTE/60 & 29 & 1.604 & 2.90 & 1.558 & 37.94 & 11.92 & 33.39 & 4.52 & 62.09 & 2.598 & 2.518 & 1.592 & 1.633 \\
\hline 02 & RTE/60 & 30 & 1.570 & 1.82 & 1.542 & 38.58 & 7.27 & 35.78 & 2.81 & 61.42 & 2.531 & 2.466 & 1.580 & 1.582 \\
\hline 03 & RTE/40 & 27 & 1.567 & 1.65 & 1.542 & 38.58 & 6.59 & 36.04 & 2.54 & 61.42 & 2.515 & 2.487 & 1.581 & 1.554 \\
\hline 04 & RTE/40 & 28 & 1.567 & & & & & & & & 2.434 & 2.458 & 1.521 & 1.517 \\
\hline 05 & RTE/20 & 25 & 1.575 & 1.88 & 1.546 & 38.41 & 7.57 & 35.51 & 2.91 & 61.59 & 2.549 & 2.502 & 1.568 & 1.552 \\
\hline 06 & RTE/20 & 26 & 1.574 & 1.87 & 1.545 & 38.43 & 7.52 & 35.54 & 2.89 & 61.57 & 2.535 & 2.516 & 1.542 & 1.544 \\
\hline 07 & UC & 3 & 1.563 & 1.33 & 1.543 & 38.54 & 5.32 & 36.49 & 2.05 & 61.46 & 2.519 & 2.583 & 1.588 & 1.562 \\
\hline 08 & UC & 4 & 1.564 & 1.36 & 1.543 & 38.51 & 5.45 & 36.42 & 2.10 & 61.49 & 2.597 & 2.561 & 1.577 & 1.573 \\
\hline 09 & UC & 5 & 1.571 & 1.49 & 1.548 & 38.33 & 6.02 & 36.03 & 2.31 & 61.67 & 2.562 & 2.627 & 1.602 & 1.600 \\
\hline 10 & UC & 6 & 1.570 & 1.51 & 1.546 & 38.39 & 6.08 & 36.06 & 2.33 & 61.61 & 2.571 & 2.614 & 1.562 & 1.565 \\
\hline 11 & DP & - & 1.576 & 1.38 & 1.555 & 38.06 & 5.64 & 35.91 & 2.15 & 61.94 & 2.564 & 2.627 & 1.537 & 1.554 \\
\hline 12 & DP & - & 1.574 & 1.38 & 1.553 & 38.13 & 5.62 & 35.99 & 2.14 & 61.87 & 2.575 & 2.587 & 1.600 & 1.606 \\
\hline 13 & DP & - & 1.568 & 1.36 & 1.547 & 38.39 & 5.48 & 36.28 & 2.10 & 61.62 & 2.472 & 2.591 & 1.505 & 1.559 \\
\hline 14 & DP & -. & 1.570 & 1.36 & 1.549 & 38.29 & 5.50 & 36.18 & 2.11 & 61.71 & 2.569 & 2.611 & 1.592 & 1.563 \\
\hline 15 & $\mathrm{HC}$ & 1 & 1.571 & 1.67 & 1.545 & 38.45 & 6.71 & 35.87 & 2.58 & 61.55 & 2.506 & 2.522 & 1.555 & 1.558 \\
\hline 16 & $\mathrm{HC}$ & 2 & 1.572 & 1.60 & 1.547 & 38.37 & 6.45 & 35.89 & 2.48 & 61.63 & 2.495 & 2.545 & 1.599 & 1.594 \\
\hline 17 & TXC/20 & 13 & 1.576 & 1.32 & 1.556 & 38.02 & 5.40 & 35.97 & 2.05 & 61.98 & 2.501 & 2.498 & 1.599 & 1.560 \\
\hline 18 & $\mathrm{TXC} / 20$ & 14 & 1.588 & 1.41 & 1.566 & 37.60 & 5.87 & 35.39 & 2.21 & 62.40 & 2.510 & 2.487 & 1.574 & 1.589 \\
\hline 23 & UX & 31 & 1.565 & 1.36 & 1.544 & 38.48 & 5.46 & 36.38 & 2.10 & 61.53 & 2.496 & 2.505 & 1.577 & 1.570 \\
\hline 24 & UX & 32 & 1.563 & 1.41 & 1.541 & 38.60 & 5.63 & 36.42 & 2.17 & 61.41 & 2.500 & 2.604 & 1.543 & 1.588 \\
\hline 25 & UX/BX & 33 & 1.574 & 1.32 & 1.554 & 38.11 & 5.38 & 36.06 & 2.05 & 61.89 & 2.569 & 2.643 & 1.585 & 1.577 \\
\hline 26 & $\mathrm{TXC} / 2.5$ & 7 & 1.581 & 1.23 & 1.562 & 37.78 & 5.08 & 35.86 & 1.92 & 62.22 & 2.518 & 2.634 & 1.555 & 1.563 \\
\hline 27 & TXC/2.5 & 8 & 1.566 & 1.32 & 1.545 & 38.43 & 5.31 & 36.39 & 2.04 & 61.57 & 2.470 & 2.502 & 1.541 & 1.524 \\
\hline 28 & TXC/5 & 9 & 1.582 & 1.20 & 1.563 & 37.74 & 4.97 & 35.86 & 1.88 & 62.26 & 2.563 & 2.496 & 1.610 & 1.565 \\
\hline 29 & TXC/5 & 10 & 1.576 & 1.19 & 1.557 & 37.95 & 4.88 & 36.10 & 1.85 & 62.05 & 2.534 & 2.591 & 1.571 & 1.590 \\
\hline
\end{tabular}




\begin{tabular}{|c|c|c|c|c|c|c|c|c|c|c|c|c|c|c|}
\hline $\begin{array}{l}\text { Test } \\
\text { Number }\end{array}$ & \begin{tabular}{|l} 
Type of \\
Test
\end{tabular} & $\begin{array}{l}\text { Plate } \\
\text { No. }\end{array}$ & $\begin{array}{l}\text { Wet } \\
\text { Density } \\
\mathrm{Mg} / \mathrm{m}^{3}\end{array}$ & $\begin{array}{l}\text { Posttest } \\
\text { Water } \\
\text { Content } \\
\%\end{array}$ & $\begin{array}{l}\text { Dry } \\
\text { Density } \\
\mathrm{Mg} / \mathrm{m}^{3}\end{array}$ & $\begin{array}{l}\text { Porosity } \\
\%\end{array}$ & $\begin{array}{l}\text { Degree of } \\
\text { Saturation } \\
\%\end{array}$ & $\begin{array}{l}\text { Volume } \\
\text { of Air } \\
\%\end{array}$ & $\begin{array}{l}\text { Volume } \\
\text { of Water } \\
\%\end{array}$ & $\begin{array}{l}\text { Volume } \\
\text { of Solids } \\
\%\end{array}$ & $\begin{array}{l}\text { Axial } \\
\text { P-Wave } \\
\text { Velocity } \\
\mathrm{km} / \mathrm{s}\end{array}$ & $\begin{array}{l}\text { Radial } \\
\text { P-Wave } \\
\text { Velocity } \\
\text { km/s }\end{array}$ & $\begin{array}{l}\text { Axial } \\
\text { S-Wave } \\
\text { Velocity } \\
\mathrm{km} / \mathrm{s}\end{array}$ & $\begin{array}{l}\text { Radial } \\
\text { S-Wave } \\
\text { Velocity } \\
\text { km/s }\end{array}$ \\
\hline 30 & TXC/10 & 11 & 1.578 & 1.23 & 1.558 & 37.91 & 5.06 & 36.00 & 1.92 & 62.09 & 2.581 & 2.639 & 1.621 & 1.606 \\
\hline 31 & $\mathrm{TXC} / 10$ & 12 & 1.579 & 1.20 & 1.560 & 37.85 & 4.95 & 35.98 & 1.87 & 62.15 & 2.549 & 2.621 & 1.540 & 1.540 \\
\hline 32 & TXC/50 & 17 & 1.577 & 1.16 & 1.559 & 37.89 & 4.77 & 36.08 & 1.81 & 62.11 & 2.585 & 2.610 & 1.617 & 1.589 \\
\hline 33 & TXC/50 & 18 & 1.581 & 1.13 & 1.563 & 37.71 & 4.68 & 35.95 & 1.77 & 62.29 & 2.569 & 2.533 & 1.559 & 1.563 \\
\hline 34 & TXC/35 & 15 & 1.574 & 1.14 & 1.556 & 38.01 & 4.67 & 36.23 & 1.77 & 61.99 & 2.527 & 2.582 & 1.541 & 1.566 \\
\hline 36 & TXC/100 & 19 & 1.583 & 1.15 & 1.565 & 37.66 & 4.78 & 35.86 & 1.80 & 62.34 & 2.612 & 2.619 & 1.582 & 1.600 \\
\hline 37 & TXC/100 & 20 & 1.569 & 1.16 & 1.551 & 38.21 & 4.71 & 36.41 & 1.80 & 61.79 & 2.483 & 2.521 & 1.570 & 1.600 \\
\hline 38 & TXC/200 & 21 & 1.579 & 1.16 & 1.560 & 37.83 & 4.78 & 36.02 & 1.81 & 62.17 & 2.519 & 2.482 & 1.577 & 1.555 \\
\hline 41 & UX/CV & 37 & 1.575 & 1.18 & 1.556 & 38.00 & 4.83 & 36.16 & 1.84 & 62.00 & 2.503 & 2.540 & 1.503 & 1.537 \\
\hline 42 & UX/CV & 38 & 1.574 & 1.19 & 1.556 & 38.02 & 4.87 & 36.17 & 1.85 & 61.98 & 2.505 & 2.515 & 1.528 & 1.539 \\
\hline 43 & UX/CV & 39 & 1.577 & 0.81 & 1.565 & 37.66 & 3.37 & 36.39 & 1.27 & 62.34 & 2.546 & 2.531 & 1.548. & 1.558 \\
\hline 44 & UX/CV & 40 & 1.578 & 1.10 & 1.561 & 37.82 & 4.54 & 36.10 & 1.72 & 62.18 & 2.569 & 2.606 & 1.623 & 1.592 \\
\hline 45 & UX/CV & 41 & 1.587 & 1.15 & 1.569 & 37.47 & 4.82 & 35.67 & 1.80 & 62.53 & 2.600 & 2.625 & 1.579 & 1.589 \\
\hline 46 & UX/BX & 34 & 1.576 & 1.19 & 1.557 & 37.95 & 4.88 & 36.10 & 1.85 & 62.05 & 2.585 & 2.547 & 1.594 & 1.567 \\
\hline 47 & UX/BX & 35 & 1.586 & 1.20 & 1.567 & 37.56 & 5.01 & 35.68 & 1.88 & 62.44 & 2.561 & 2.593 & 1.585 & 1.572 \\
\hline 48 & UX/BX & 36 & 1.582 & 1.18 & 1.564 & 37.70 & 4.90 & 35.85 & 1.85 & 62.30 & 2.593 & 2.624 & 1.600 & 1.606 \\
\hline 49 & TXC/35 & 16 & 1.567 & 1.18 & 1.549 & 38.30 & 4.77 & 36.48 & 1.83 & 61.70 & 2.540 & 2.536 & 1.575 & 1.542 \\
\hline 51 & TXC/200 & 22 & 1.580 & 1.12 & 1.563 & 37.74 & 4.64 & 35.99 & 1.75 & 62.26 & 2.196 & 2.201 & 1.381 & 1.409 \\
\hline 52 & TXC/400 & 23 & 1.580 & 1.07 & 1.563 & 37.71 & 4.44 & 36.04 & 1.67 & 62.29 & 2.166 & 2.147 & 1.313 & 1.347 \\
\hline 53 & TXC/400 & 24 & 1.572 & 1.08 & 1.555 & 38.05 & 4.41 & 36.37 & 1.68 & 61.95 & 2.087 & 2.194 & 1.355 & 1.393 \\
\hline $\mathrm{N}$ & & & 45 & 44 & 44 & 44 & 44 & 44 & 44 & 44 & 45 & 45 & 45 & 45 \\
\hline Mean & & & 1.575 & 1.34 & 1.554 & 38.07 & 5.48 & 35.98 & 2.09 & 61.93 & 2.514 & 2.534 & 1.557 & 1.558 \\
\hline Stdv & & & 0.008 & 0.327 & 0.008 & 0.325 & 1.307 & 0.479 & 0.504 & 0.325 & 0.107 & 0.110 & 0.063 & 0.053 \\
\hline Max & & & 1.604 & 2.90 & 1.569 & 38.59 & 11.92 & 36.49 & 4.52 & 62.53 & 2.612 & 2.643 & 1.623 & 1.633 \\
\hline Min & & & 1.563 & 0.81 & 1.541 & 37.47 & 3.37 & 33.39 & 1.27 & 61.41 & 2.087 & 2.147 & 1.313 & 1.347 \\
\hline
\end{tabular}


velocity was then computed by dividing the transit distance by the transit time. A matching pair of $1-\mathrm{MHz}$ piezoelectric transducers was used to transmit and receive the ultrasonic $\mathrm{P}$-waves. A pair of 2.25-MHz piezoelectric transducers was used to transmit and receive the ultrasonic $\mathrm{S}$-waves. The transit time was measured with a 100-MHz digital oscilloscope and the transit distance with a digital micrometer. All of these velocity determinations were made under atmospheric conditions, i.e., no prestress of any kind was applied to the specimens. The tests were conducted in accordance with procedures given in ASTM C 597 (ASTM 2005c).

One P-wave and one S-wave velocity were determined axially through each specimen. Six radial P-wave velocities were determined, i.e., two transverse to each other at elevations of $1 / 4,1 / 2$, and $3 / 4$ of the specimen height. Two radial S-wave velocities were measured; both of these determinations were made at the mid-height of the specimen transverse to each other. The various $\mathrm{P}$ - and $\mathrm{S}$-wave velocities determined for the test specimens are provided in Table 1 . The radial-wave velocities listed in Table 1 are the average values.

\section{Mechanical property tests}

Forty-five mechanical property tests were successfully performed on the type $\mathrm{N}$ mortar specimens to characterize the strength and constitutive properties of the material. All of the mechanical property tests were conducted quasi-statically with axial strain rates on the order of $10^{-4}$ to $10^{-5}$ per second and times to peak load on the order of 5 to $30 \mathrm{~min}$. Mechanical property data were obtained along several stress and strain paths. Undrained compressibility data were obtained during the hydrostatic loading phases of the triaxial compression (TXC) tests and from two hydrostatic compression (HC) tests. Shear and failure data were obtained from unconfined compression (UC) tests, unconsolidated-undrained TXC tests, direct pull (DP) tests, and reduced triaxial extension (RTE) tests. One-dimensional compressibility data were obtained from undrained uniaxial strain (UX) tests with lateral stress measurements, or $\mathrm{K}_{\mathrm{o}}$ tests. Two types of undrained strain-path tests were conducted during the test program. All of the strain-path tests were initially loaded under uniaxial strain boundary conditions to a prescribed level of stress or strain. At the end of the UX loading, constant axial-to-radial-strain ratios (ARSR) of 0 and -2.o were applied. The ARSR $=0$ path is a constant axial strain unloading path and produces a forced state of volumetric expansion; these tests will be 
referred to as $\mathrm{UX} / \mathrm{BX}$ tests. The $\mathrm{ARSR}=\mathbf{- 2 . 0}$ path is a constant volume strain loading path, and these tests will be referred to as UX/CV tests. The terms undrained and unconsolidated signify that no pore fluid (liquid or gas) was allowed to escape or drain from the membrane-enclosed specimens. The completed test matrix is presented in Table 2, which lists the types of tests conducted, number of tests, test numbers for each group, test numbers of the specimens that had cyclic loading, and nominal peak radial stress applied to specimens prior to shear loading or during the $\mathrm{HC}, \mathrm{UX}$, or strain-path loadings.

\section{Specimen preparation}

The mechanical property test specimens were cut from sections of type $\mathrm{N}$ mortar using a diamond-bit core barrel by following the procedures provided in ASTM C 42 (ASTM 2005b). The test specimens were cut to the correct length, and the ends were ground flat and parallel to each other and perpendicular to the sides of the core in accordance with procedures in ASTM D 4543 (ASTM 2005e). The prepared test specimens had a nominal height of $110 \mathrm{~mm}$ and diameter of $50 \mathrm{~mm}$.

Prior to testing, each specimen was placed between a hardened steel top and base caps. With the exception of the UC and the DP test specimens, two o.6-mm-thick membranes and an Aqua seal $®$ membrane were placed around the specimen and the exterior of the outside membrane was coated with a liquid synthetic rubber to inhibit deterioration caused by the confining-pressure fluid (Figure 1). The fluid was a mixture of kerosene and hydraulic oil. Finally, the specimen, along with its top-cap and basecap assembly, was placed on the instrumentation stand of the test apparatus, and the instrumentation setup was initiated.

\section{Test devices}

Four sets of test devices were used in this test program. The axial load for all of the UC tests was provided by a 3.3-MN $(750,000-\mathrm{lb})$ loader. The application of load was manually controlled with this test device. No pressure vessel was required for the UC tests; only a base, load cell, vertical and radial deformeters were necessary.

Direct pull tests were performed by using the direct pull apparatus, in which end caps were attached to unconfined specimens with a highmodulus, high-strength epoxy. A manual hydraulic pump was used 
Table 2. Completed type $\mathrm{N}$ mortar test matrix.

\begin{tabular}{|c|c|c|c|c|}
\hline Type of Test & No. of Tests & Test Nos. & $\begin{array}{l}\text { Cycles in Test } \\
\text { Nos. }\end{array}$ & $\begin{array}{l}\text { Nominal Peak } \\
\text { Radial Stress, } \\
\text { MPa }\end{array}$ \\
\hline Hydrostatic Compression & 2 & $15-16$ & 16 & Max \\
\hline \multirow[t]{10}{*}{ Triaxial Compression } & 4 & $07-10$ & & 0 \\
\hline & 2 & $26-27$ & & 2.5 \\
\hline & 2 & 28,29 & & 5 \\
\hline & 2 & 30,31 & 31 & 10 \\
\hline & 2 & 17,18 & 18 & 20 \\
\hline & 2 & 34,49 & 49 & 35 \\
\hline & 2 & 32,33 & 33 & 50 \\
\hline & 2 & 36,37 & 37 & 100 \\
\hline & 2 & 38,51 & 51 & 200 \\
\hline & 2 & $52-53$ & 53 & 400 \\
\hline UX Strain & 2 & 23,24 & 24 & Max \\
\hline \multirow[t]{2}{*}{ UX/BX } & 2 & 46,47 & & 25 \\
\hline & 2 & 25,48 & & 50 \\
\hline \multirow[t]{3}{*}{ UX/CV } & 2 & 44,45 & & 20 \\
\hline & 2 & 41,42 & & 50 \\
\hline & 1 & 43 & & 100 \\
\hline \multirow[t]{3}{*}{ RTE } & 2 & 05,06 & & 20 \\
\hline & 2 & 03,04 & & 40 \\
\hline & 2 & 01,02 & & 60 \\
\hline DP & 4 & $11-14$ & & 0 \\
\hline Total \# Tests: & 45 & & & \\
\hline
\end{tabular}

to pressurize the direct pull chamber. When the direct pull chamber was pressurized, a piston retracted and produced tensile loading on the test specimen. Measurements for the loading of the specimen were recorded by the load cell. 


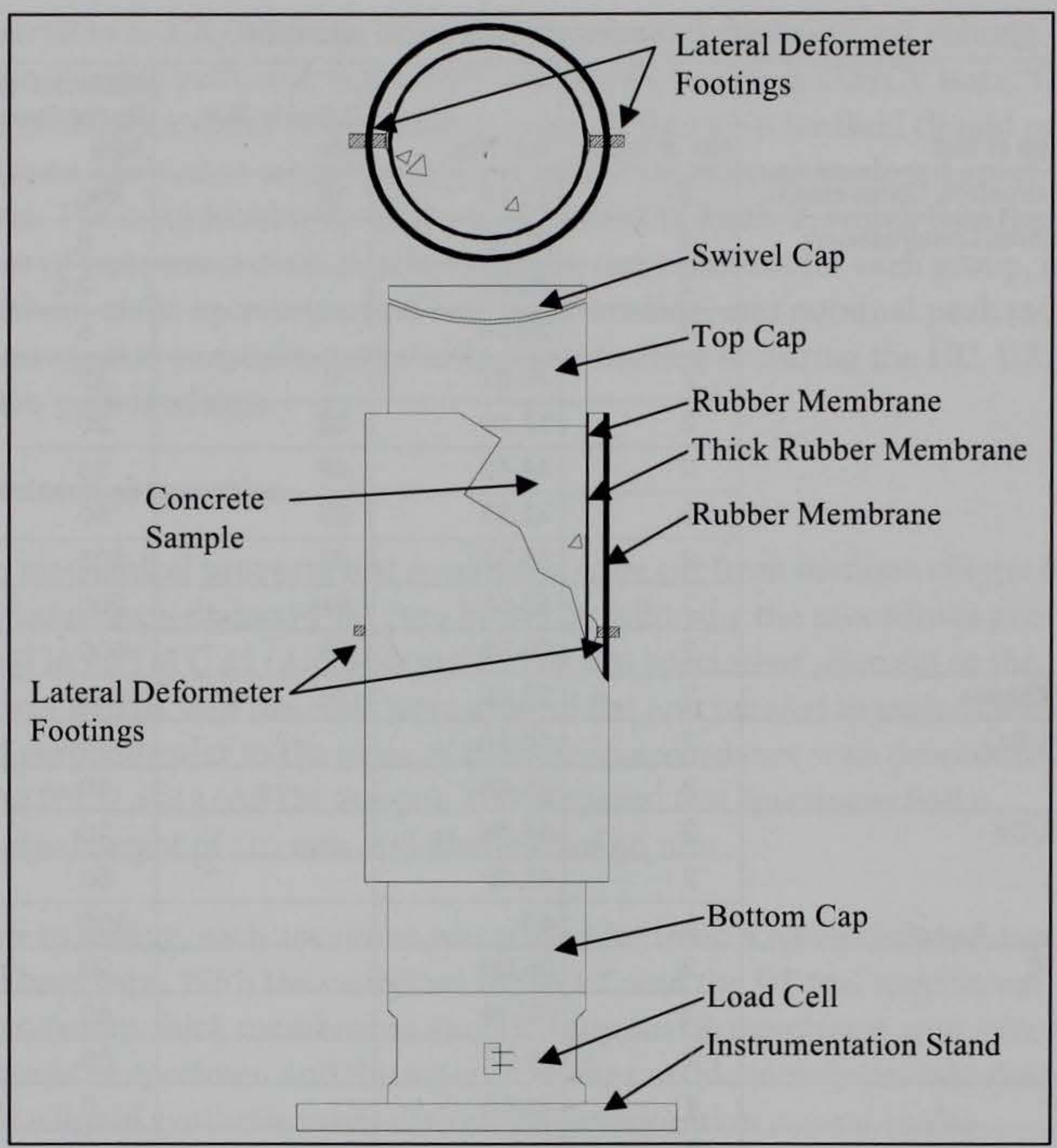

Figure 1. Typical test specimen setup.

To perform a RTE test, a static high-pressure triaxial test (HPTX) device (Figure 2) was used. This device was manually controlled and can be pressurized up to $100 \mathrm{MPa}$. The pumping equipment that was used during the operation of this device limited the peak pressure to $70 \mathrm{MPa}$. When the triaxial extension top cap was used with the HPTX device, independent control of the vertical and lateral stresses was permitted. The specimen top cap was bolted to the extension loading piston, and the surface on top of the piston was pressurized. During a RTE test, the confining pressure (or radial stress) was kept constant while the vertical stress was reduced (Akers et al. 1986). 


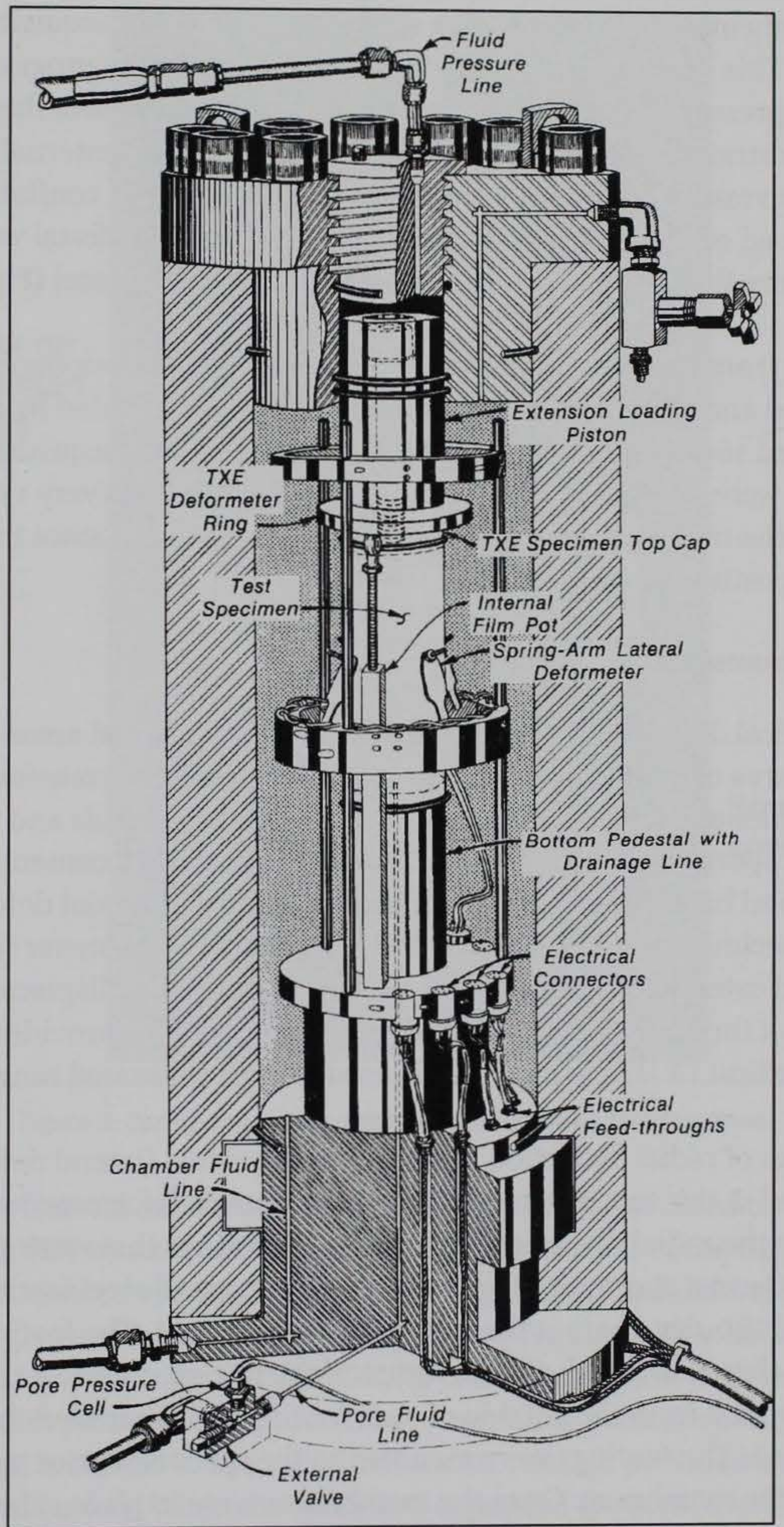

Figure 2. HPTX test device with TXE top cap.

All of the remaining tests were conducted in a 600-MPa-capacity pressure vessel, and the axial load was provided by an $8.9-\mathrm{MN}$ loader. With the 8.9-MN (2-million-lb) loader, the application of load, pressure, and axial 
displacement were regulated by a servo-controlled data acquisition system. This servo-controlled system allowed the user to program rates of load, pressure, and axial displacement in order to achieve the desired stress or strain path. Confining pressure was measured external to the pressure vessel by a pressure transducer mounted in the confining fluid line. A load cell mounted in the base of the specimen pedestal was used to measure the applied axial loads inside the pressure vessel (Figure 1).

Outputs from the various instrumentation sensors were electronically amplified and filtered, and the conditioned signals recorded by computercontrolled 16-bit analog-to-digital converters. The data acquisition systems were programmed to sample the data channels every 1 to $5 \mathrm{sec}$, convert the measured voltages to engineering units, and store the data for further posttest processing.

\section{Test instrumentation}

The vertical deflection measurement system in all the test areas except the DP test area consisted of two linear variable differential transformers (LVDTs) mounted vertically on the instrumentation stands and positioned 180-deg apart. They were oriented to measure the displacement between the top and base caps, thus providing a measure of the axial deformations of the specimen. For the confined tests, a linear potentiometer was mounted external to the pressure vessel to measure the displacement of the piston through which axial loads were applied. This provided a backup to the vertical LVDTs in case they exceeded their calibrated range.

Two types of radial deflection measurement systems (lateral deformeters) were used in this test program. The output of each deformeter was calibrated to the radial displacement of the two footings that were glued to the sides of the test specimen (Figure 1). These two small steel footings were mounted 180-deg apart at the specimen's mid-height. The footing faces were machined to match the curvature of the test specimen. A threaded post extended from the outside of each footing and protruded through the membrane. The footings were mounted to the specimen prior to placement of the membrane. Once the membranes were in place, steel caps were screwed onto the threaded posts to seal the membrane to the footing. The lateral deformeter ring was attached to these steel caps with setscrews. The completed specimen lateral deformeter setup is shown in Figure 3. 


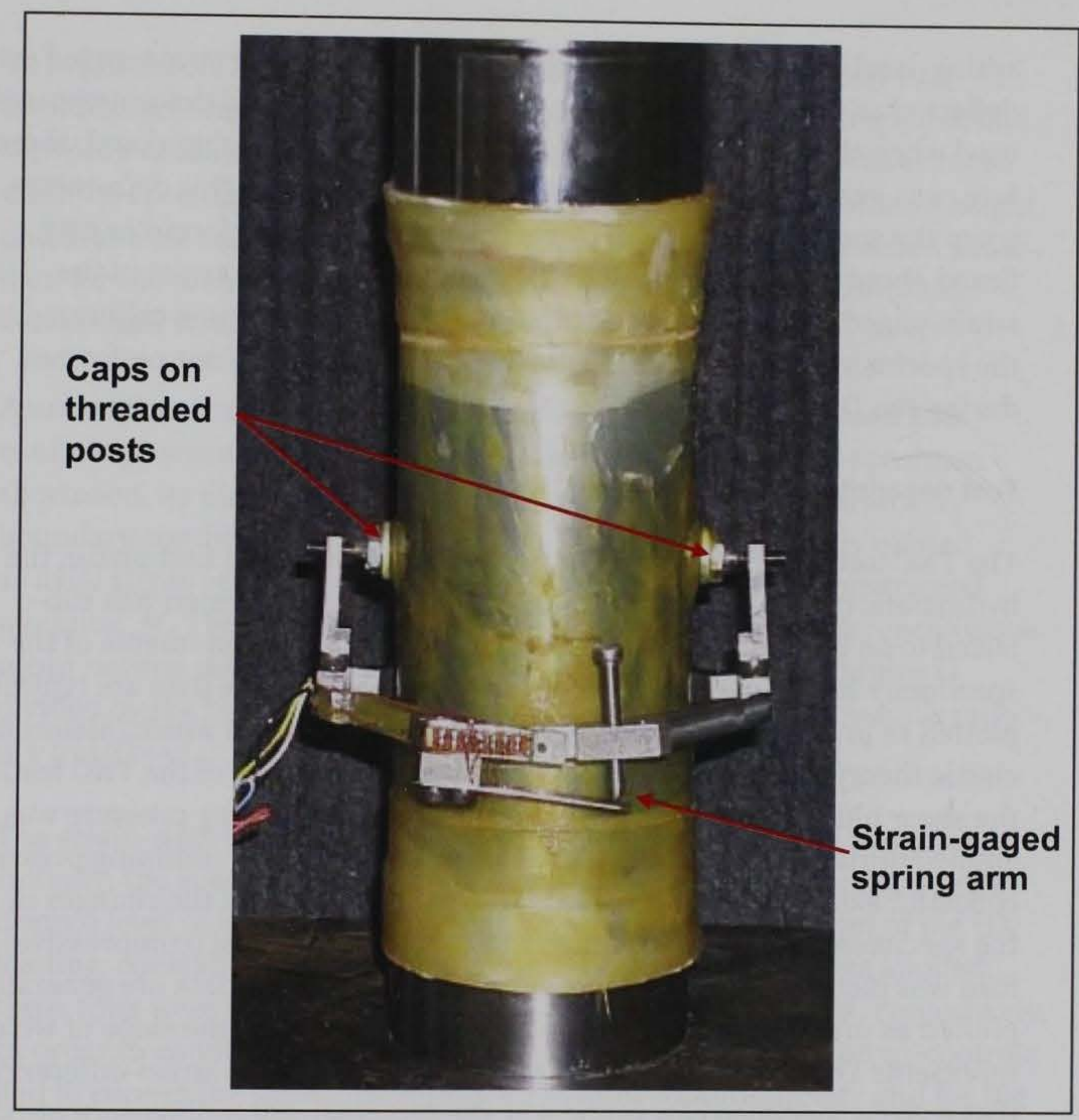

Figure 3. Spring-arm lateral deformeter mounted on test specimen.

One type of lateral deformeter consisted of an LVDT mounted on a hinged ring; the LVDT measured the expansion or contraction of the ring. This lateral deformeter was used over smaller ranges of radial deformation when the greatest measurement accuracy was required. This lateral deformeter was used for all of the HC, UC, UX, and strain-path tests and for TXC test specimen 26 conducted at a confining pressure of 2.5 MPa. This design is similar to the radial-deformeter design provided by Bishop and Henkel (1962). When the specimen expanded (or contracted), the hinged-deformeter ring opened up (or closed) causing a change in the electrical output of the horizontally mounted LVDT.

The second type of lateral deformeter, which was used for all of the TXC tests excluding test specimen 26 , consisted of two strain-gaged 
spring-steel arms mounted on a double-hinged ring; the strain-gaged arms deflected as the ring expanded or contracted. This lateral deformeter was used when the greatest radial deformation range was required and, therefore, was less accurate than the LVDT deformeter. With this deformeter, when the specimen expanded or contracted, the rigid deformeter ring flexed about its hinge causing a change in the electrical output of the strain-gaged spring-arm. The output of the spring-arms was calibrated to the specimen's deformation. Radial measurements were not performed during the DP tests.

\section{Test descriptions}

The TXC tests were conducted in two phases. During the first phase, the hydrostatic compression phase, the cylindrical test specimen was subjected to an increase in hydrostatic pressure while measurements of the specimen's height and diameter changes were made. The data are typically plotted as pressure versus volumetric strain, the slope of which, assuming elastic theory, is the bulk modulus, $K$. The second phase of the TXC test, the shear phase, was conducted after the desired confining pressure was applied during the $\mathrm{HC}$ phase. While holding the desired confining pressure constant, axial load was increased, and measurements of the changes in the specimen's height and diameter were made. The axial (compressive) load was increased until the specimen failed. The shear data are generally plotted as principal stress difference versus axial strain, the slope of which represents Young's modulus, $E$. The maximum principal stress difference that a given specimen can support or the principal stress difference at $15 \%$ axial strain during the shear loading, whichever occurs first, is defined as the peak strength.

The UC tests were performed in accordance with ASTM C 39 (ASTM 2005a). The UC test is a TXC test in which no confining pressure is applied. The maximum principal stress difference observed during a UC test is defined as the unconfined compressive strength of the material.

Extension shear data were obtained for type $\mathrm{N}$ mortar by performing direct pull (DP) tests and reduced triaxial extension (RTE) tests. The DP tests have no confining pressure during the tests. To conduct the DP tests, end caps were attached with epoxy to the specimen. The end caps were screwed into the direct pull apparatus, and the specimen was pulled apart vertically when pressure was applied to the piston. The RTE tests were conducted with the HPTX device and the TXE top cap (Figure 2). 
To begin the RTE test, the specimen was loaded hydrostatically to a desired confining pressure. After the hydrostatic loading was applied and while the radial stress was held constant, the vertical stress was reduced until the specimen failed. Throughout the RTE test, the specimen's height and diameter changes were recorded (Akers et al. 1986). Extension shear data for the material is generally plotted as principal stress difference versus axial strain.

A uniaxial strain (UX) test was conducted by applying axial load and confining pressure simultaneously so that, as the cylindrical specimen shortened, its diameter remained unchanged, i.e., zero radial strain boundary conditions were maintained. The data are generally plotted as axial stress versus axial strain, the slope of which is the constrained modulus, $M$. The data are also plotted as principal stress difference versus mean normal stress, the slope of which is twice the shear modulus $G$ divided by the bulk modulus $K$, i.e., $2 G / K$, or, in terms of Poisson's ratio $v$, $3(1-2 v) /(1+v)$.

The strain-path tests in this test program were conducted in two phases. Initially, the specimen was subjected to a uniaxial-strain loading up to a desired level of mean normal, radial, or axial stress. At the end of the UX loading, constant axial-to-radial-strain ratios of $\mathrm{o}$ or -2.0 were applied; these tests were identified earlier as $\mathrm{UX} / \mathrm{BX}$ and $\mathrm{UX} / \mathrm{CV}$ tests, respectively. In order to conduct these tests, the software controlling the servo-controls had to correct the measured inputs for system compressibility and for the nonlinear calibrations of specific transducers.

\section{Definition of stresses and strains}

During the mechanical property tests, measurements were typically made of the axial and radial deformations of the specimen as confining pressure and/or axial load was applied or removed. These measurements along with the pretest measurements of the initial height and diameter of the specimen were used to convert the measured test data to true stresses and engineering strains. ${ }^{1}$

Axial strain, $\varepsilon_{a}$, was computed by dividing the measured axial deformation, $\Delta h$ (change in height), by the original height $h_{o}$, i.e., $\varepsilon_{\mathrm{a}}=\Delta h / h_{o}$. Similarly, radial strain, $\varepsilon$, was computed by dividing the measured radial deforma-

${ }_{1}^{1}$ Compressive stresses and strains are positive in this report. 
tion, $\Delta d$ (change in diameter), by the original diameter $d_{o}$, i.e., $\varepsilon_{r}=\Delta d / d_{o}$. For this report, volumetric strain was assumed to be the sum of the axial strain and twice the radial strain, $\varepsilon_{v}=\varepsilon_{a}+2 \varepsilon_{r}$.

The principal stress difference, $q$, was calculated by dividing the axial load by the cross-sectional area of the specimen $A$, which is equal to the original cross-sectional area, $A_{0}$, multiplied by $\left(1-\varepsilon_{\mathrm{r}}\right)^{2}$. In equation form,

$$
q=\left(\sigma_{a}-\sigma_{r}\right)=\frac{\text { Axial Load }}{A_{\mathrm{o}}\left(1-\varepsilon_{r}\right)^{2}}
$$

where $\sigma_{a}$ is the axial stress and $\sigma_{r}$ is the radial stress. The axial stress is related to confining pressure and principal stress difference by

$$
\sigma_{a}=q+\sigma_{r}
$$

The mean normal stress, $p$, is the average of the applied principal stresses. In cylindrical geometry,

$$
p=\frac{\left(\sigma_{a}-2 \sigma_{r}\right)}{3}
$$

\section{Results}

Results from all of the mechanical property tests except from the direct pull tests are presented in Plates 1 through 41. One data plate is presented for each test with reliable results. Results from the $\mathrm{HC}$ tests are presented on the plates in four plots, i.e., (a) mean normal stress versus volumetric strain, (b) mean normal stress versus axial strain, (c) radial versus axial strain, and (d) mean normal stress versus radial strain. Each plate for the UC, TXC, RTE, UX, and strain-paths tests displays four plots, i.e., (a) principal stress difference versus mean normal stress, (b) principal stress difference versus axial strain, (c) volumetric strain versus mean normal stress, and (d) volumetric strain versus axial strain. 


\section{Analysis of Test Results}

\section{Hydrostatic compression test results}

Undrained compressibility data were obtained from two $\mathrm{HC}$ tests and during the hydrostatic loading phases of the 18 TXC tests. The pressurevolume data from the two $\mathrm{HC}$ tests are plotted in Figure 4. Unload-reload cycles were applied to $\mathrm{HC}$ test specimen 16 to obtain unload-reload data at intermediate levels of confining stress. The initial dry densities of the specimens for $\mathrm{HC}$ tests 15 and 16 were 1.545 and $1.547 \mathrm{Mg} / \mathrm{m}^{3}$, respectively. Figure 5 presents the pressure time-histories for the $\mathrm{HC}$ tests. During the $\mathrm{HC}$ tests, the pressure was intentionally held constant for a period of time prior to the unloading cycles. During each hold in pressure, the volume strains continued to increase, indicating that type $\mathrm{N}$ mortar is susceptible to creep (Figures 4 and 5). Test specimen 15 pressure was held at $232 \mathrm{MPa}$ for $165 \mathrm{sec}$, during which time a volumetric strain of $0.45 \%$ occurred. At the peak of the first cycle for test specimen 16, the pressure was held at $108 \mathrm{MPa}$ for $260 \mathrm{sec}$, during which time a volumetric strain of $0.64 \%$ occurred. During the second cycle, the pressure was held at $245 \mathrm{MPa}$ for $399 \mathrm{sec}$, and a volumetric strain of $0.50 \%$ occurred.

Pressure-volume data were also obtained during the hydrostatic loading phases of the TXC tests (Figures 6 and 7). The type $\mathrm{N}$ mortar begins to exhibit inelastic strains at a pressure level of approximately $4 \mathrm{MPa}$ and at a volumetric strain of approximately $0.51 \%$. This is the pressure and strain level at which the pressure-volume response and the initial bulk modulus begin to soften appreciably. Pressure-volume data from all of the TXC tests conducted at confining pressures of $100 \mathrm{MPa}$ and above and the $\mathrm{HC}$ curves from Figure 4 are plotted in Figure 7. Based on the data from HC tests and the TXC tests, the initial elastic bulk modulus (K) for type N mortar is approximately $0.71 \mathrm{GPa}$.

\section{Triaxial compression test results}

Shear and failure data were successfully obtained from four unconfined compression tests and 18 unconsolidated-undrained TXC tests. Recall from Chapter 2 that the second phase of the TXC test, the shear phase, is conducted after the desired confining pressure was applied during the $\mathrm{HC}$ phase. The UC tests are a special type of TXC test without the application 


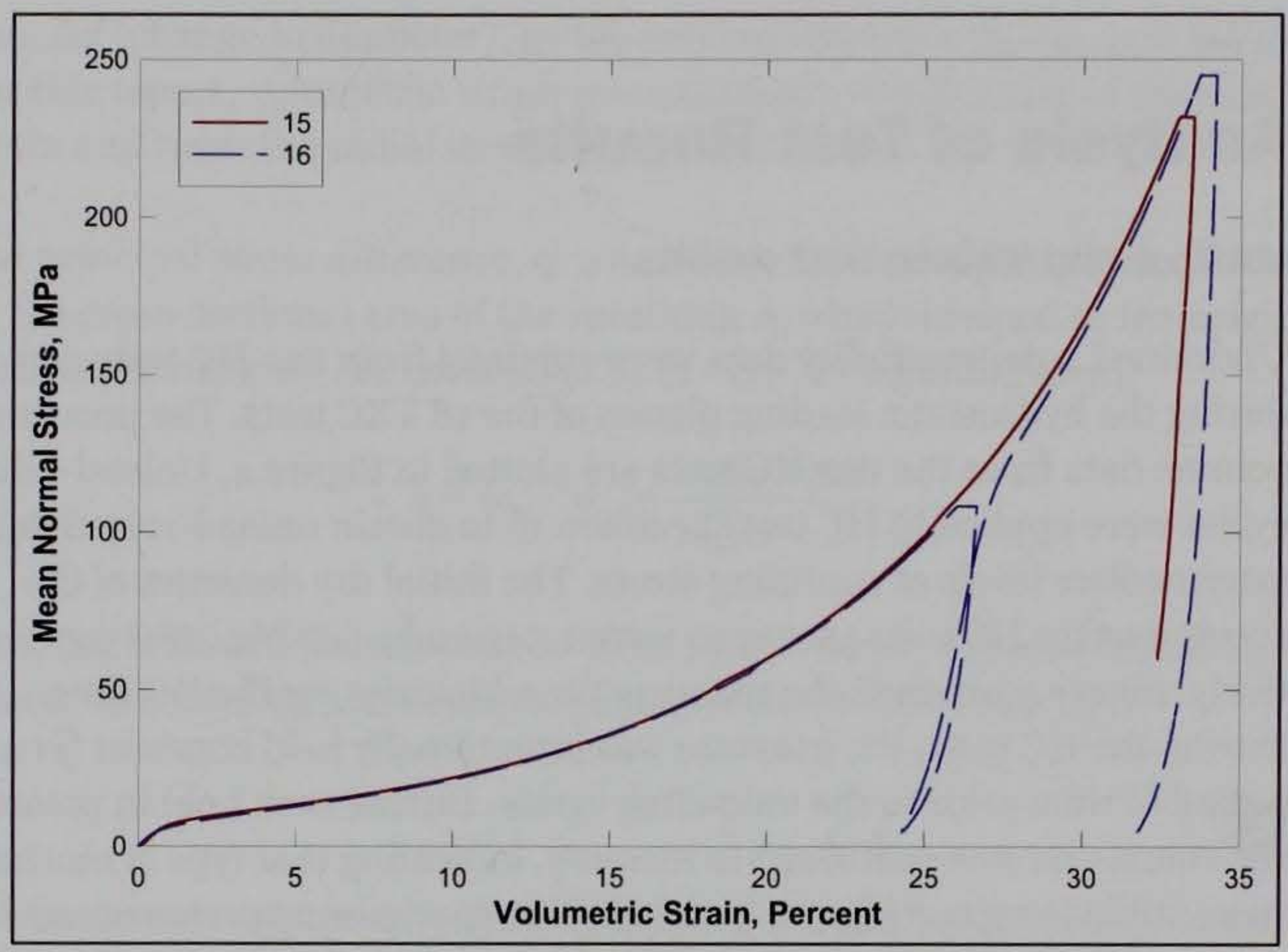

Figure 4. Pressure-volume responses from the $\mathrm{HC}$ tests.

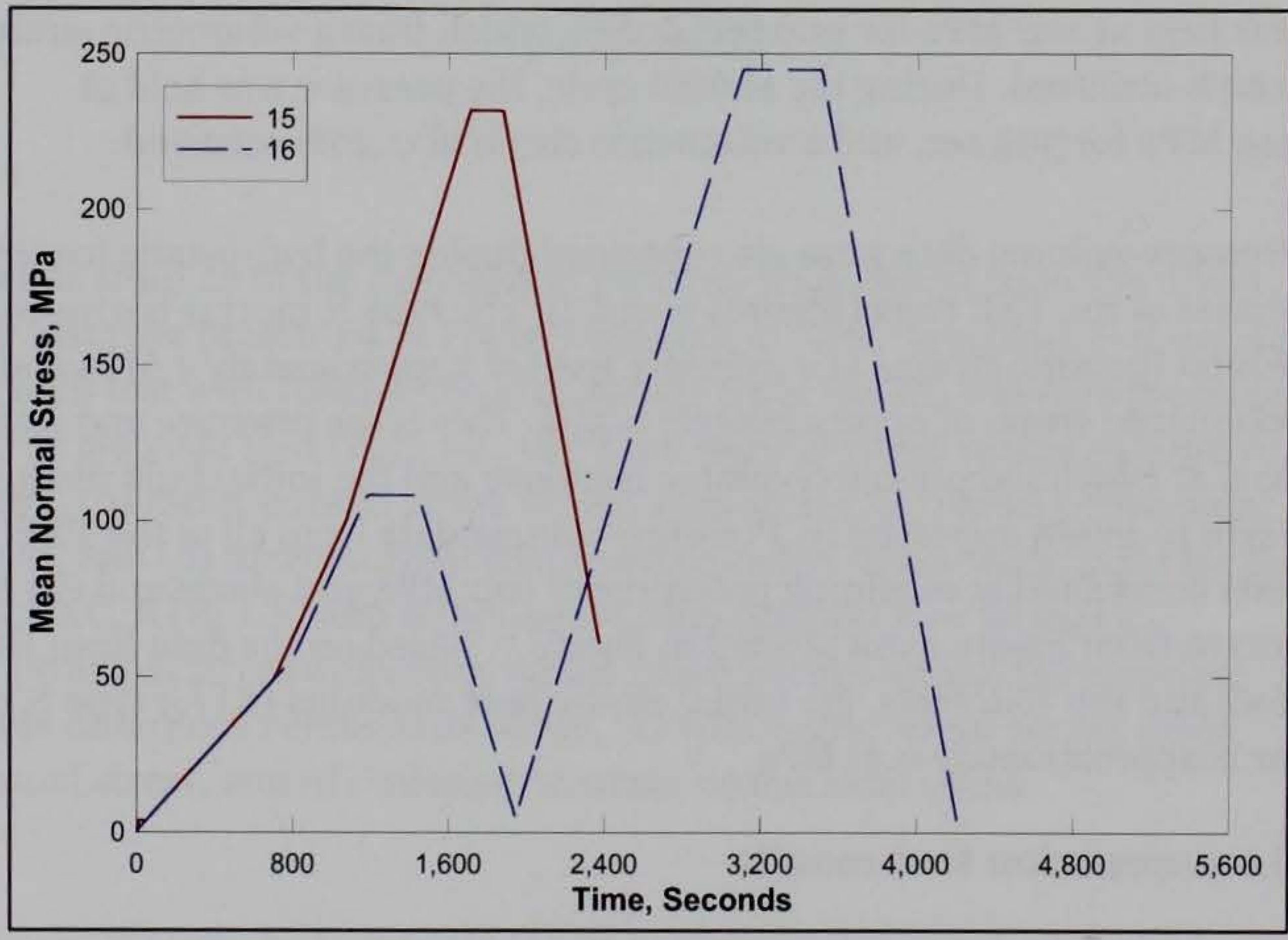

Figure 5. Pressure time-histories from the HC tests. 


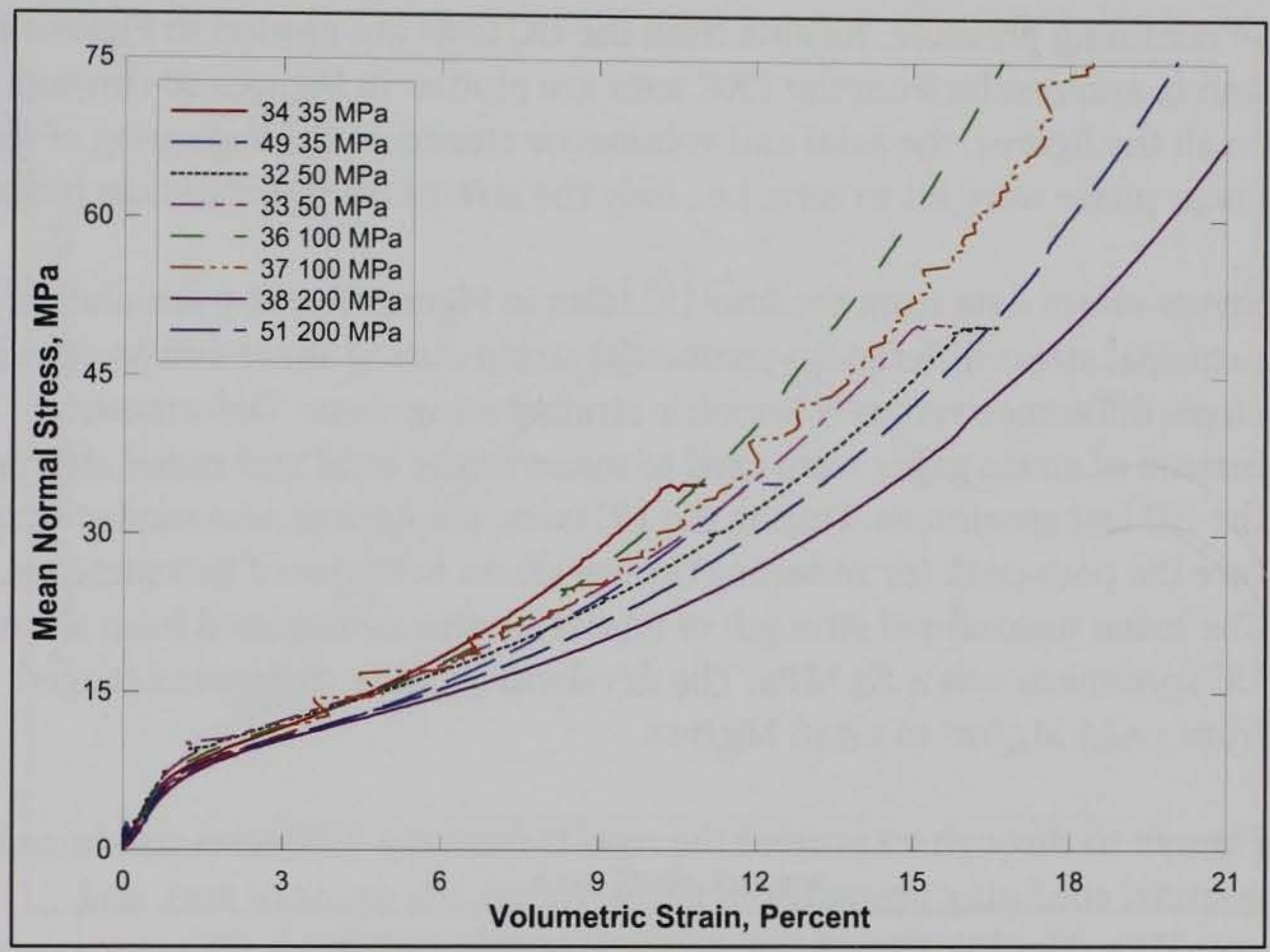

Figure 6. Pressure-volume responses from selected TXC tests.

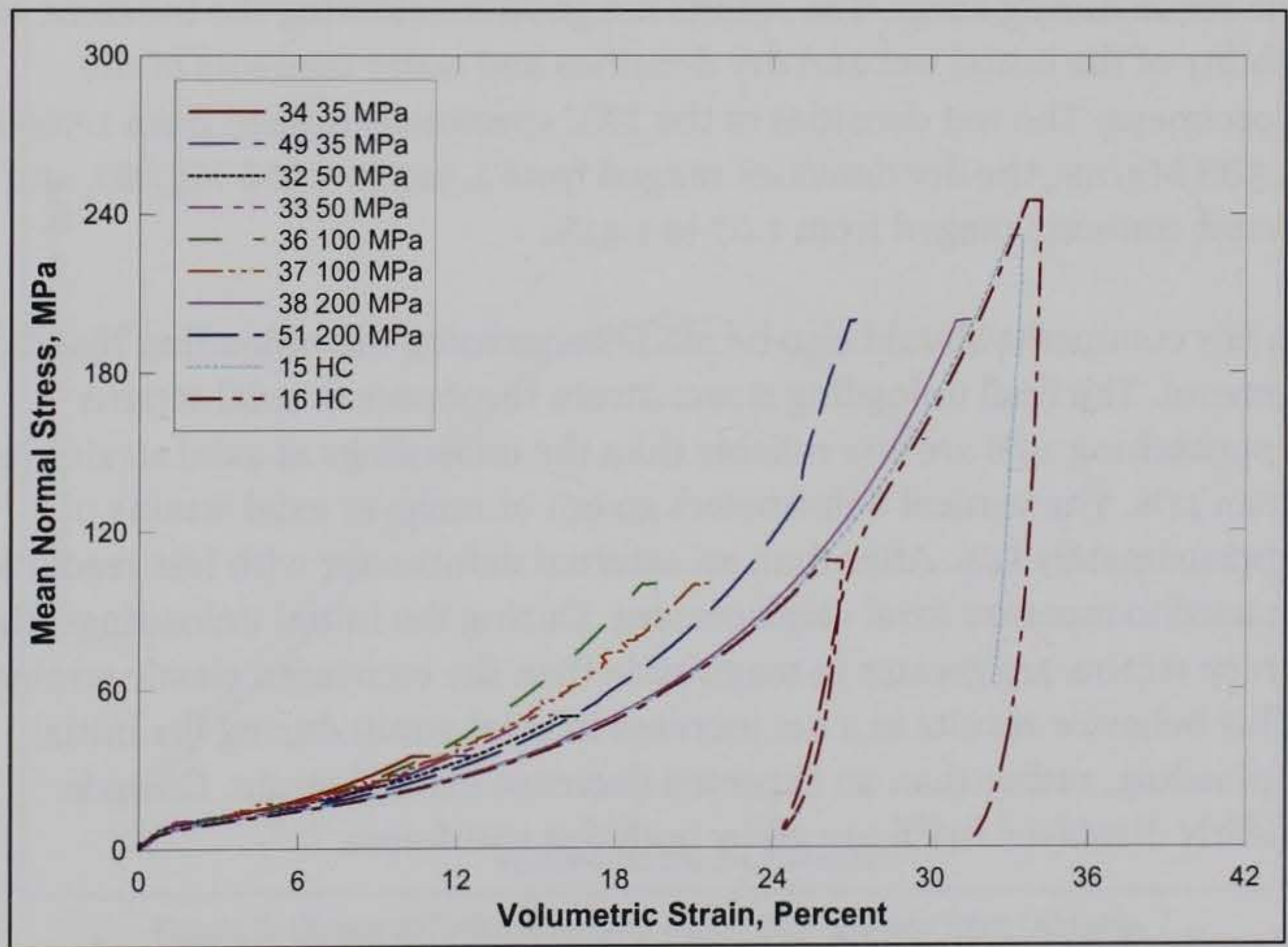

Figure 7. Pressure-volume responses from $\mathrm{HC}$ and TXC tests. 
of confining pressure. Results from the UC tests are plotted in Figures 8 and 9, and results from the TXC tests are plotted in Figures 10 through 27. In all the figures, the axial and volumetric strains at the beginning of the shear phase were set to zero, i.e., only the strains during shear are plotted.

Stress-strain data from the four UC tests in Figures 8 and 9 are plotted as principal stress difference versus axial strain during shear and as principal stress difference versus volumetric strain during shear. Deformeters instead of strain gages were used to measure the axial and radial strains of the UC test specimens. During the UC tests, no attempt was made to capture the post-peak (or softening) stress-strain behavior of this material. The mean unconfined strength of type $\mathrm{N}$ mortar determined from all the UC specimens was $4.85 \mathrm{MPa}$. The dry density of the specimens ranged from $1.543 \mathrm{Mg} / \mathrm{m}^{3}$ to $1.548 \mathrm{Mg} / \mathrm{m}^{3}$.

Figures 10 through 27 present the results from the TXC tests conducted at nominal confining pressures of 2.5, 5, 10, 20,35,50, 100, 200, and $400 \mathrm{MPa}$. The TXC results are plotted as principal stress difference versus axial strain during shear and as principal stress difference versus volumetric strain during shear. The results are good considering the inherent variability of the initial wet and dry densities and water contents of the specimens. The wet densities of the TXC specimens ranged from 1.566 to $1.588 \mathrm{Mg} / \mathrm{m}^{3}$, the dry densities ranged from 1.545 to $1.566 \mathrm{Mg} / \mathrm{m}^{3}$, and the water contents ranged from 1.07 to $1.41 \%$.

A few comments should also be made concerning the unloading results in general. The final unloading stress-strain responses at axial strains approaching $15 \%$ are less reliable than the unloadings at axial strains less than $11 \%$. The vertical deformeters go out of range at axial strains of approximately $11 \%$. After that, an external deformeter with less resolution is used to measure axial displacement. During the initial unloadings, the creep strains are greater in magnitude than the recovered elastic strains. This behavior results in a net increase in axial strain during the initial unloading, rather than an expected decrease in axial strain. Creep is clearly displayed in Figure 26 by both test specimens.

Results of TXC tests conducted at a constant confining pressure of 2.5 MPa are shown in Figures 10 and 11. The dry densities for specimens 26 and 27 were 1.562 and $1.545 \mathrm{Mg} / \mathrm{m}^{3}$, respectively. Test specimen 27 displays some strain softening in Figure 10. The volumetric 


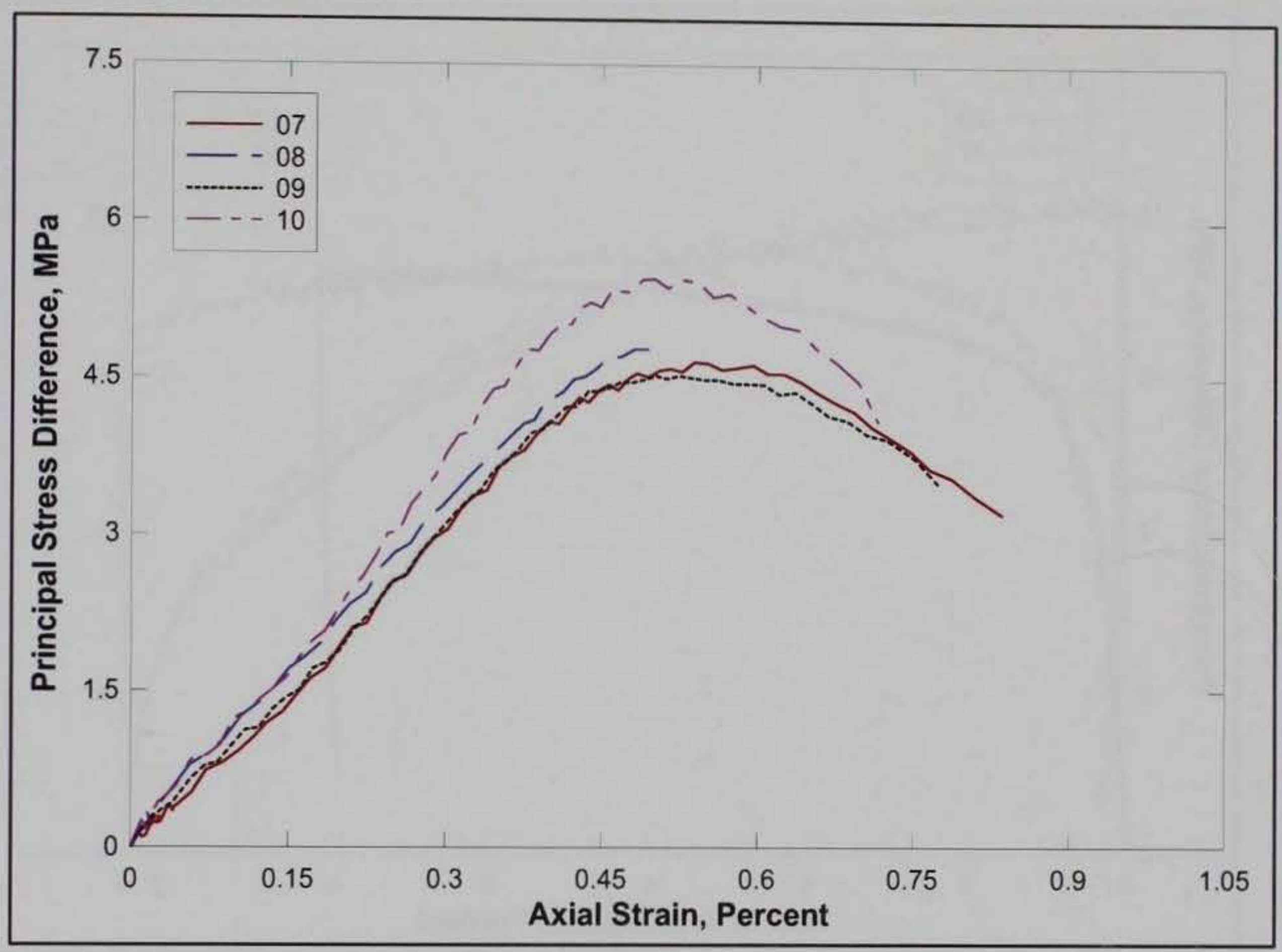

Figure 8. Stress-strain data from UC tests.

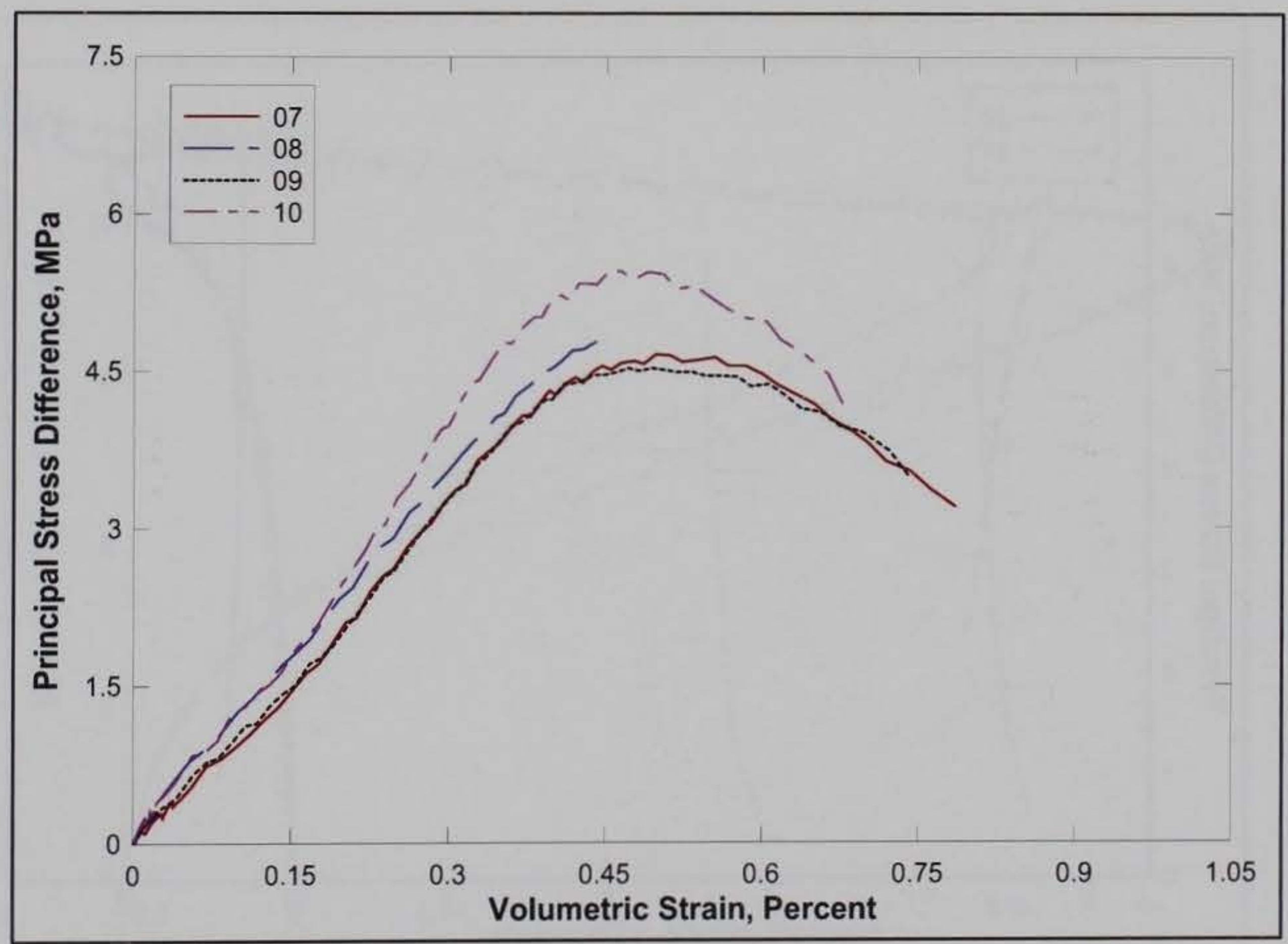

Figure 9. Stress difference-volume strain during shear from UC tests. 


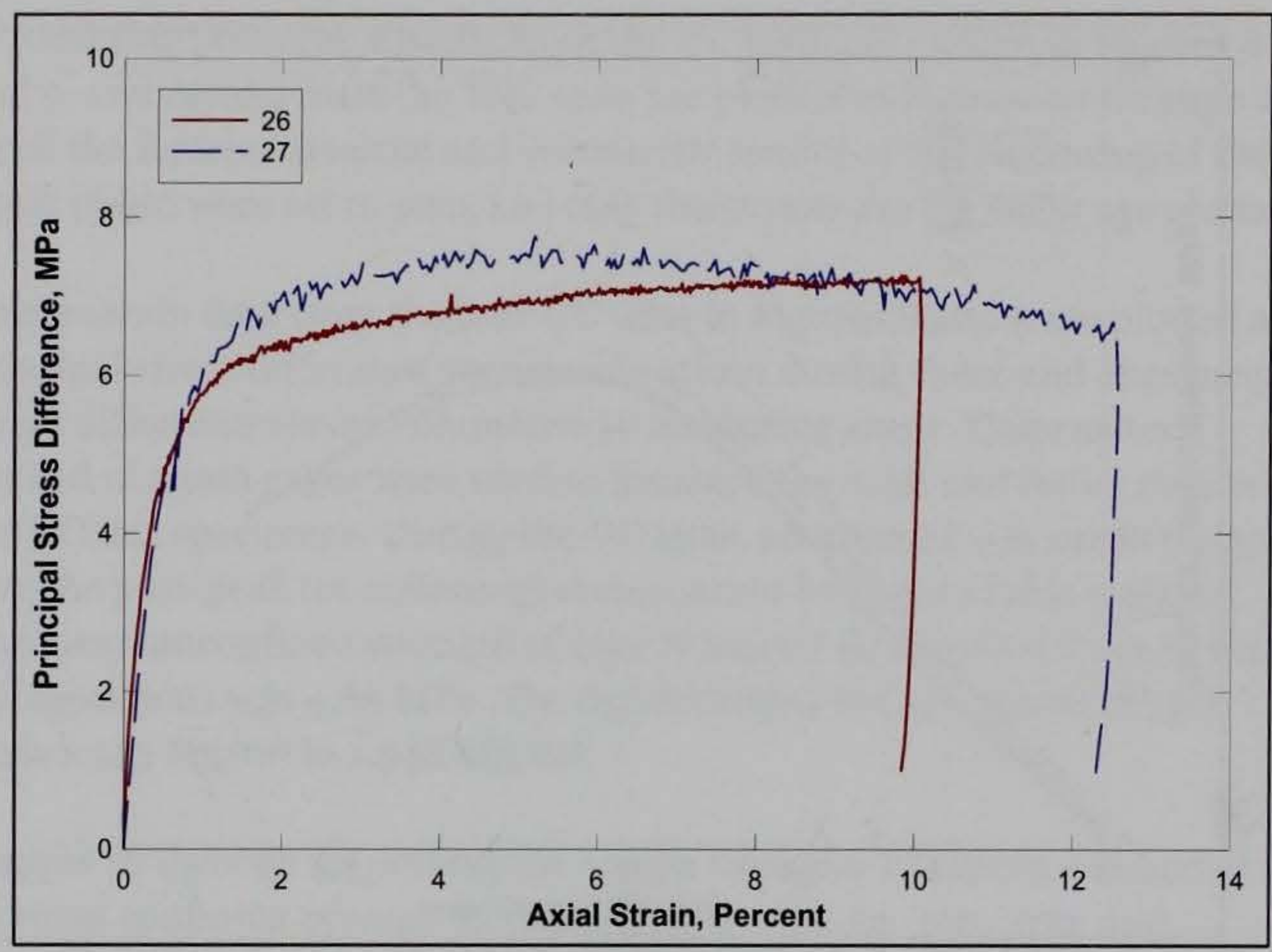

Figure 10. Stress-strain data from TXC tests at a confining pressure of $2.5 \mathrm{MPa}$.

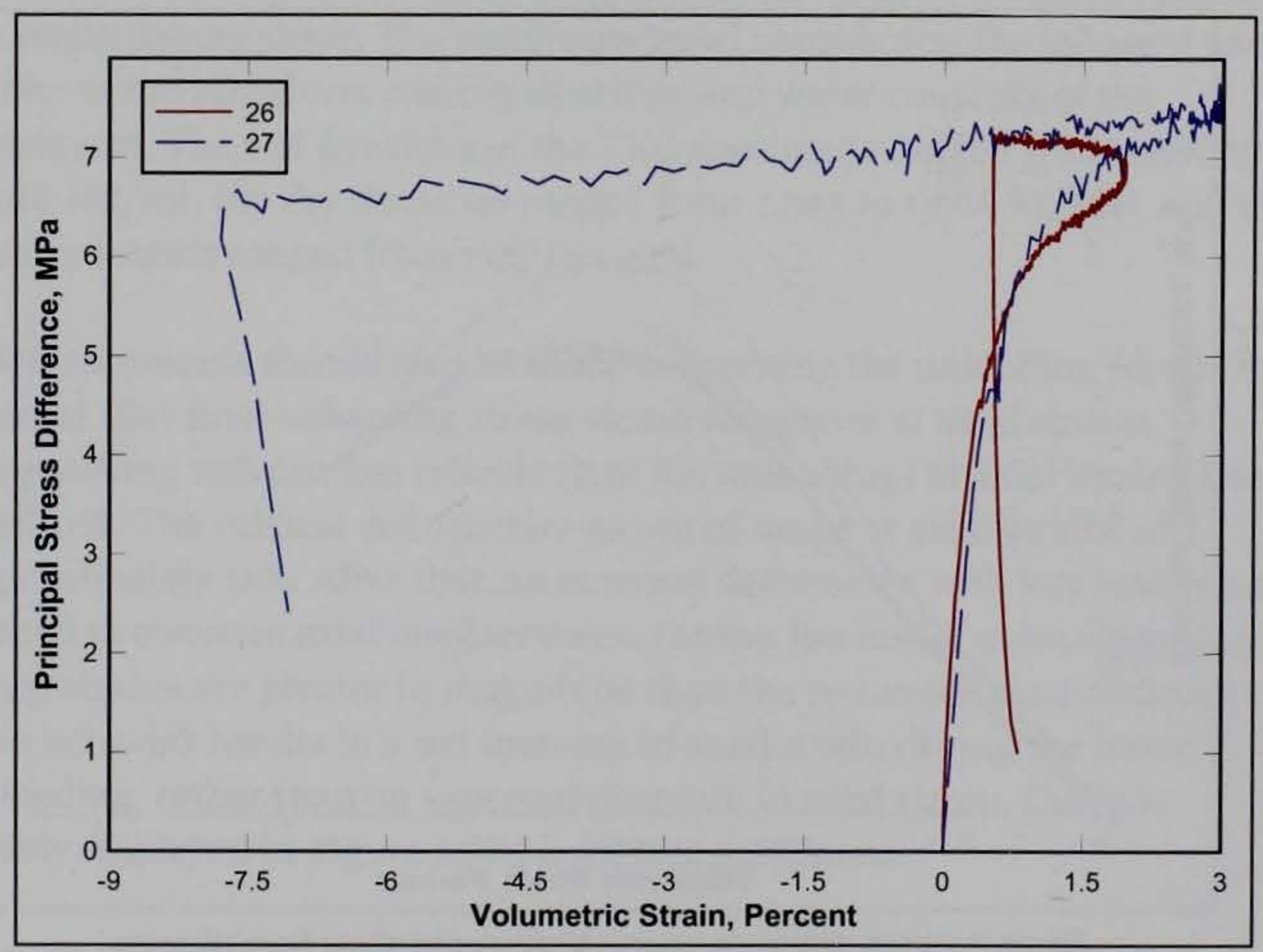

Figure 11. Stress difference-volume strain during shear from TXC tests at a confining pressure of $2.5 \mathrm{MPa}$. 


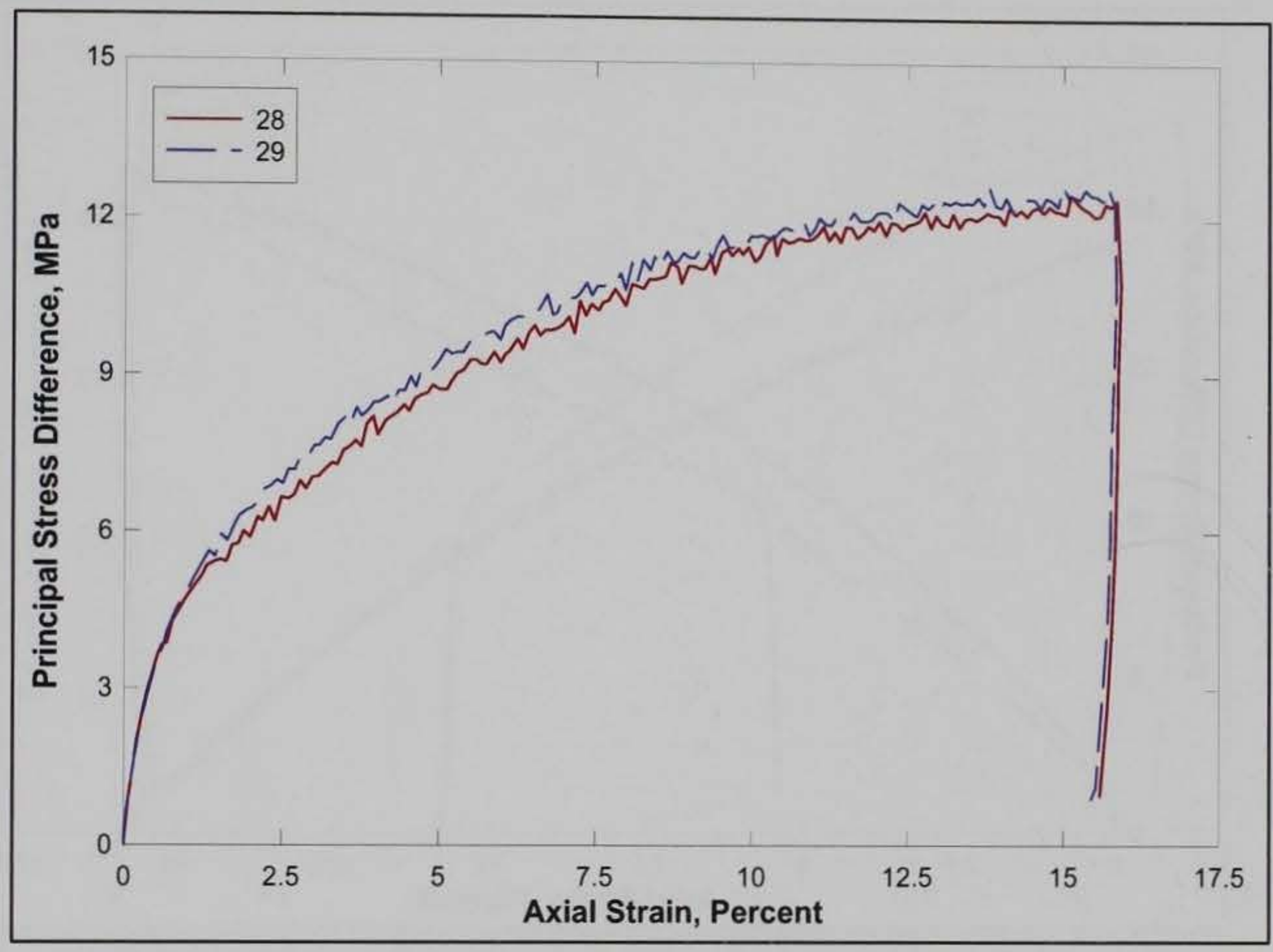

Figure 12. Stress-strain data from TXC tests at a confining pressure of $5 \mathrm{MPa}$.

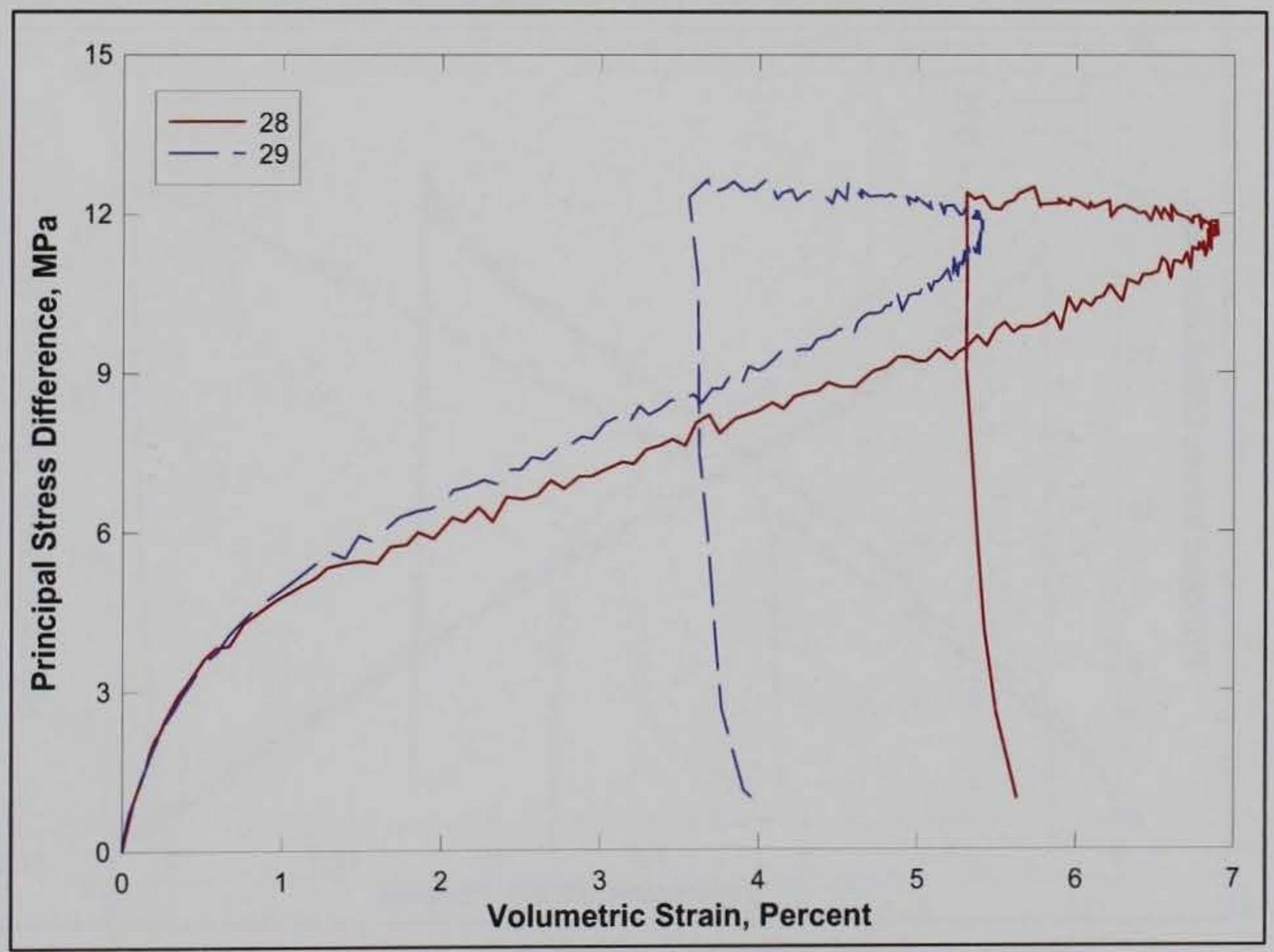

Figure 13. Stress difference-volume strain during shear from TXC tests at a confining pressure of $5 \mathrm{MPa}$. 


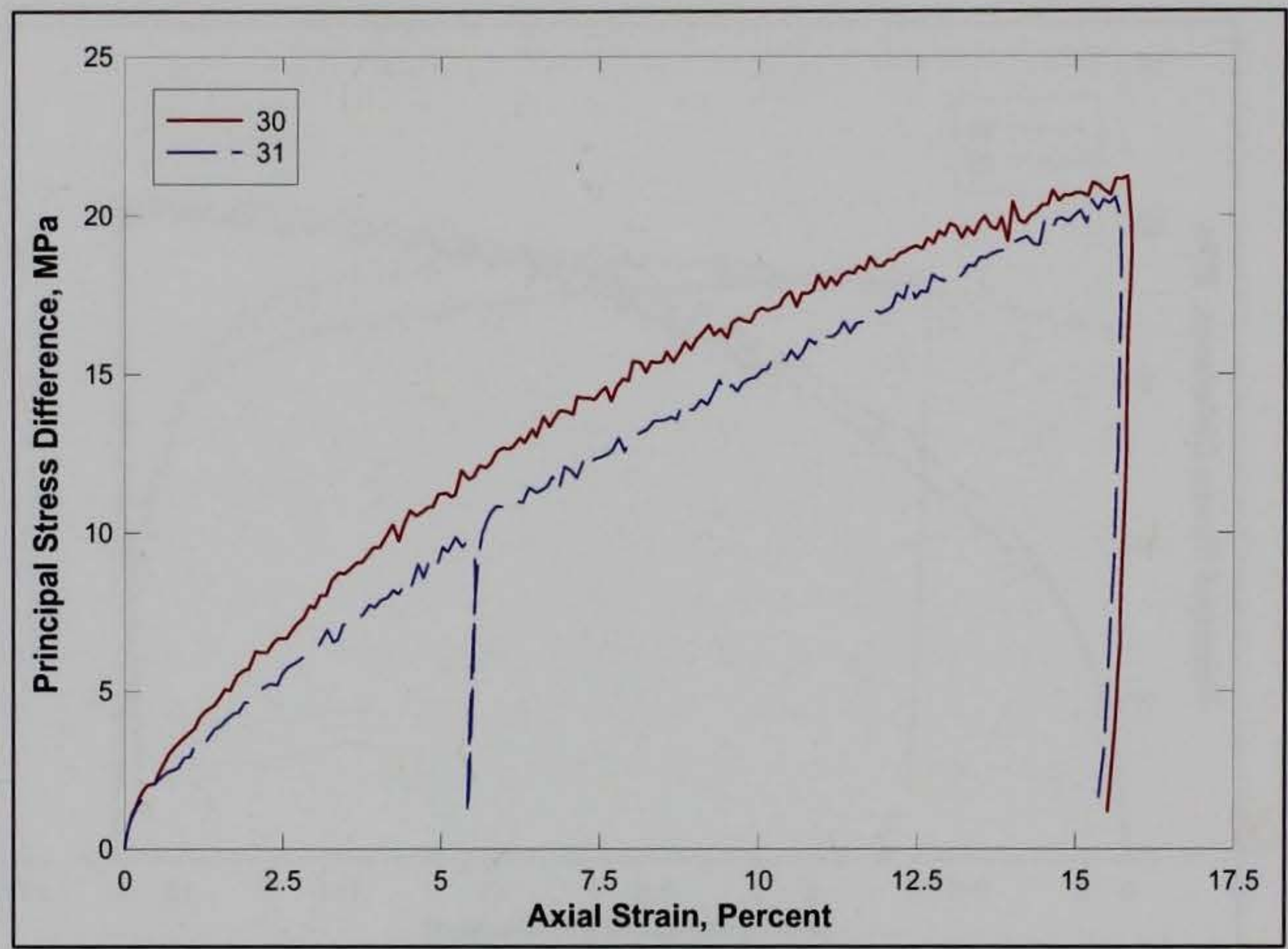

Figure 14. Stress-strain data from TXC tests at a confining pressure of $10 \mathrm{MPa}$.

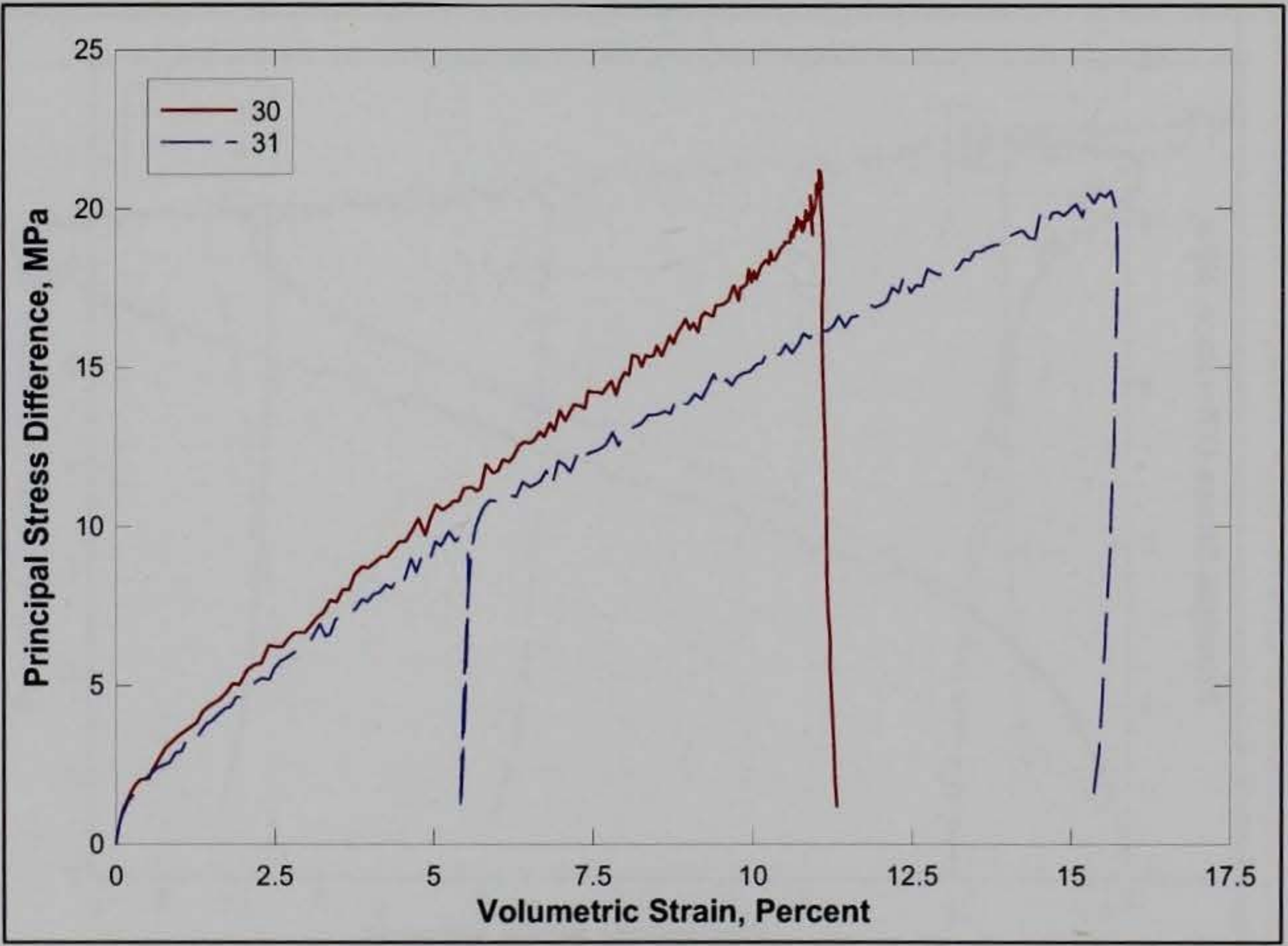

Figure 15. Stress difference-volume strain during shear from TXC tests at a confining pressure of $10 \mathrm{MPa}$. 


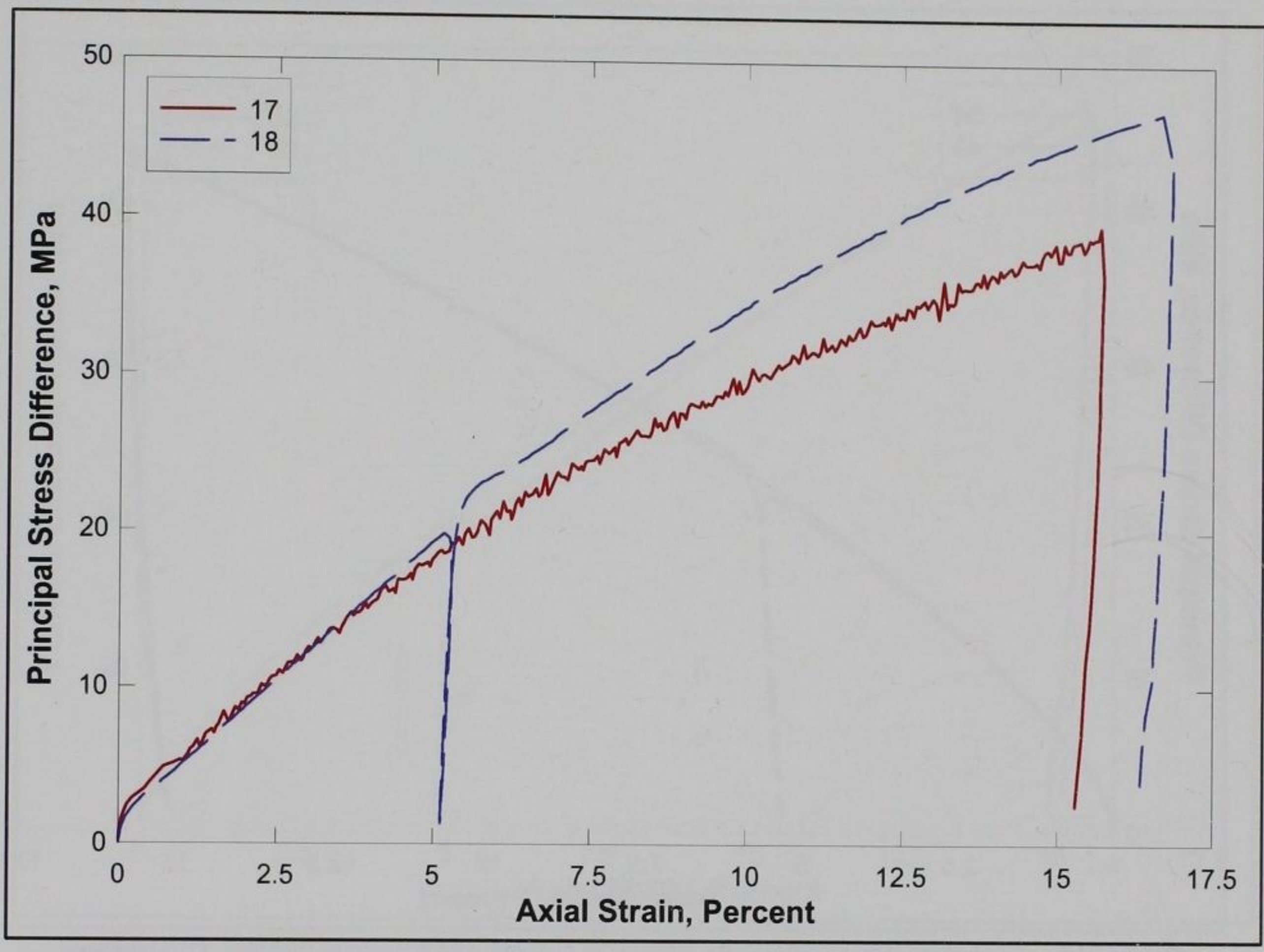

Figure 16. Stress-strain data from TXC tests at a confining pressure of $20 \mathrm{MPa}$.

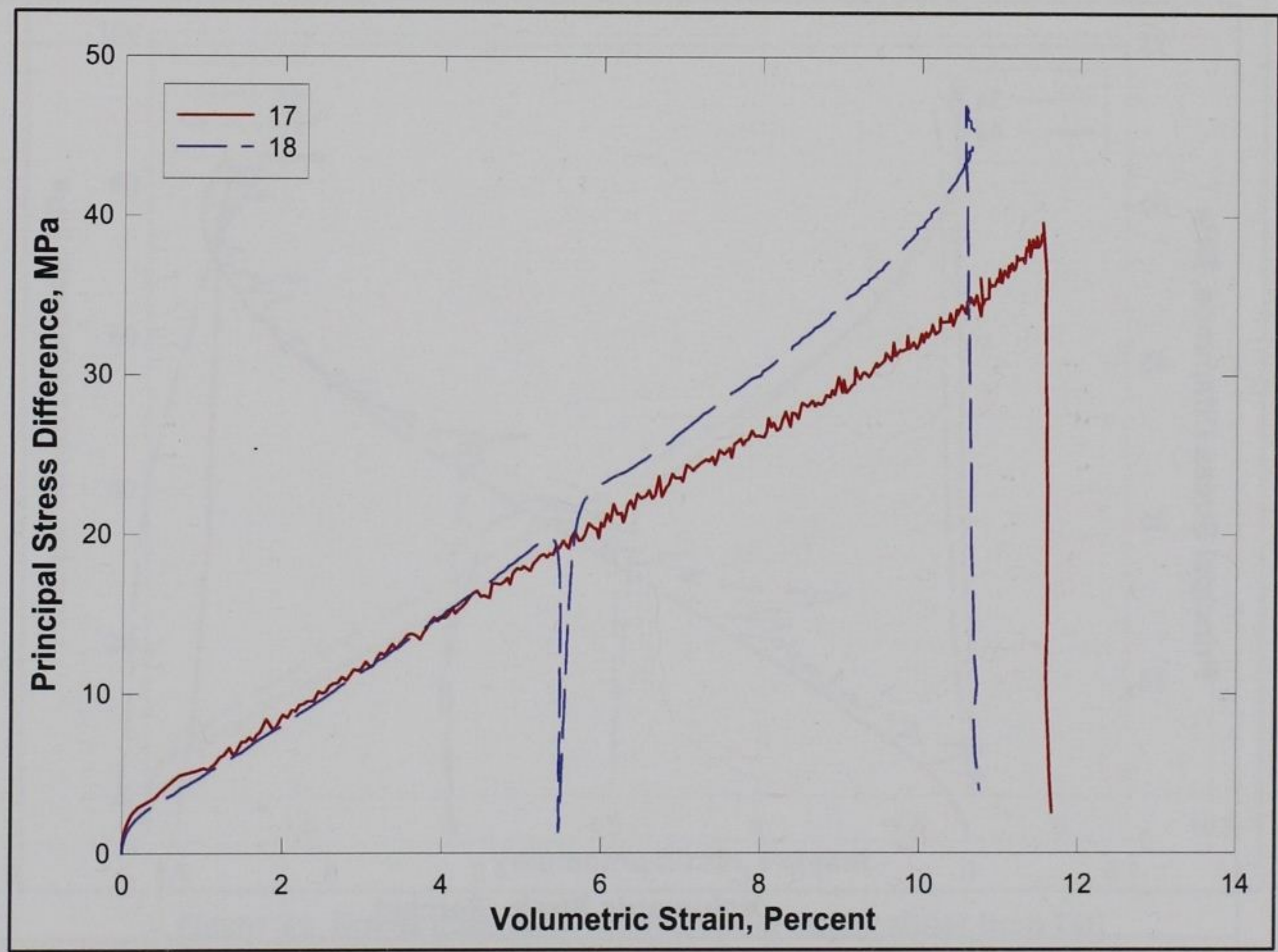

Figure 17. Stress difference-volume strain during shear from TXC tests at a confining pressure of $20 \mathrm{MPa}$. 


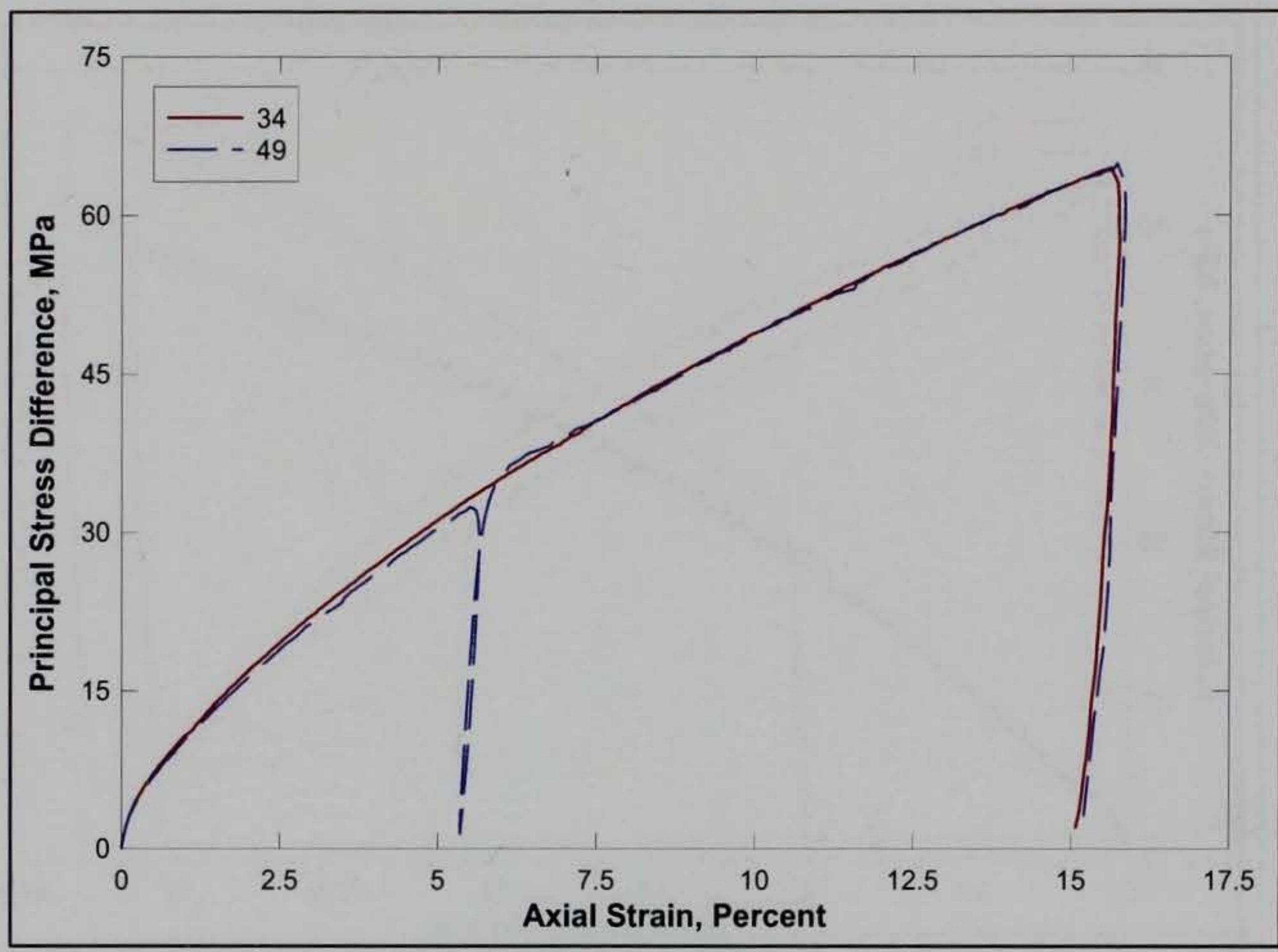

Figure 18. Stress-strain data from TXC tests at a confining pressure of $35 \mathrm{MPa}$.

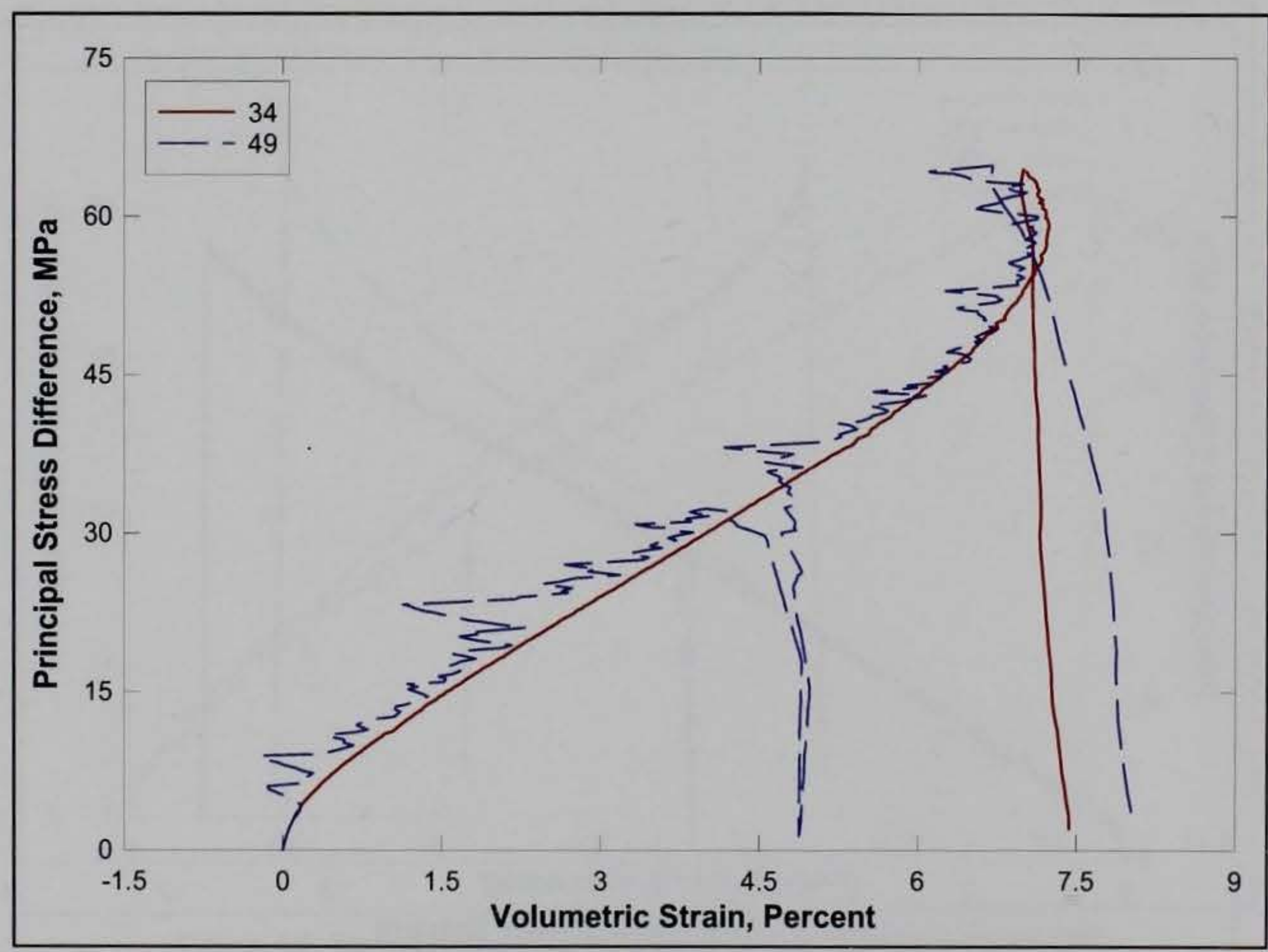

Figure 19. Stress difference-volume strain during shear from TXC tests at a confining pressure of $35 \mathrm{MPa}$. 


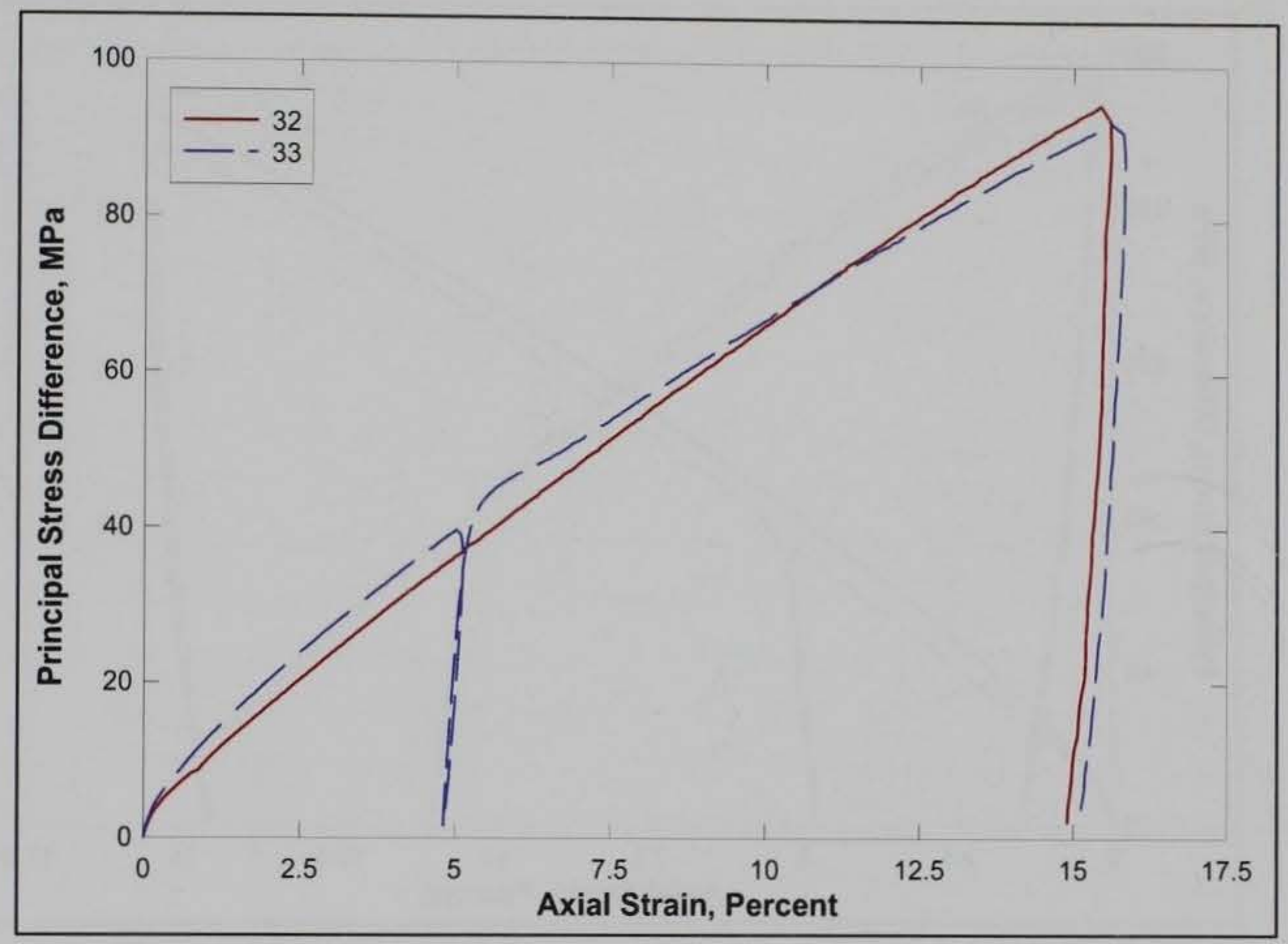

Figure 20. Stress-strain data from TXC tests at a confining pressure of $50 \mathrm{MPa}$.

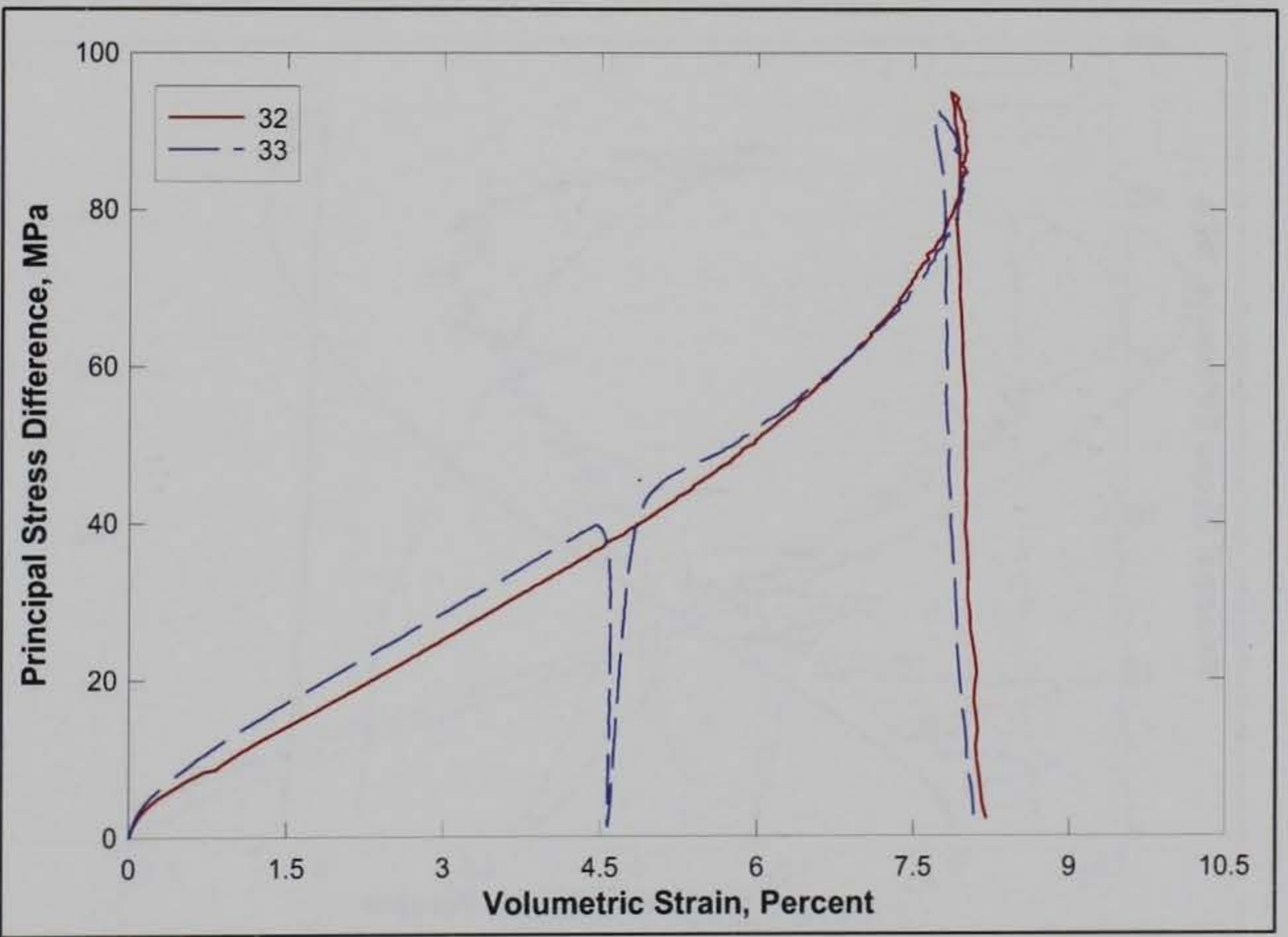

Figure 21. Stress difference-volume strain during shear from TXC tests at a confining pressure of $50 \mathrm{MPa}$. 


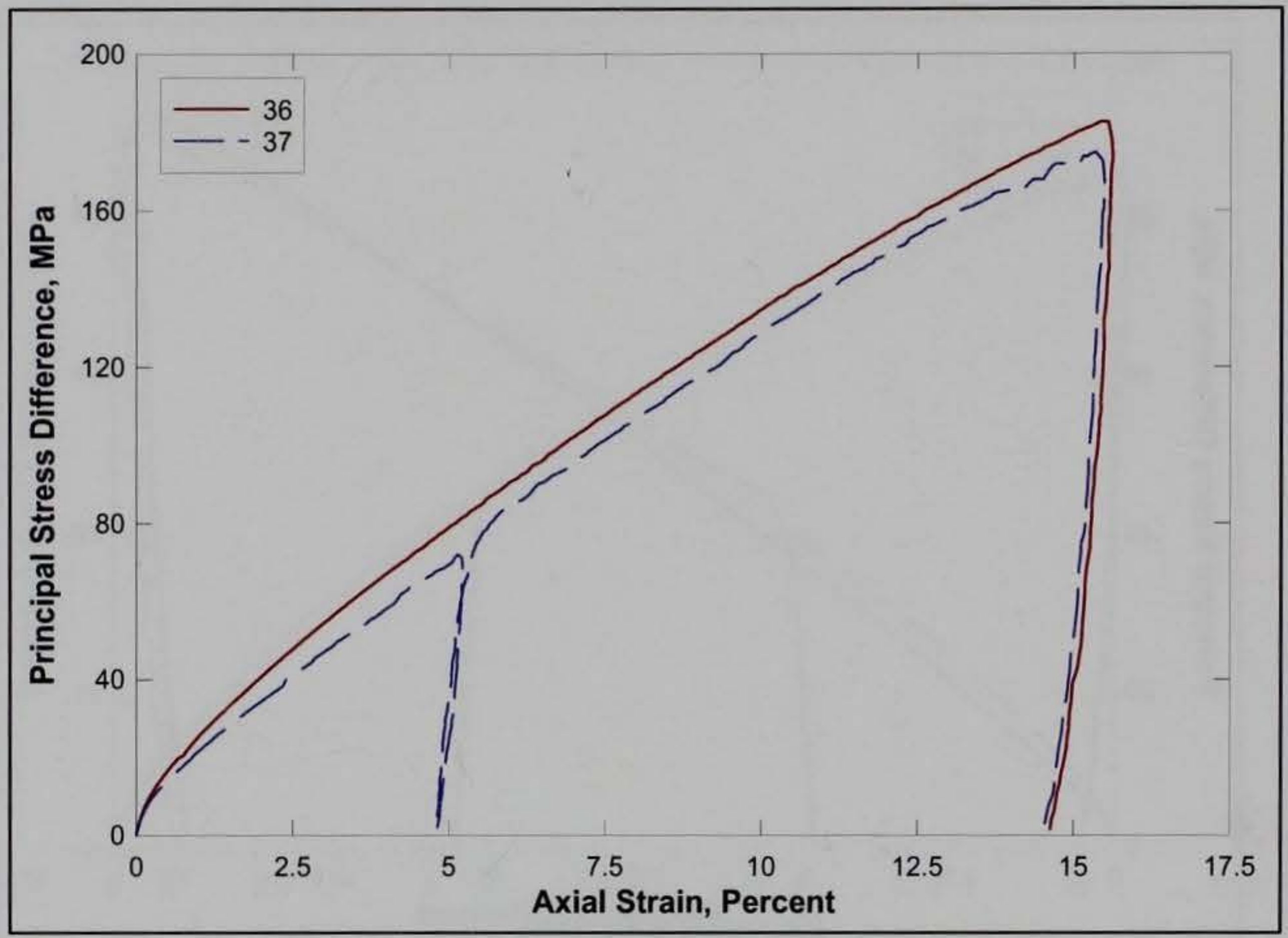

Figure 22. Stress-strain data from TXC tests at a confining pressure of $100 \mathrm{MPa}$.

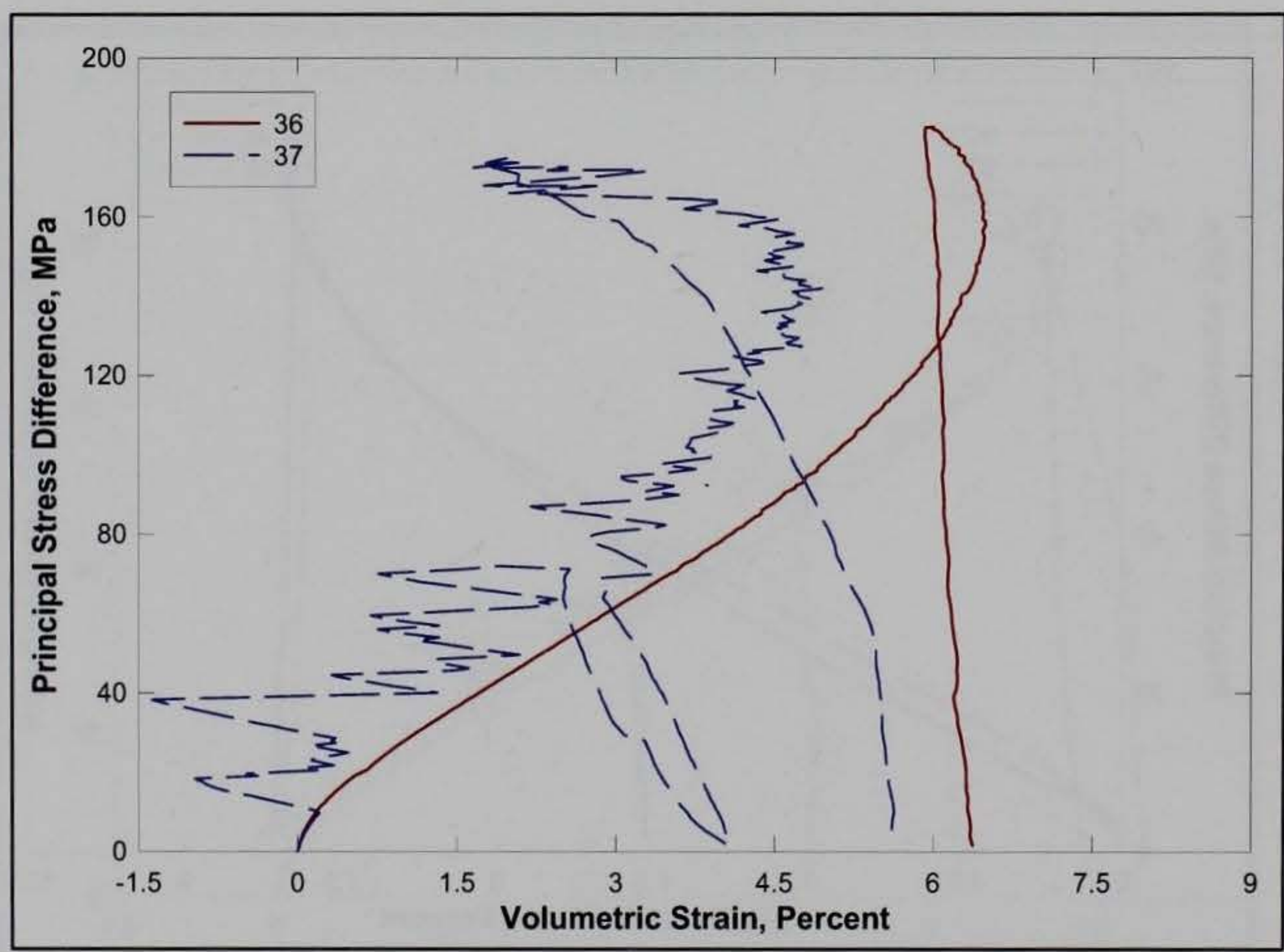

Figure 23. Stress difference-volume strain during shear from TXC tests at a confining pressure of $100 \mathrm{MPa}$. 


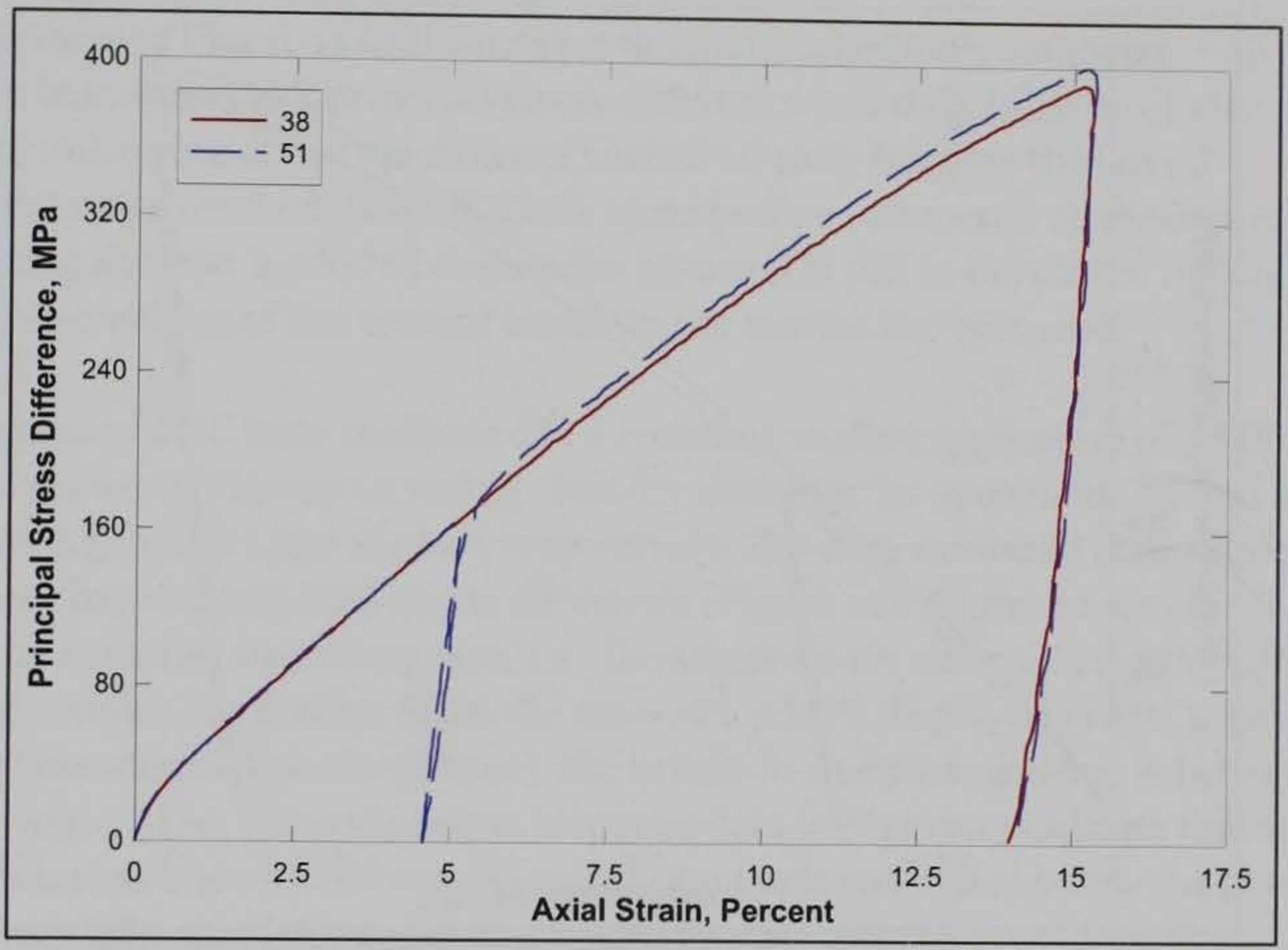

Figure 24. Stress-strain data from TXC tests at a confining pressure of $200 \mathrm{MPa}$.

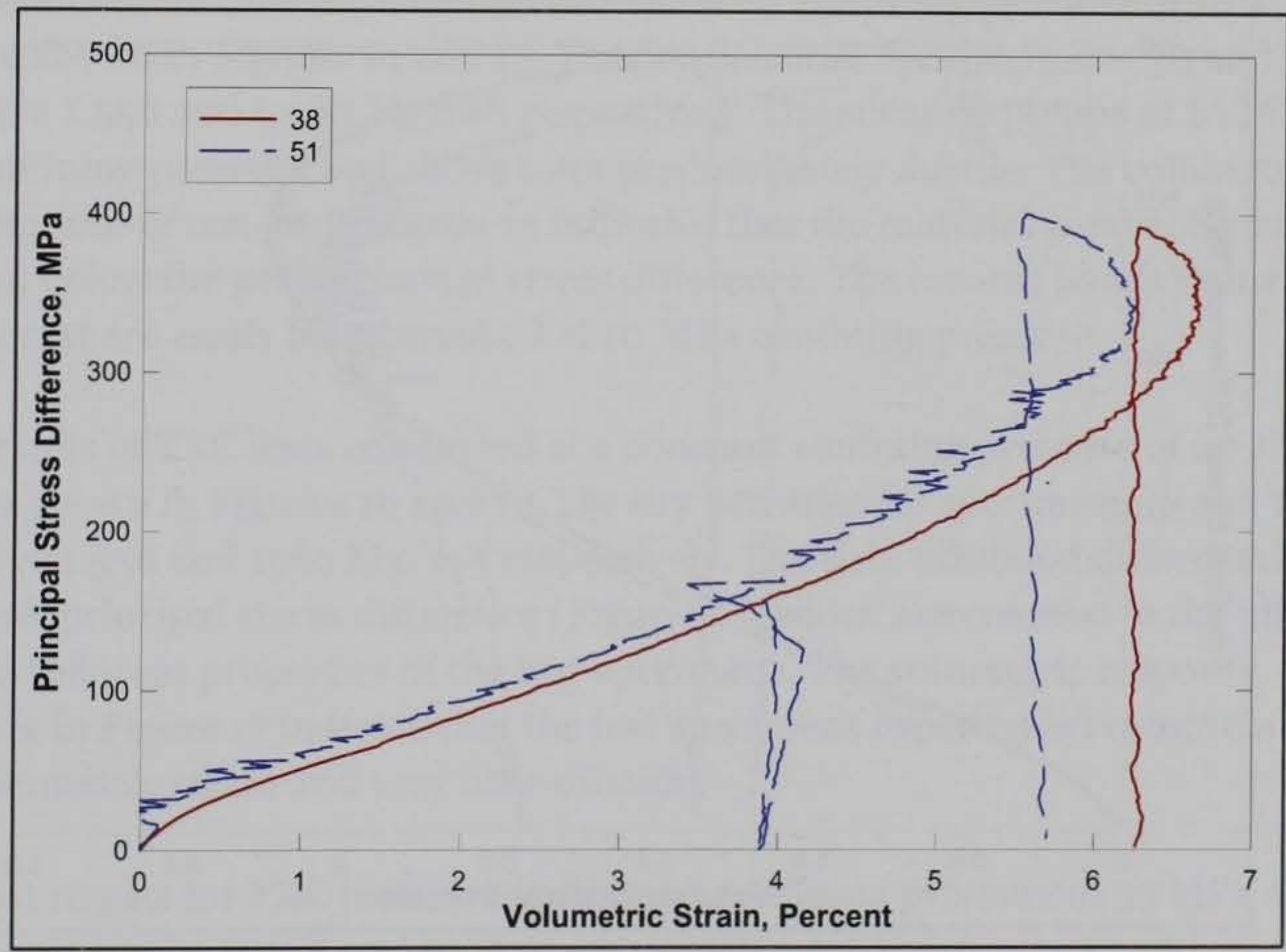

Figure 25. Stress difference-volume strain during shear from TXC tests at a confining pressure of $200 \mathrm{MPa}$. 


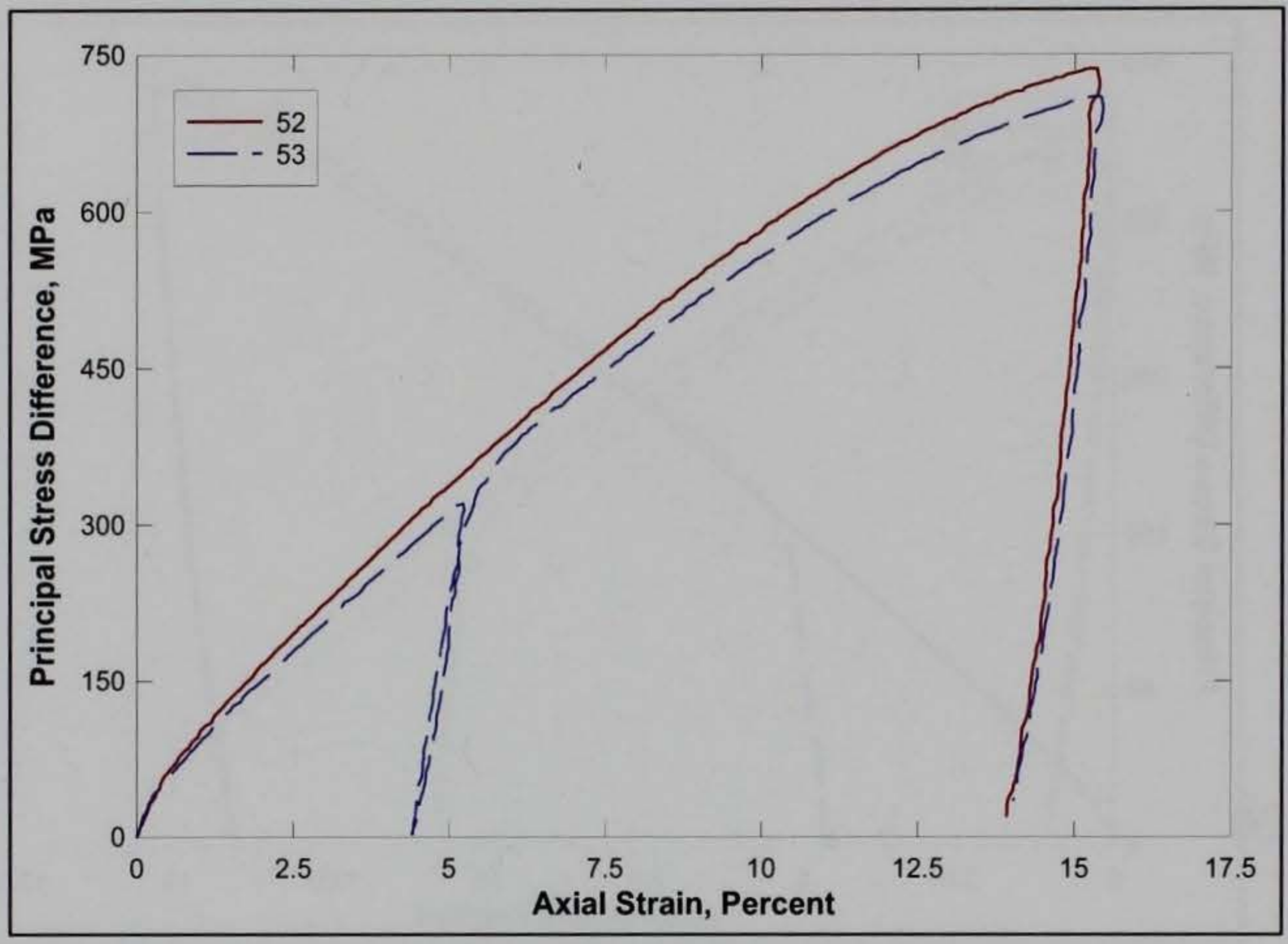

Figure 26. Stress-strain data from TXC tests at a confining pressure of $400 \mathrm{MPa}$.

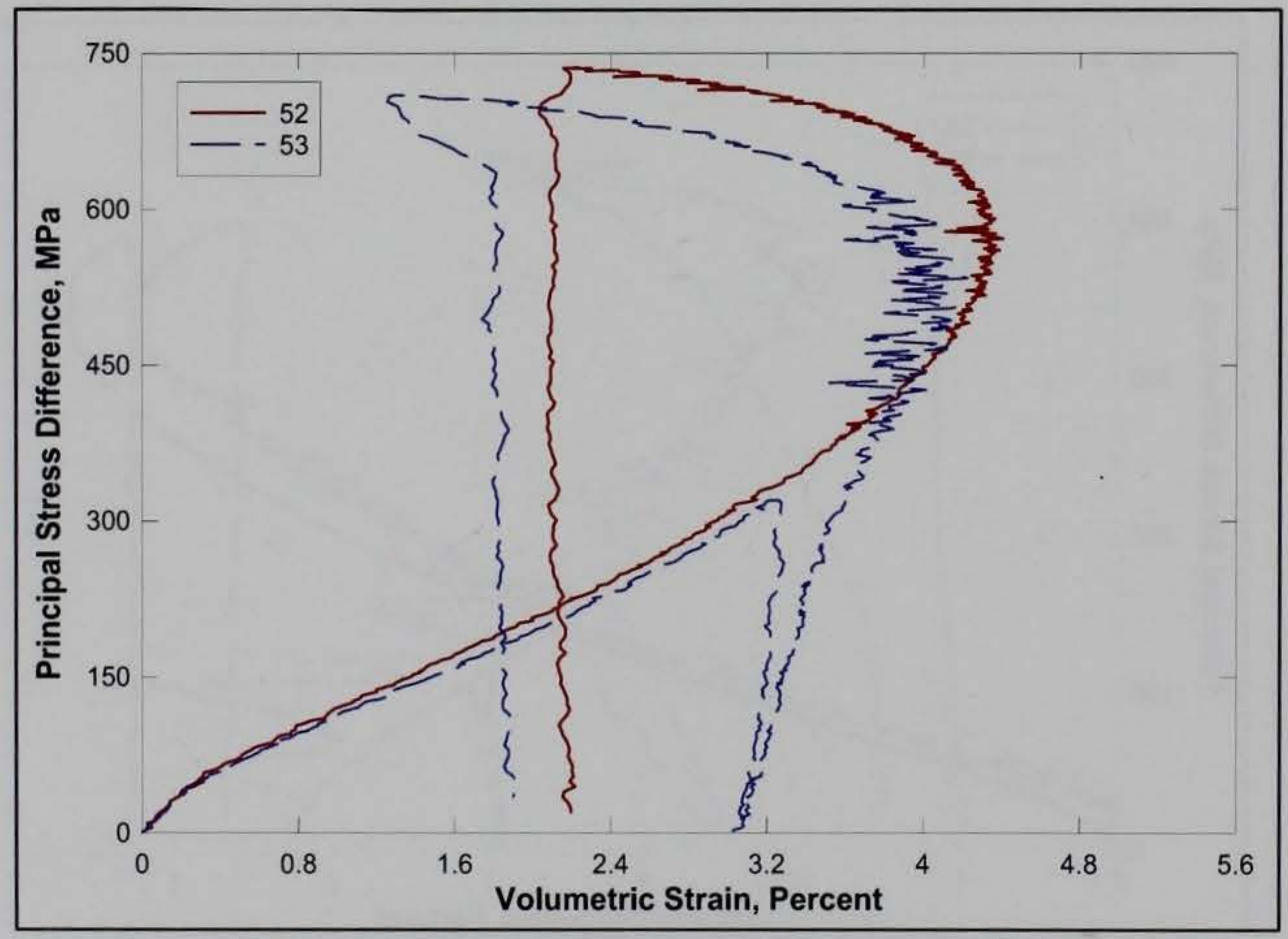

Figure 27. Stress difference-volume strain during shear from TXC tests at a confining pressure of $400 \mathrm{MPa}$. 
response in Figure 11 indicates that the material initially compacts until just below the peak principal stress difference and then starts to dilate. The unloading of test specimen 27 occurred early because the lateral deformeter reached its limit. Little compressive volumetric strain occurs during shear at 2.5 MPa because the material is still in the elastic region. Some crushing of the cement bonds in the mortar has occurred.

Results of TXC tests conducted at a constant confining pressure of $5 \mathrm{MPa}$ are shown in Figures 12 and 13. The dry densities for specimens 28 and 29 were 1.563 and $1.557 \mathrm{Mg} / \mathrm{m}^{3}$, respectively. The data exhibited little differences in peak principal stress difference (Figure 12). Figure 12 also displays a ductile shear response, i.e., the stress-strain curves start exhibiting slight strain hardening. Since the tests at 2.5 MPa displayed brittle behavior (the material strain-softens), the brittle-to-ductile transition is between 2.5 and $5 \mathrm{MPa}$. The volumetric response data in Figure 13 indicate that the specimens experienced compressive volumetric strain just below the peak stress difference before dilating approximately $2 \%$.

Results of TXC tests conducted at a constant confining pressure of $10 \mathrm{MPa}$ are shown in Figures 14 and 15. The dry densities for specimens 30 and 31 were 1.558 and $1.560 \mathrm{Mg} / \mathrm{m}^{3}$, respectively. The shear responses at $10 \mathrm{MPa}$ confining pressure and above were predominately ductile. The volumetric response of test 30 in Figure 15 indicates that the material compacts until just below the peak principal stress difference. The cement bonds in the mortar are easily being crushed at $10 \mathrm{MPa}$ confining pressure.

Results of TXC tests conducted at a constant confining pressure of $20 \mathrm{MPa}$ are shown in Figures 16 and 17. The dry densities for specimens 17 and 18 were 1.556 and $1566 \mathrm{Mg} / \mathrm{m}^{3}$, respectively. The data exhibited differences in peak principal stress difference (Figure 16), which are credited to the initial inherent properties of the test specimens. The volumetric response data in Figure 17 indicate that the test specimens experienced compressive volumetric strain and very little dilation.

Test results for TXC tests conducted at a confining pressure of $35 \mathrm{MPa}$ are shown in Figures 18 and 19. The dry densities for specimens 34 and 49 were 1.556 and $1.549 \mathrm{Mg} / \mathrm{m}^{3}$, respectively. The data exhibited little differences in peak principal stress difference (Figure 18). The volumetric responses exhibited some dilation just prior to the peak strength. 
Test results for TXC tests conducted at a confining pressure of $50 \mathrm{MPa}$ are shown in Figures 20 and 21. The dry densities for specimens 32 and 33 were 1.559 and $1.563 \mathrm{Mg} / \mathrm{m}^{3}$, respectively. The data exhibited little differences in peak principal stress difference (Figure 20). The volumetric responses were similar to the volumetric responses of the specimens tested at $35 \mathrm{MPa}$ confining pressure.

Results of TXC tests conducted at a confining pressure of $100 \mathrm{MPa}$ are shown in Figures 22 and 23. The dry densities for specimens 36 and 37 were 1.565 and $1.551 \mathrm{Mg} / \mathrm{m}^{3}$, respectively. The volumetric response for test specimen 36 in Figure 23 indicates that at $100 \mathrm{MPa}$ confining pressure, the specimens compacted, but prior to reaching peak principal stress difference, the test specimen dilated approximately $0.5 \%$. There was a problem with the lateral deformeter during the testing of test specimen 37 , which produced an invalid volumetric strain response (Figure 23)

Test results for TXC tests conducted at a confining pressure of $200 \mathrm{MPa}$ are shown in Figures 24 and 25. The dry densities for specimens 38 and 51 were 1.560 and $1.563 \mathrm{Mg} / \mathrm{m}^{3}$, respectively. The volumetric responses were similar to the volumetric responses of the specimens tested at $100 \mathrm{MPa}$ confining pressure.

Results of TXC tests conducted at a confining pressure of $400 \mathrm{MPa}$ are shown in Figures 26 and 27. The dry densities for specimens 52 and 53 were 1.563 and $1.555 \mathrm{Mg} / \mathrm{m}^{3}$, respectively. The data in Figure 27 displays volumetric dilation just prior to peak strength of approximately $3 \%$. After completing the TXC tests, it was determined that none of the specimens reached full saturation during the shear loading. The stress-strain curves continued to exhibit increases in principal stress difference over the entire range of imposed confining stresses.

For comparison purposes, stress-strain curves from selected TXC tests between confining pressures of 2.5 and $20 \mathrm{MPa}$ are plotted in Figure 28 while stress-strain curves from selected TXC tests between confining pressures of 35 and $400 \mathrm{MPa}$ are plotted in Figure 29. Stress-strain data from the TXC tests in Figures 28 and 29 are plotted in Figures 30 and 31 as principal stress difference versus volumetric strain during shear. The initial loading of the TXC stress-strain data are a function of the material's volume changes during shear and thus are dependent on the magnitude of the applied confining pressure and the position on the material's 


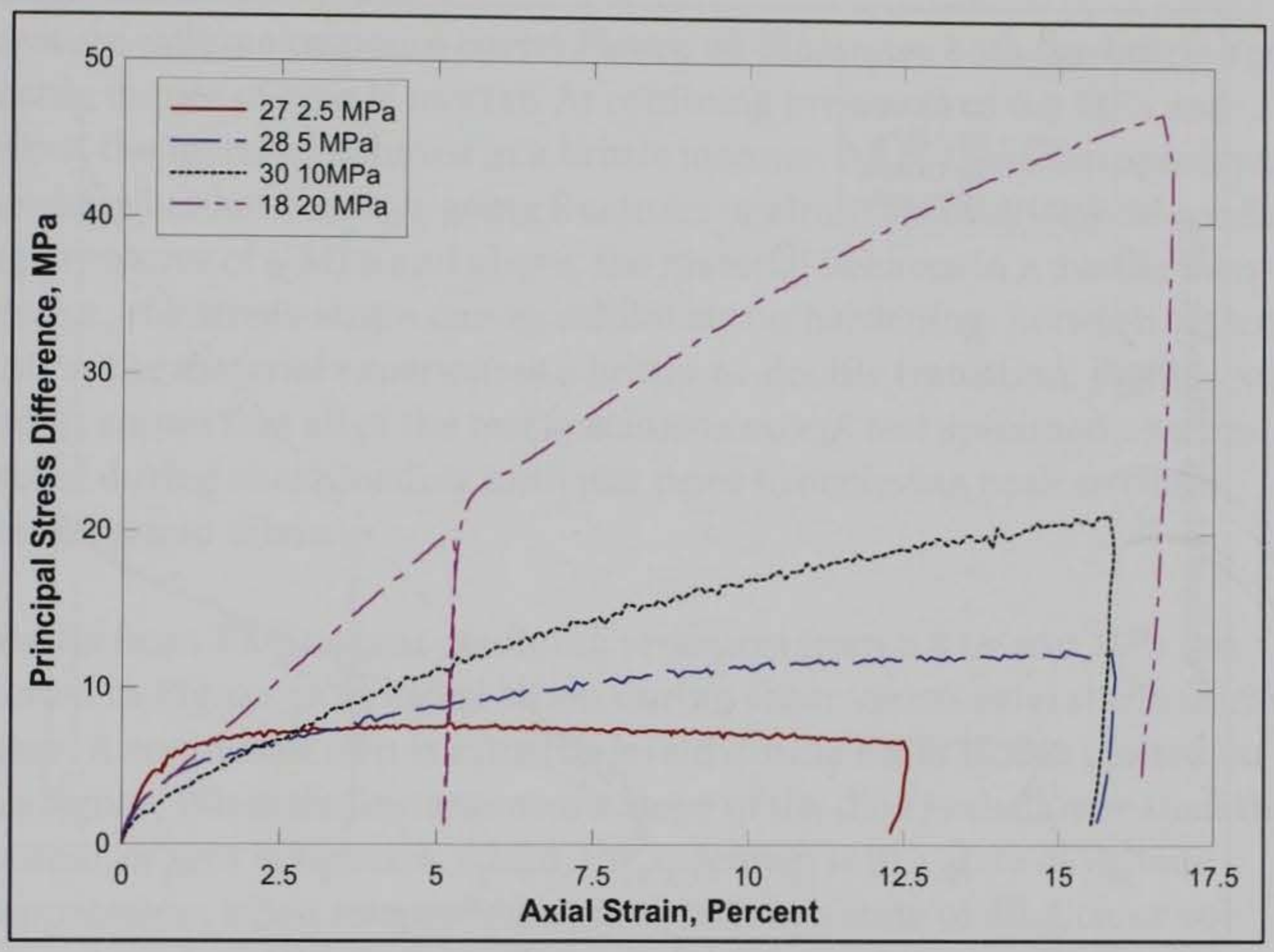

Figure 28. Stress-strain data from selected TXC tests at confining pressures between 2.5 and $20 \mathrm{MPa}$.

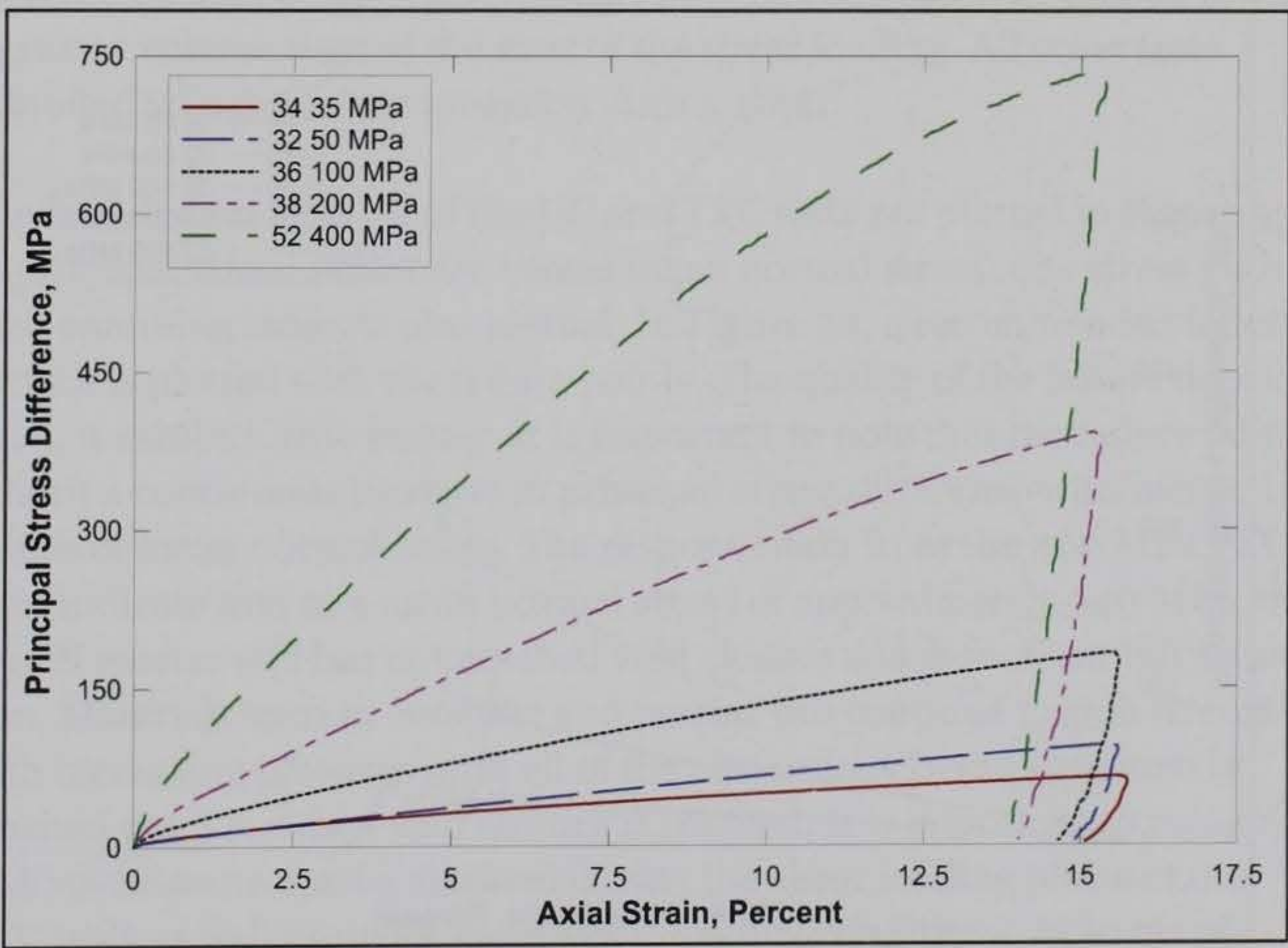

Figure 29. Stress-strain data from selected TXC tests at confining pressures between 35 and $400 \mathrm{MPa}$. 


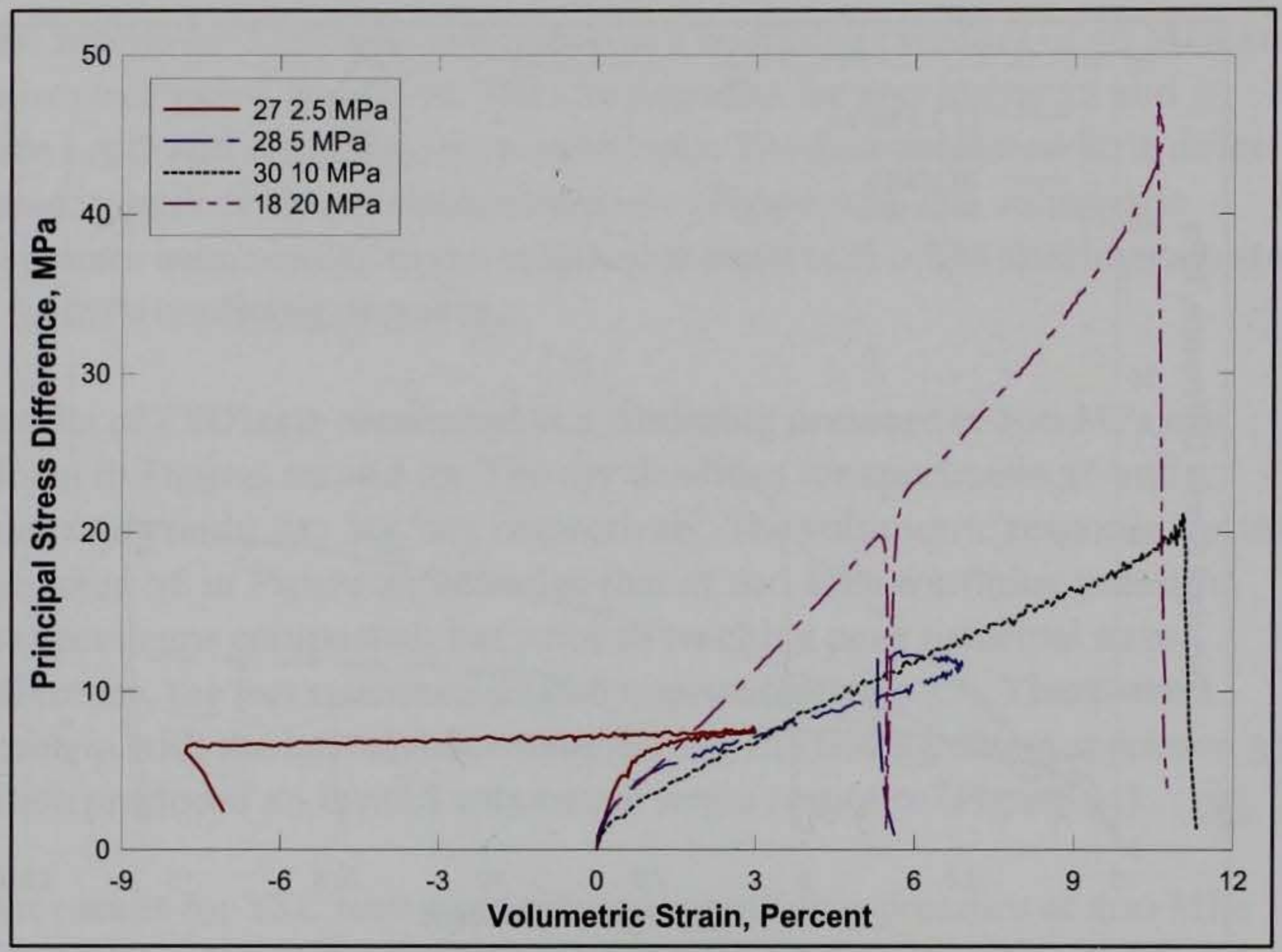

Figure 30. Stress difference-volume strain during shear from selected TXC tests at confining pressures between 2.5 and $20 \mathrm{MPa}$.

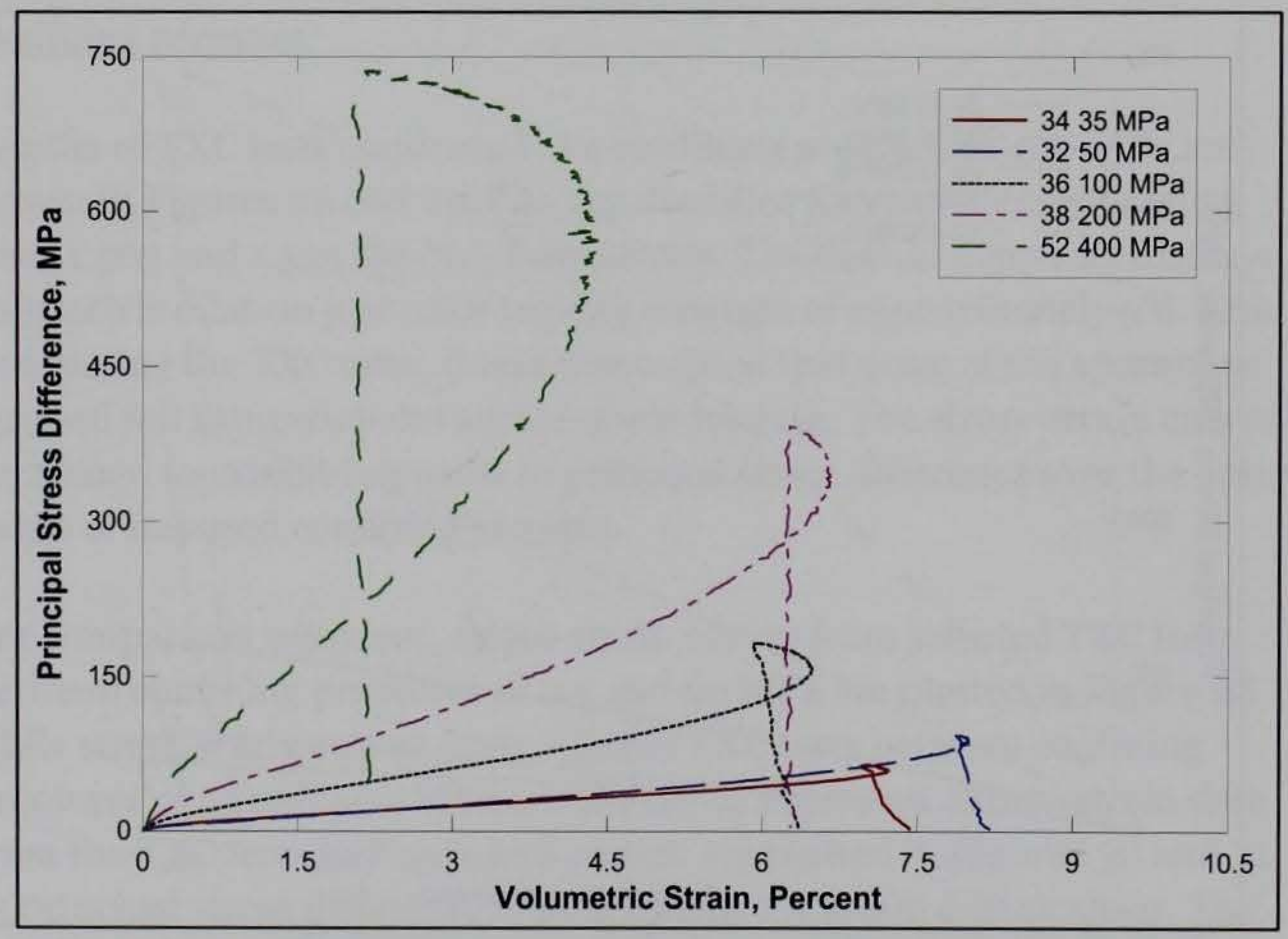

Figure 31. Stress difference-volume strain during shear from selected TXC tests at confining pressures between 35 and $400 \mathrm{MPa}$. 
pressure-volume response curve. Figure 28 illustrates both the brittle and ductile nature of type $\mathrm{N}$ mortar. At confining pressures of $2.5 \mathrm{MPa}$ and below, the material behaves in a brittle manner. All of these test specimens developed either through-going fractures or strain localizations. At confining pressures of $5 \mathrm{MPa}$ and above, the material behaves in a ductile manner, i.e., the stress-strain curves exhibit strain hardening. Between 2.5 and $5 \mathrm{MPa}$, the material experiences a brittle-to-ductile transition. Figures 30 and 31 shows that all of the test specimens except test specimen 27 compacted during shear loading until just prior to achieving peak strength then began to dilate.

Results from TXC tests at confining pressures from 2.5 to $400 \mathrm{MPa}$ are plotted in Figure 32 as radial strain during shear versus axial strain during shear. A contour of zero volumetric strain during shear is also plotted on this figure. When the instantaneous slope of the data is shallower than the contour of zero volumetric strain, the specimen is in a state of volume compression; when steeper, the specimen is in a state of dilation or volume expansion. Data points plotting below the contour signify that a test specimen has dilated, and the current volume of the specimen is greater than the volume at the start of shear. Only test specimen 27 dilated to have a greater volume than at the start of the shear loading. All other tests exhibited volumetric compression during shear.

The failure data from all of the UC and TXC tests are plotted in Figure 33 as principal stress difference versus mean normal stress; one stress path at each confining stress is also plotted. In Figure 34, a recommended failure surface is plotted with the failure points. The quality of the failure data is good; it exhibits little scatter. It is important to note that the failure points exhibit a continuous increase in principal stress difference with increasing values of mean normal stress. The response data from the 400 MPa TXC tests indicate that at a mean normal stress of approximately $640 \mathrm{MPa}$, the type $\mathrm{N}$ mortar still has not reached void closure and is far from full saturation. Materials such as concrete and mortar can continue to gain strength with increasing pressure until all of the air porosity in the specimen is crushed out, i.e., when void closure is reached. It is important to recognize that void closure can be attained during the shear loading phase of the TXC tests as well as under hydrostatic loading conditions. At levels of mean normal stress above void closure, the failure surface will have a minimal slope. 


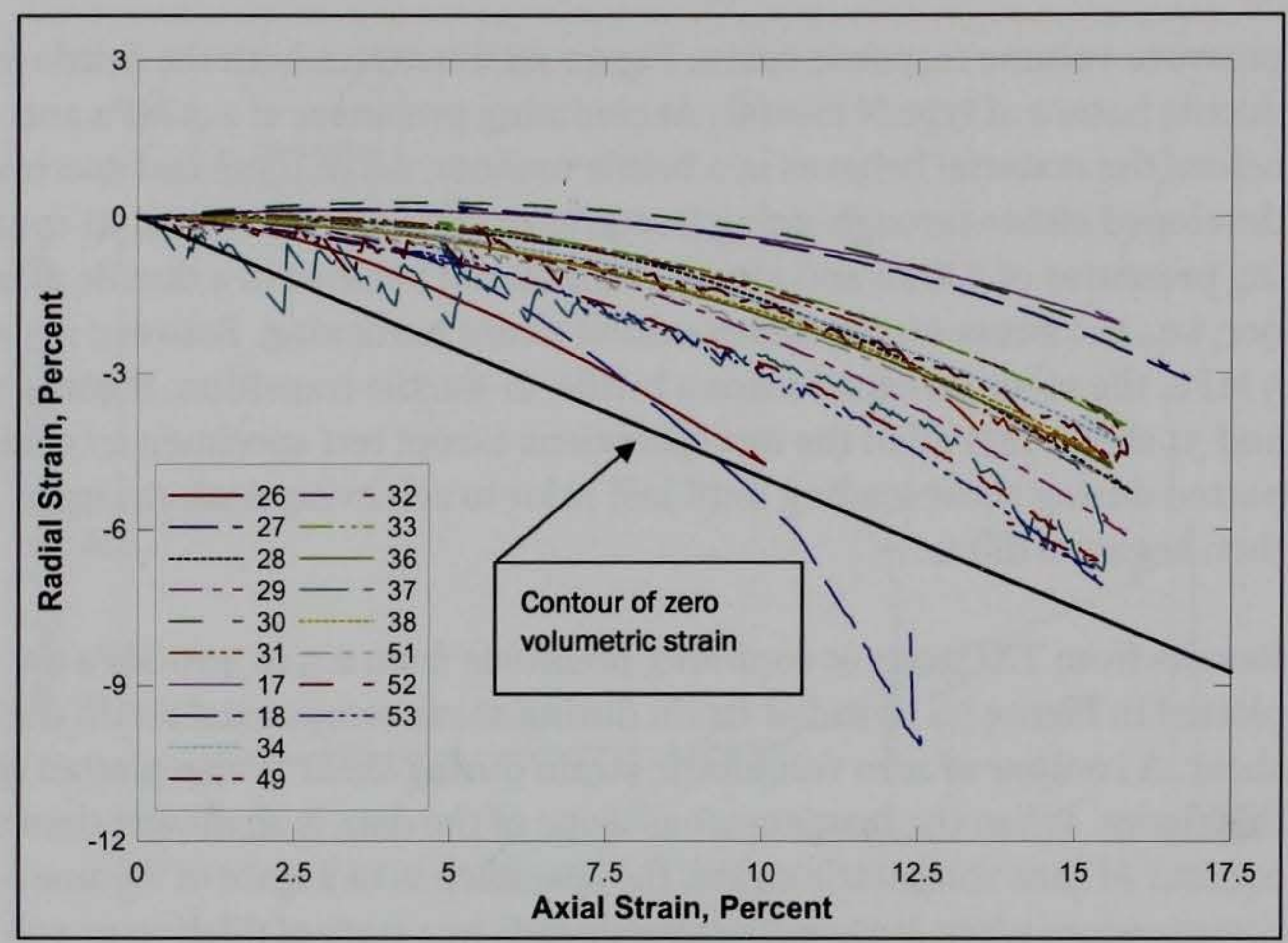

Figure 32. Radial strain-axial strain data during shear from TXC tests at confining pressures between 2.5 and $400 \mathrm{MPa}$.

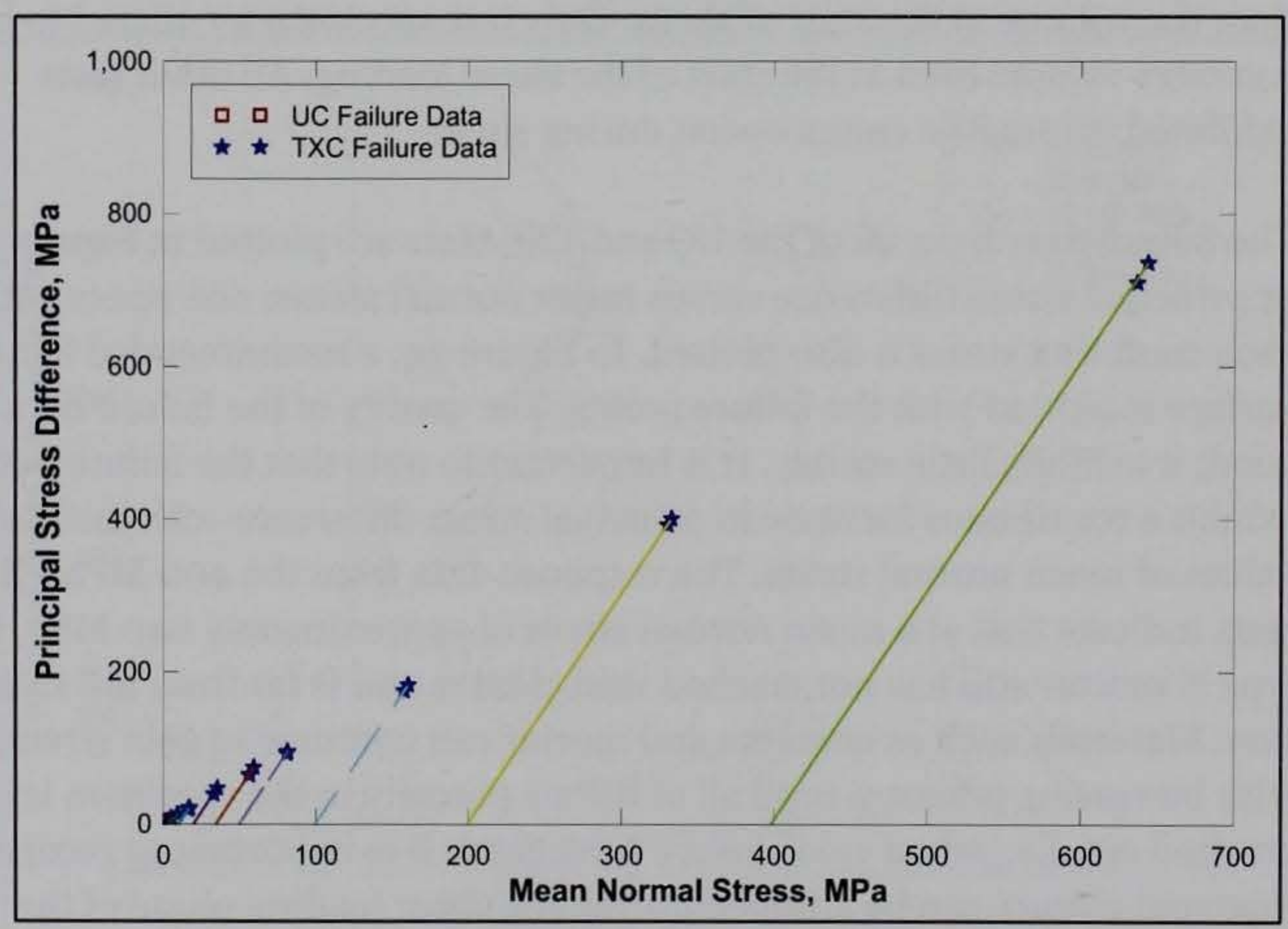

Figure 33. Failure points from UC and TXC tests. 


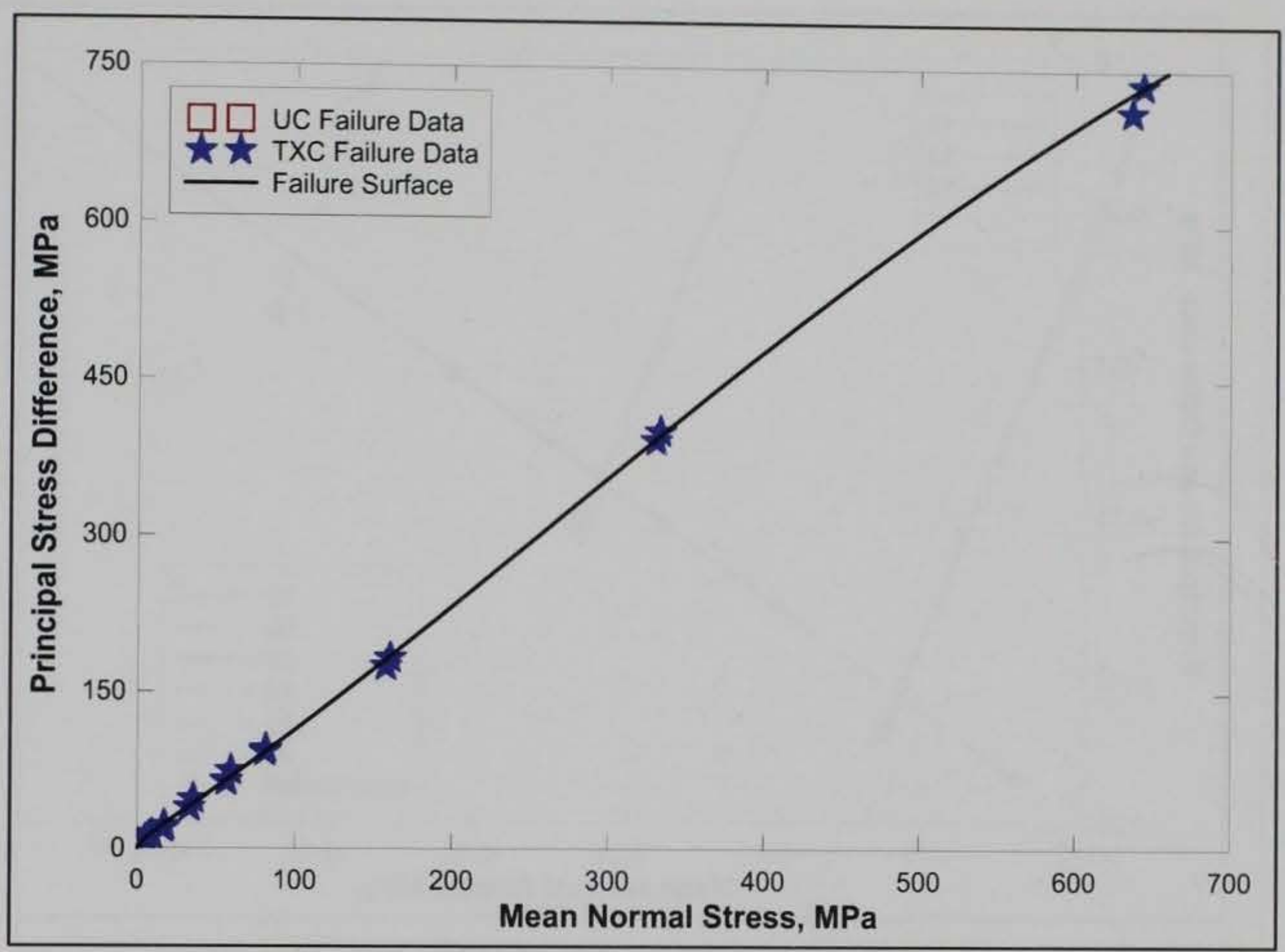

Figure 34. Failure points from UC and TXC tests and recommended failure surface.

\section{Reduced triaxial extension test results}

Extension stress-strain and failure data were successfully obtained from four direct pull tests and six unconsolidated-undrained RTE tests. The DP tests are a special type of RTE test without the application of confining pressure. Results from the DP tests are plotted in Figure 35, results from the RTE tests are plotted in Figures 36 and 37, and the recommended failure surface from the triaxial extension test results are plotted in Figure 38. Data from the DP tests exhibit some scatter. The stress-strain data in Figure 36 displays the RTE test results conducted at confining pressures of approximately 20, 40, and $60 \mathrm{MPa}$. All of the RTE specimens fractured. Slight variations during the loading were caused by the manual operation of the equipment used for RTE tests. Only the DP, RTE, and UC tests included in this test program used manual operation rather then a servo-controlled data acquisition system to control the load and confining pressure. Figure 39 displays failure data from the UC, TXC, DP, and RTE tests and the recommended compression and extension failure surfaces for type $\mathrm{N}$ mortar. The resulting compression and extension failure surfaces were well defined and nonsymmetric about the mean normal stress axis. Type $\mathrm{N}$ mortar can withstand more deviatoric stress in compression than extension before failure occurs. 


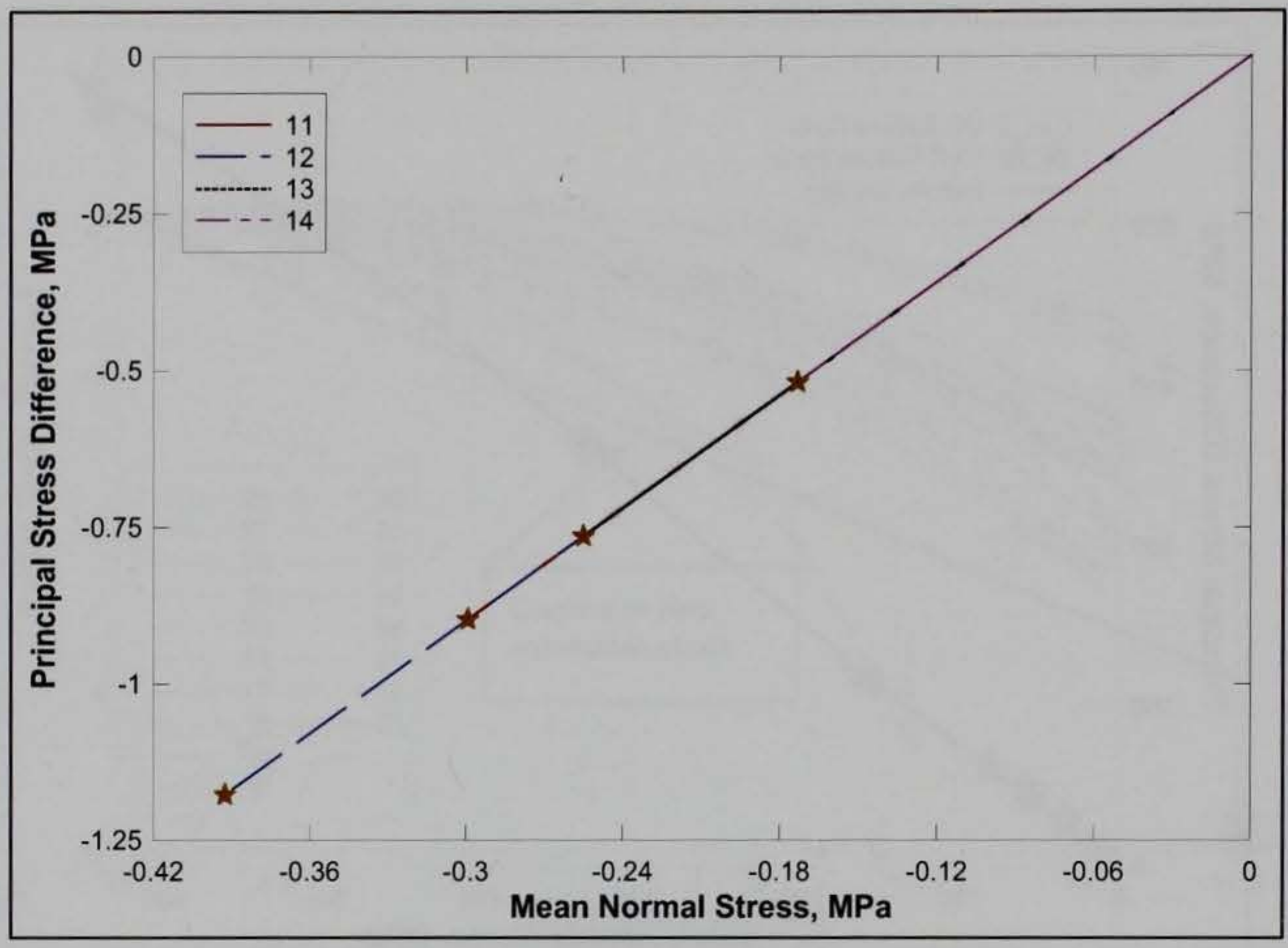

Figure 35. Stress paths and failure data from DP tests.

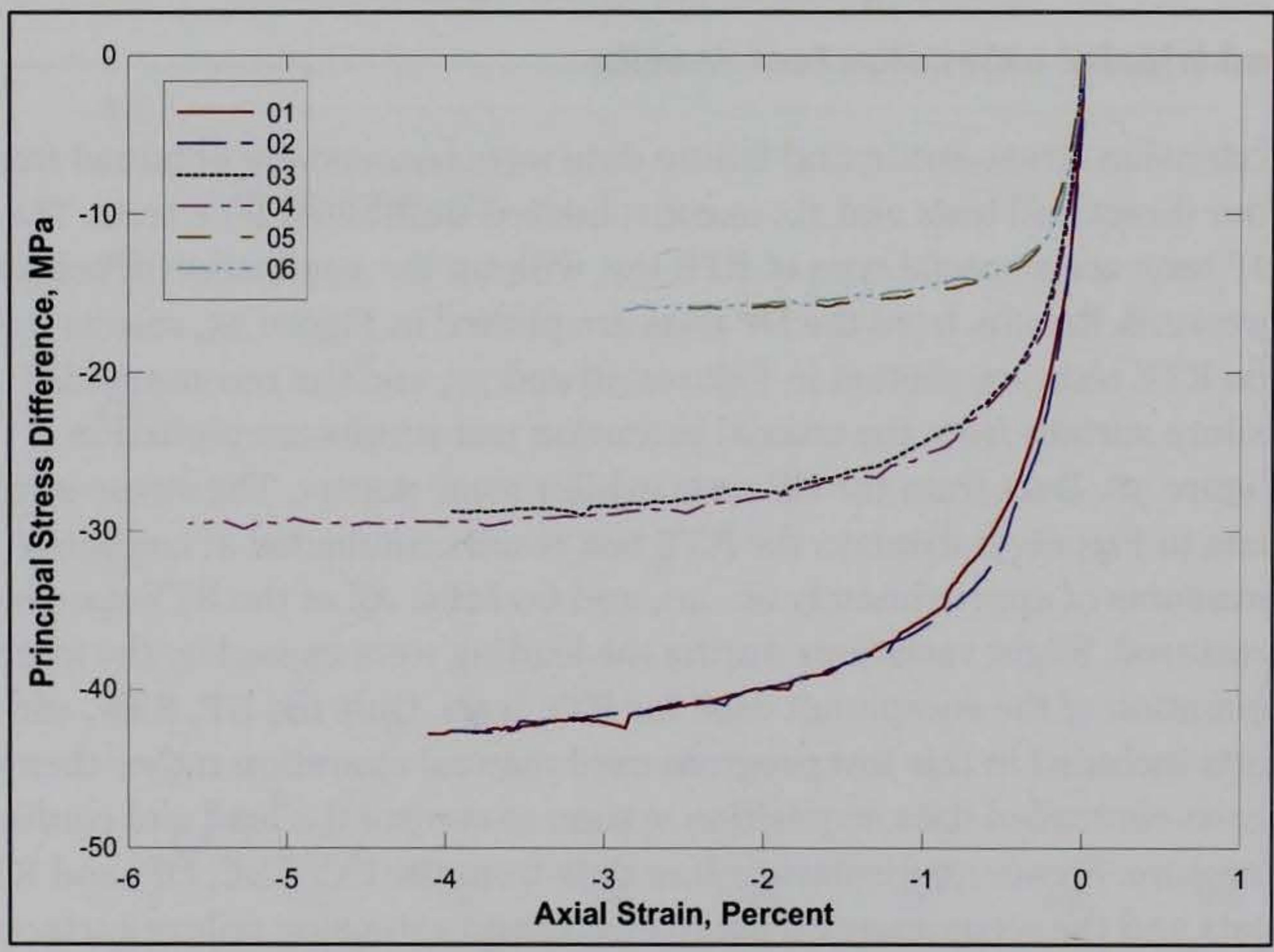

Figure 36. Stress-strain data from RTE tests. 


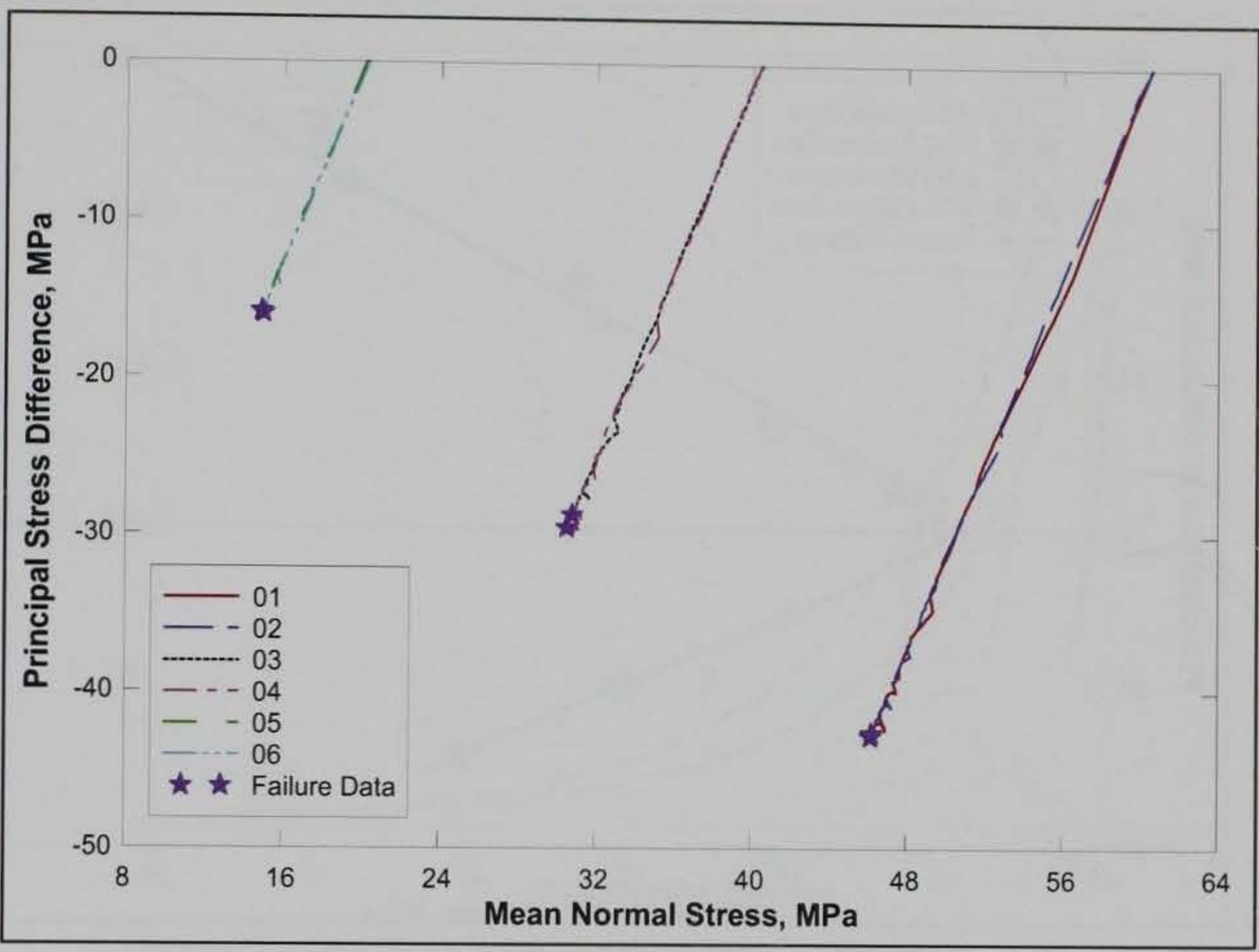

Figure 37. Stress path data from RTE tests.

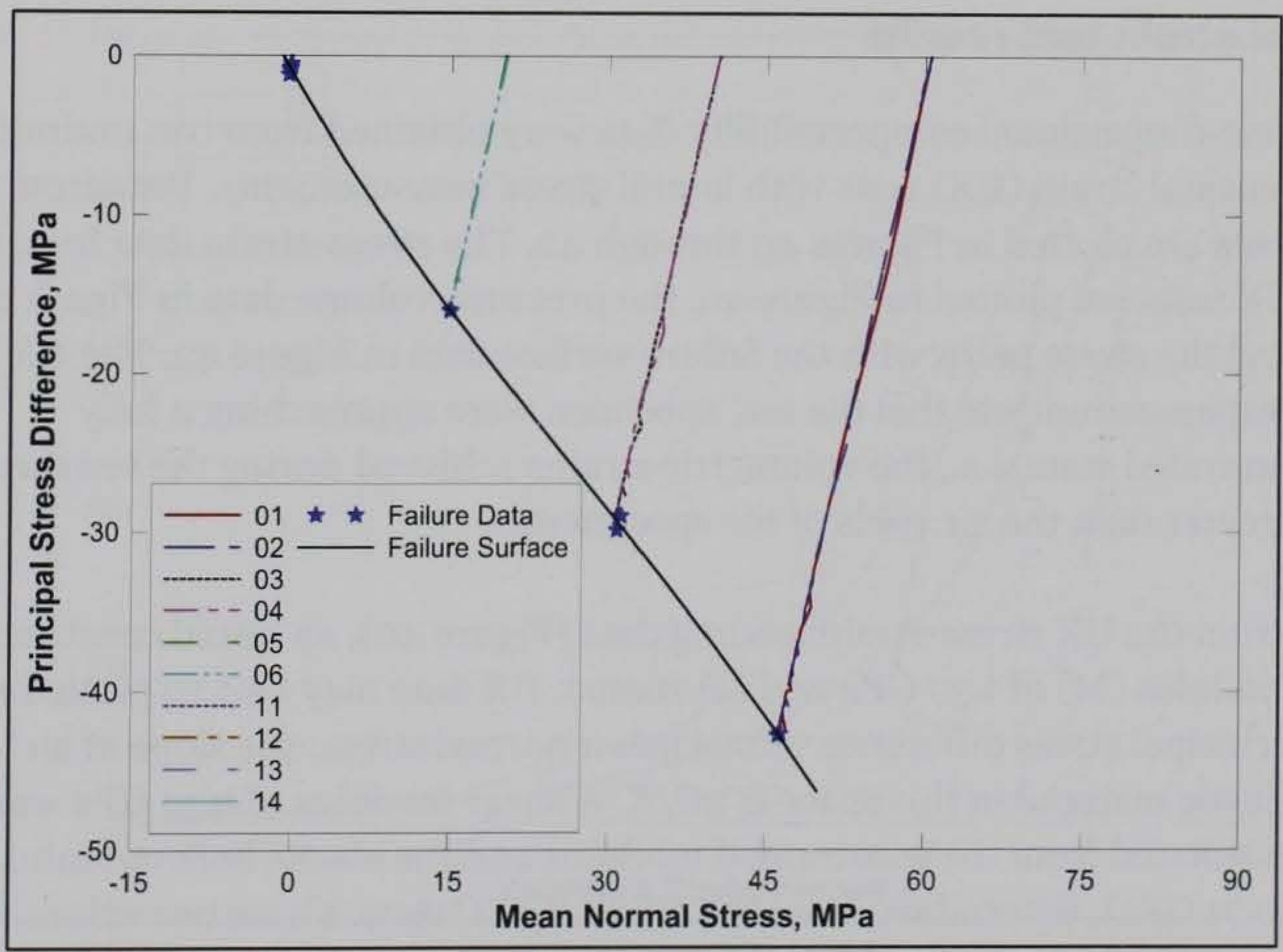

Figure 38. Failure data from DP and RTE tests and recommended failure surface. 


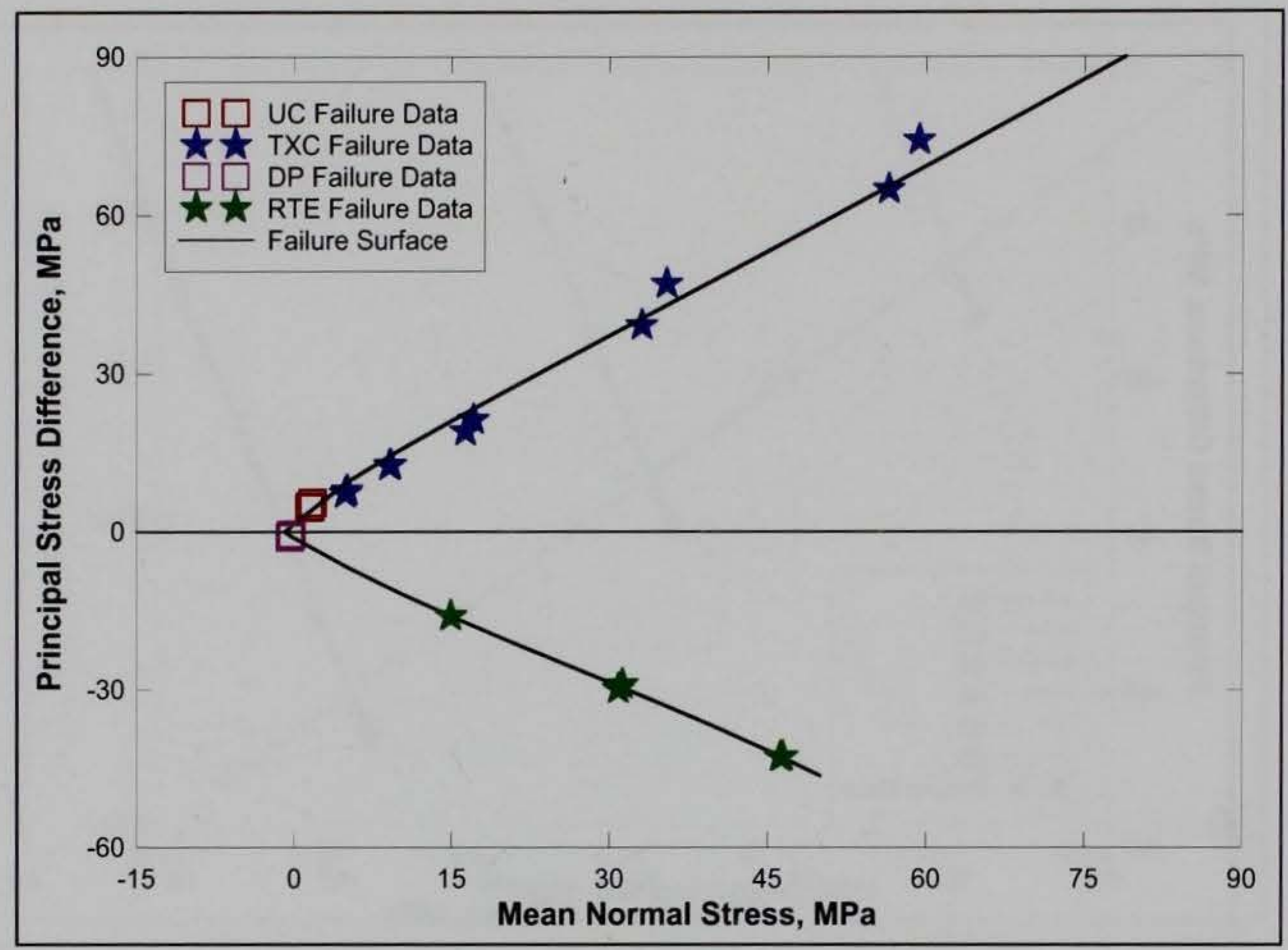

Figure 39. Failure surfaces and failure data from UC, TXC, DP, and RTE tests.

\section{Uniaxial strain test results}

One-dimensional compressibility data were obtained from two undrained uniaxial strain (UX) tests with lateral stress measurements. Data from the tests are plotted in Figures 40 through 42 . The stress-strain data from the UX tests are plotted in Figure 40, the pressure-volume data in Figure 41, and the stress paths with the failure surface data in Figure 42. The UX responses indicate that the test specimen were approaching a fully saturated state, i.e., the volumetric strains achieved during the tests were greater than the air voids of the specimens.

From the UX stress-strain loading data (Figure 40), an initial constrained modulus (M) of $1.37 \mathrm{GPa}$ was calculated. UX data may also be plotted as principal stress difference versus mean normal stress; the slope of an elastic material in this space is $2 G / K$. A shear modulus of $0.51 \mathrm{GPa}$ was calculated from the constrained modulus and the elastic bulk modulus, $K$ ( $0.71 \mathrm{GPa}$ ), determined from the $\mathrm{HC}$ and TXC tests. These two values may be used to calculate any of the other elastic constants. The Young's modulus is $1.21 \mathrm{GPa}$ and Poisson's ratio is 0.21 .

The stress paths from the UX tests and the failure surface are plotted in Figure 42. The UX stress paths almost reach the TXC recommended 


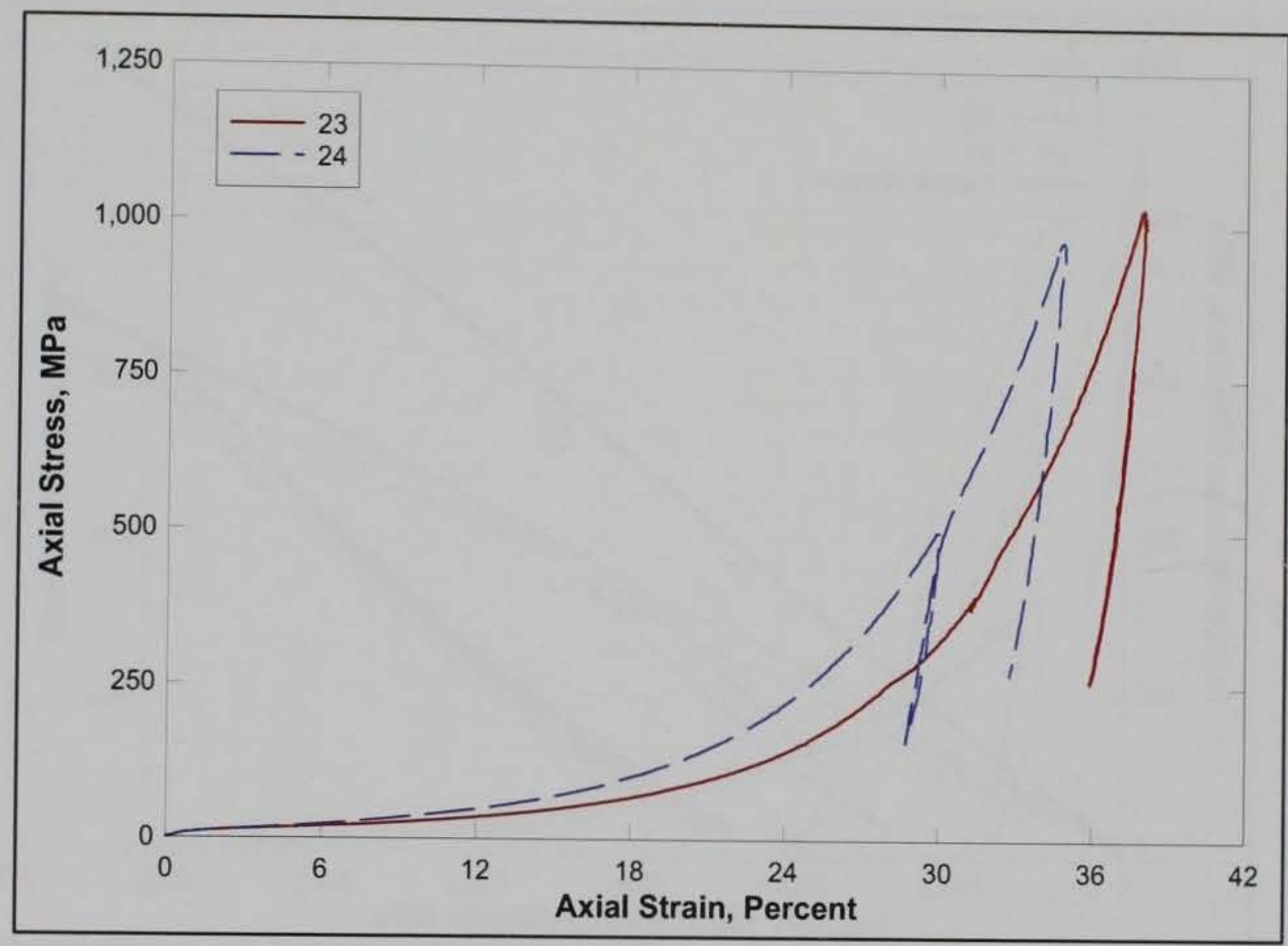

Figure 40. Stress-strain data from UX tests.

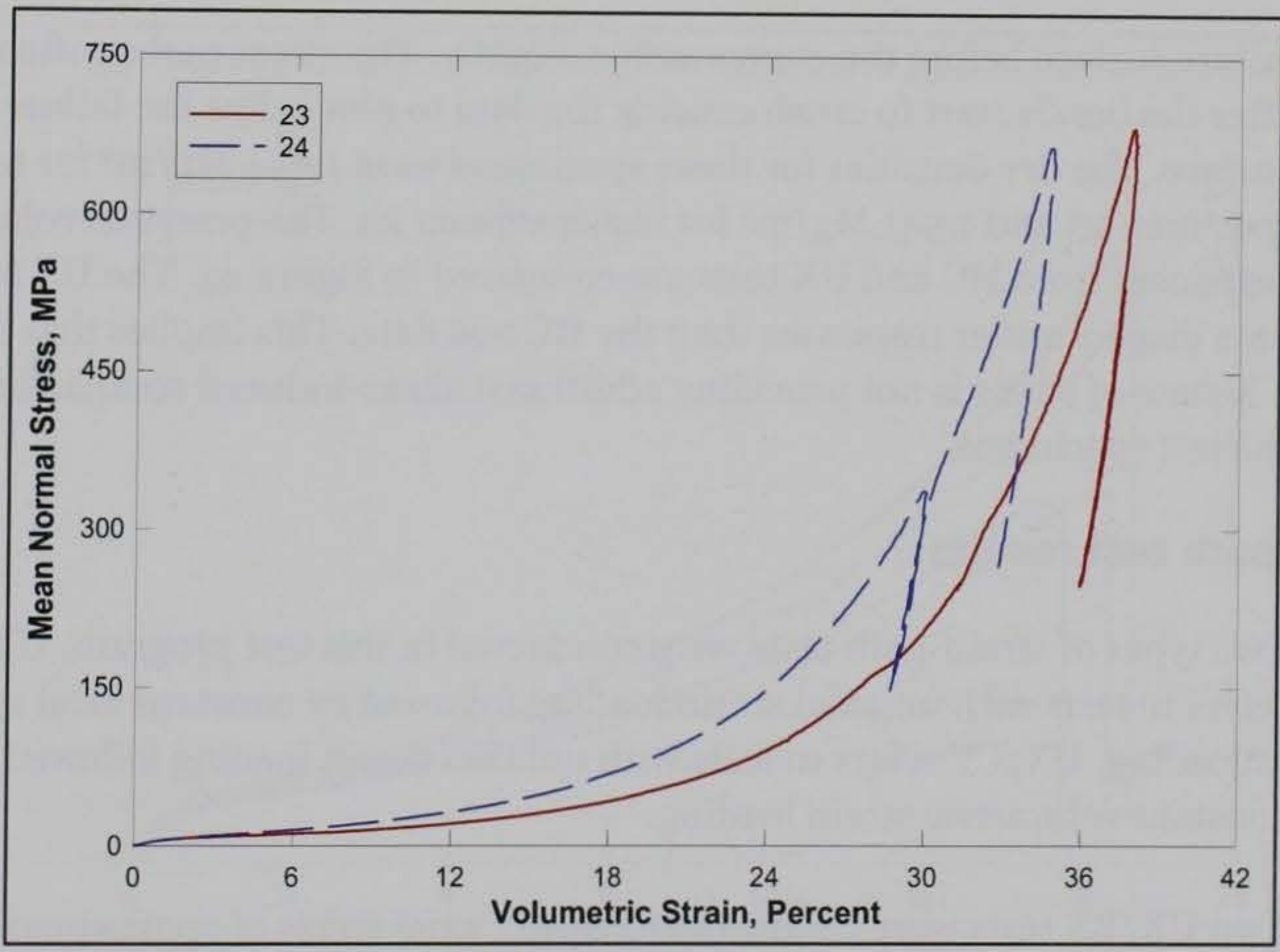

Figure 41. Pressure-volume data from UX tests. 


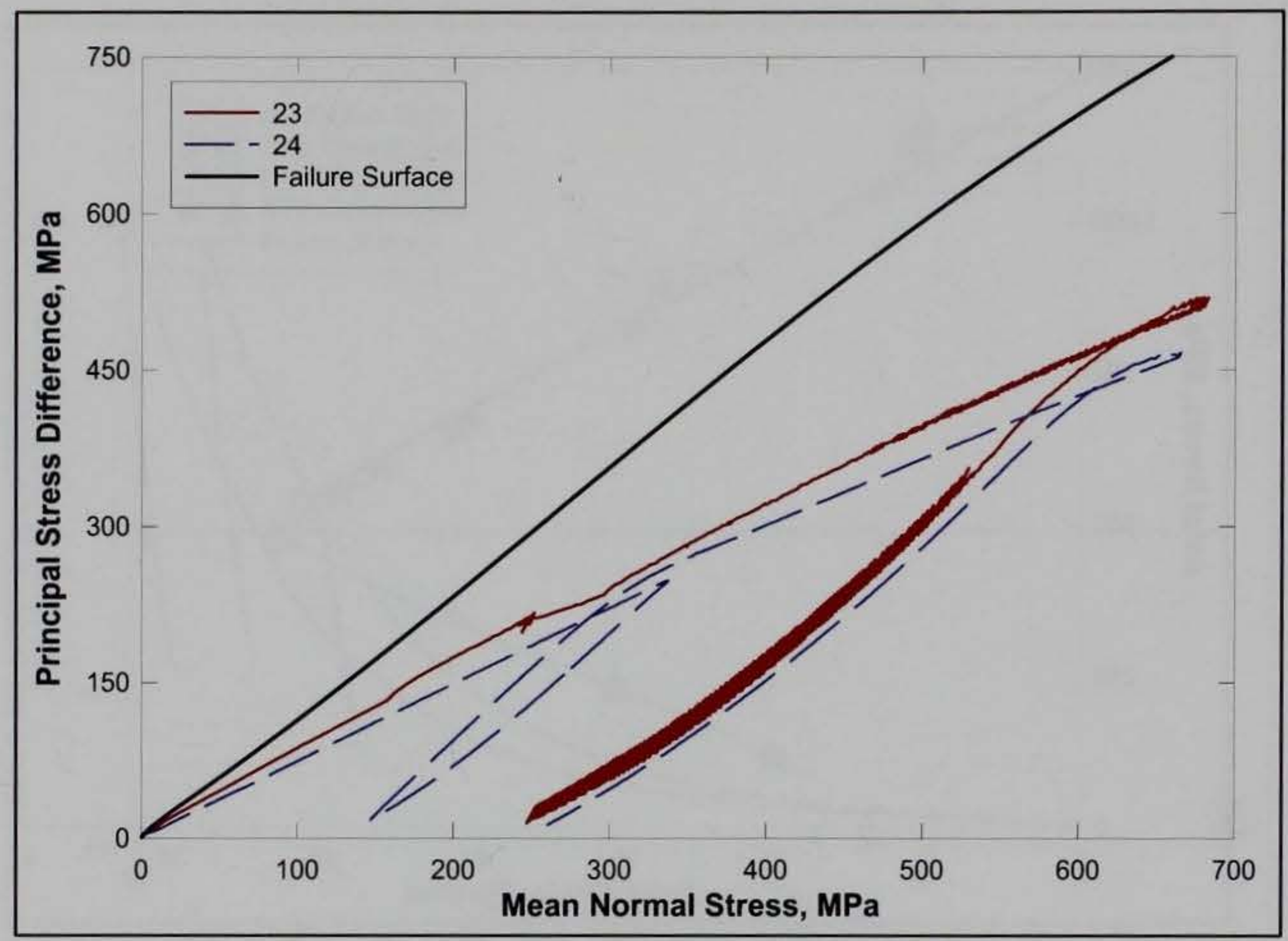

Figure 42. Stress paths from UX tests and failure surface from TXC tests.

failure surface before the curves soften slightly. The stress paths soften after the bonds start to crush causing the data to plot below the failure surface. The dry densities for these specimens were $1.544 \mathrm{Mg} / \mathrm{m}^{3}$ for test specimen 23 and $1.541 \mathrm{Mg} / \mathrm{m}^{3}$ for test specimen 24 . The pressure-volume responses from $\mathrm{HC}$ and UX tests are compared in Figure 43. The UX test data display stiffer responses than the $\mathrm{HC}$ test data. This implies that the UX state of stress is not providing additional shear-induced compaction to the test specimens.

\section{Strain path test results}

Two types of strain-path tests were conducted in this test program. UX/BX refers to tests with uniaxial strain loading followed by constant axial strain unloading. UX/CV refers to tests with uniaxial strain loading followed by constant volumetric strain loading.

Two UX/BX tests were conducted to a peak axial stress of approximately $60 \mathrm{MPa}$, and the other two tests were conducted to a peak axial stress of approximately $100 \mathrm{MPa}$. Data from the tests are plotted in Figures 44 through 47. The stress-strain data from the UX/BX tests are plotted in Figure 44, the pressure-volume data in Figure 45, the stress paths with the failure surface data in Figure 46, and the strain paths in Figure 47. In 


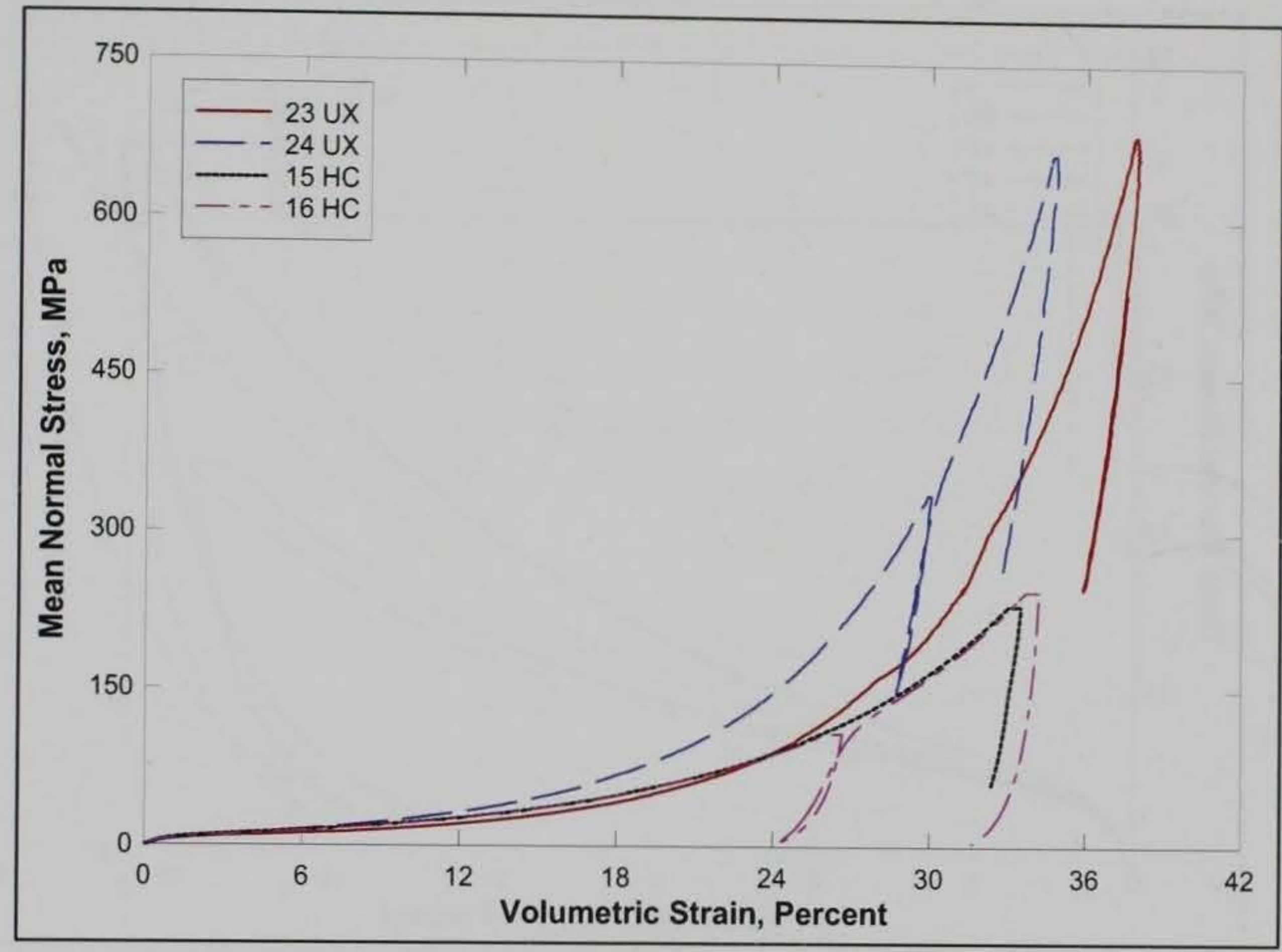

Figure 43. Comparison of pressure-volume data from $\mathrm{HC}$ and $\mathrm{UX}$ tests.

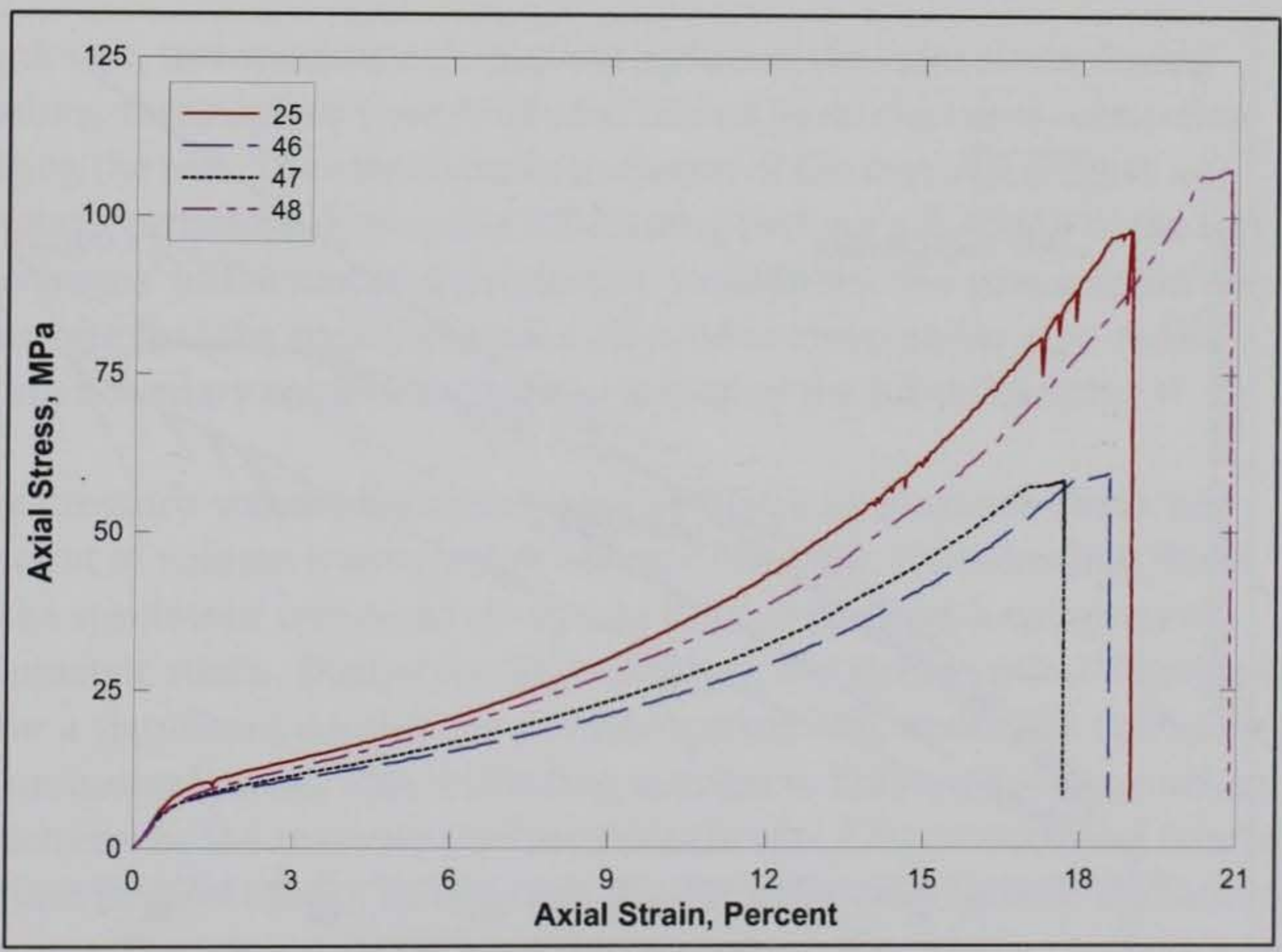

Figure 44. Stress-strain data from UX/BX tests. 


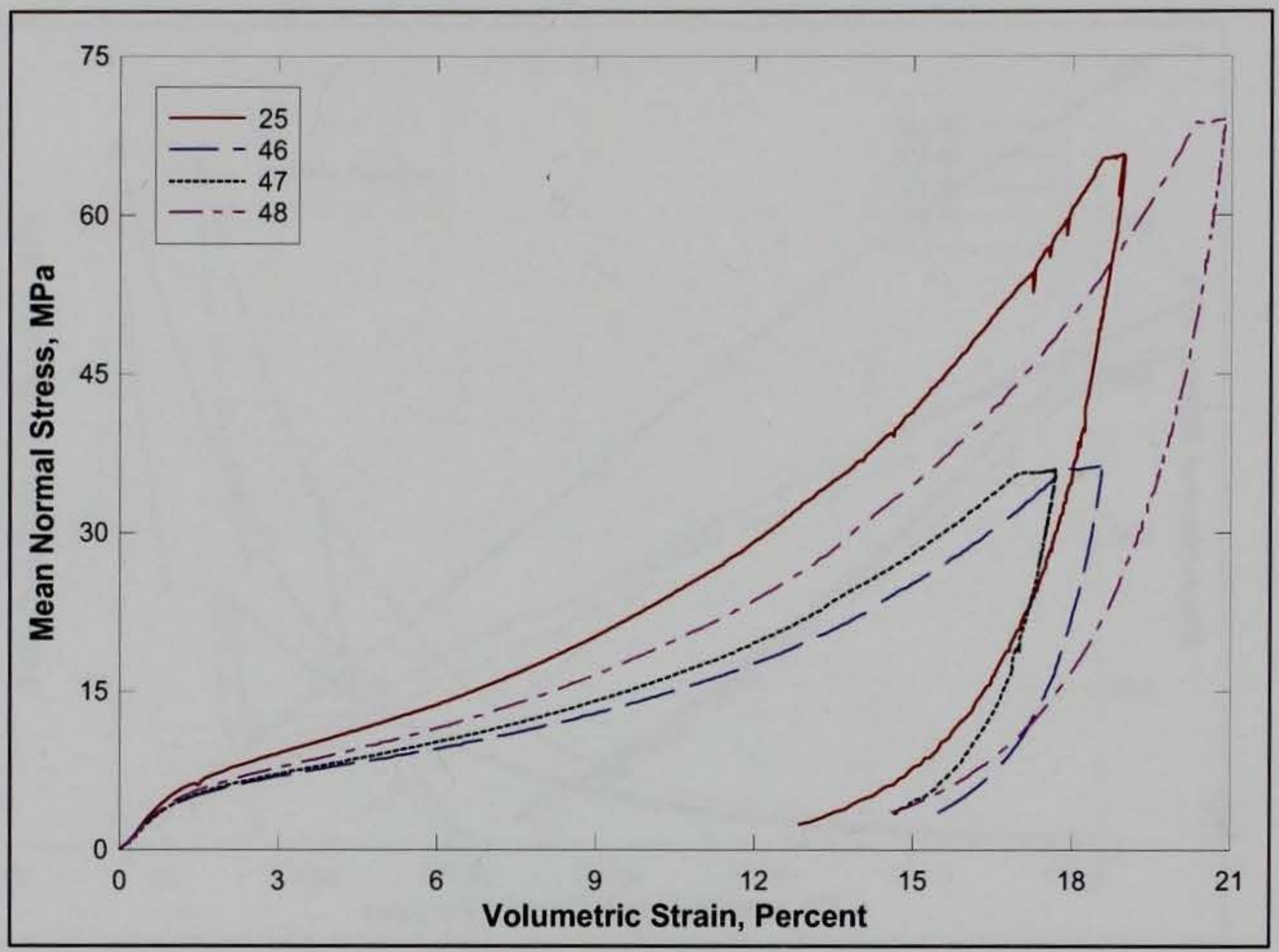

Figure 45. Pressure-volume data from UX/BX tests.

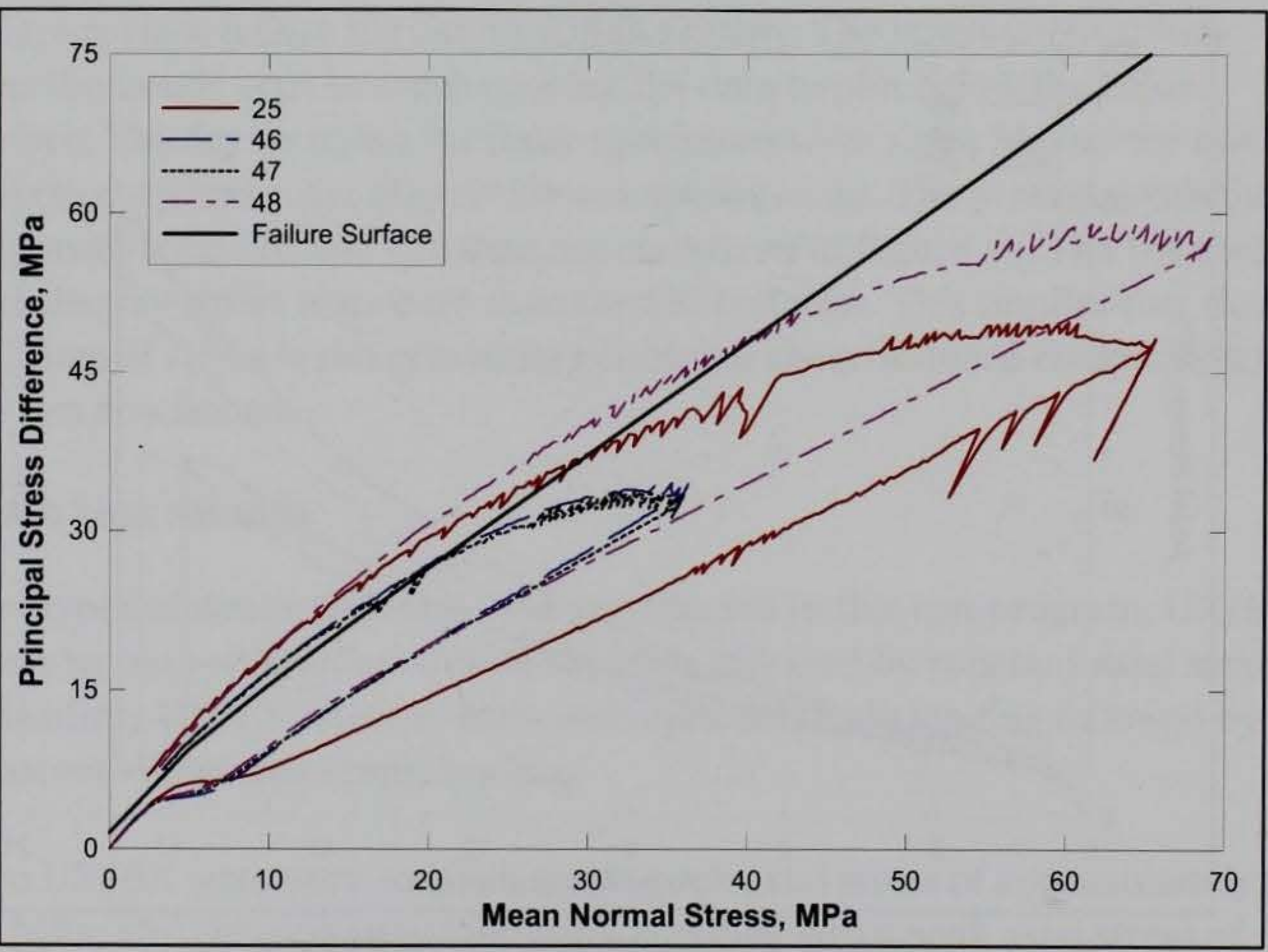

Figure 46. Stress paths from UX/BX tests and failure surface from TXC tests. 


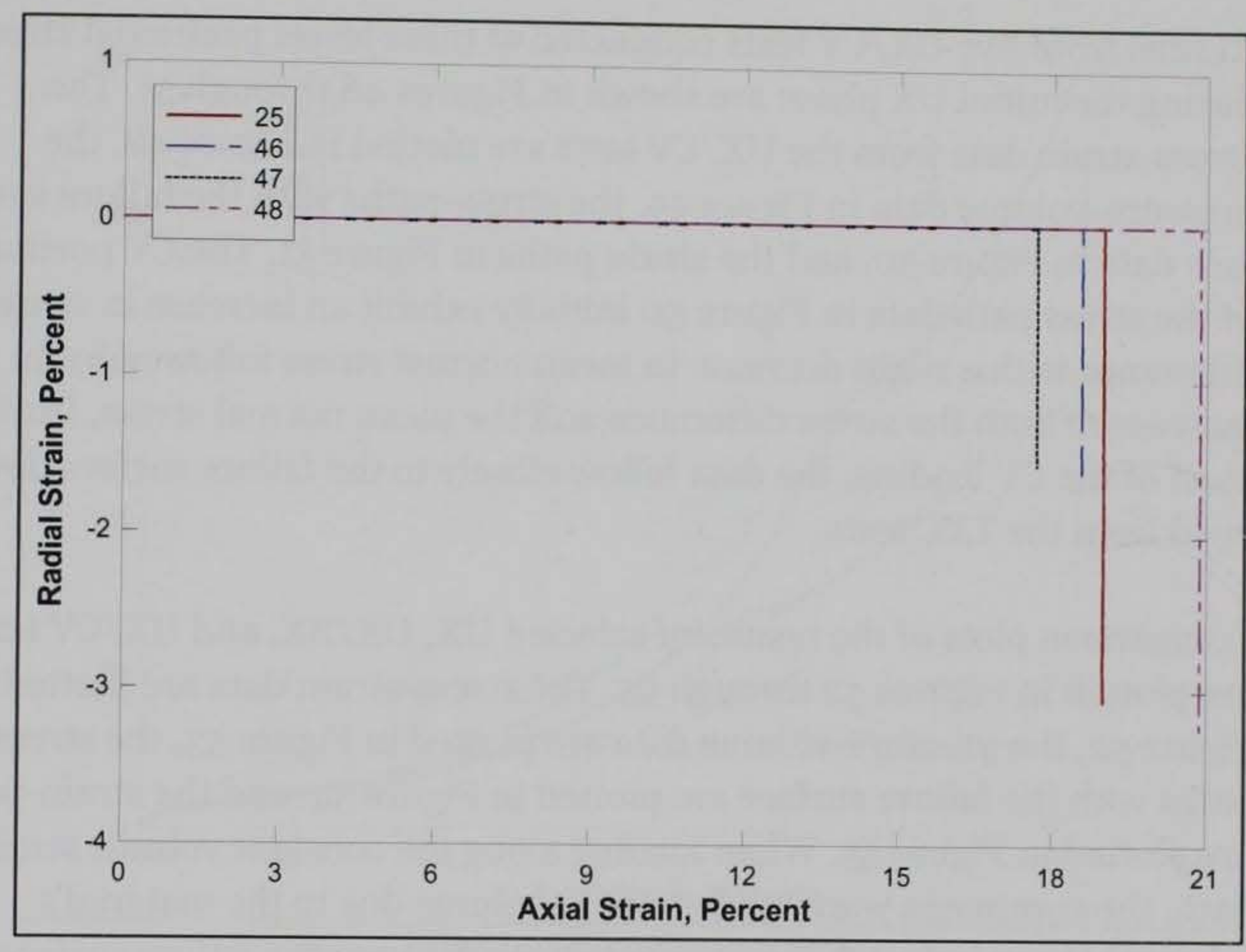

Figure 47. Strain paths from UX/BX tests.

Figure 44, test specimen 25 displays spikes in the axial stress during loading; these spikes were produced from a loose electrical connection during the test. The stress-strain response of the material (Figure 44) displays variations during the UX loading that are a function of the test specimens' initial material properties. In addition, the stress-strain data illustrate that the specimens were allowed to creep under zero-radialstrain boundary conditions prior to initiating the BX unloading.

The pressure-volume data presented in Figure 45 illustrate the large amount of volume recovery that occurs during the BX unloading. Most of the specimens recovered about one third of their peak compressive volumetric strain. During the BX unloading, the stress-paths (Figure 46) show a significant decrease in principal stress difference with decreasing mean normal stress. This unloading appears to follow a limiting surface, which can be the material's failure relation (the TXC recommend failure surface in most cases). In this case, the BX unloading exceeds the failure relation. The reason the failure relation exceeds the limiting surface is that the test specimen density is increased during the UX loading. When the $\mathrm{BX}$ unloading initiates, the test specimen is too dense to follow along the failure surface determined from the TXC test data. Figure 47 displays the strain paths for the four UX/BX test specimens. 
Results from five UX/CV tests conducted at three levels peak axial stress during the initial UX phase are shown in Figures 48 through 51 . The stress-strain data from the UX/CV tests are plotted in Figure 48, the pressure-volume data in Figure 49, the stress-paths with the failure surface data in Figure 50, and the strain paths in Figure 51. The CV portions of the stress path data in Figure 50 initially exhibit an increase in stress difference with a slight decrease in mean normal stress followed by an increase of both the stress difference and the mean normal stress. During most of the CV loading, the data follow closely to the failure surface developed from the TXC tests.

Comparison plots of the results of selected UX, UX/BX, and UX/CV tests are plotted in Figures 52 through 55 . The stress-strain data are plotted in Figure 52, the pressure-volume data are plotted in Figure 53, the stresspaths with the failure surface are plotted in Figure 54, and the strain-paths are plotted in Figure 55. When loading along the constant volume strain path, the specimens want to increase in volume due to the material's inherent shear-induced dilation characteristics near the failure surface. Increasing levels of pressure are required to maintain constant volume boundary conditions (Figure 53). The boundary conditions applied during the BX unloading require significant amounts of volume expansion. To maintain the boundary conditions, pressure must be reduced. In Figure 54, one stress path for each of the different strain path tests and the TXC failure surface are overlaid to illustrate the merger of the data in the vicinity of a failure surface. The convergence of the data from the $\mathrm{UX} / \mathrm{CV}$ tests validates the recommended TXC failure surface. 


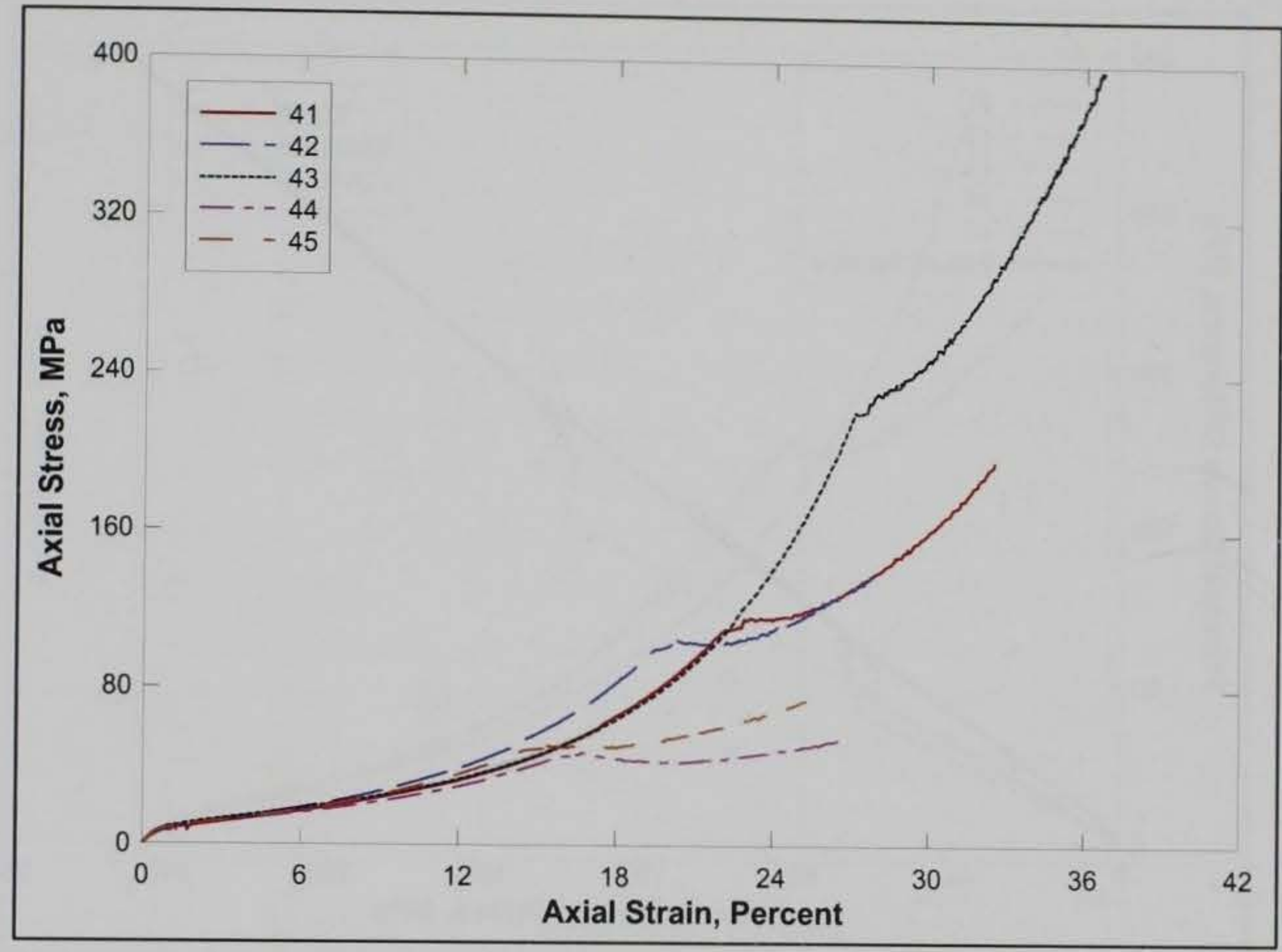

Figure 48. Stress-strain data from UX/CV tests.

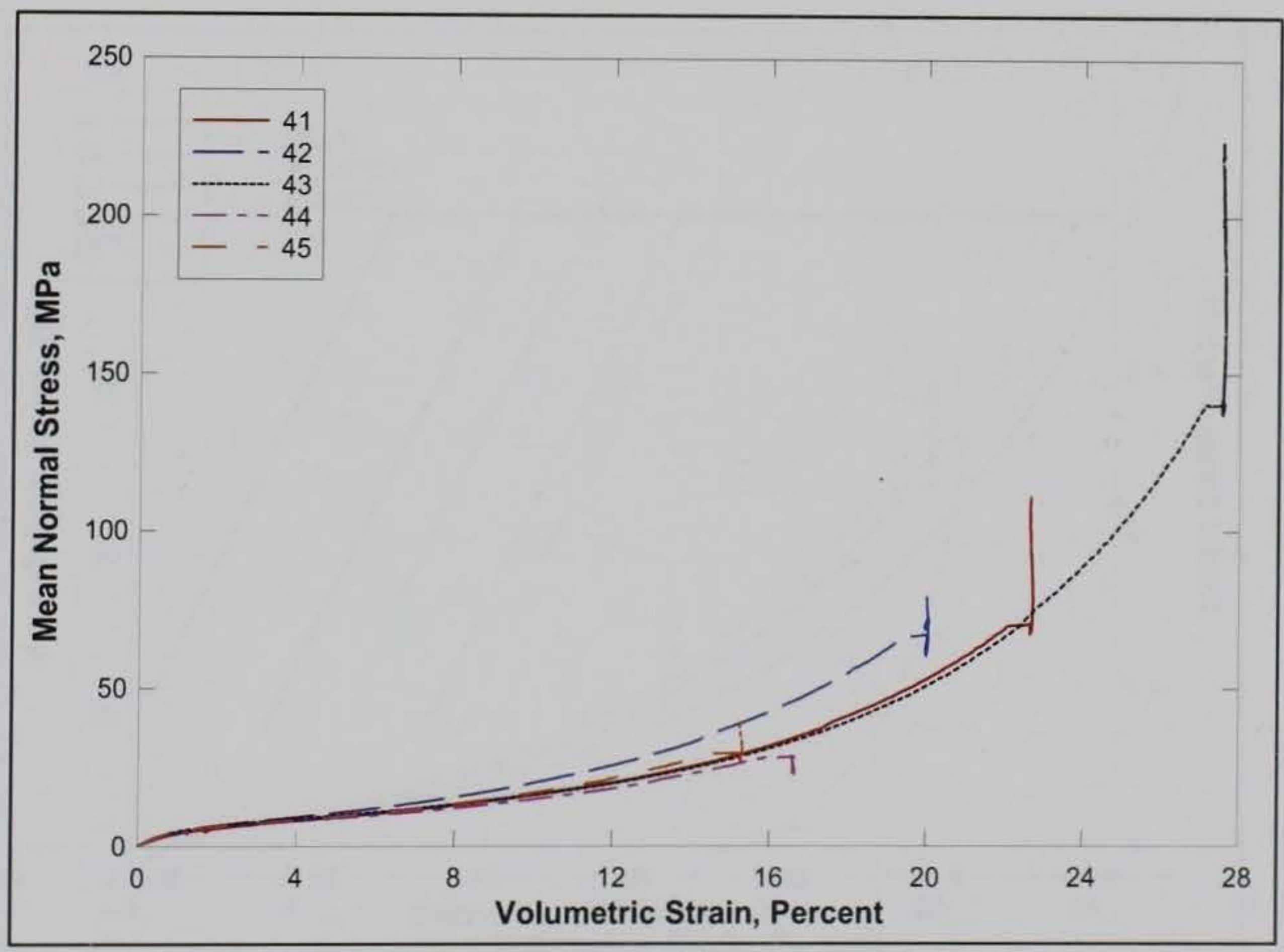

Figure 49. Pressure-volume data from UX/CV tests. 


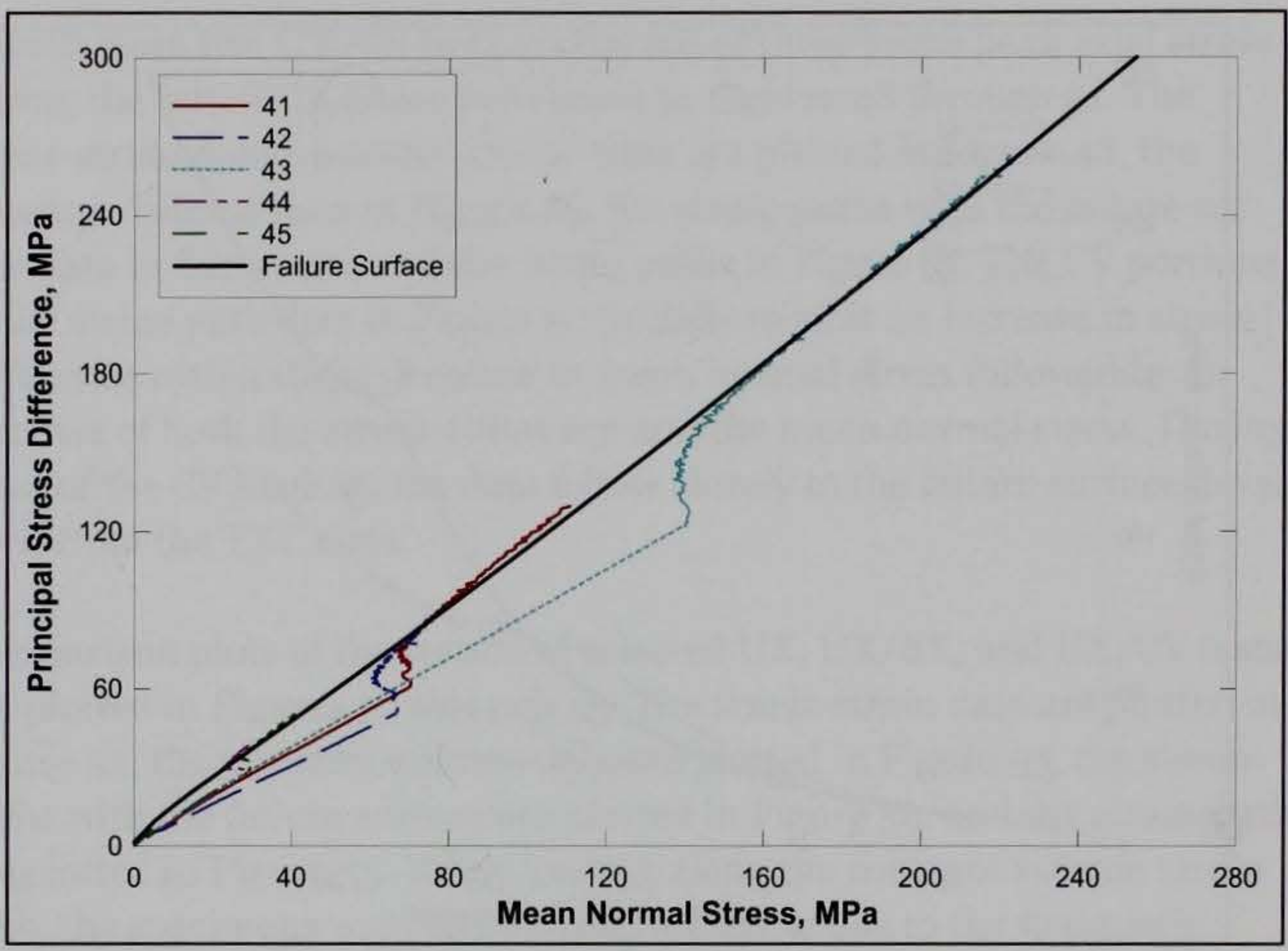

Figure 50. Stress paths from UX/CV tests and failure surface from TXC tests.

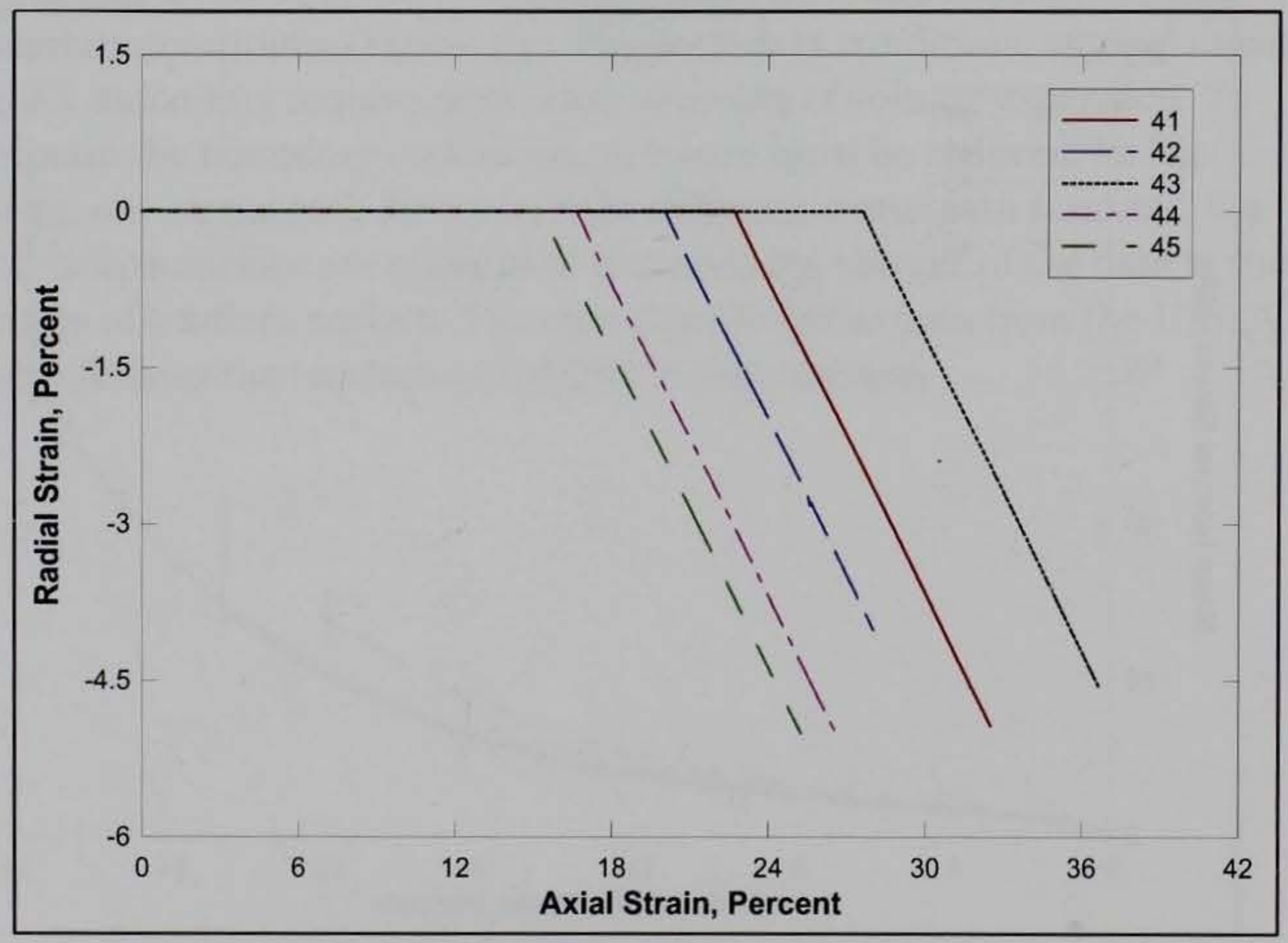

Figure 51. Strain paths from UX/CV tests. 


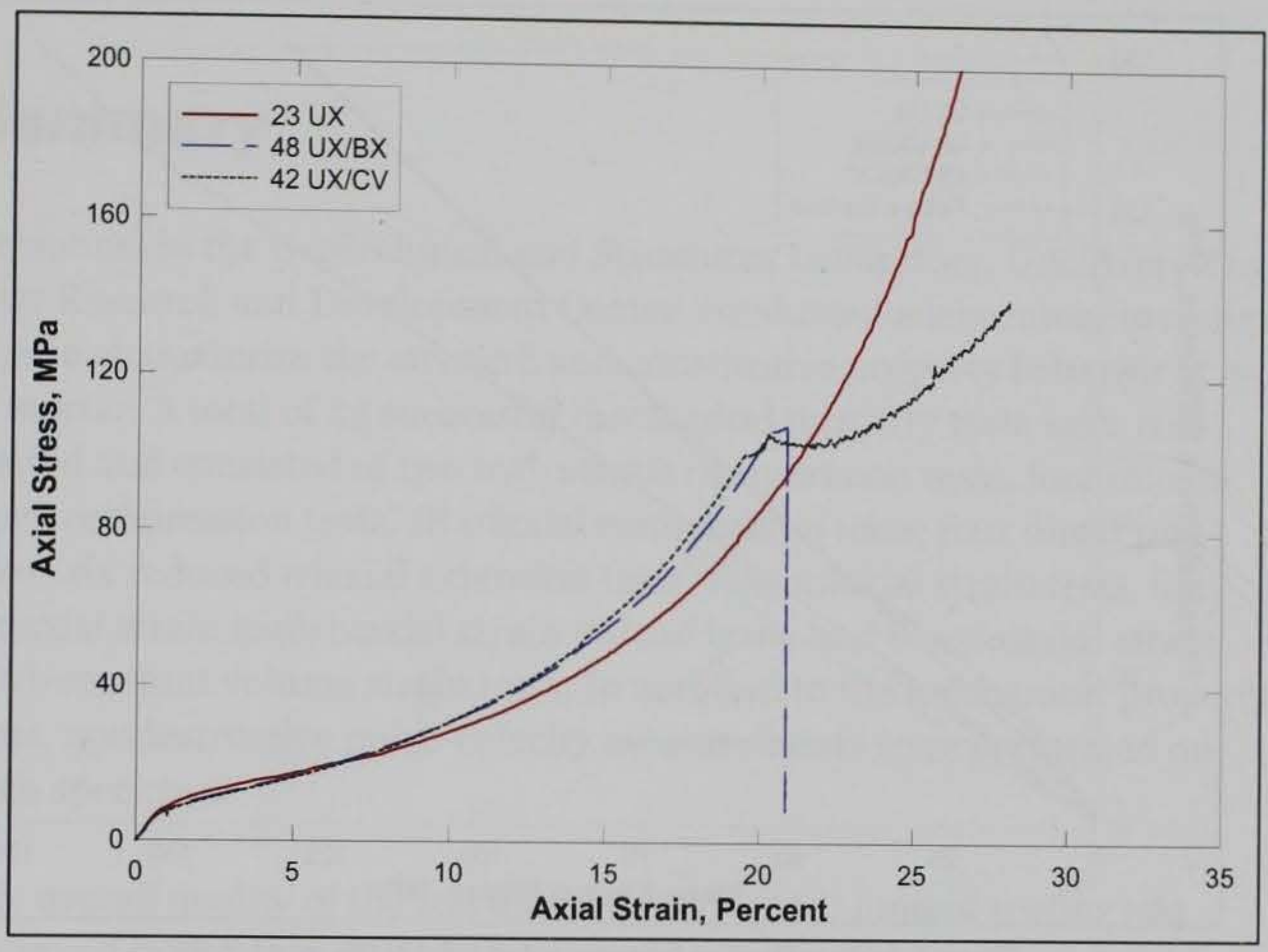

Figure 52. Stress-strain data from selected UX, UX/BX, and UX/CV tests.

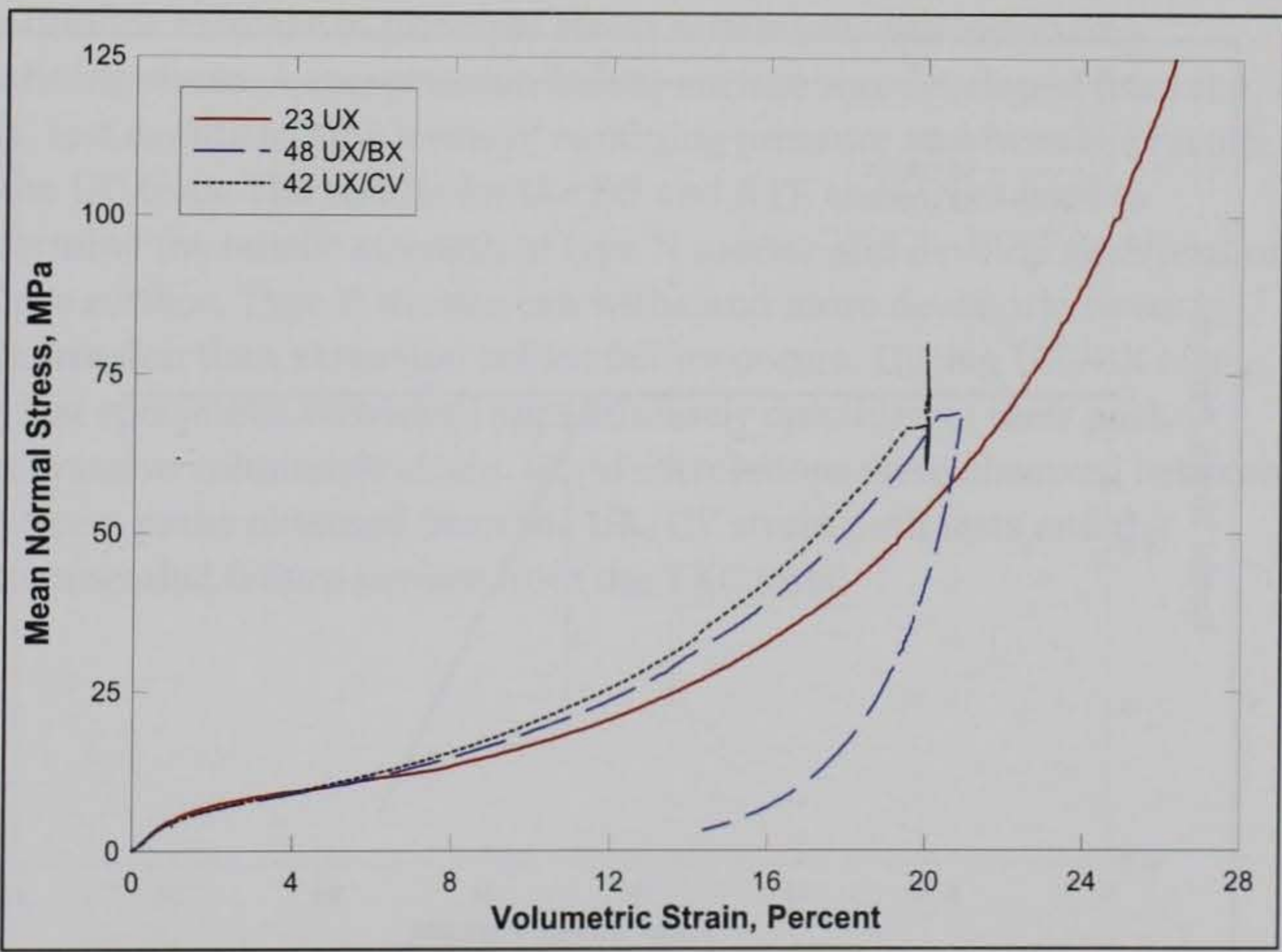

Figure 53. Pressure-volume data from selected UX, UX/BX, and UX/CV tests. 


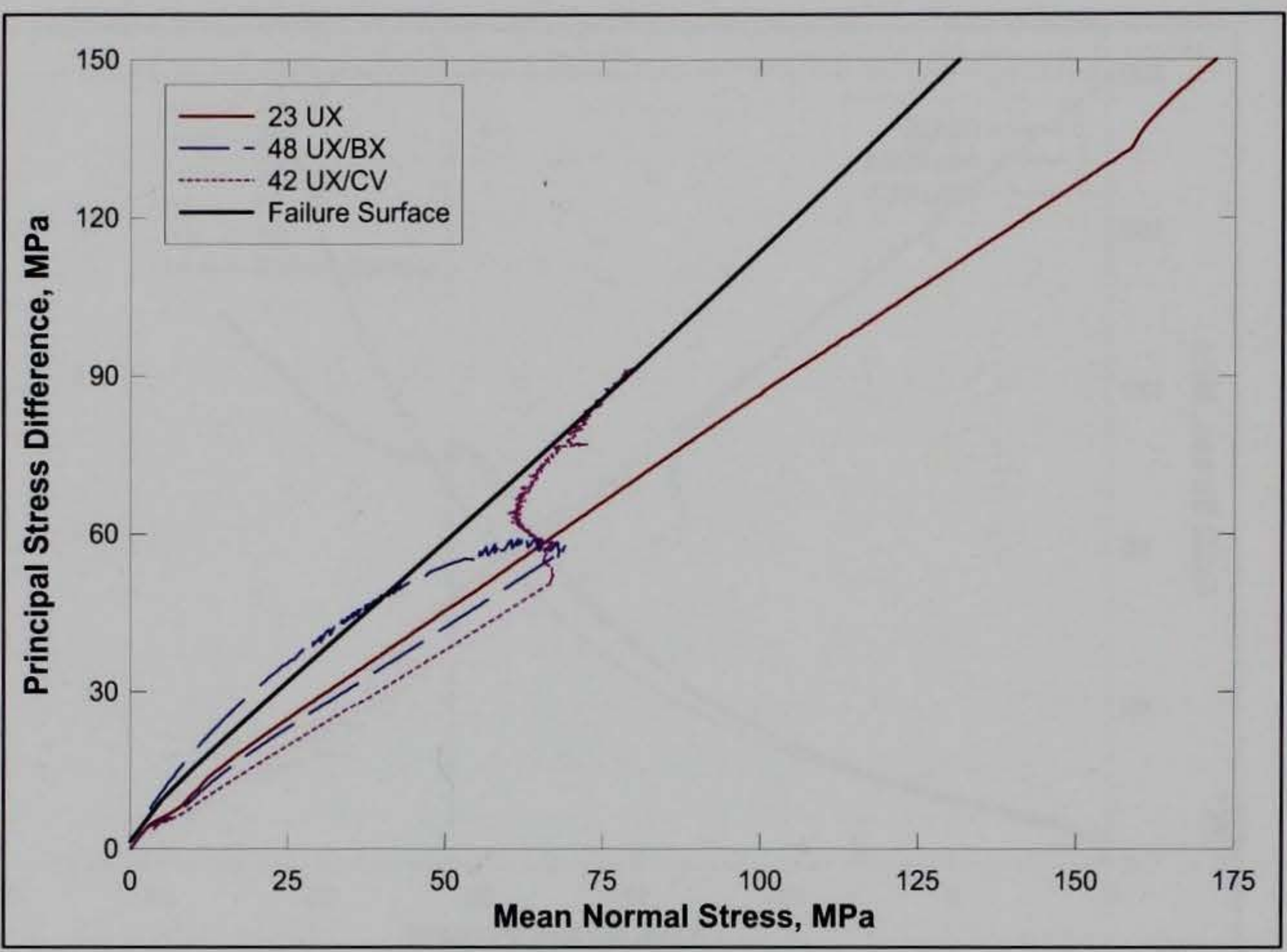

Figure 54. Stress paths from selected UX, UX/BX and UX/CV tests and failure surface from TXC tests.

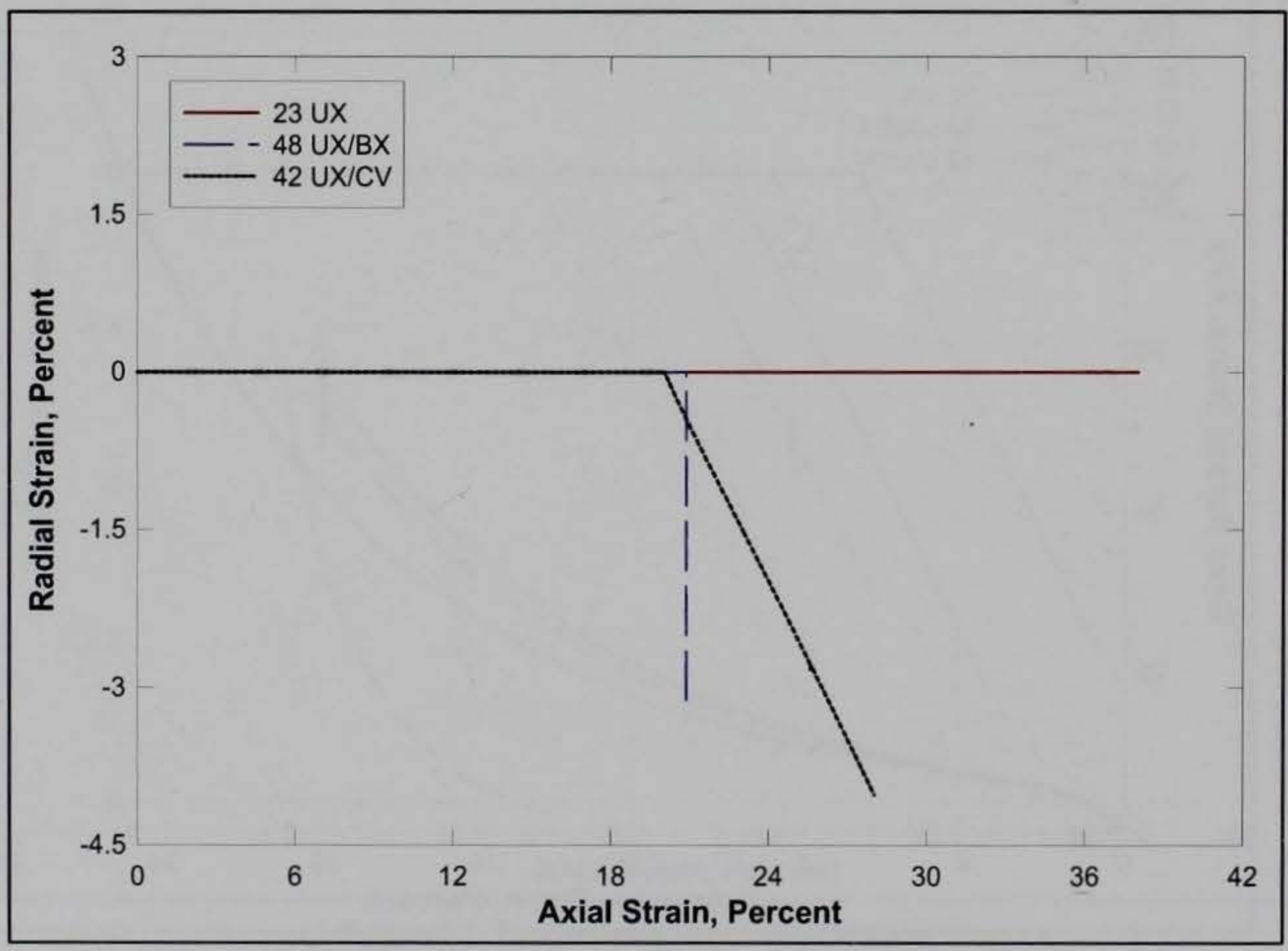

Figure 55. Strain paths from selected UX, UX/BX, and UX/CV tests. 


\section{Summary}

Personnel in the Geotechnical and Structures Laboratory, U.S. Army Engineer Research and Development Center, conducted a laboratory investigation to characterize the strength and constitutive property behavior of type $\mathrm{N}$ mortar. A total of 45 successful mechanical property tests were conducted and consisted of two hydrostatic compression tests, four unconfined compression tests, 18 triaxial compression tests, four direct pull tests, six reduced triaxial extension tests, two uniaxial strain tests, four uniaxial strain load/biaxial strain unload tests, and five uniaxial strain load/constant volume strain tests. In addition to the mechanical property tests, nondestructive pulse-velocity measurements were performed on each specimen.

The overall quality of the test data was very good; limited scatter was observed in the data over repeated loading paths. Creep was observed during the $\mathrm{HC}$ and UX/BX tests. Results from the TXC tests exhibited a continuous increase in principal stress difference with increasing confining stress. A compression failure surface was developed from the TXC test results at nine levels of confining pressure and from the results of the UC tests. The results for the DP and RTE tests were used to determine the tensile strength of type $\mathrm{N}$ mortar and develop an extension failure surface. Type N mortar can withstand more deviatoric stress in compression than extension before failure occurs. During UX/BX tests, the test specimens recovered approximately one third of their peak compressive volumetric strain. Good correlations were observed between the stress paths obtained from the UX/CV strain path tests and the recommended failure surface from the TXC tests. 


\section{References}

Akers, S. A., P. A. Reed, and J. Q. Ehrgott. 1986. WES high-pressure uniaxial strain and triaxial shear test equipment. Miscellaneous Paper SL-86-11. Vicksburg, MS: U.S. Army Engineer Waterways Experiment Station.

American Society for Testing and Materials. 2005. 2005 annual book of ASTM standards, Philadelphia, PA.

a. Designation C 39-05. Standard test method for compressive strength of cylindrical concrete specimens.

b. Designation C 42-04. Standard test method for obtaining and testing drilled cores and sawed beams of concrete.

c. Designation C 597-02. Standard test method for pulse velocity through concrete.

d. Designation D 2216-05. Standard test method for laboratory determination of water (moisture) content of soil and rock by mass.

e. Designation D 4543-04. Standard practices for preparing rock core as cylindrical test specimens and verifying conformance to dimensional and shape tolerances.

Bishop, A. W., and D. J. Henkel. 1962. The measurement of soil properties in the triaxial test. London: Edward Arnold, Ltd. 72-74. 


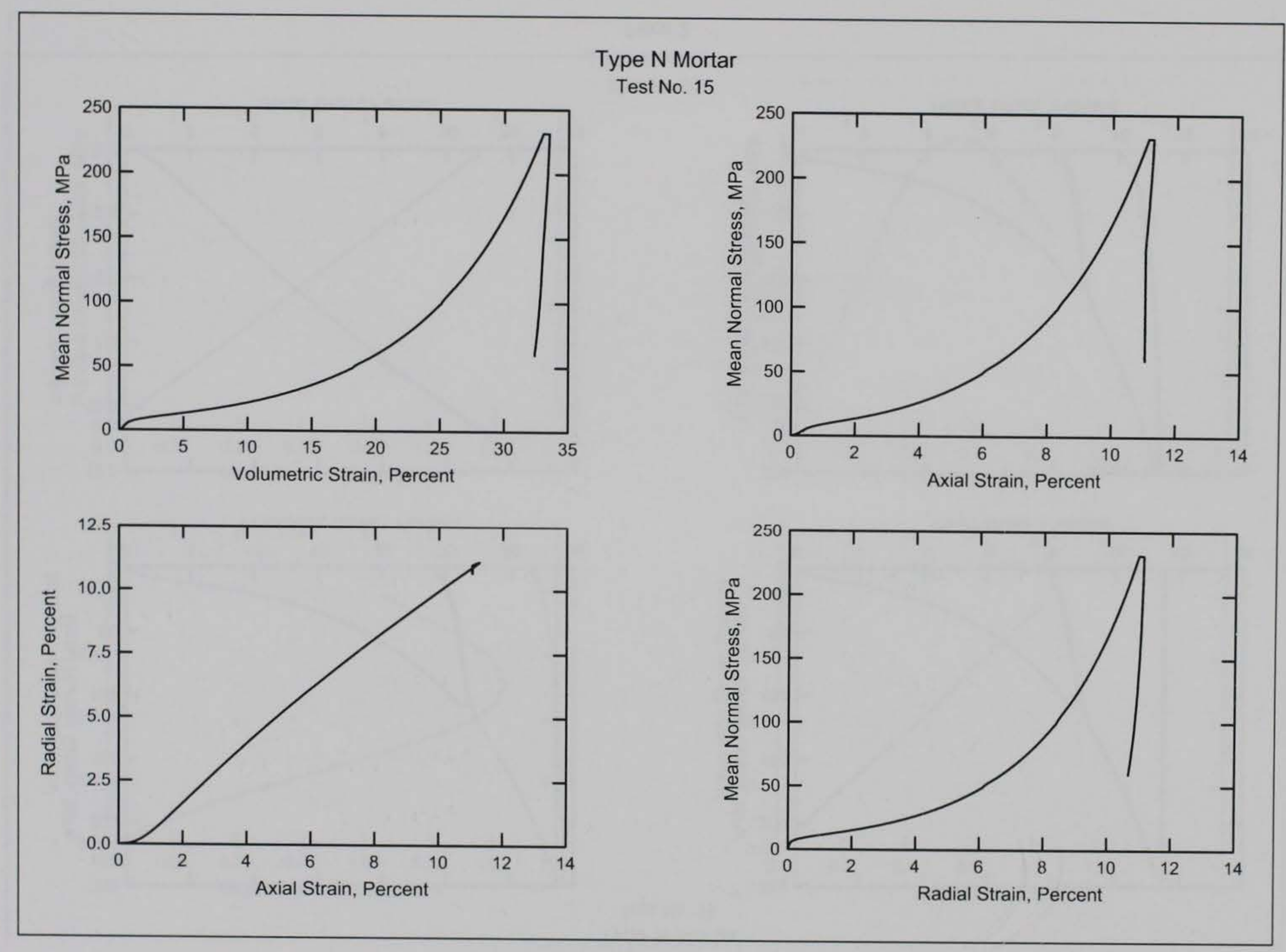




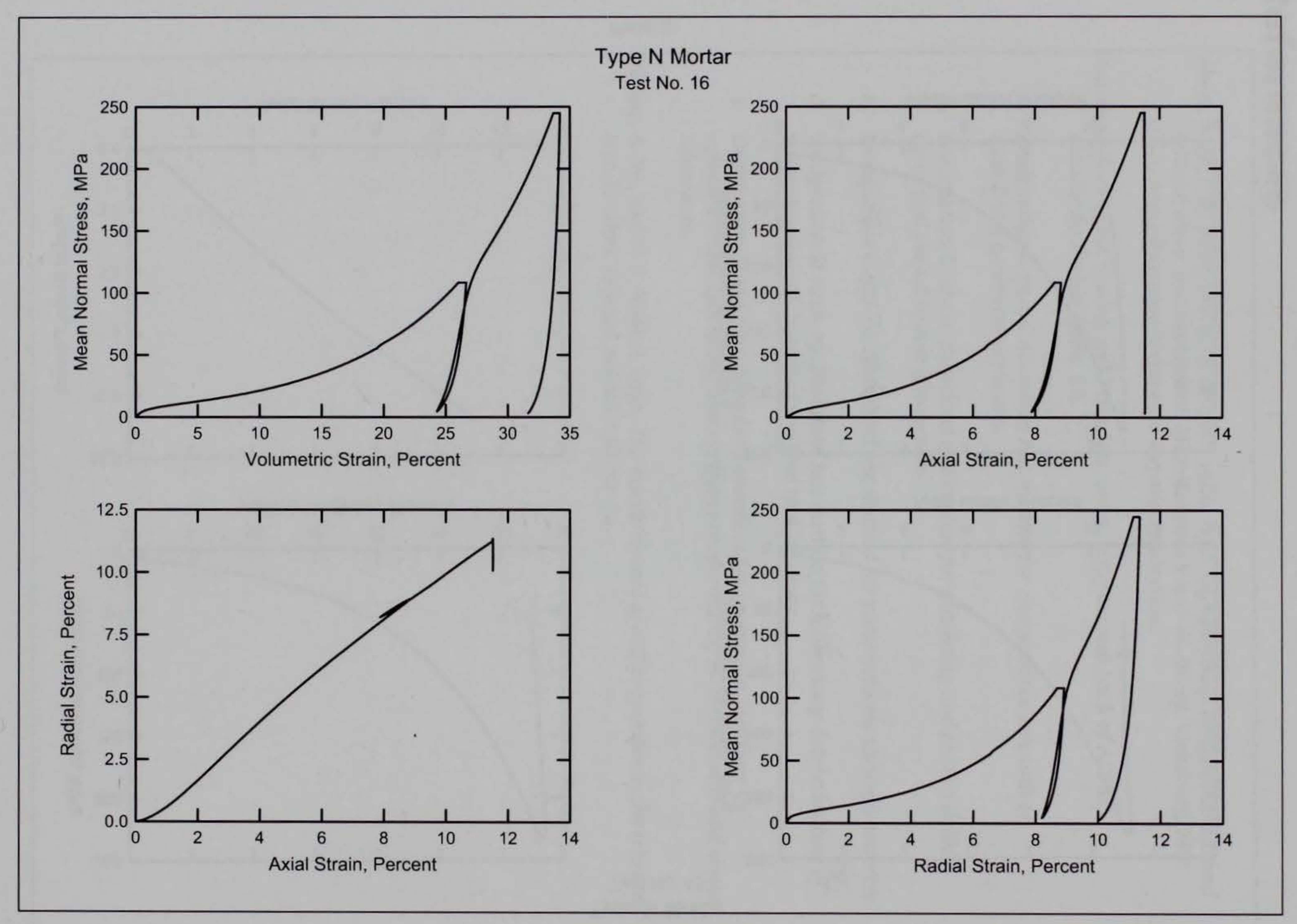




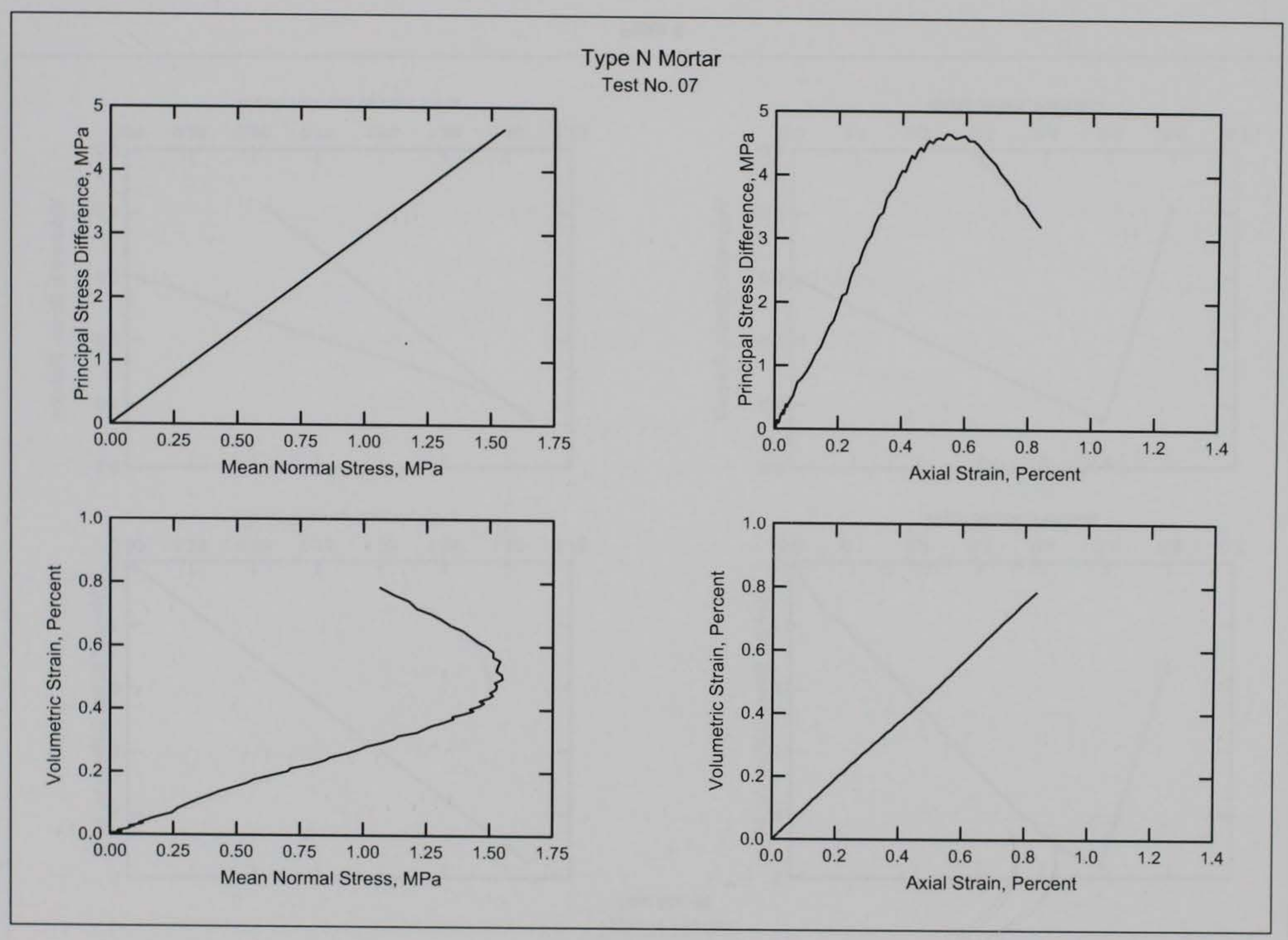

Plate 3 


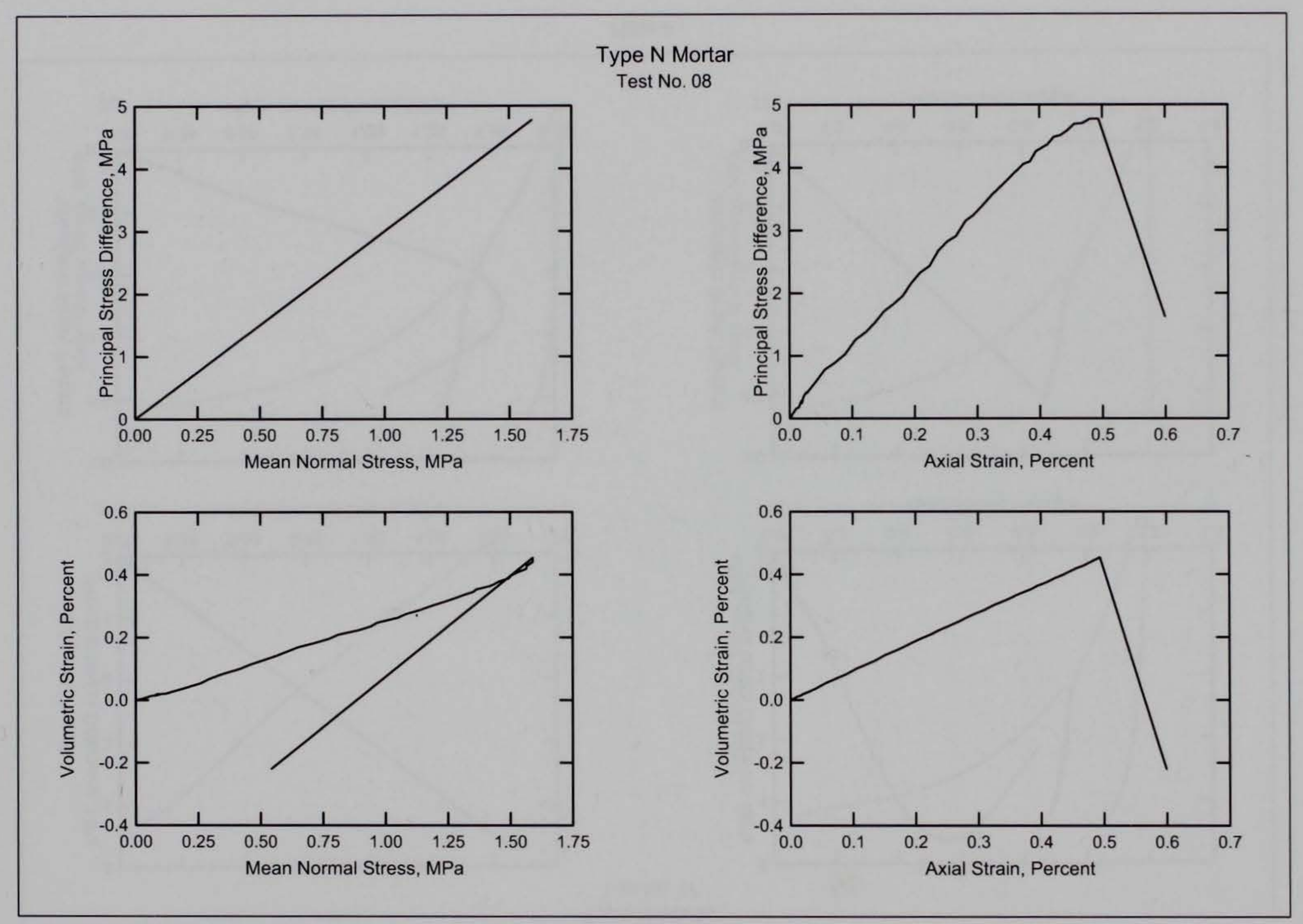

Plate 4 


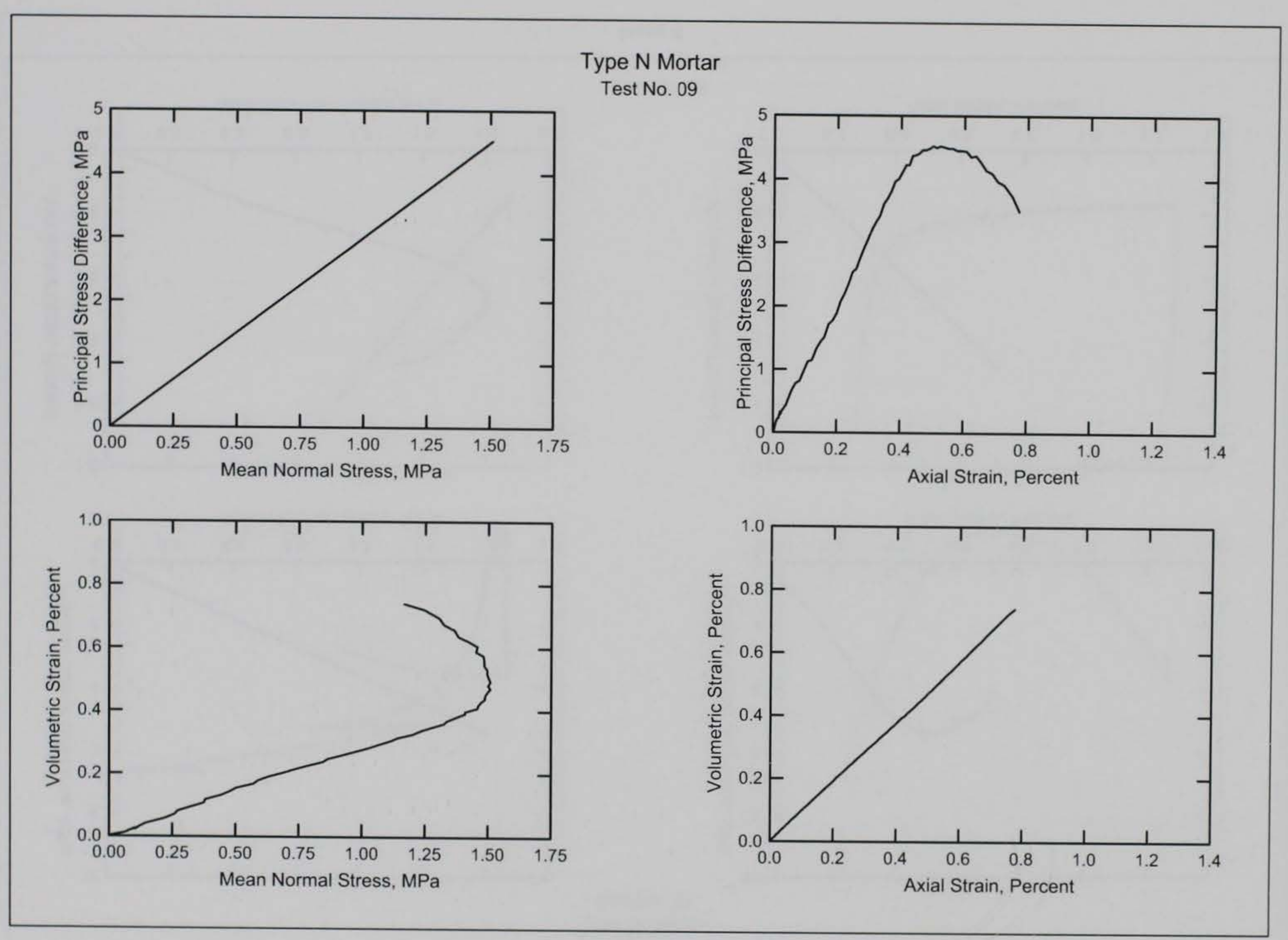




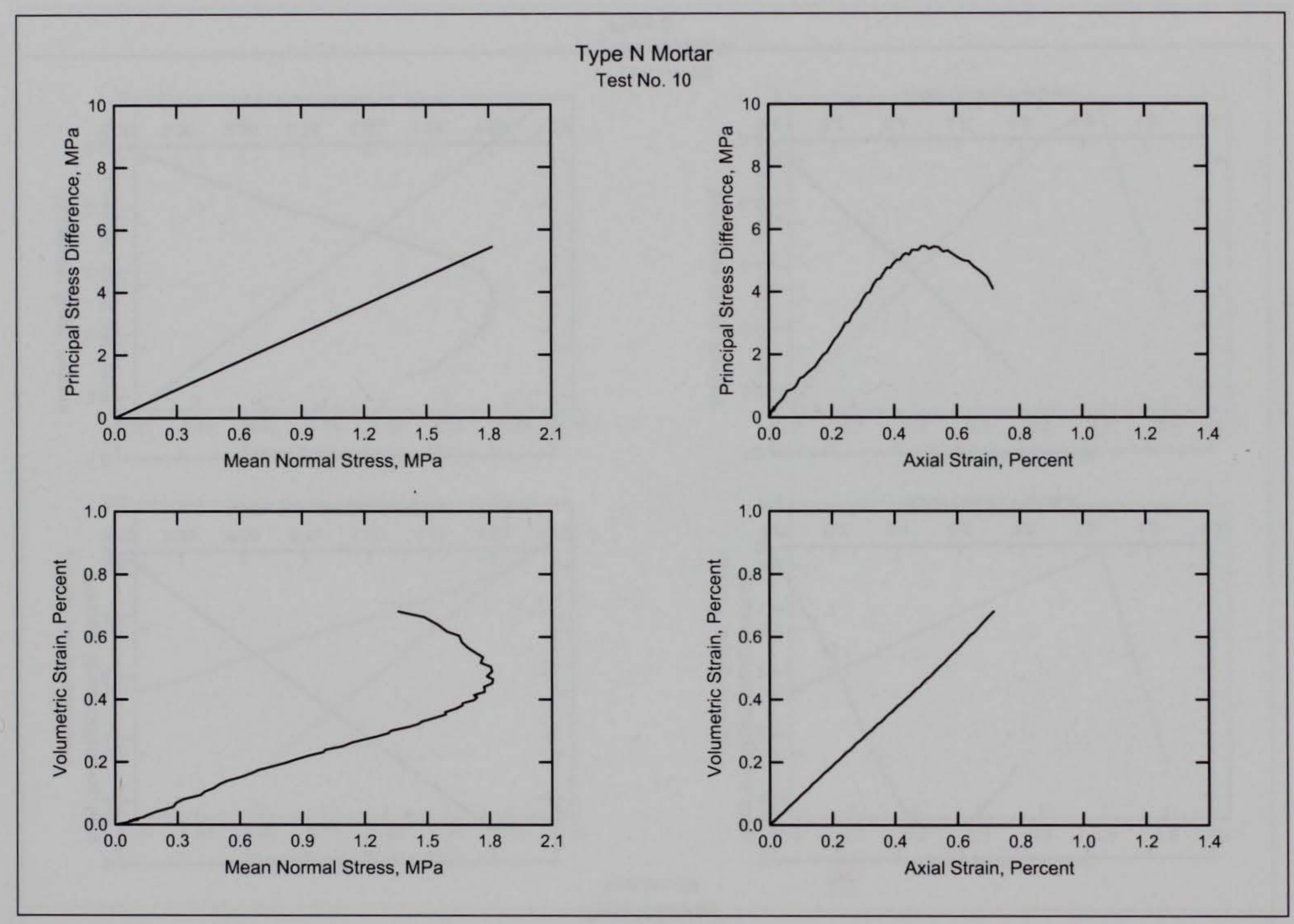

Plate 6 


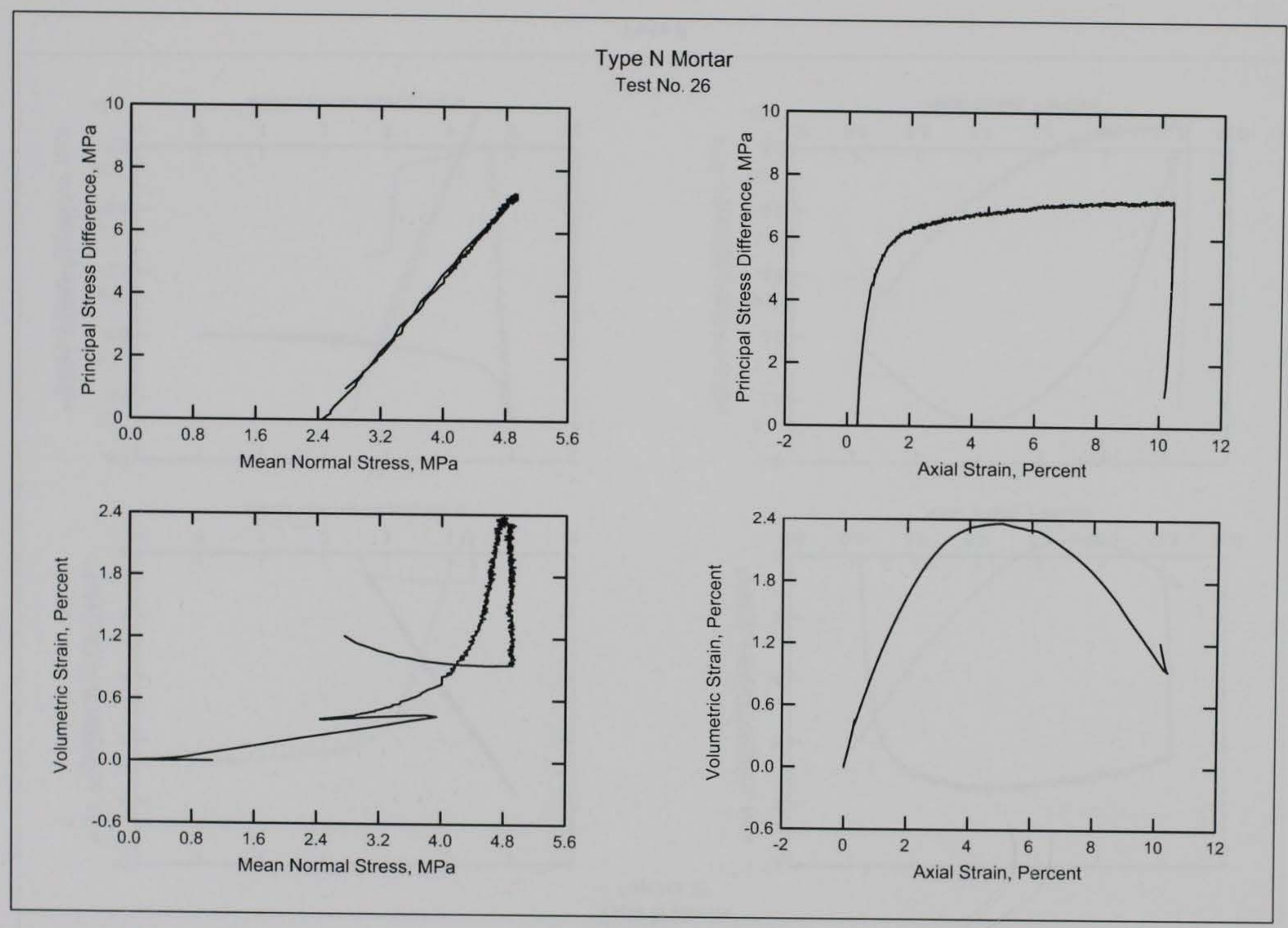




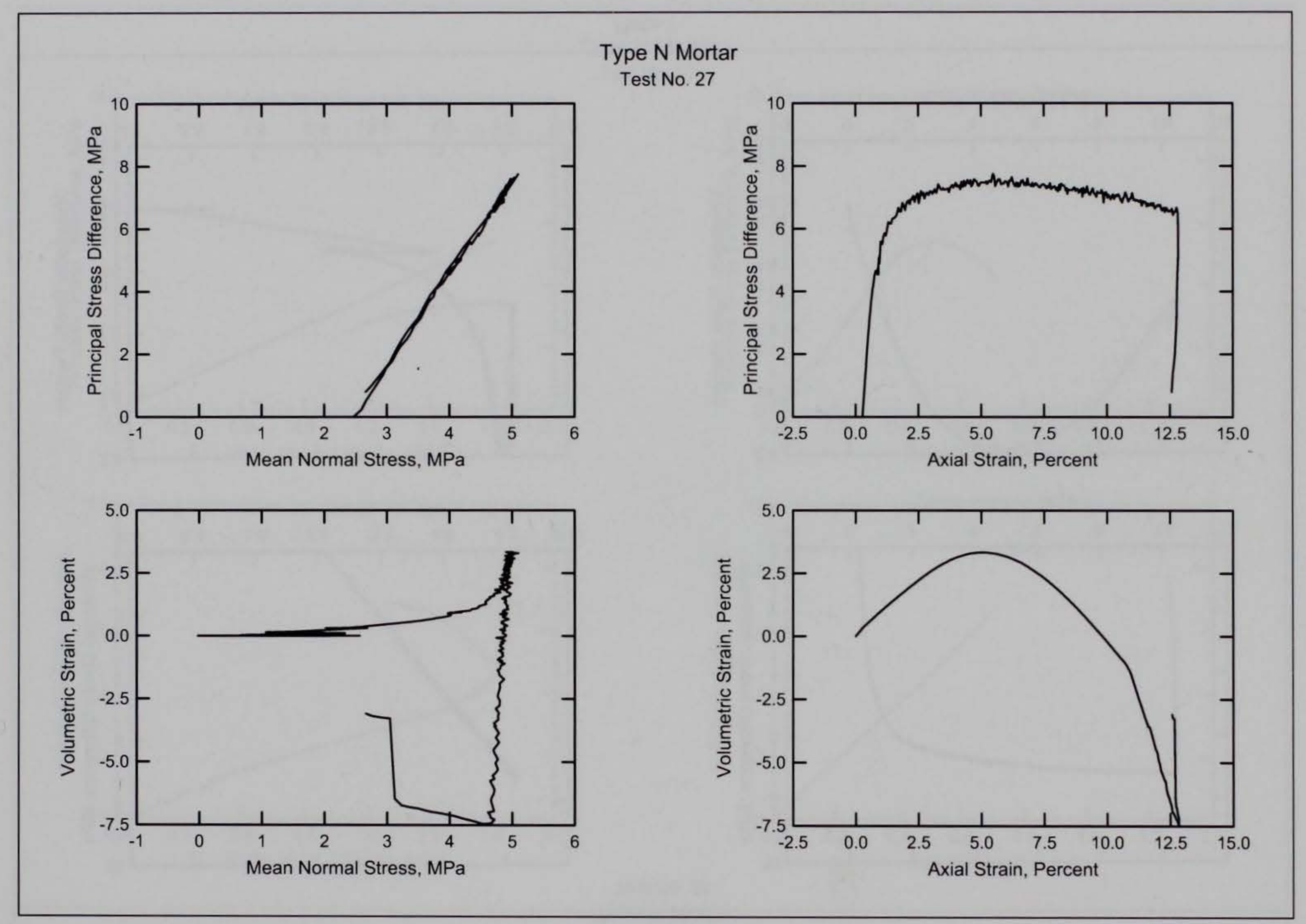




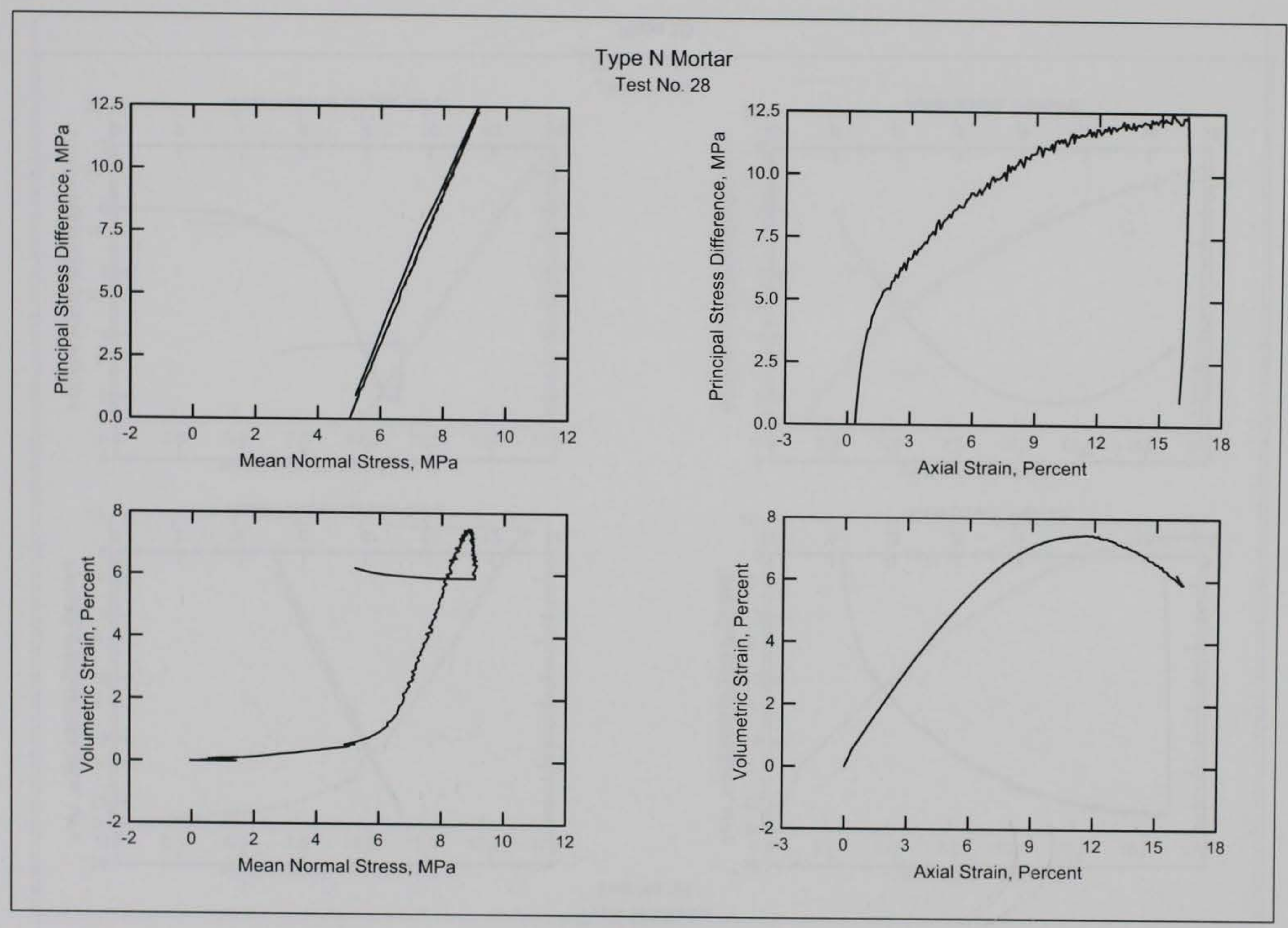




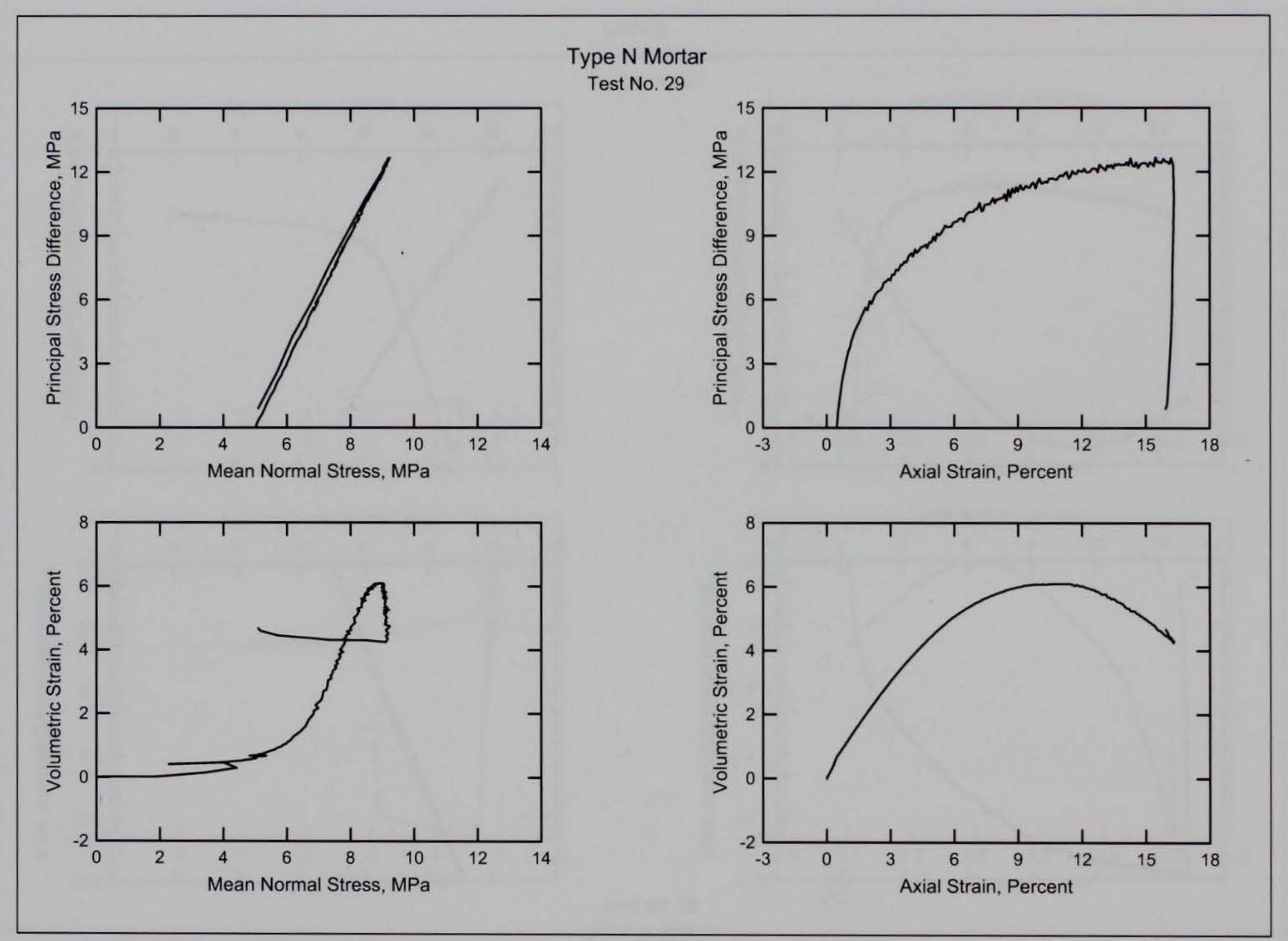




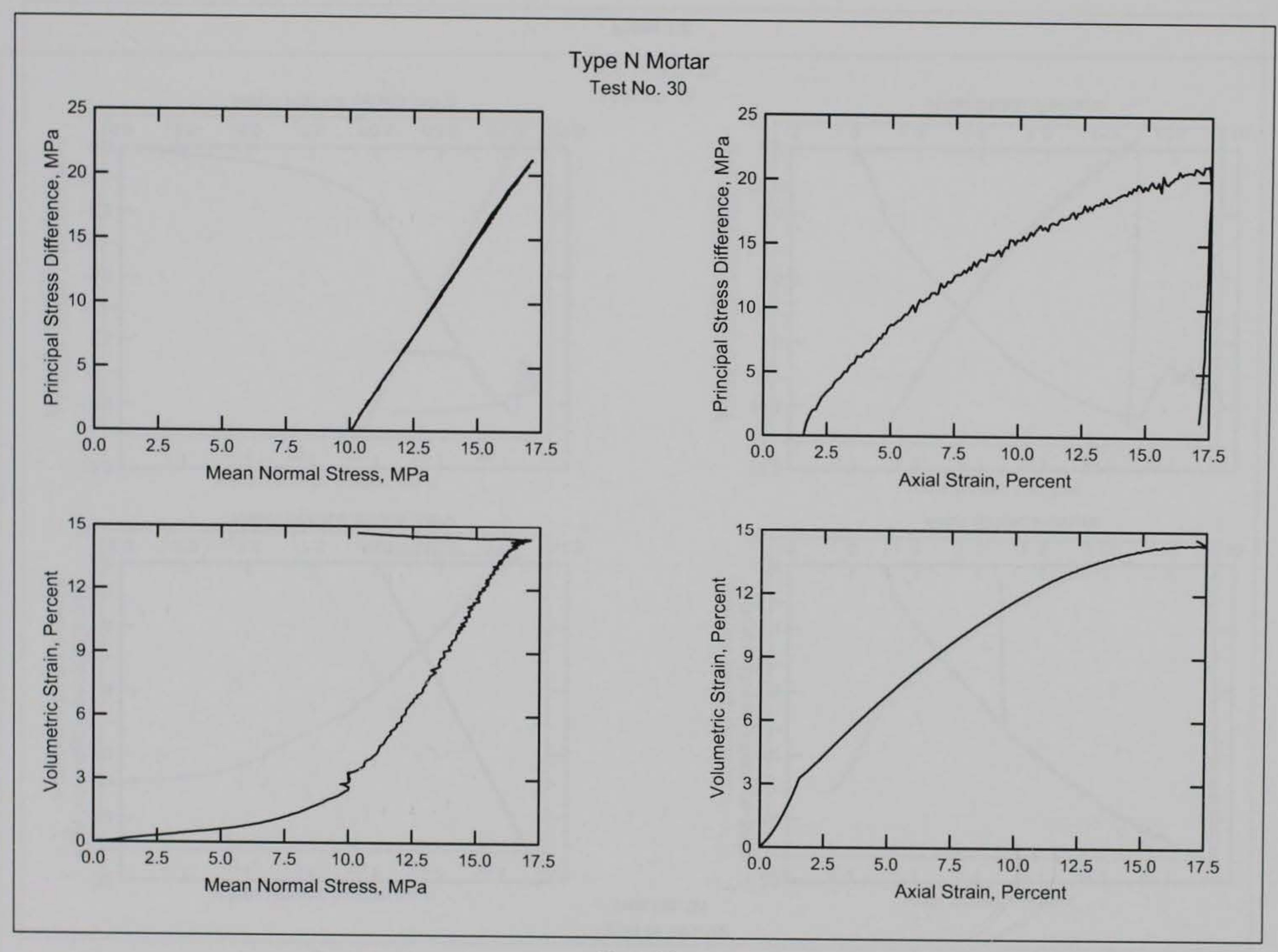




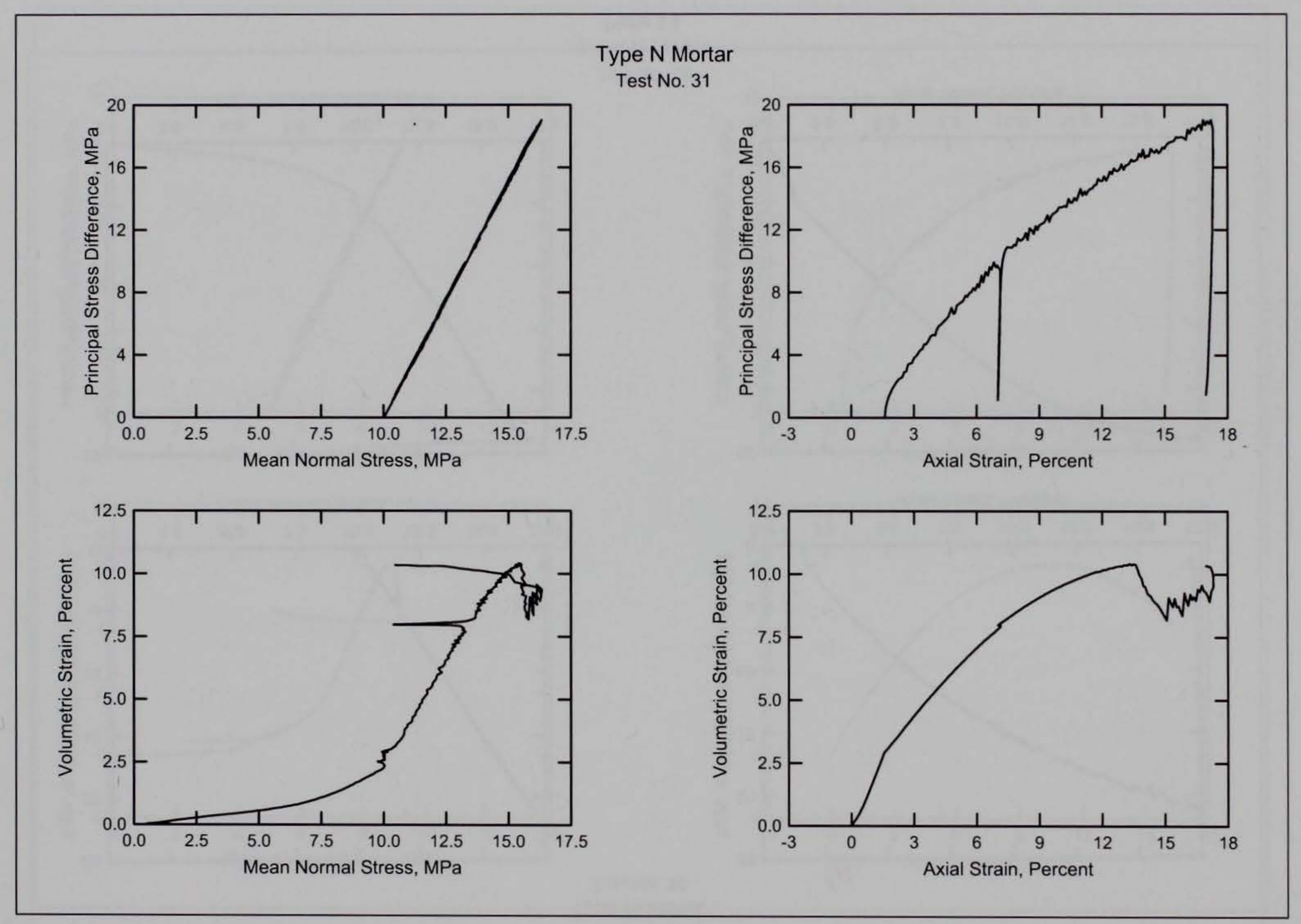

Plate 12 


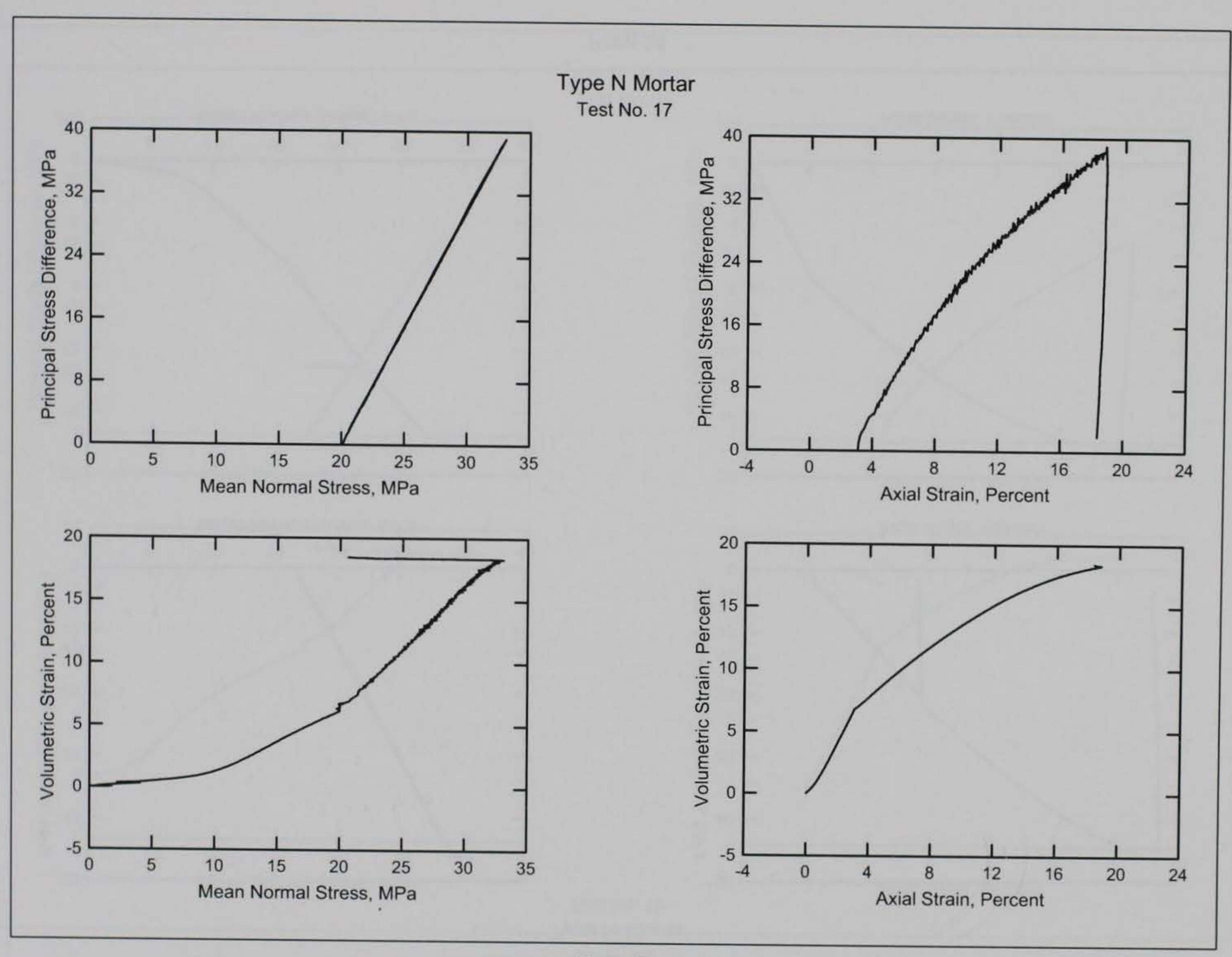




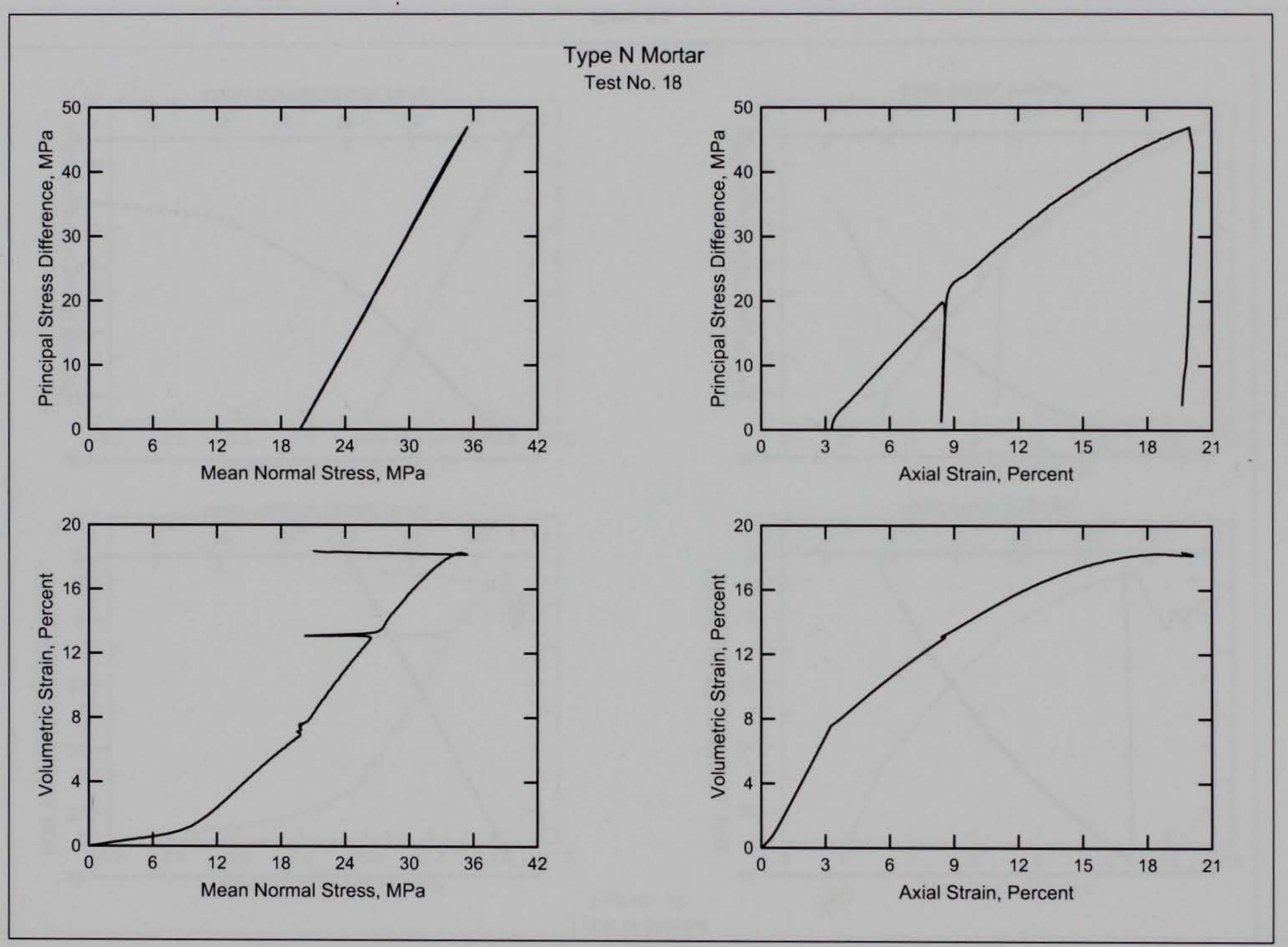




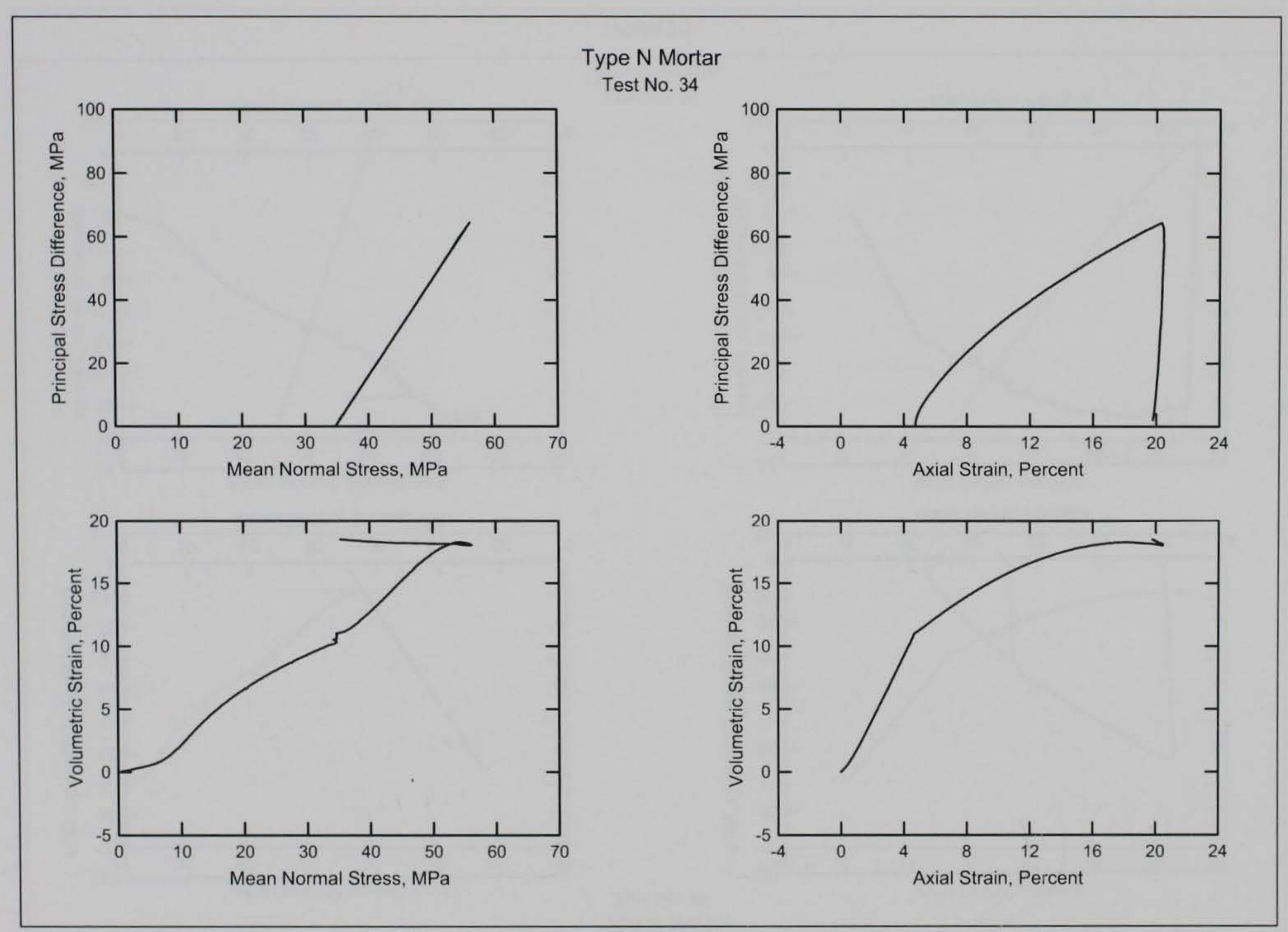




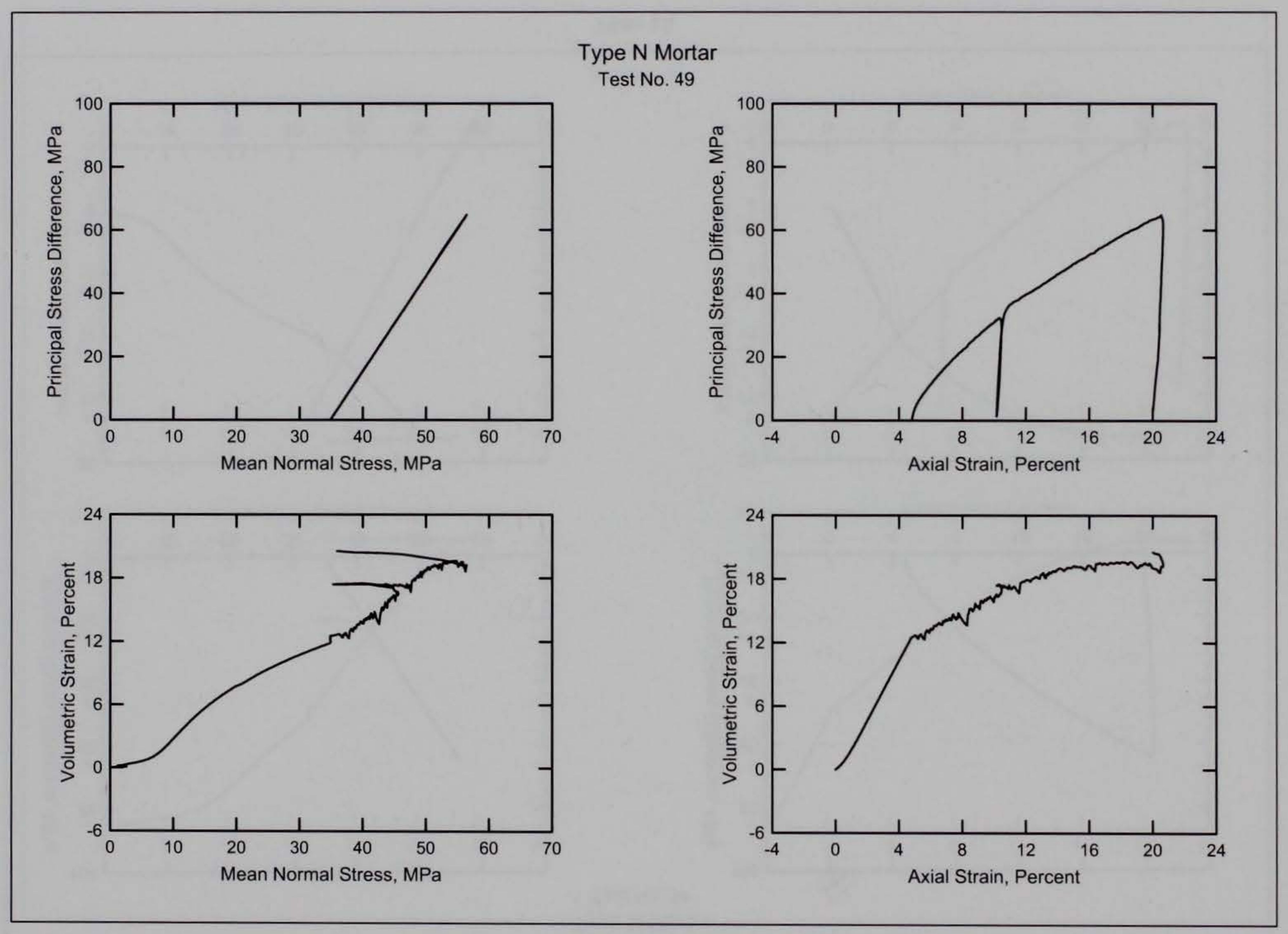




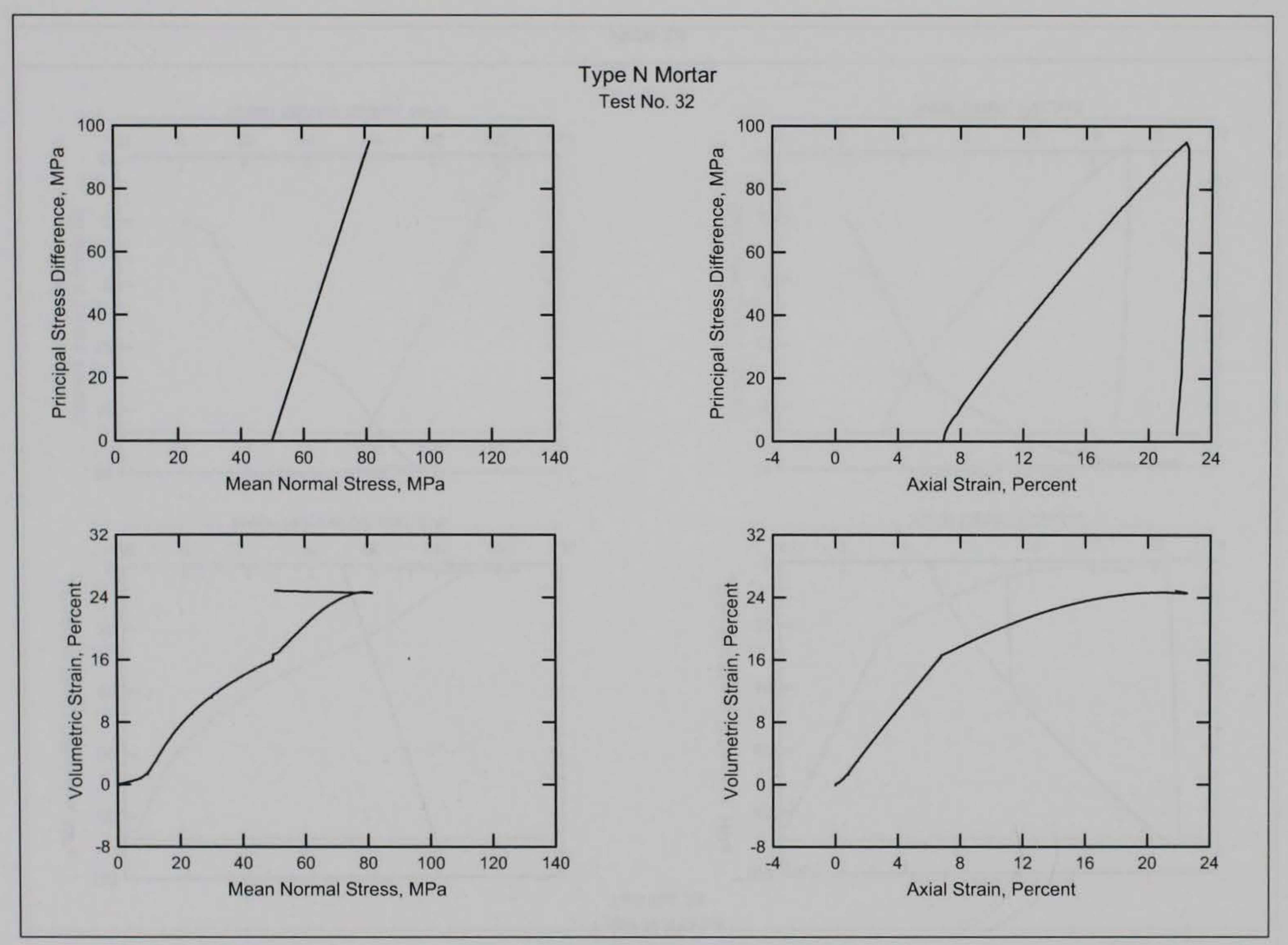

Plate 17 


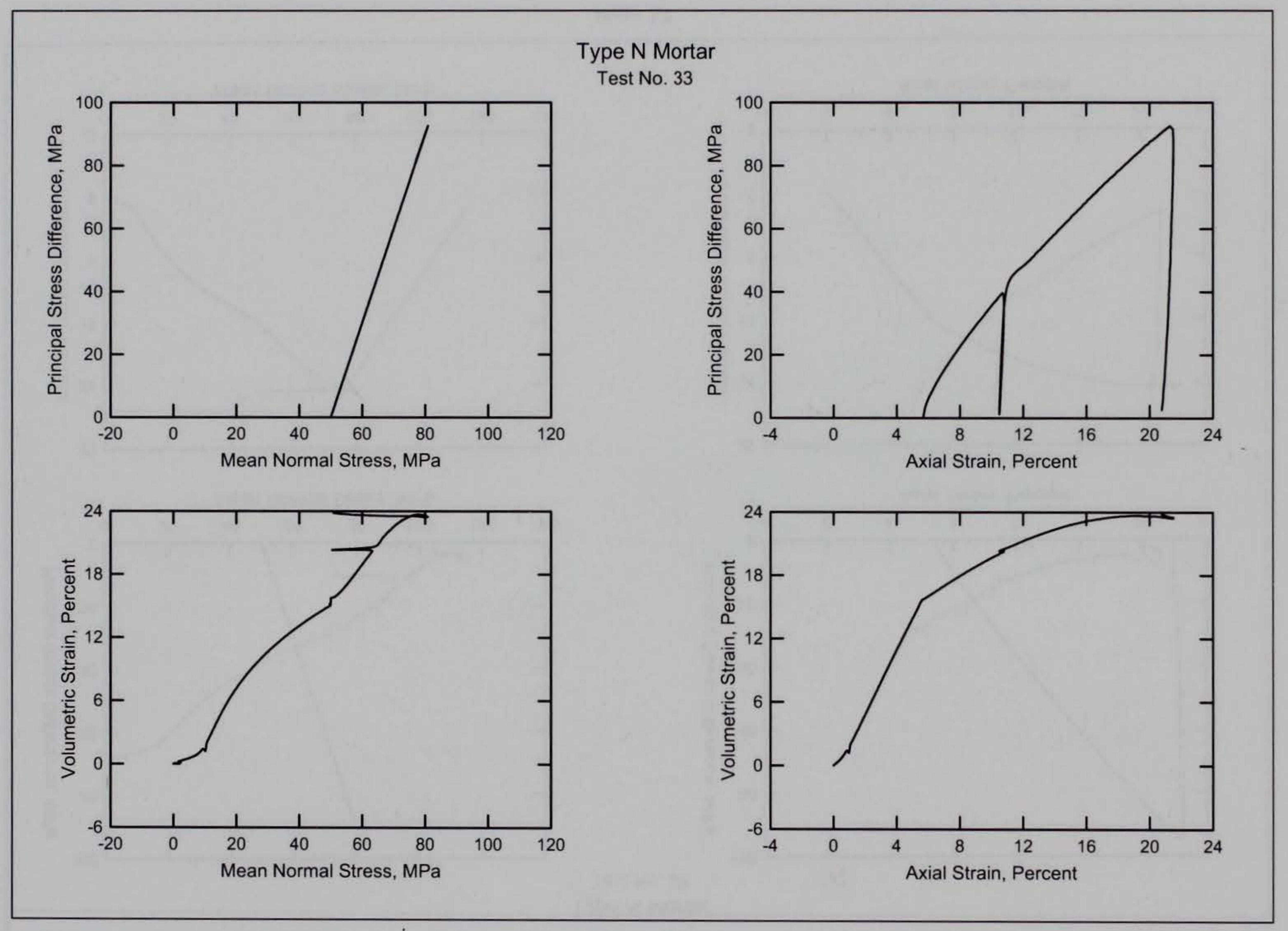




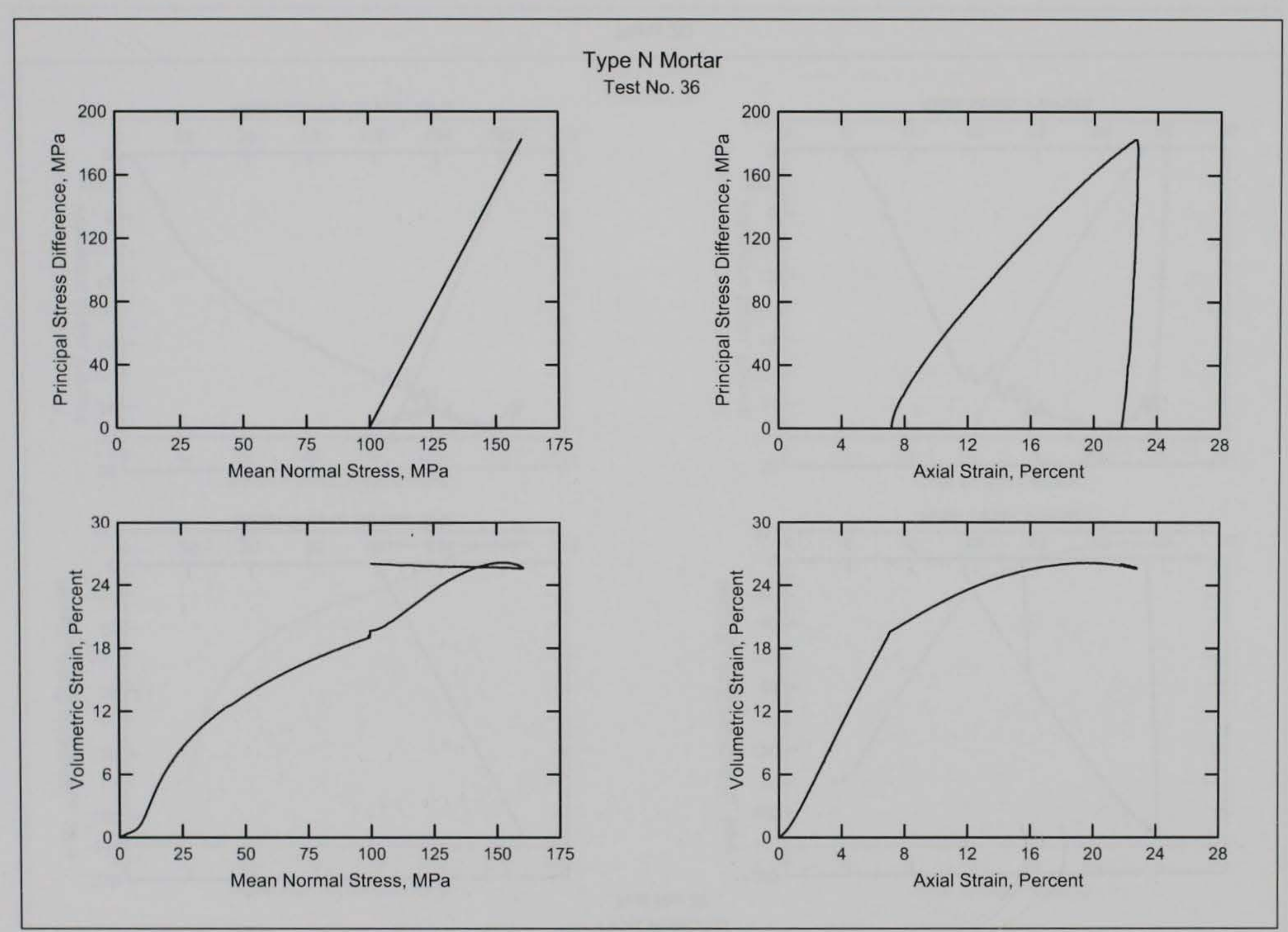

Plate 19 


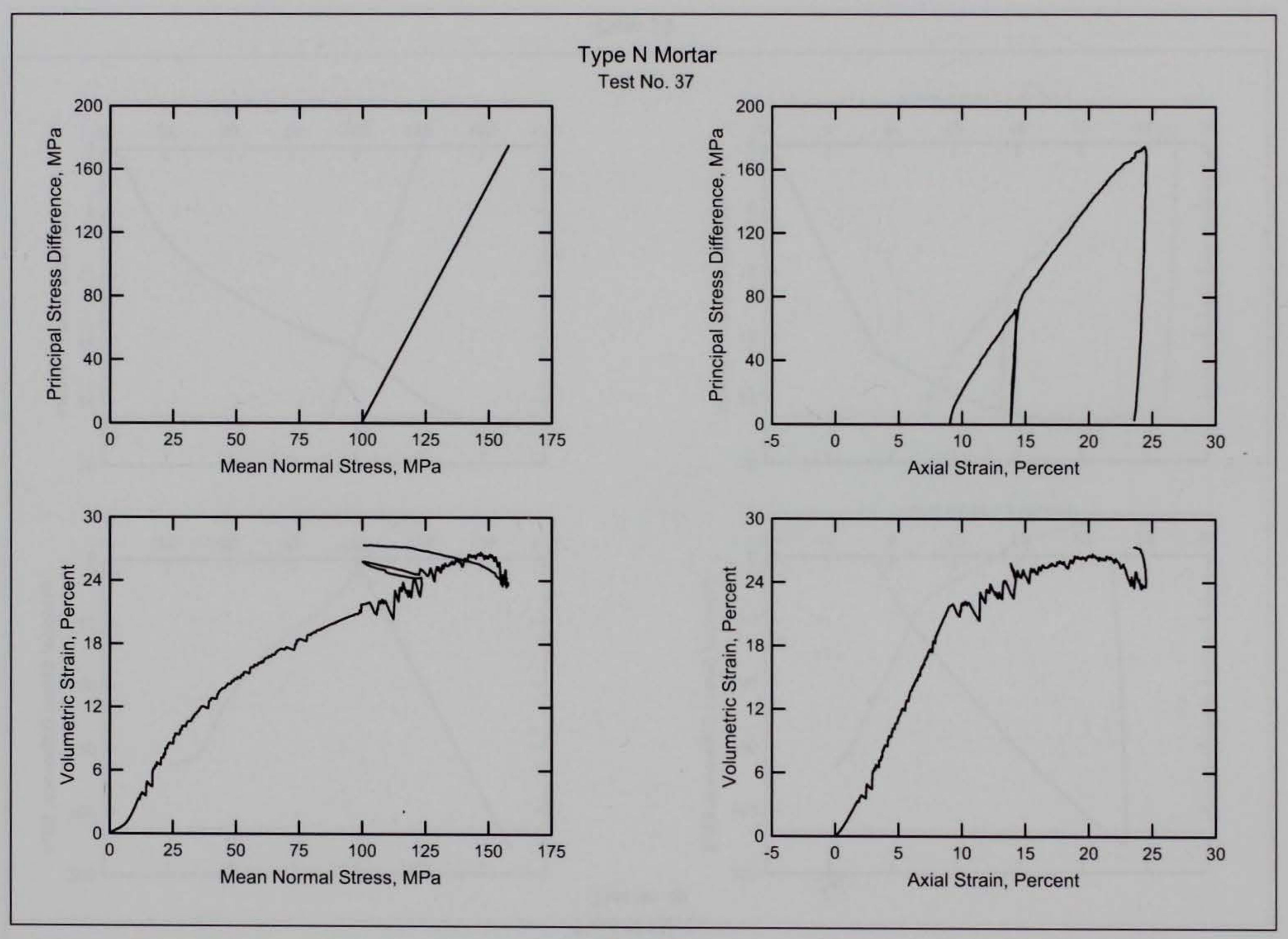




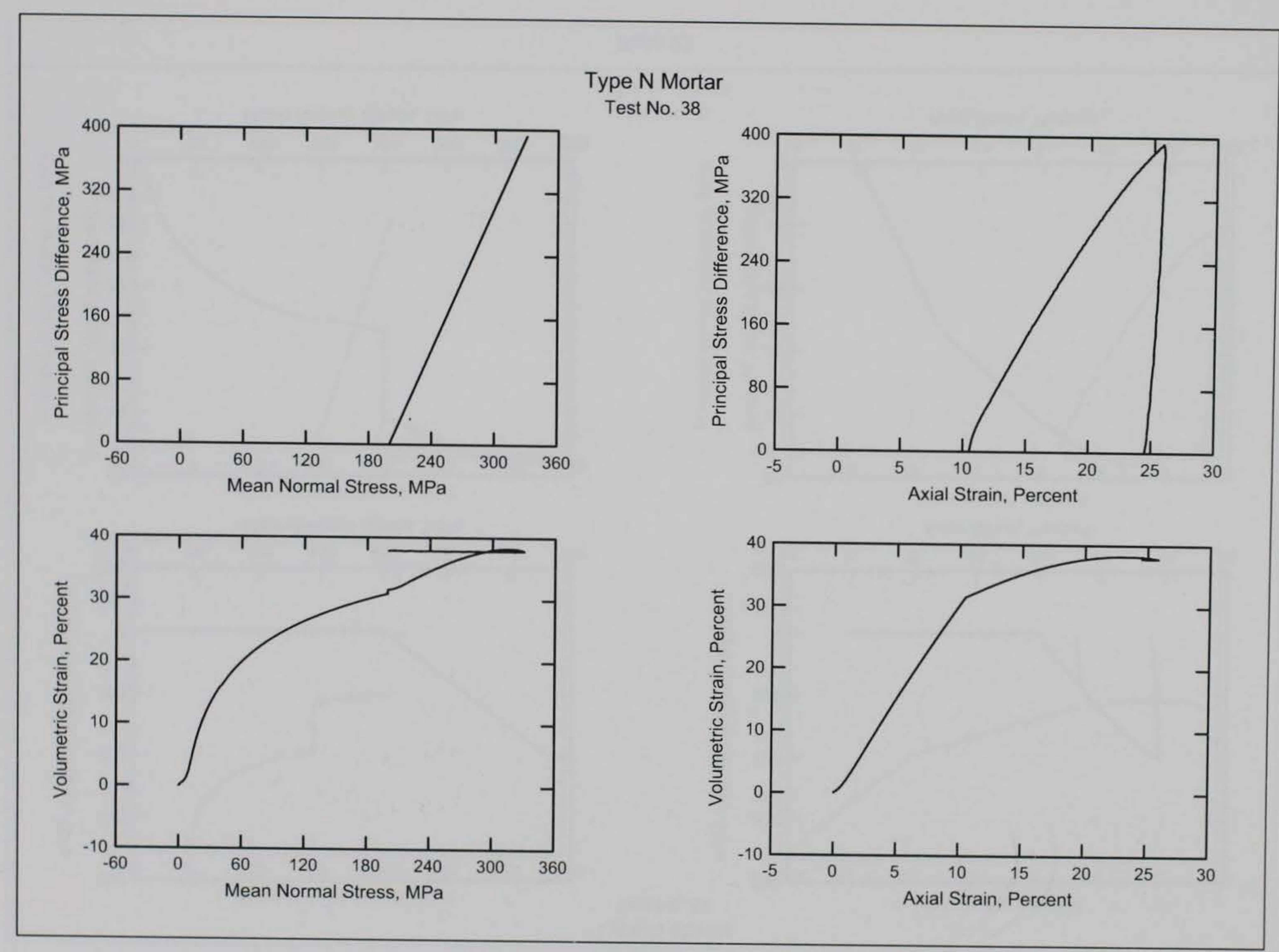

Plate 21 


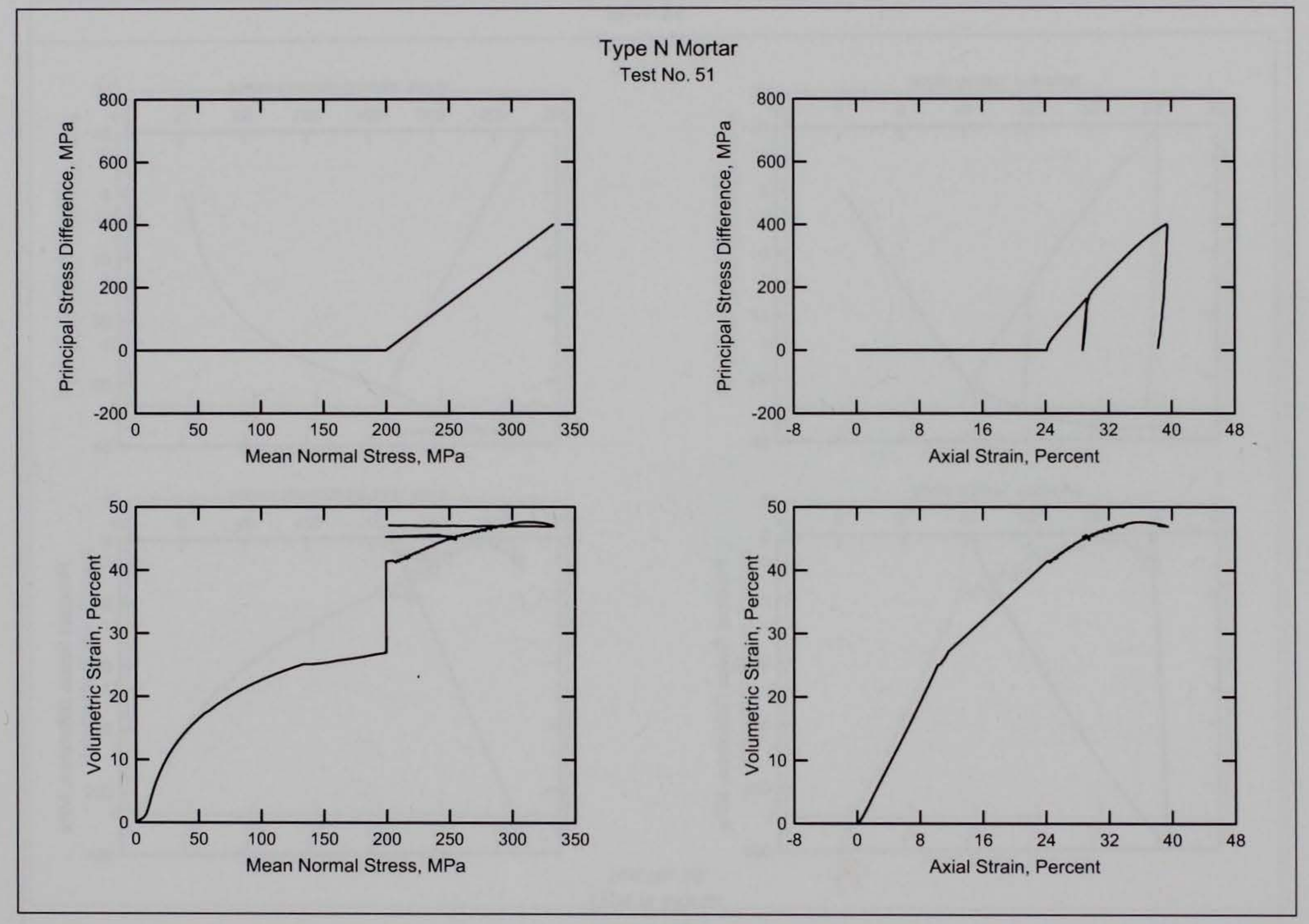




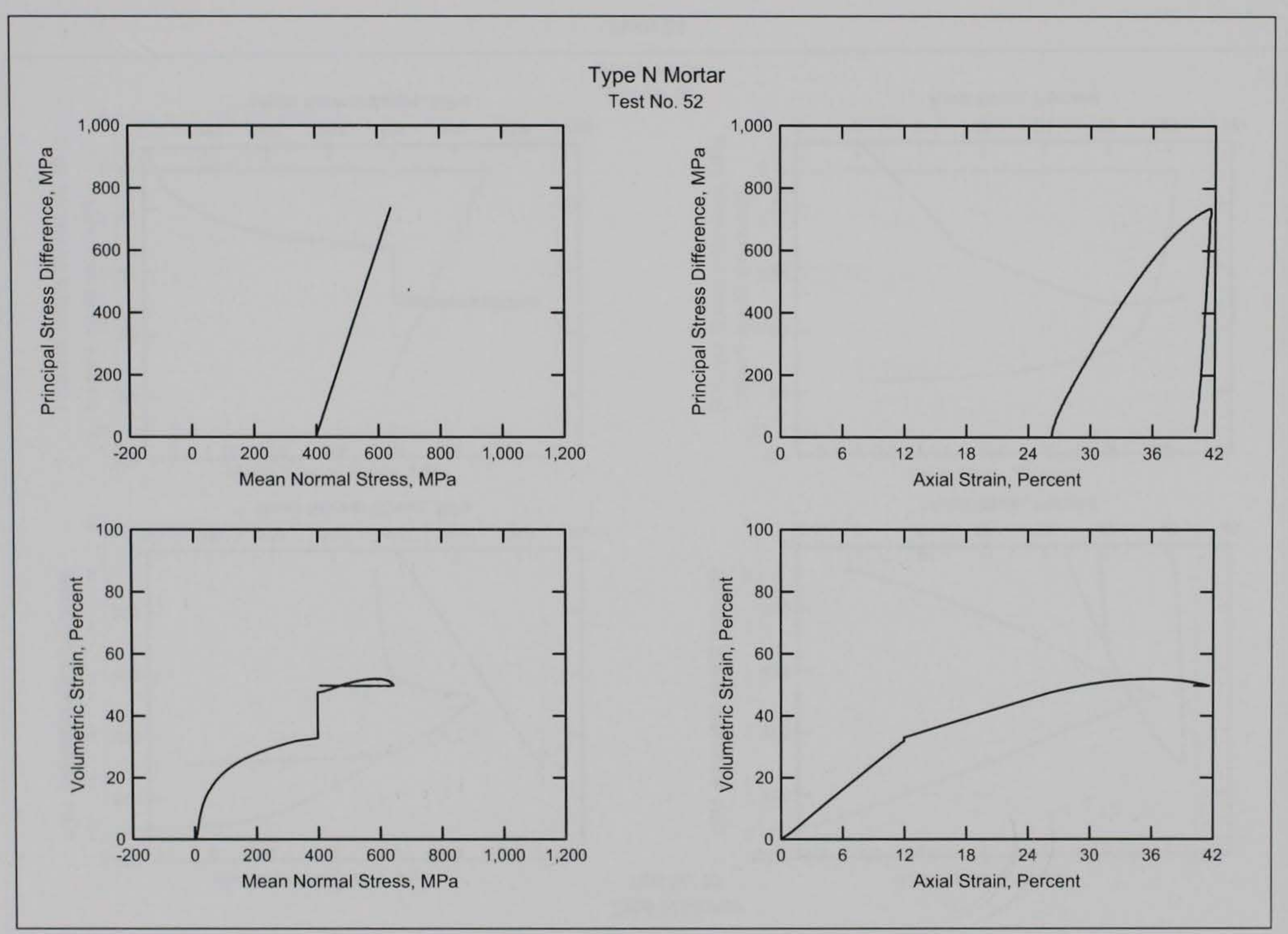




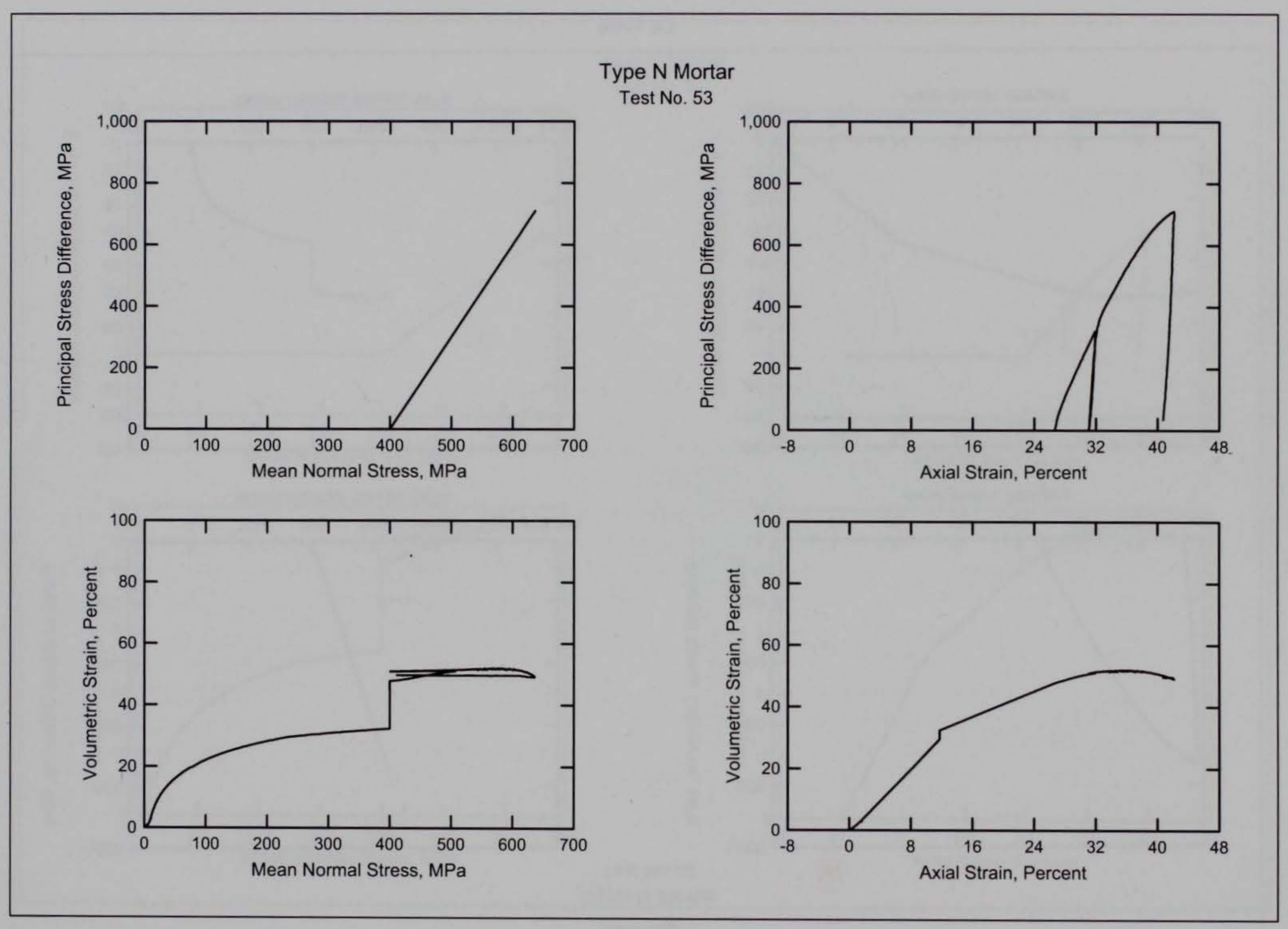

Plate 24 

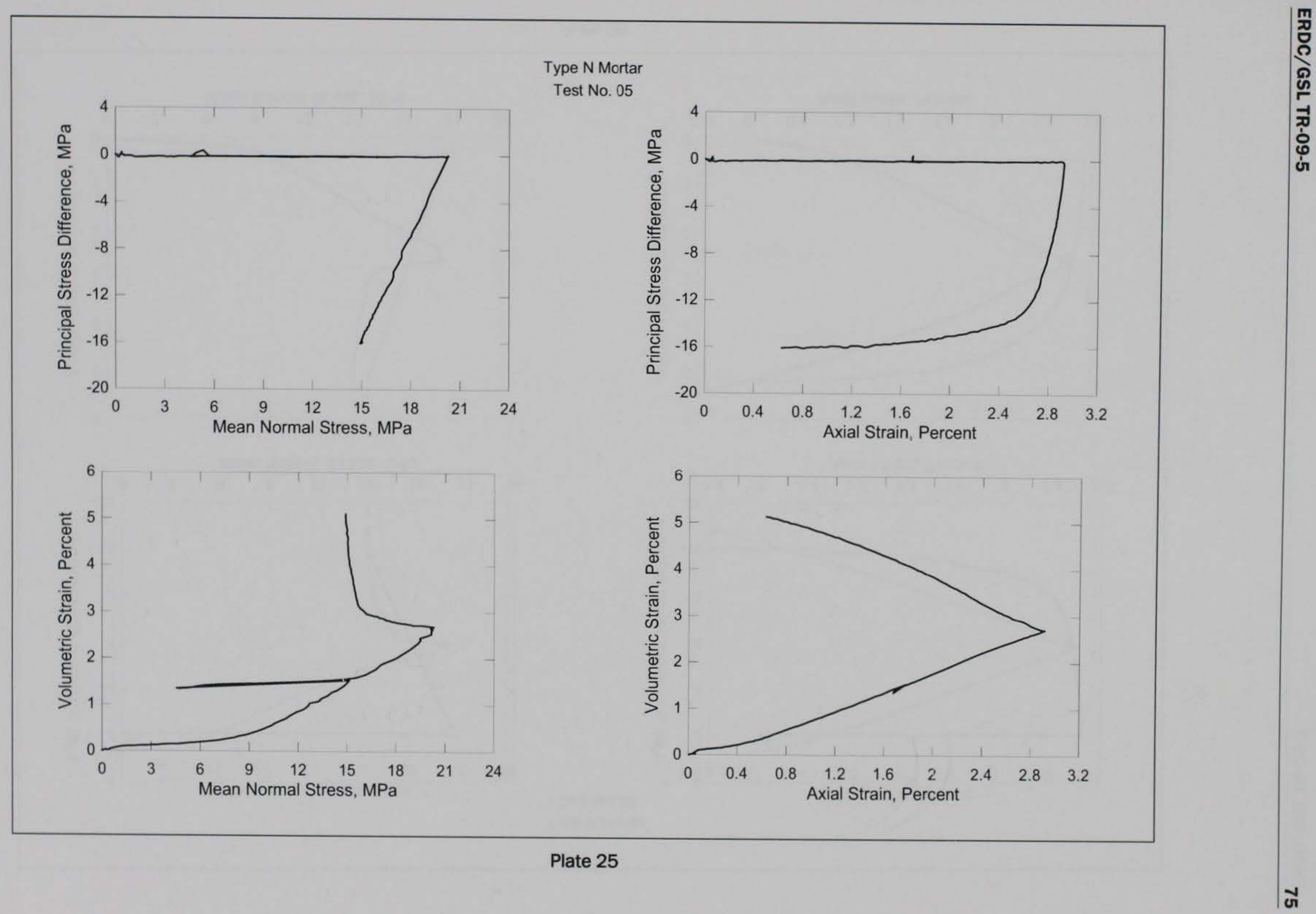


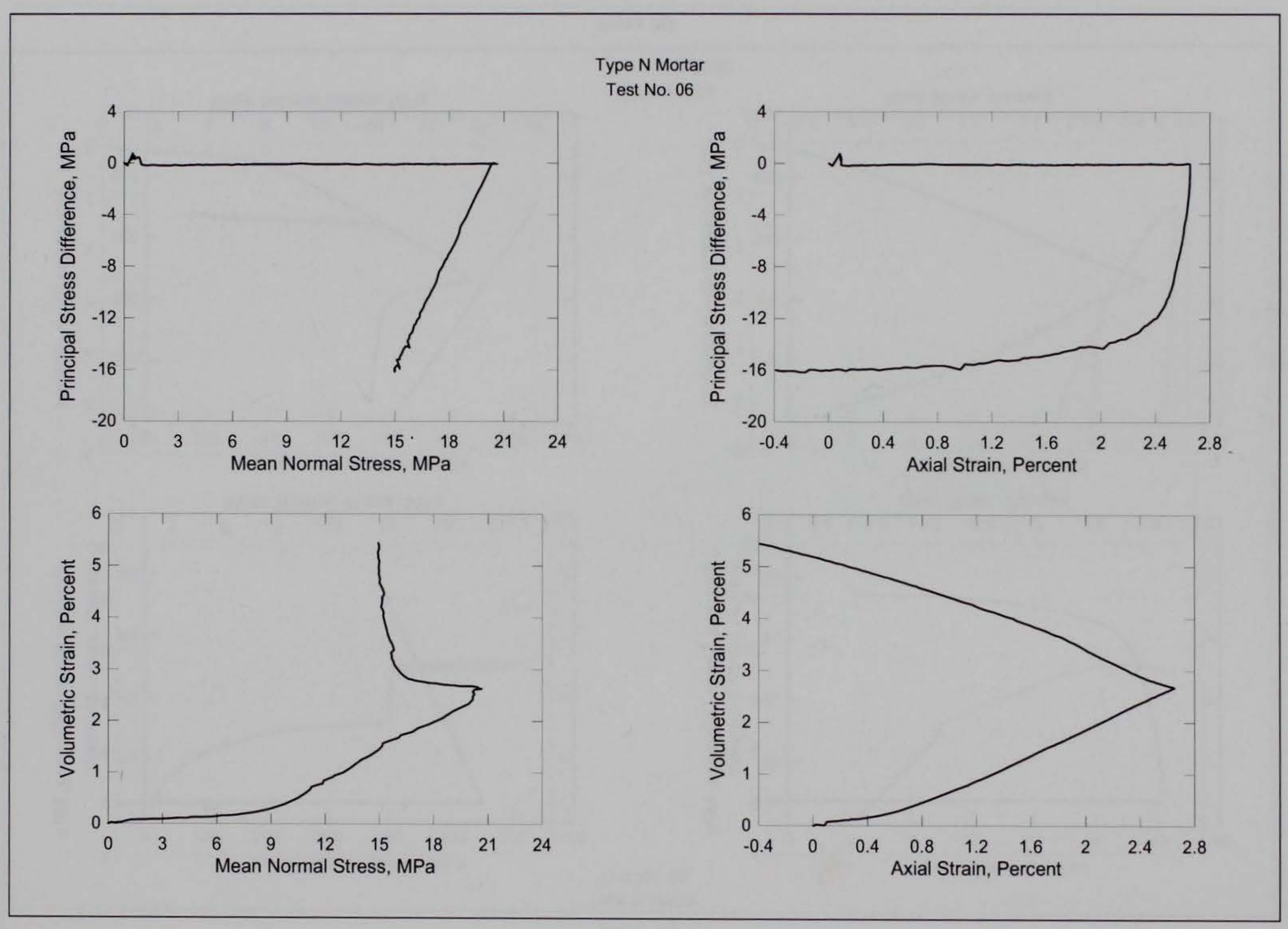

Plate 26 

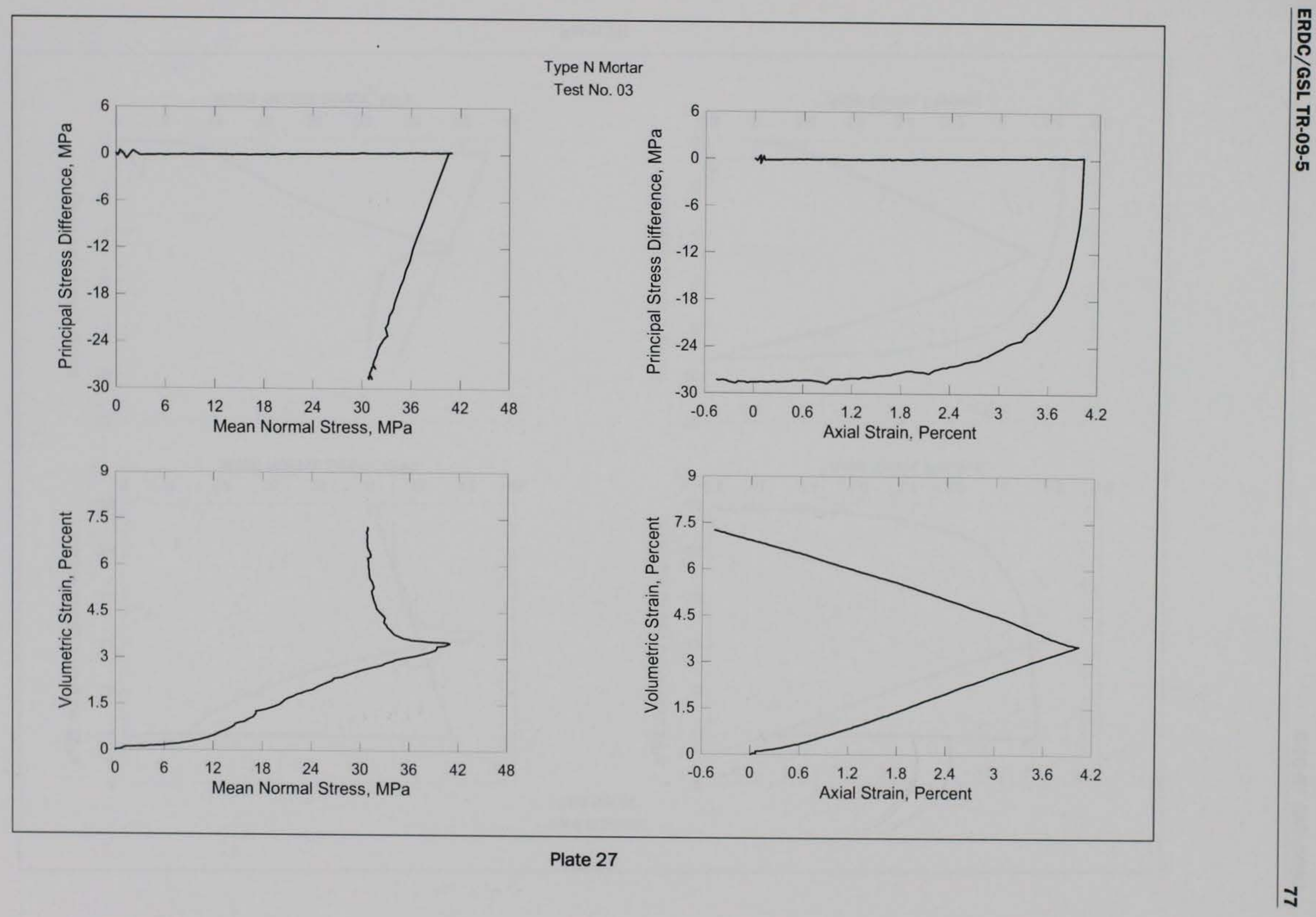


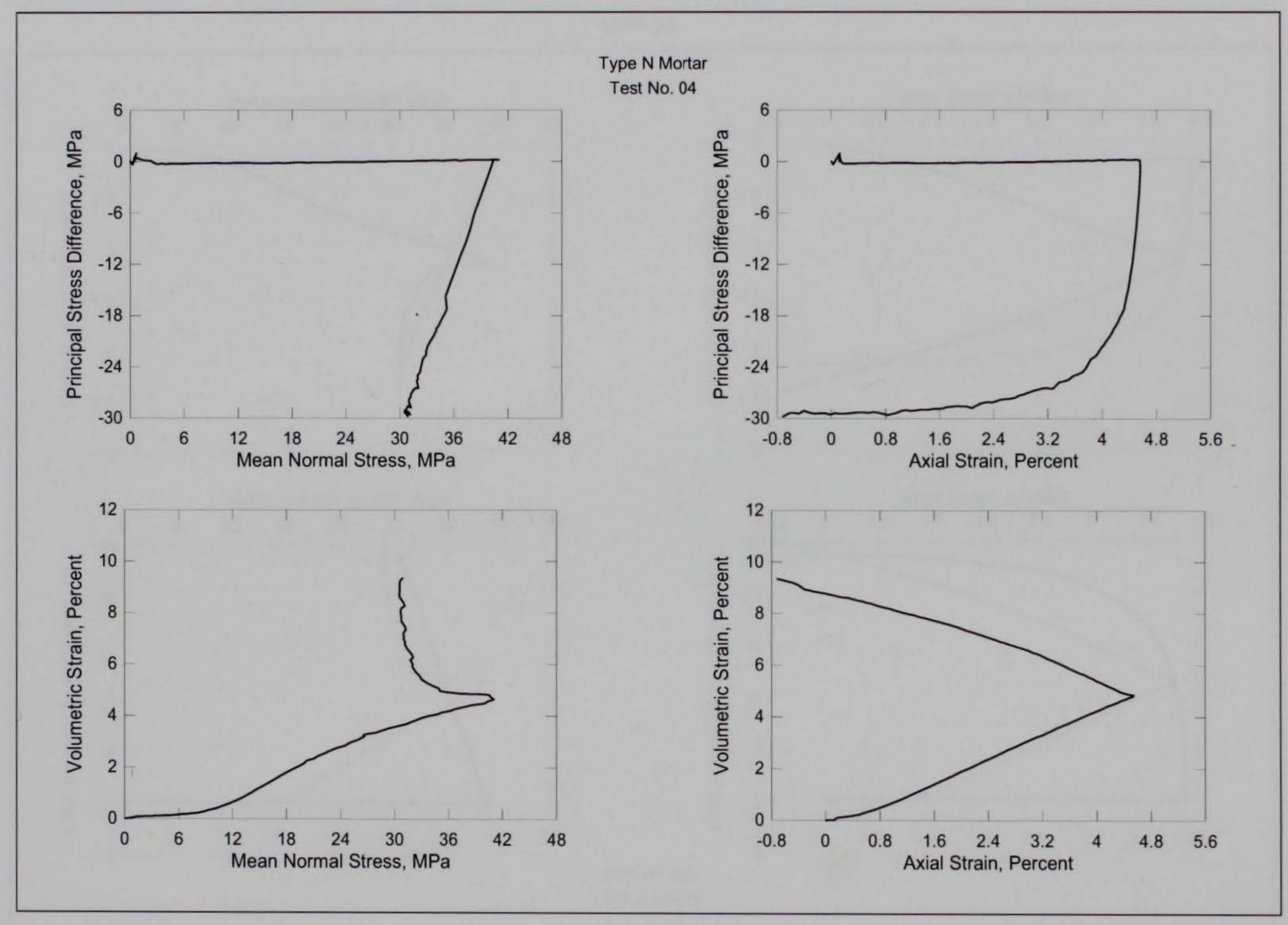

Plate 28 


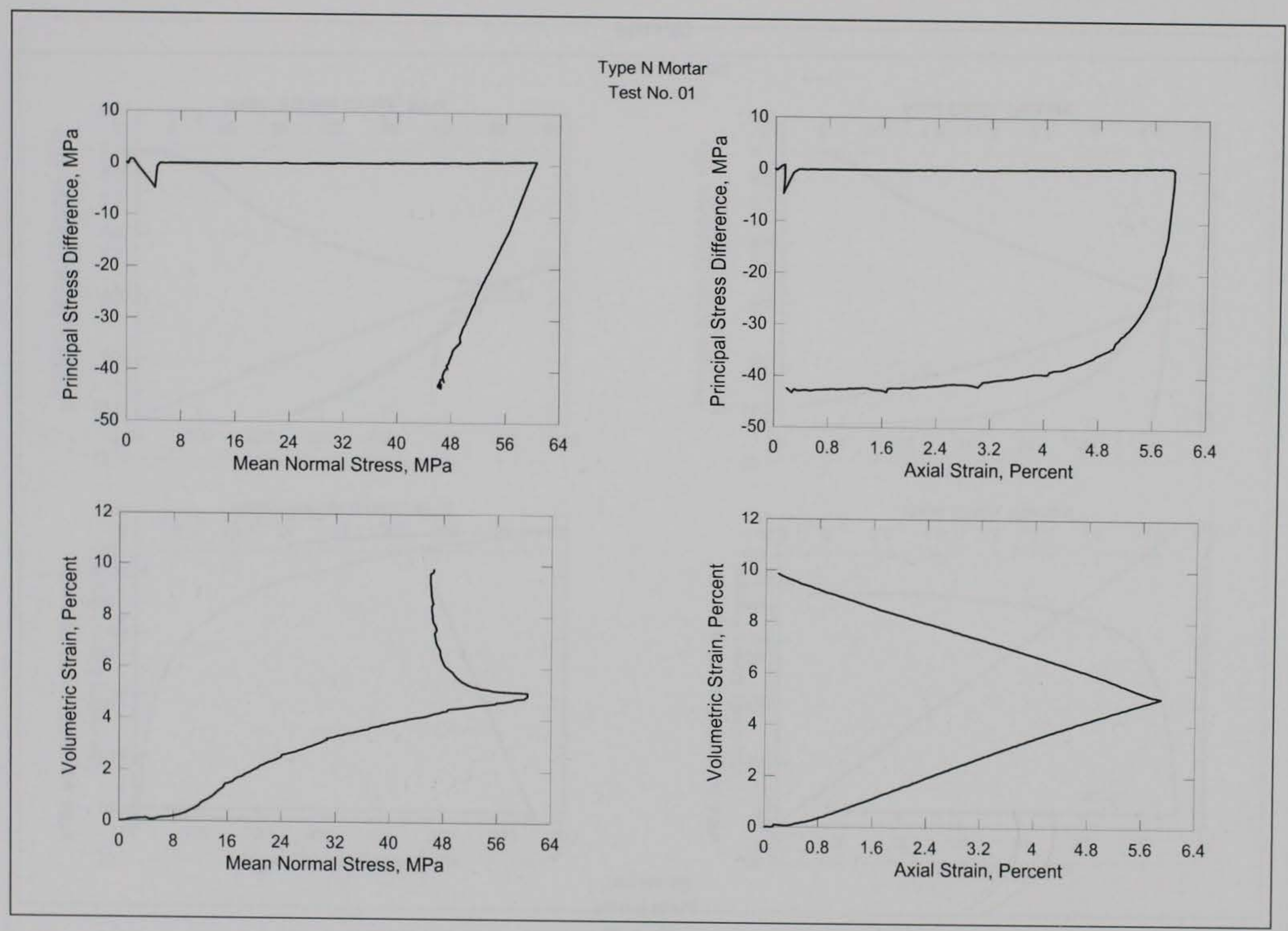




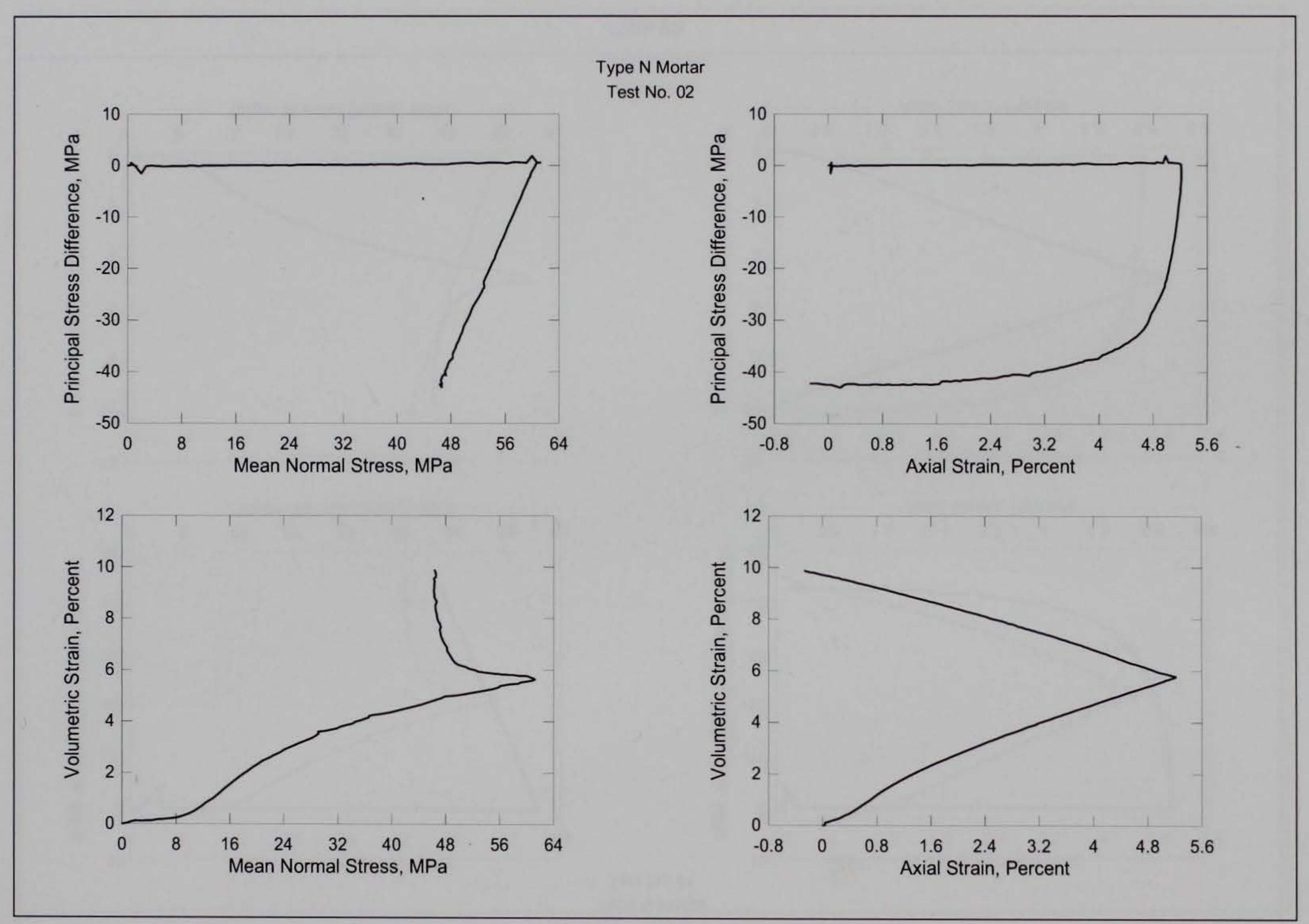

Plate 30 


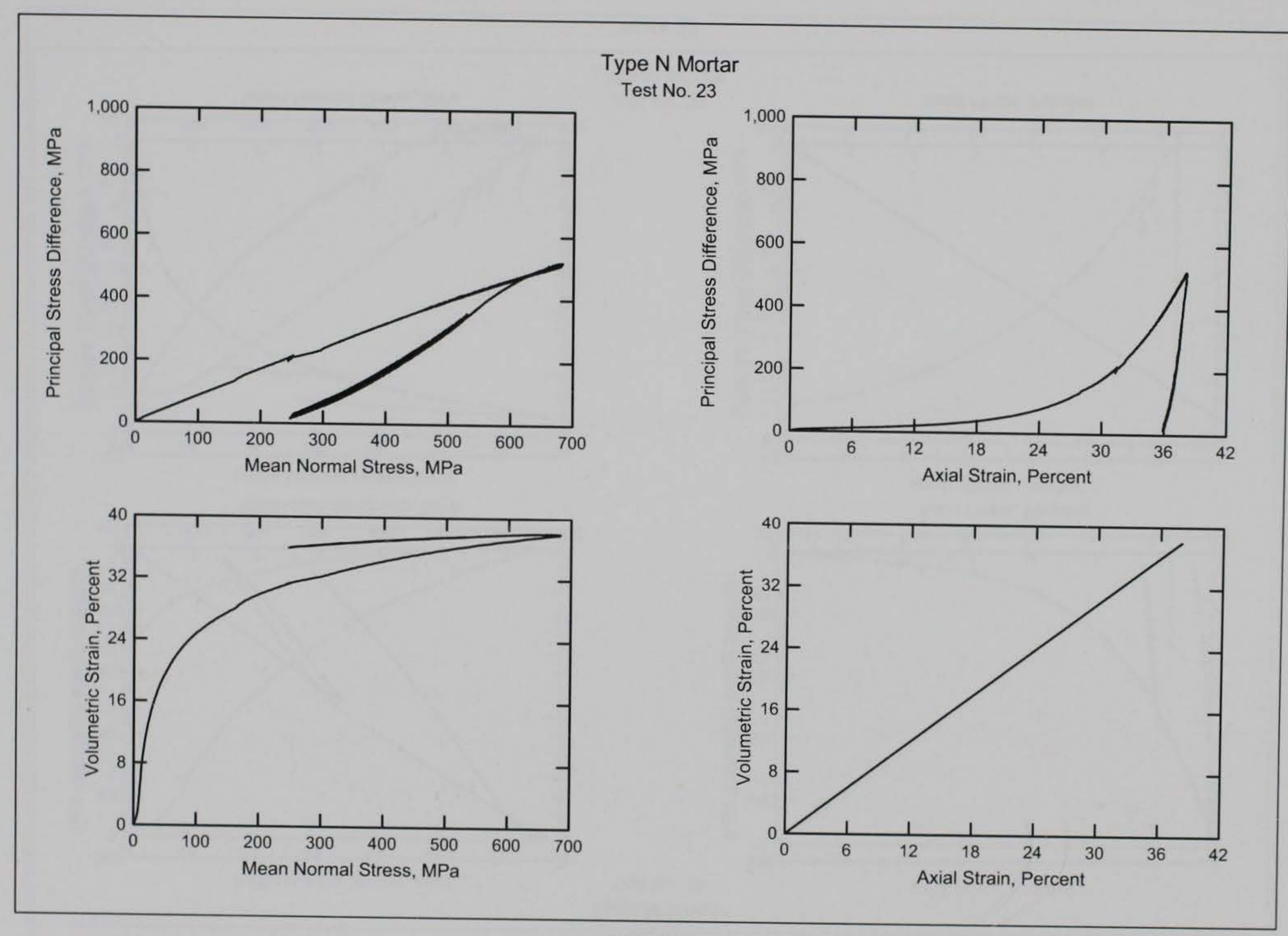

Plate 31 


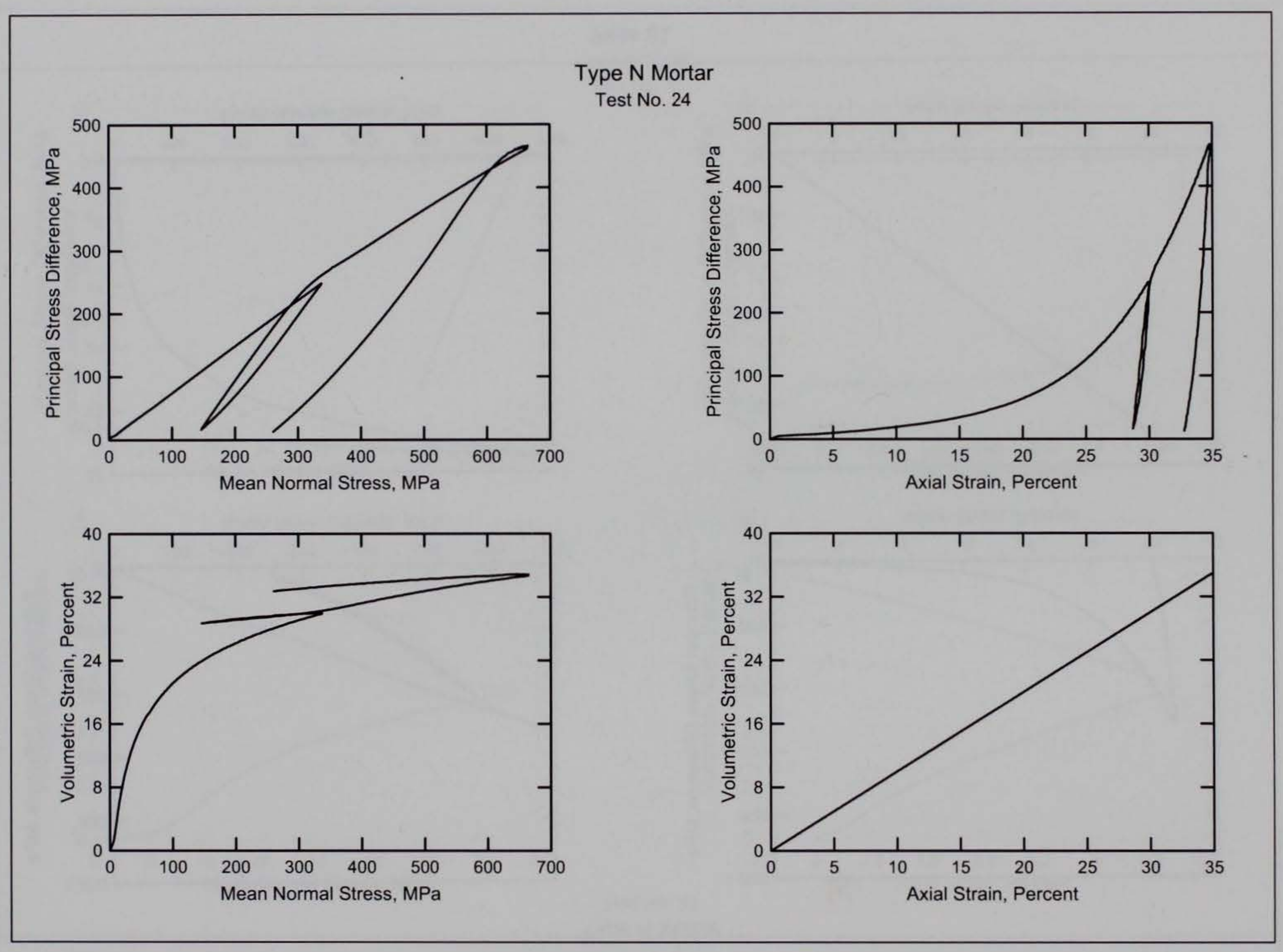

Plate 32 


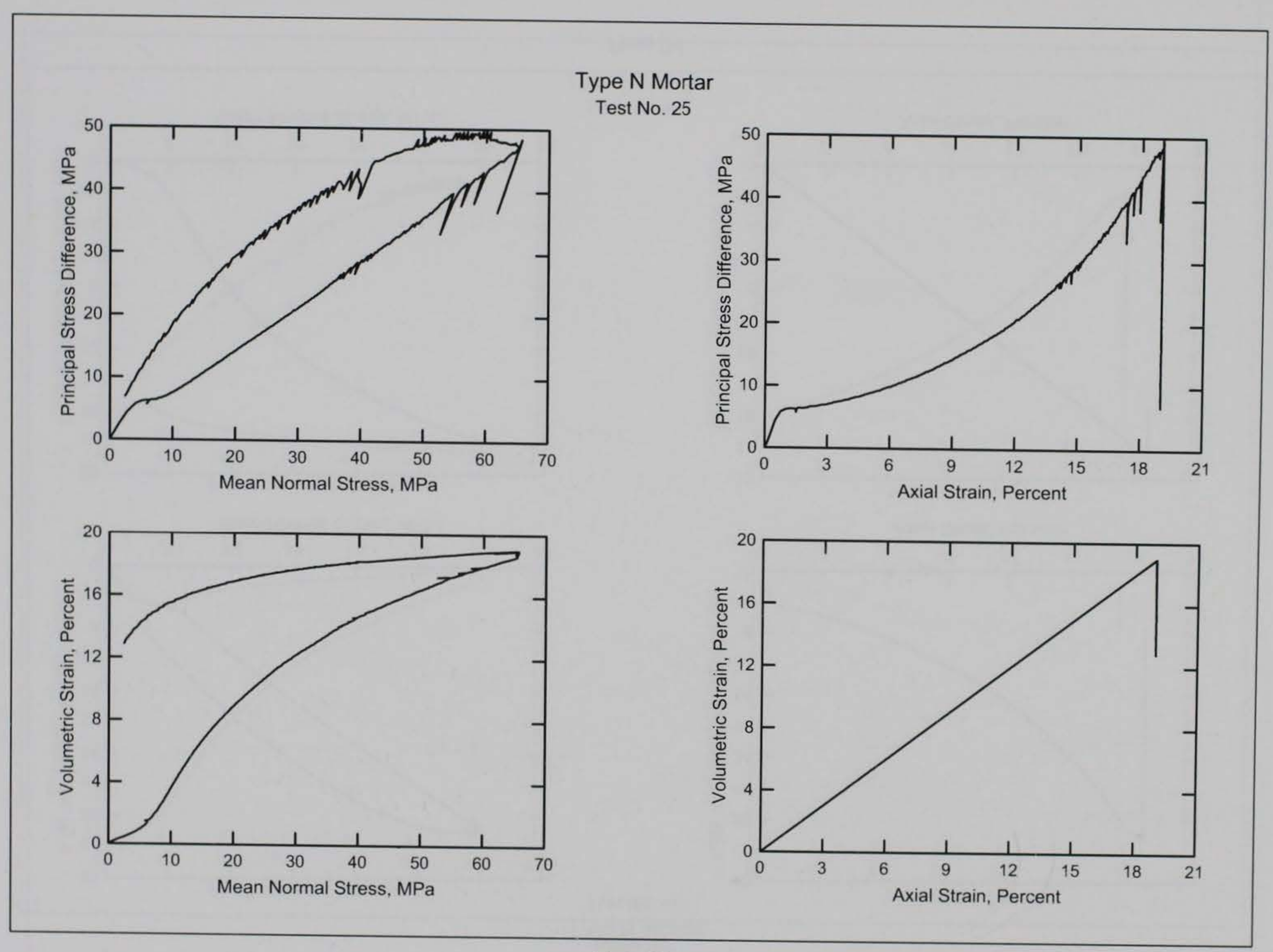




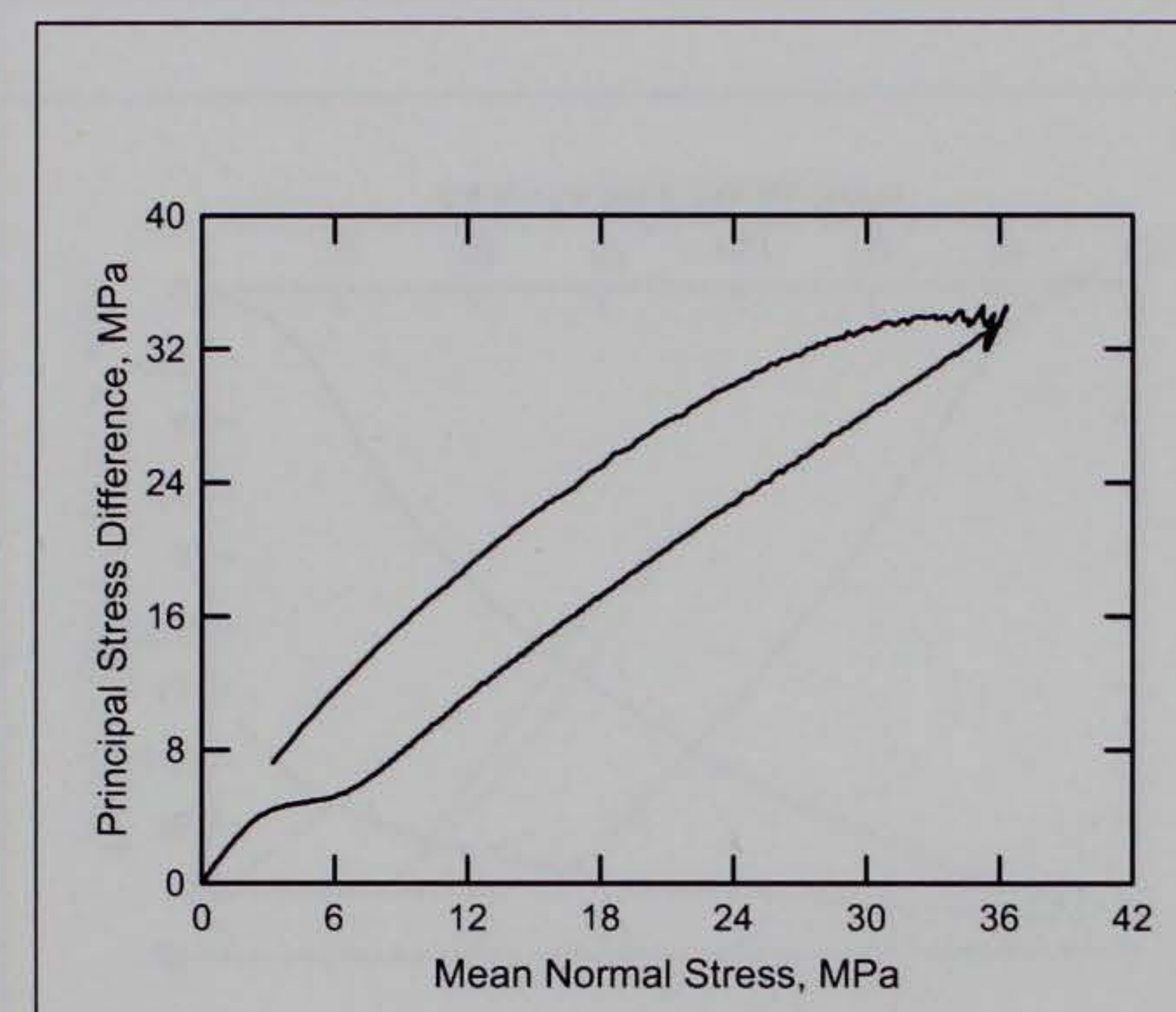

Type N Mortar

Test No. 46
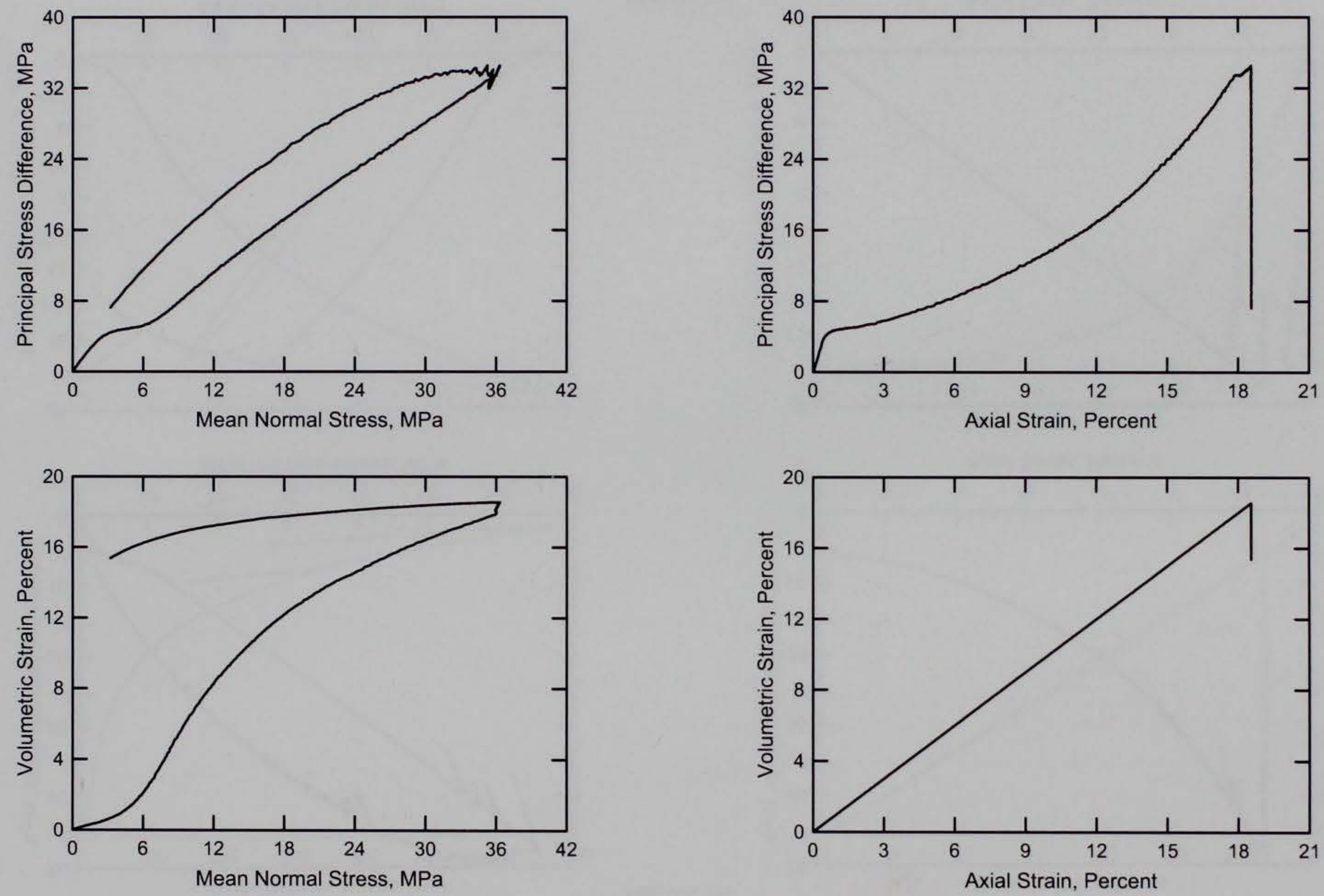

Plate 34 


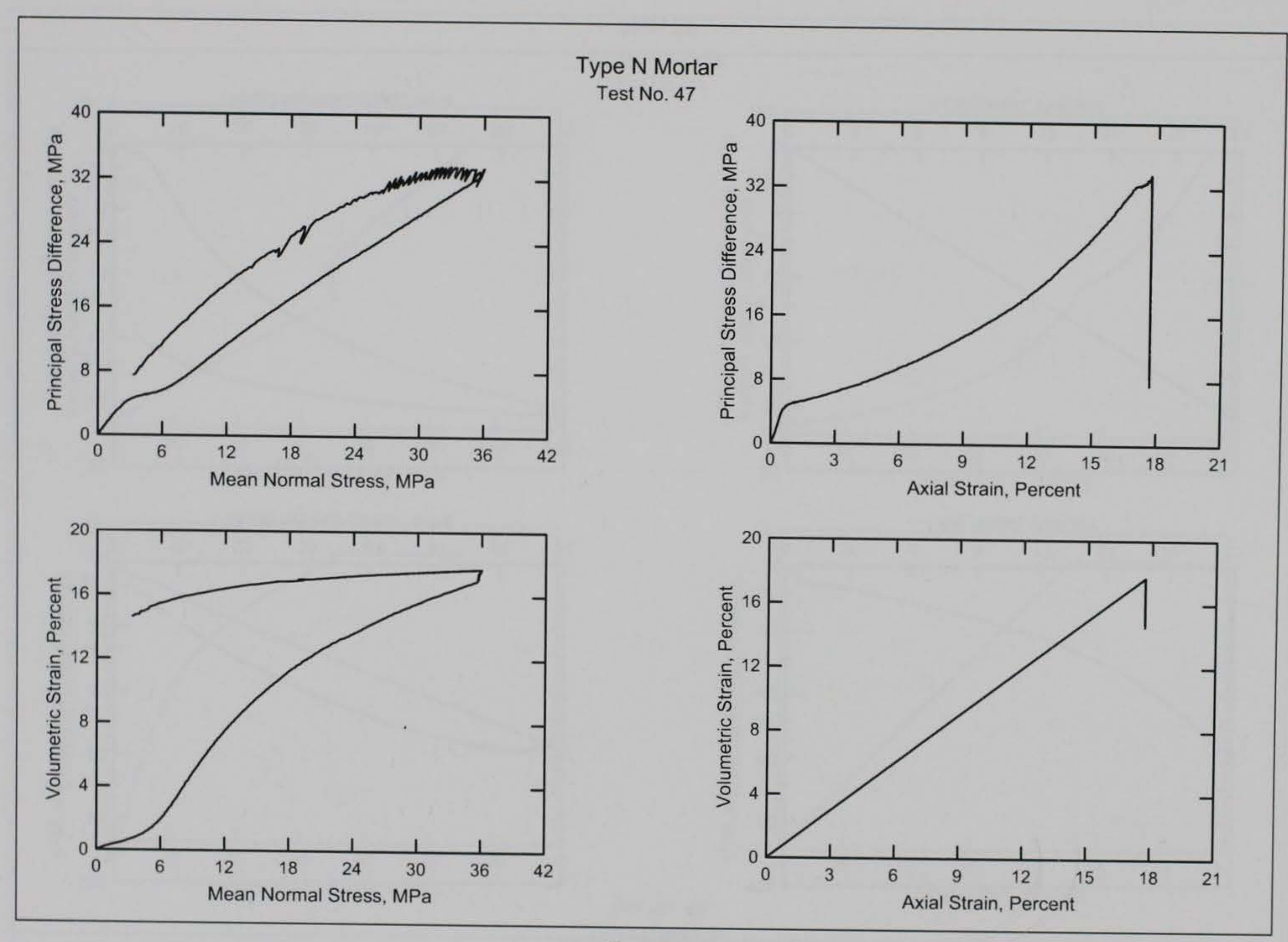




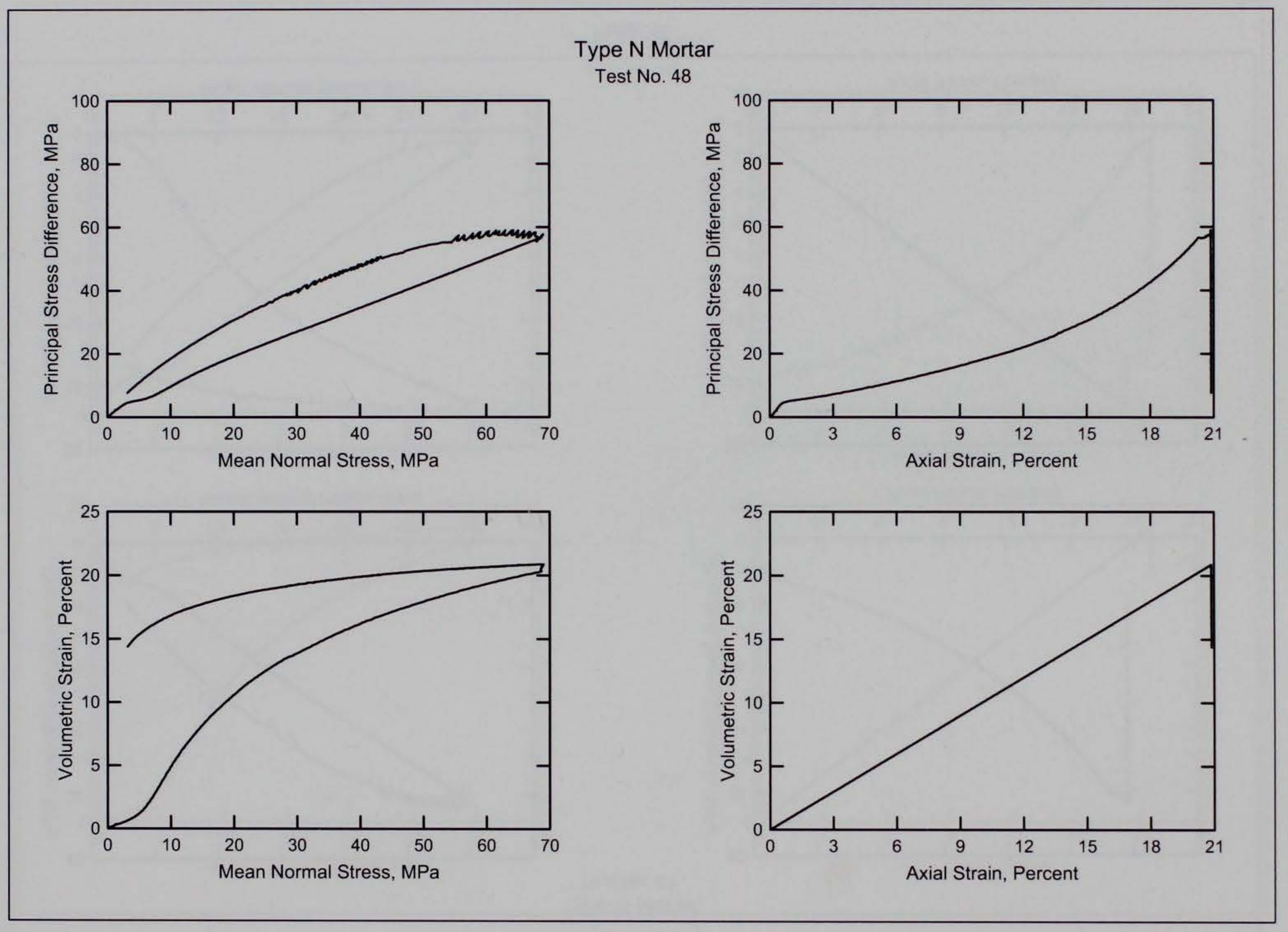

Plate 36 


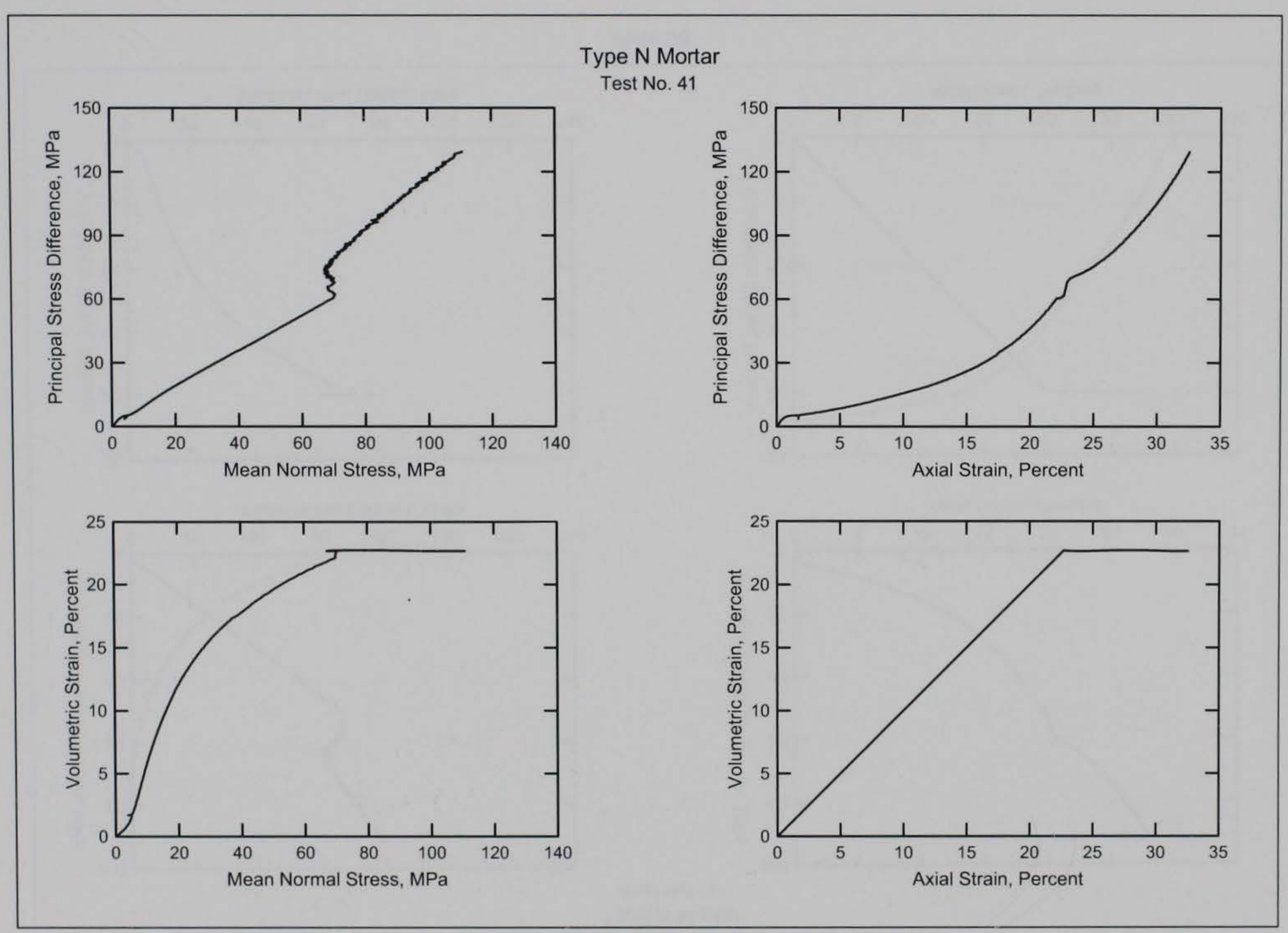

Plate 37 


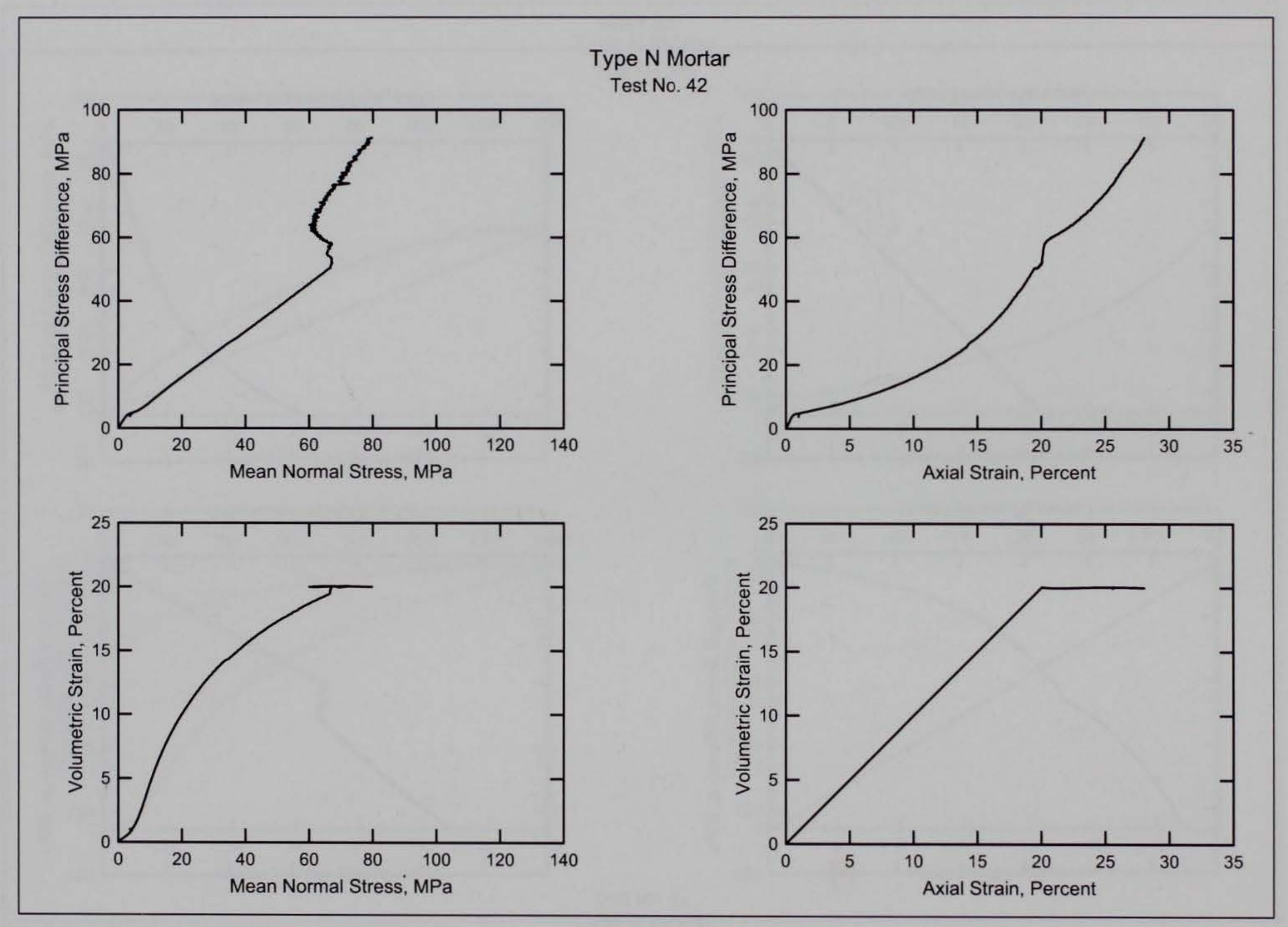




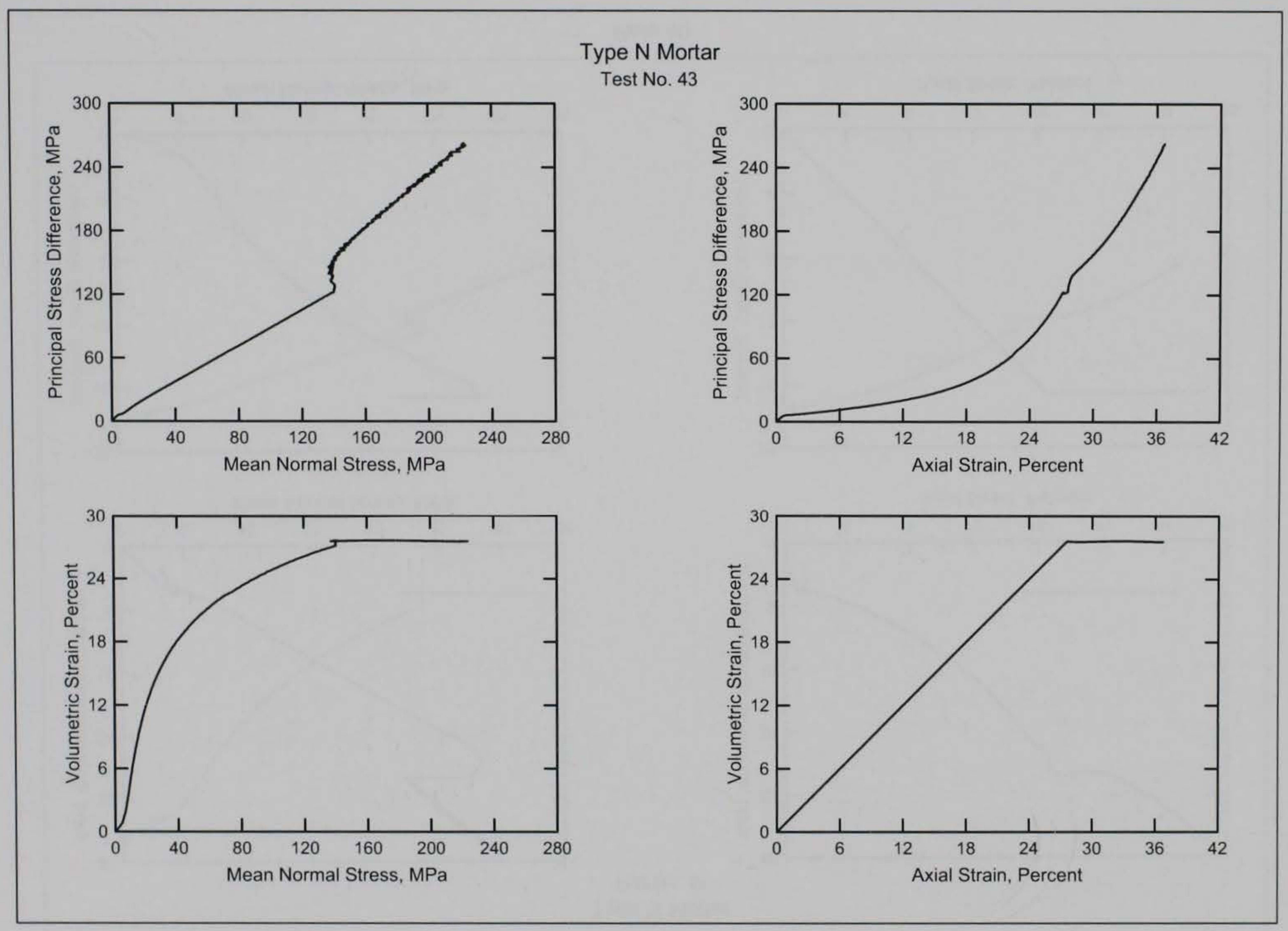




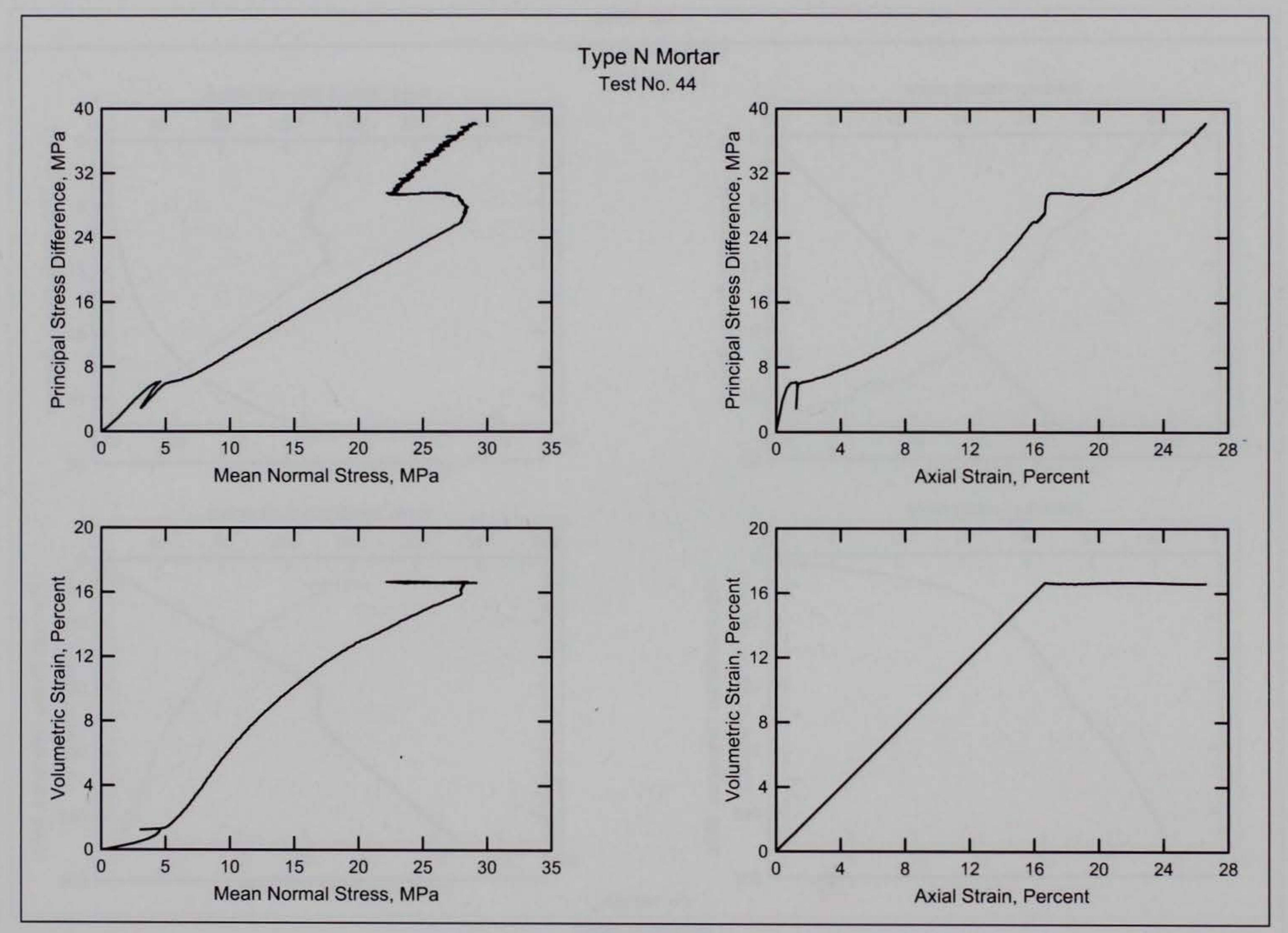

Plate 40 


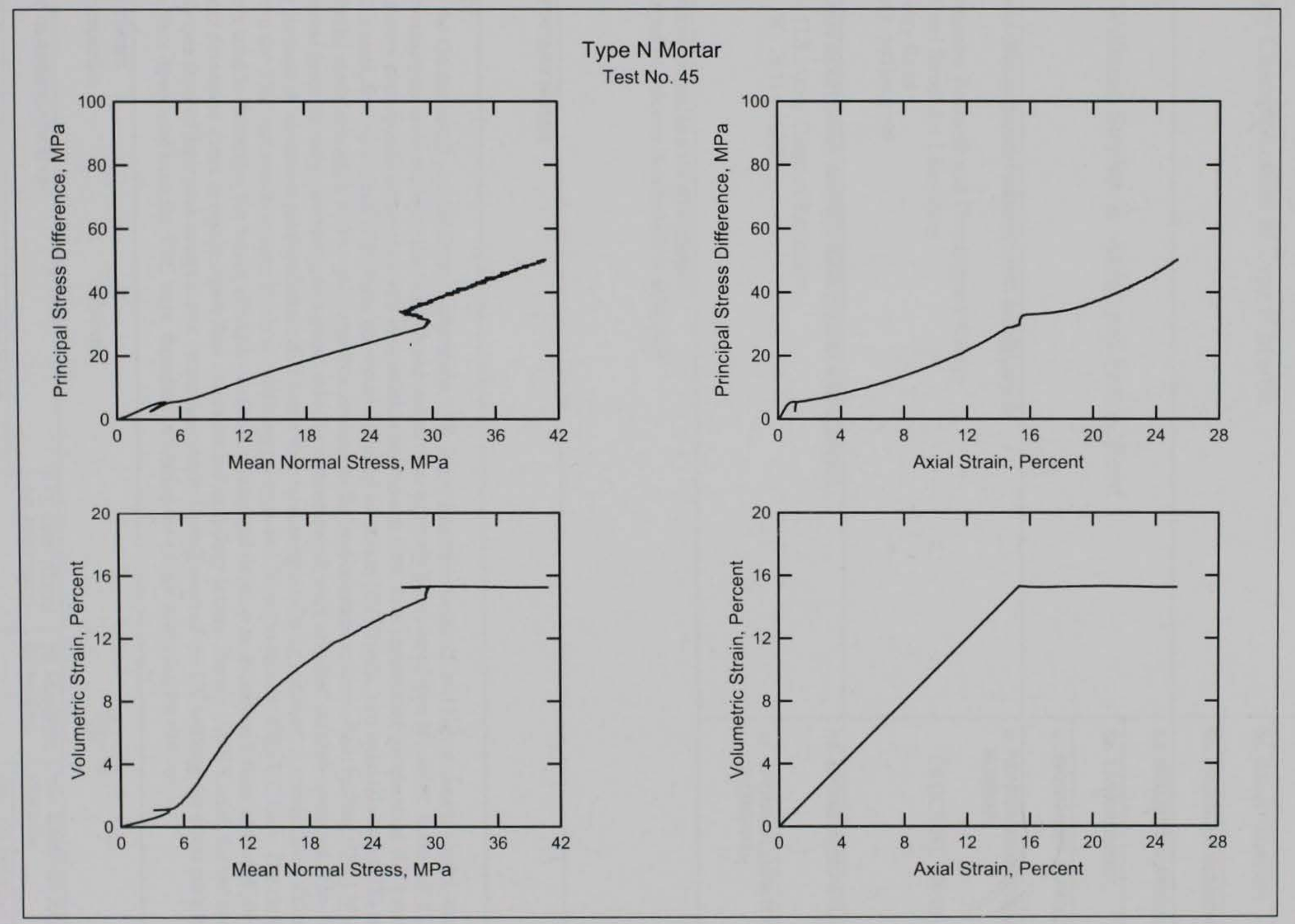




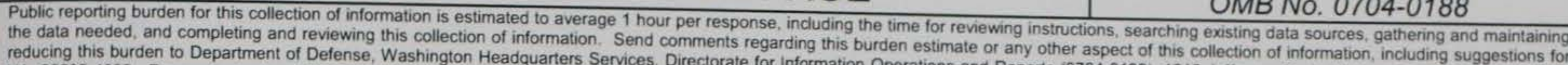

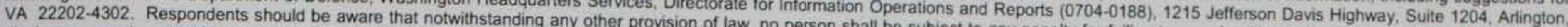

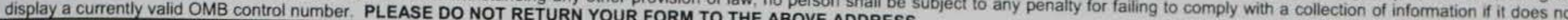

\begin{tabular}{l|l} 
1. REPORT DATE (DD-MM-YYYY) & 2. REPORT TYPE
\end{tabular}

March 2009

4. TITLE AND SUBTITLE Final report

3. DATES COVERED (From - To)

5a. CONTRACT NUMBER

Laboratory Characterization of Type N Mortar

5b. GRANT NUMBER

5c. PROGRAM ELEMENT NUMBER

6. AUTHOR(S)

Erin M. Williams, Stephen A. Akers, and Paul A. Reed

5d. PROJECT NUMBER

5e. TASK NUMBER

5f. WORK UNIT NUMBER

\section{PERFORMING ORGANIZATION NAME(S) AND ADDRESS(ES)}

8. PERFORMING ORGANIZATION REPORT NUMBER

U.S. Army Engineer Research and Development Center

Geotechnical and Structures Laboratory

3909 Halls Ferry Road

ERDC/GSL TR-09-5

Vicksburg, MS 39180-6199

9. SPONSORING / MONITORING AGENCY NAME(S) AND ADDRESS(ES)

Headquarters, U.S. Army Corps of Engineers

Washington, DC 20314-1000

10. SPONSOR/MONITOR'S ACRONYM(S)

11. SPONSOR/MONITOR'S REPORT NUMBER(S)

12. DISTRIBUTION / AVAILABILITY STATEMENT

Approved for public release; distribution is unlimited.

\section{SUPPLEMENTARY NOTES}

\section{ABSTRACT}

Personnel of the Geotechnical and Structures Laboratory, U.S. Army Engineer Research and Development Center, conducted a laboratory investigation to characterize the strength and constitutive property behavior of type $\mathrm{N}$ mortar. A total of 45 mechanical property tests were successfully completed: two hydrostatic compression tests, four unconfined compression (UC) tests, 18 triaxial compression (TXC) tests, four direct pull (DP) tests, six reduced triaxial extension (RTE) tests, two uniaxial strain (UX) tests, four uniaxial strain load/biaxial strain unload (UX/BX) tests, and five uniaxial strain load/constant volume strain loading (UX/CV) tests. In addition to the mechanical property tests, nondestructive pulse-velocity measurements were obtained on each specimen. The TXC tests exhibited a continuous increase in maximum principal stress difference with increasing confining pressure. A compression failure surface was developed from the TXC test results at nine levels of confining pressure and from the results of the UC tests. The results for the DP and RTE tests were used to determine the tensile strength of type $\mathrm{N}$ mortar and develop an extension failure surface. Type $\mathrm{N}$ mortar can withstand more deviatoric stress in compression than extension before failure occurs. During UX/BX tests, the test specimens recovered approximately one third of their peak compressive volumetric strain. During most of the CV loading, the stress path followed closely to the failure surface developed from the TXC tests, therefore validating the compression failure surface.

\section{SUBJECT TERMS}

Mechanical properties
Mortar
Type $\mathrm{N}$

\section{SECURITY CLASSIFICATION OF:}

a. REPORT

UNCLASSIFIED
b. ABSTRACT
UNCLASSIFIED

c. THIS PAGE

UNCLASSIFIED
17. LIMITATION OF ABSTRACT

\section{NUMBER} OF PAGES

98 19a. NAME OF RESPONSIBLE PERSON

19b. TELEPHONE NUMBER (include area code) 